Ph.D. Dissertation

\title{
TrANSCRIPTIONAL ACTIVATOR CUER PROTEIN: PURIFICATION, CHARACTERIZATION AND POTENTIAL BIOANALYTICAL APPLICATION
}

RiA KATALIN BALOGH

Supervisors:

DR. ATTILA JANCSÓ

Assistant Professor

DR. BÉLA GYURCSIK

Associate Professor

Doctoral SchOOL OF ChEMISTRY

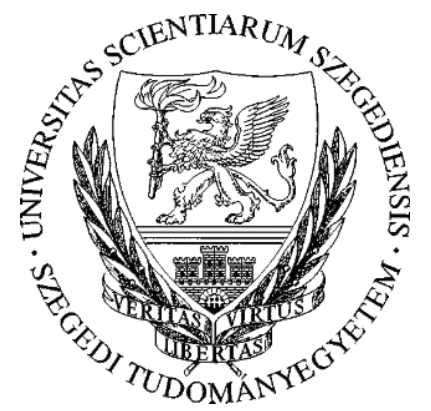

University of Szeged

Faculty of Science and Informatics Department of Inorganic and Analytical Chemistry 



\section{TABLE OF CONTENTS}

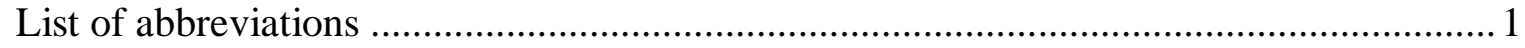

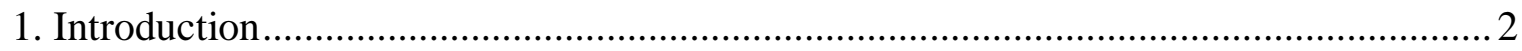

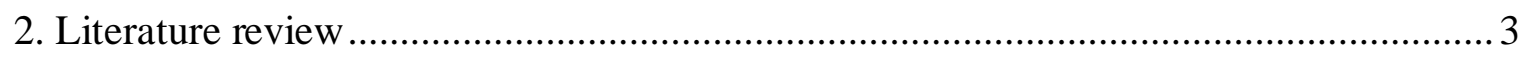

2.1. Prokaryotic metalloregulator families ........................................................... 3

2.2. Copper homeostasis in Escherichia coli .......................................................... 8

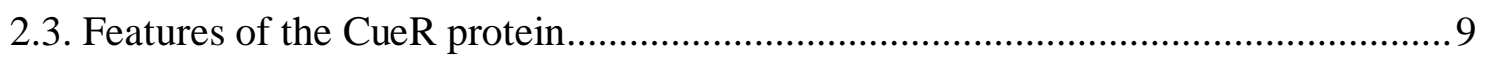

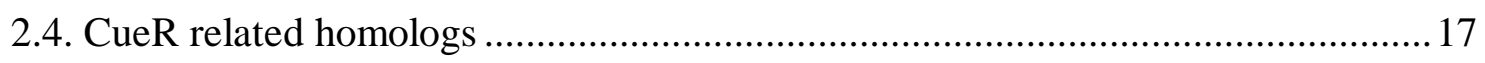

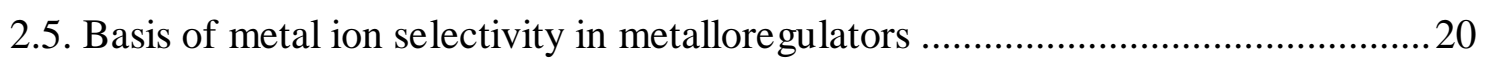

2.6. An application of metalloregulators: Whole cell based biosensors ....................... 22

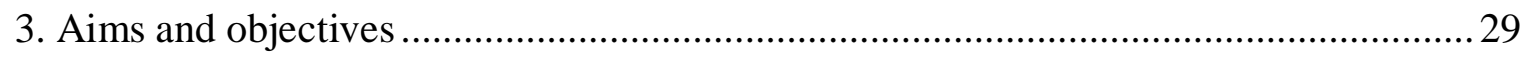

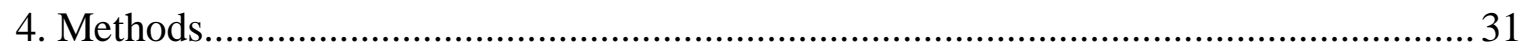

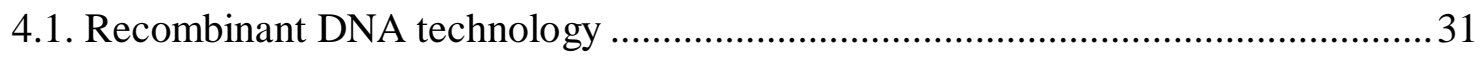

4.2. Recombinant protein expression and purification ................................................ 34

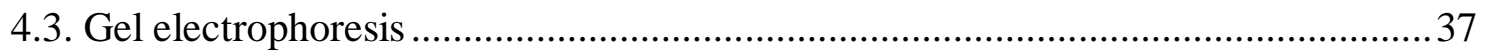

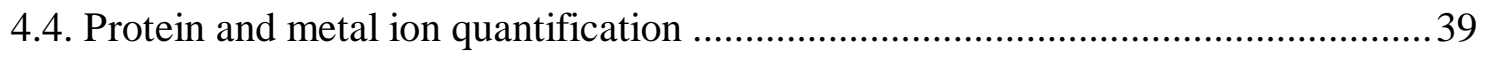

4.5. Protein identification and characterization by mass spectrometry ........................ 40

4.6. UV spectroscopy for studying metal ion-thiolate interactions ............................44

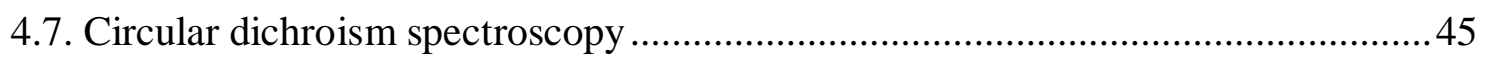

4.8. Fluorescence measurements: fluorescent spectroscopy and microscopy ................46

4.9. Perturbed angular correlations of $\gamma$-rays spectroscopy.......................................49

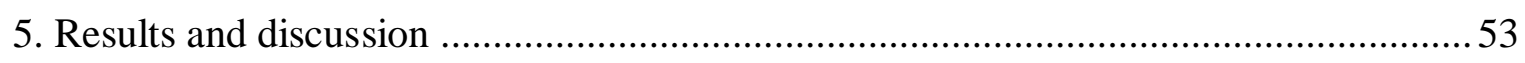

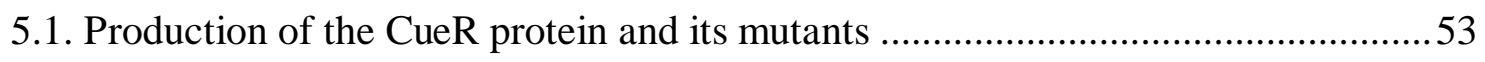

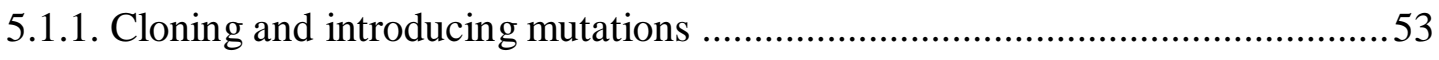

5.1.2. Building up the purification procedure of the WT CueR protein: difficulties and

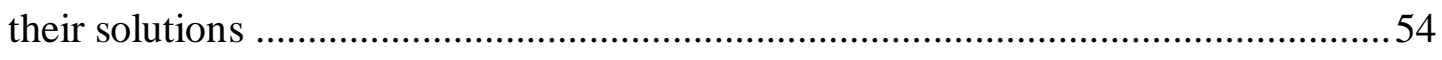

5.1.3. Optimizing the procedure for purifying mutant $\mathrm{CueR}$ proteins ......................57 
5.1.3. Validating the obtained proteins with MS, CD and EMSA

5.2. The effect of $\mathrm{pH}$, metal ions and DNA on secondary structure of WT CueR.........61

5.2.1 Structural switch of CueR induced by $\mathrm{pH}$ change ...........................................62

5.2.2. The effect of metal ions on the secondary structure of CueR..........................65

5.2.3. Locking the secondary structure of CueR by DNA binding ..........................67

5.2.4. Denaturation curves of CueR by increasing temperature ...............................67

5.3. Metal ion recognition - Characterization of metal ion binding properties ..............68

5.3.1. Investigation of the $\mathrm{Hg}(\mathrm{II})$ binding of $\mathrm{WT}$ and $\triangle \mathrm{C} 7-\mathrm{CueR}$ with mass spectrometry

5.3.2. Analysis of the coordination environment of $\mathrm{Hg}(\mathrm{II})$ in $\mathrm{WT}$ and $\Delta \mathrm{C} 7-\mathrm{CueR}$ with $199 \mathrm{~m} H \mathrm{P}$ PAC.

5.3.3. Characterization of the $\mathrm{Hg}(\mathrm{II})$ binding to WT and $\triangle \mathrm{C} 7-\mathrm{Cu}$ R with UV

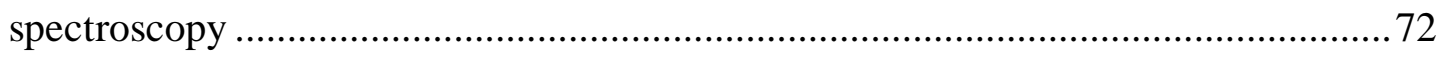

5.3.4. A mechanism to prevent transcriptional activation by $\mathrm{Hg}$ (II) ions ..................75

5.3.5. Investigation of the $\mathrm{Ag}(\mathrm{I})$ and $\mathrm{Cd}(\mathrm{II})$ binding of WT CueR with mass

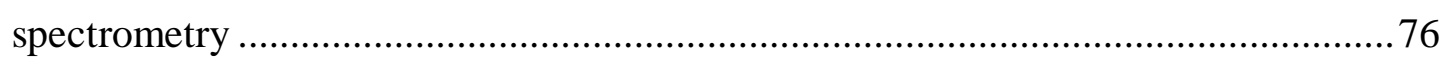

5.3.6. Characterization of $\mathrm{Ag}(\mathrm{I})$ binding of CueR and its variants ........................... 77

5.3.7. Flexibility of the metal ion binding site of WT CueR ....................................78

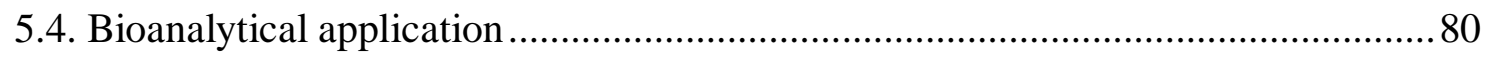

5.4.1. Strategy of establishing a fluorescent reporter system ................................. 80

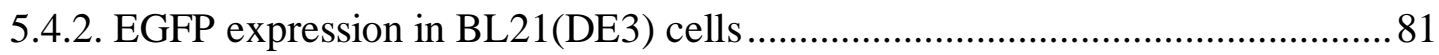

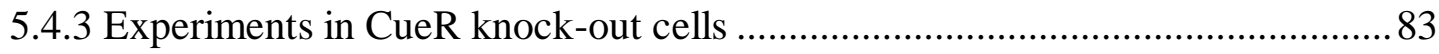

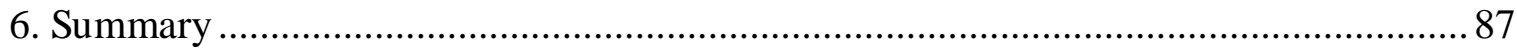

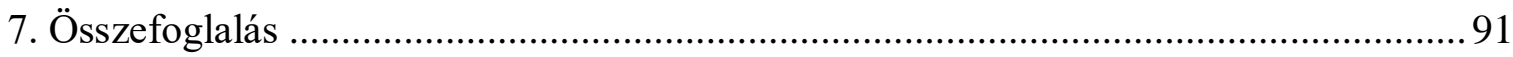

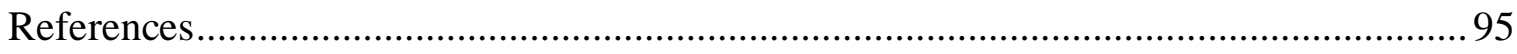

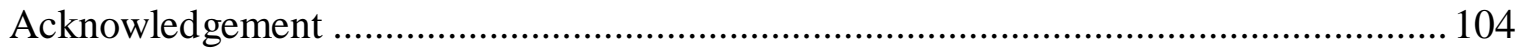

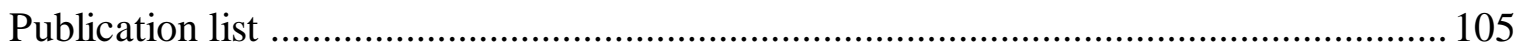

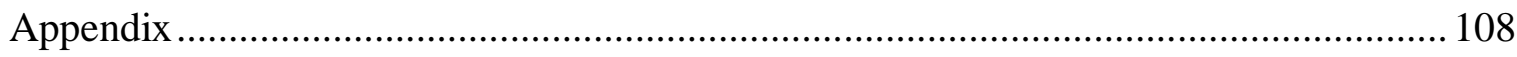




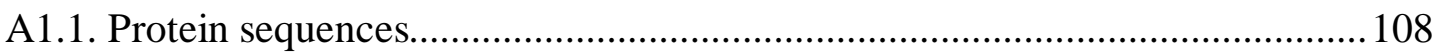

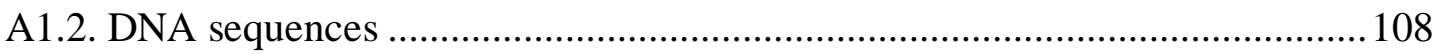

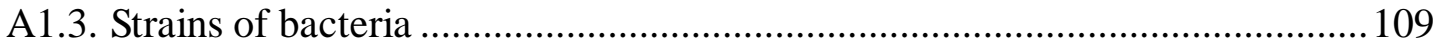

A.2. Cloning, expression and purification of CueR and its mutants ...........................109

A.2.1. Plasmid construction for protein expression ............................................... 109

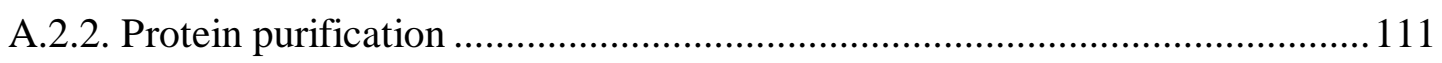

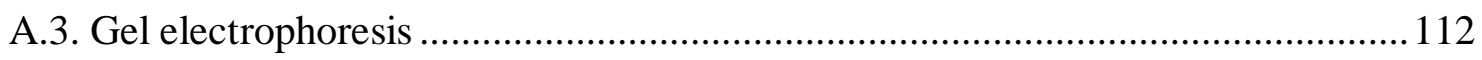

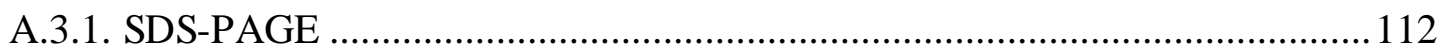

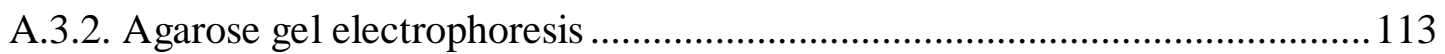

A.4. Functionality test of purified proteins with EMSA …........................................ 113

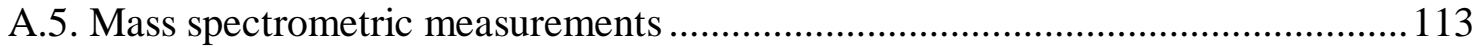

A.5.1. Sample preparation for intact mass measurements ...................................... 114

A.5.2. Sample preparation for native MS .......................................................... 114

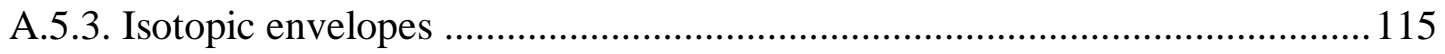

A.6. Peptide Mass fingerprint identification ...................................................... 118

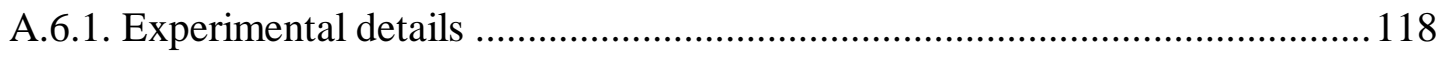

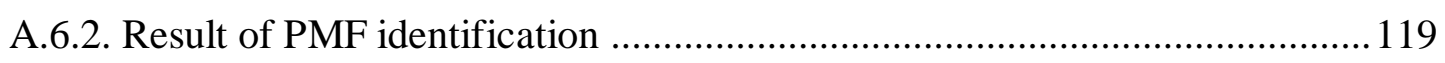

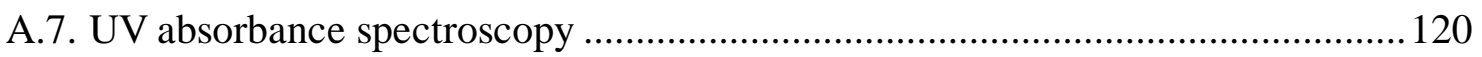

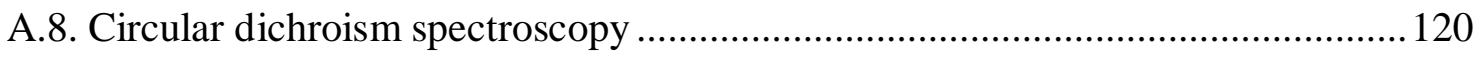

A.9. Perturbed angular correlation of $\gamma$-rays spectroscopy ….................................... 121

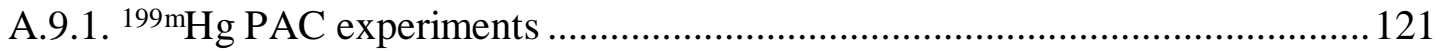

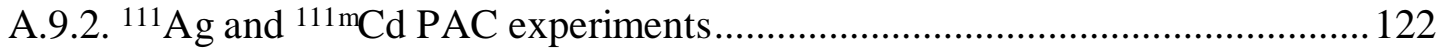

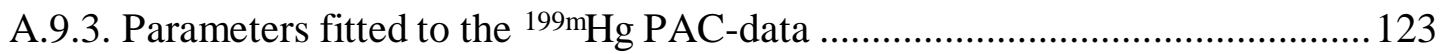

A.9.4. Parameters fitted to the ${ }^{111} \mathrm{Ag}$ and ${ }^{111 \mathrm{~m}} \mathrm{Cd}$ PAC-data ................................... 124

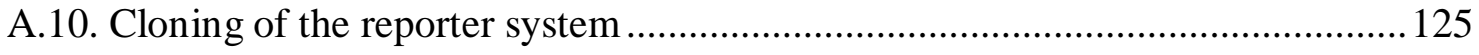

A.11. Detection of EGFP expression: Fluorescence spectroscopy and microscopy .... 126 


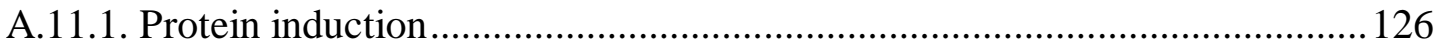

A.11.2. Sample preparation and imaging with fluorescent microscopy ...................126

A.11.3. Sample preparation and measurement with fluorescent microplate reader.127 


\section{LIST OF ABBREVIATIONS}
AAA Amino acid analysis
AC Affinity chromatography
bp / kbp base pair / kilo base pair
CBB Coomassie Billiant Blue stain
CD Circular dichroism
CID Collision-induced dissociation
CT Charge transfer
DAPI 4',6-diamidino-2-phenolindole
dNTP Deoxynucleoside-triphosphate
dsDNA Double stranded DNA
DTT Dithiothreitol
EFG Electric field gradient
EGFP Enhanced green fluorescent protein
EMSA Electrophoretic mobility shift assay
ESI Electrospray ionization
$\mathrm{EtBr} \quad$ Ethidium bromide
FPLC Fast protein liquid chromatography
GE Gel electrophoresis
GF Gel filtration
GFP Green fluorescent protein
HPLC High-performance liquid chromatography
IEX Ion exchange
IPTG Isopropyl $\beta$-D-1-thiogalactopyranoside
LB Luria-Bertani broth
LMCT Ligand-to-metal CT
MALDI Matrix assisted laser desorption ionization
MO Molecular orbital
MS Mass spectrometry
MS/MS Tandem mass spectrometry
NQI Nuclear quandrupole interaction
PAC Perturbed angular correlations of $\gamma$-rays
PAGE Polyacrylamide gel electrophoresis
PCR Polymerase chain reaction
PMF Peptide mass fingerprint
RHH Ribbon-helix-helix motif
RNAP RNA polymerase
SC-XRD Single-crystal X-ray diffraction
SD Shine-Dalgarno sequence
SDS Sodium dodecyl sulphate
UV-Vis Ultraviolet or visible electromagnetic radiation
WCB Whole cell based biosensors
WT Wild type 


\section{INTRODUCTION}

Biological evolution started about 3.5 billion years ago and at that time the reducing atmosphere of the Earth changed as the oxygen level increased due to photosynthesis. Simultaneously, the bioavailability of certain chemical elements, especially of metal ions, changed. For instance, copper became more accessible because the reduced $\mathrm{Cu}(\mathrm{I})$ ions were previously deposited in water-insoluble salts (mainly sulfides), but under an oxidative atmosphere $\mathrm{Cu}(\mathrm{I})$ ions were oxidized to $\mathrm{Cu}$ (II) form which has water-soluble salts. Throughout biological evolution, copper became an essential trace element for living organisms. It is found in many enzymes as a cofactor, it participates in numerous vital processes like electron transfer, $\mathrm{O}_{2}$ transport or redox reaction catalysis. On the other hand, a too high cellular concentration of copper is highly toxic since the excess ions causes malfunction by interacting with thiol groups and/or occupying non-endogenous metal binding sites of proteins. Moreover, $\mathrm{Cu}(\mathrm{I})$ ions promote the formation of ROS (reactive oxygen species) in Fenton-like reactions which may cause significant damage on cell compartments.

Maintaining the intracellular concentration of metal ions at an optimal level is a particularly important task for all organisms. Therefore, highly specialized processes have been evolved in order to secure the metal ion homeostasis and to protect the cell from harmful effects. In prokaryotes and some eukaryotes these processes are managed by a system of metallore gulatory proteins which selectively recognise a group of metal ions and regulate their intracellular concentration.

In this thesis, the metal binding features and structure of the $\mathrm{CueR}(\underline{\mathrm{Cu}} \underline{\text { efflux }}$

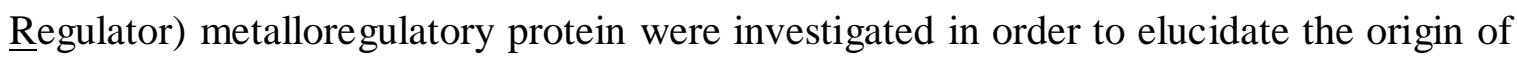
its metal ion selectivity. The results presented here may contribute to understand the details of bacterial metal ion regulatory mechanisms, and may also forward the design of molecules for selective metal ion binding/accumulation or the development of sensitive metal ion-detection methods. 


\section{LITERATURE REVIEW}

\subsection{Prokaryotic metalloregulator families}

The maintenance of the cellular copper concentration within an optimal range is crucial for living organisms. In prokaryotes several processes have been developed that serve the removal of the excess of accumulated metal ions from the cell in order to avoid harmful effects. Generally, bacteria have specific resistance systems which respond to a given or a group of metal ion, without disturbing the homeostasis of other essential metal ions. The intracellular level of metal ions can be reduced via several pathways, like regulating the nutrient accumulation, sequestrating the ions in macromolecules, converting a metal ion to an inert form or exporting the excess ions out from the cytoplasm. [1]

Metal-responsive transcriptional control is exceptionally well advanced in prokaryotes, where various metalloregulatory proteins collectively manage the overall metal ion homeostasis of a cell. Therefore, sensitive response and selective recognition of a certain metal ion - or a group of metal ions - are crucial features of these proteins.[2] Sensing and regulation can happen in two steps carried out by two-protein systems (like PcoRS, CusRS, SilRS), or in one step handled by only one protein (such as CueR, NikR etc.). Here, I will focus on proteins from the latter group.

In the last decades numerous metalloregulators have been identified owing to the advancement of genomics and proteomics methods. Based on structural homology, evolutionary related orthologues were classified into at least 10 families named after the first identified members, i.e. archetype (Table 1).[2-4] Metalloregulatory proteins mostly possess dimeric quaternary structure, rarely tetrameric $e . g$. NikR, which is basically a dimer of dimers. This two-fold rotational symmetric structure of proteins is necessary to interact with two-fold symmetric DNA operator sites. Furthermore, because of their DNA binding feature, metalloregulators have a winged-helix structured $N$-terminal DNA binding domain except for NikR and CsoR families. The winged-helix motif is a helix-turn-helix followed by one or two $\beta$-hairpin wings that contact the major groove of the DNA.[5]

Metalloregulators operate via three distinguishable regulatory mechanisms depending on the regulated processes (Figure 1). (i) Proteins regulating uptake systems are usually repressors (Fur, DtxR, NikR, MarR). The binding of a cognate metal ion to the repressor initiates the DNA binding of the protein. By this, transcription of uptake proteins is repressed and thereby further uptake of the metal ion is prevented. In this mechanism the metal ion is an obligate co-factor for repressing the transcription. (ii) If the regulated genes 
code for efflux or secreting proteins the mechanism is usually derepression (ArsR CsoR, CopY), that is, binding of an appropriate metal ion to the regulator allosterically inhibits the DNA-protein interaction. Hence, the protein dissociates from the DNA resulting in the initiation of transcription. (iii) An activation mechanism was observed in the MerR family. Here, metal ion binding to the regulator allosterically activates transcription while the metallated (holo-)protein remains bound to the DNA.[5] In the following, I will discuss the protein families on the basis of the regulatory mechanism (Table 1).

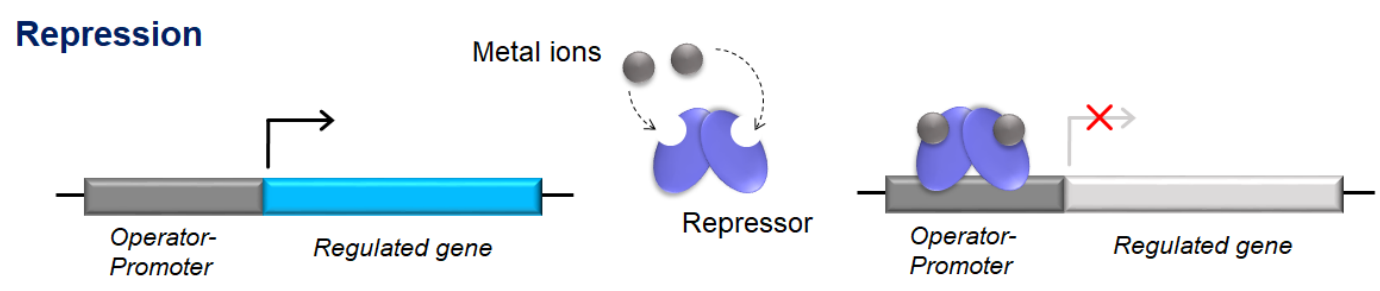

\section{Derepression}
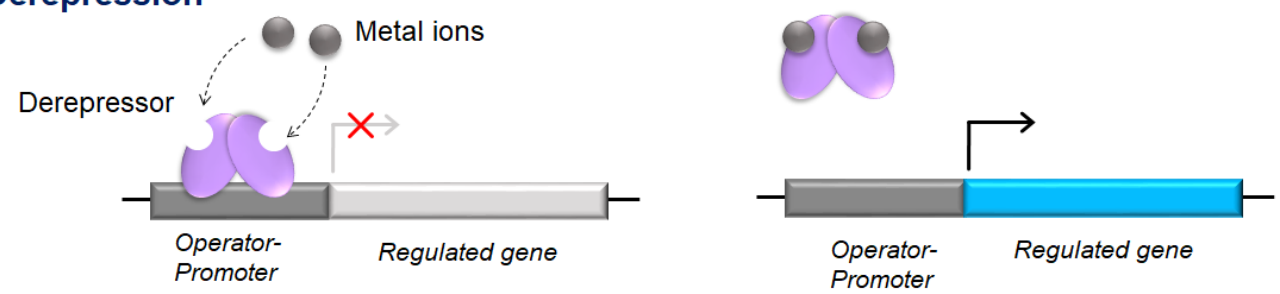

Activation
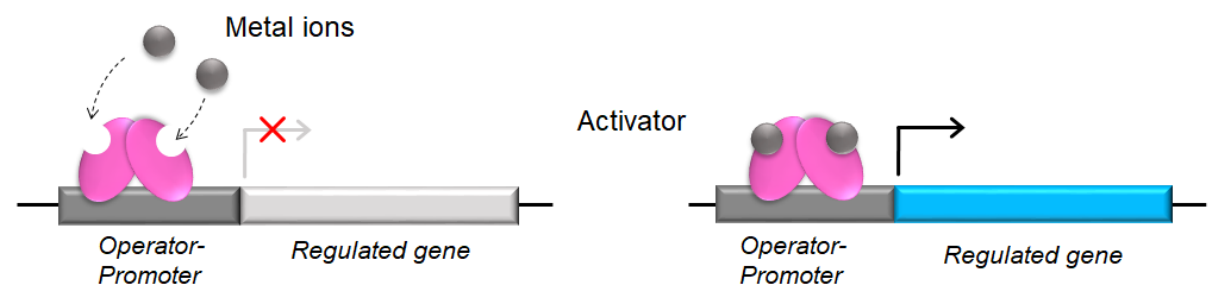

Figure 1: Schematic representation of repression, derepression and activation mechanisms in prokaryotic metalloregulation.

The largest repressor family is the Fur family, which was named after its founding member the Escherichia coli (E. coli) Fur protein which regulates the expression of iron uptake proteins. Fur homologs are the $\mathrm{Zn}$ (II) regulator Zur, the Mn(II) regulator Mur, the $\mathrm{Ni}(\mathrm{II})$ regulator Nur and the non-metalloregulator $\mathrm{H}_{2} \mathrm{O}_{2}$ responsive PerR. The structure of Fur proteins can be divided into two main parts: a $N$-terminal winged helix DNA binding domain and a $C$-terminal dimerization helix. Binding of a cognate metal ion occurs at the dimer interface stabilizing the structure. After dimerization, the protein is able to bind to 
the DNA and repress the transcription.[2] There are representatives of manganese and iron regulators, such as MntR and DtxR, also in the DtxR family. These proteins have two distinct metal binding sites. Metal ion binding induces a slight decrease in the distance between the DNA binding domains of the dimer, thereby the regulator is achieving an optimal structure for DNA recognition and binding.[2]

A structurally outstanding family is NikR named after the nickel responsive $E$. coli $\mathrm{NikR}$ repressor. This is the only family which includes tetrameric proteins belonging to the RHH(ribbon-helix-helix)-superfamily of transcription factors. The apoprotein binds DNA weakly and nonspecifically. A NikR tetramer can bind $4 \mathrm{Ni}(\mathrm{II})$ ions at the four tetrameric interfaces. The metal ion coordination causes the ordering of an otherwise

Table 1: Examples of prokaryotic metalloregulators.

\begin{tabular}{|c|c|c|c|}
\hline & Family & $\begin{array}{c}\text { Regulatory } \\
\text { protein }\end{array}$ & $\begin{array}{l}\text { Recognized metal } \\
\operatorname{ion}(s)\end{array}$ \\
\hline \multirow{10}{*}{ 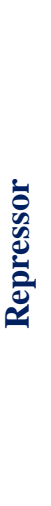 } & \multirow{4}{*}{ Fur } & Fur & $\mathrm{Fe}(\mathrm{II})$ \\
\hline & & Zur & $\mathrm{Zn}(\mathrm{II})$ \\
\hline & & Nur & $\mathrm{Ni}(\mathrm{II})$ \\
\hline & & Mur & $\mathrm{Mn}(\mathrm{II})$ \\
\hline & \multirow{2}{*}{ DtxR } & DtxR & $\mathrm{Fe}(\mathrm{II})$ \\
\hline & & MntR & $\operatorname{Mn}(\mathrm{II}), \mathrm{Cd}(\mathrm{II})$ \\
\hline & NikR & NikR & $\mathrm{Ni}(\mathrm{II})$ \\
\hline & \multirow{2}{*}{ MarR } & AdcR & $\mathrm{Zn}(\mathrm{II})$ \\
\hline & & ZitR & $\mathrm{Zn}(\mathrm{II})$ \\
\hline & LTTR & ModE & $\mathrm{MoO}_{4}^{2-}$ \\
\hline \multirow{11}{*}{ 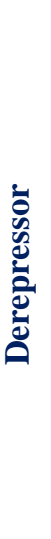 } & \multirow{7}{*}{ ArsR } & \multirow{7}{*}{$\begin{array}{c}\text { ArsR } \\
\text { SmtB } \\
\text { ZiaR } \\
\text { CadC } \\
\text { CmtR } \\
\text { NmtR }\end{array}$} & $\mathrm{As}(\mathrm{III}), \mathrm{Sb}(\mathrm{III})$ \\
\hline & & & $\mathrm{Zn}(\mathrm{II})$ \\
\hline & & & $\mathrm{Zn}(\mathrm{II})$ \\
\hline & & & $\mathrm{Cd}(\mathrm{II}), \mathrm{Pb}(\mathrm{II})$, \\
\hline & & & $\mathrm{Bi}(\mathrm{III})$ \\
\hline & & & $\mathrm{Cd}(\mathrm{II}), \mathrm{Pb}(\mathrm{II})$ \\
\hline & & & $\mathrm{Ni}(\mathrm{II}), \mathrm{Co}(\mathrm{II})$ \\
\hline & \multirow{2}{*}{ CsoR } & CsoR & $\mathrm{Cu}(\mathrm{I})$ \\
\hline & & RenR & $\mathrm{Ni}(\mathrm{II}), \mathrm{Co}(\mathrm{II})$ \\
\hline & CopY & CopY & $\mathrm{Cu}(\mathrm{I})$ \\
\hline & TetR & SczA & $\mathrm{Zn}(\mathrm{II})$ \\
\hline \multirow{7}{*}{ 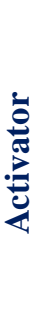 } & \multirow{7}{*}{ MerR } & MerR & $\operatorname{Hg}($ II) \\
\hline & & ZntR & $\mathrm{Zn}($ II) \\
\hline & & PbrR & $\mathrm{Pb}(\mathrm{II})$ \\
\hline & & CadR & $\mathrm{Cd}(\mathrm{II})$ \\
\hline & & CoaR & $\operatorname{Co}(\mathrm{II})$ \\
\hline & & CueR & $\mathrm{Cu}(\mathrm{I}), \operatorname{Au}(\mathrm{I}), \operatorname{Ag}(\mathrm{I})$ \\
\hline & & Gols & $\mathrm{Au}(\mathrm{I})$ \\
\hline
\end{tabular}
disordered helix that has an important role in the DNA recognition of the protein. A further important step of the regulatory mechanism of $\mathrm{NikR}$ is the binding of cellular abundant cations (i.e. $\mathrm{K}^{+}$) or excess $\mathrm{Ni}$ (II) ions in between the metal ion and the DNA binding domains. By this, the DNA binding domain is oriented properly to bind to the operator repressing the transcription of downstream genes.[2, 6]

Two recently identified repressor families are the MarR and Lys-type transcriptional regulator family (LTTR). These regulator families also have metal ion responsive members, such as the $\mathrm{Zn}$ (II) responsive AdcR regulator and the molybdate recognizing repressor, ModE.[2] 
ArsR is the largest and the most functionally diverse derepressor type metalloregulator family. It includes proteins responsible for the efflux of essential metal ions and the detoxification of poisonous metal ions. The founding member, E. coli ArsR, is unique among metalloregulators, since it regulates the metalloids $\mathrm{As}$ (III) and $\mathrm{Sb}$ (III). The SmtB and ZiaR proteins are both $\mathrm{Zn}$ (II) regulators sharing $50 \%$ sequence similarity. Members of the ArsR family are extensively studied since these proteins represent remarkable examples of how metalloregulators evolved diverse metal binding specificities via altering structurally distinct coordination sites while maintaining the same protein fold. Metal ions are bound by the $N$ - or $C$-terminal "tails" of one monomer and residues of the other monomer. Metal ion coordination negatively regulates DNA binding, hence the holoprotein dissociates from the DNA allowing to proceed the transcription. [2]

The archetype of the CopY derepressor family is the CopY protein form E. hirae with a unique, metal ion competition based mechanism of operation. Generally, the $\mathrm{Zn}$ (II) bound form of CopY binds to the operator-promoter region and represses the transcription. If the intracellular concentration of $\mathrm{Cu}(\mathrm{I})$ increases, it replaces the $\mathrm{Zn}(\mathrm{II})$ ion forming a highly luminescent $\mathrm{S}_{4}-\mathrm{Cu}_{2}$ cluster.[7] The $\mathrm{Cu}(\mathrm{I})$ bound $\mathrm{CopY}$, dissociates from the DNA resulting derepression of transcription.[2]

The CsoR family also participates in copper regulation. The founding member of the family is the $M$. tuberculosis $\mathrm{CsoR}$, a $\mathrm{Cu}(\mathrm{I})$ sensitive repressor. It was shown that upon $\mathrm{Cu}(\mathrm{I})$ binding the DNA binding affinity of the protein is greatly reduced, accordingly with the derepression model. However, the protein lacks the classical DNA binding motif and the molecular details of the DNA binding the negative regulation of that by $\mathrm{Cu}(\mathrm{I})$ ions are still unclear. A distantly related orthologue of CsoR is the $\mathrm{Ni}(\mathrm{II})$ and $\mathrm{Co}(\mathrm{II})$ sensor E. coli RenR.[2]

The most recently classified derepressor family, TetR, includes only one reported metalloregulator, the $\mathrm{Zn}(\mathrm{II})$ regulator SczA protein.[2]

The MerR family includes nearly exclusively activator proteins broadly distributed in bacteria. Similarly to the ArsR family, MerR family members sense essential metal ions, heavy metal pollutants, or respond even to oxidative stress. MerR proteins regulate a wide range of metal ions: the archetype MerR senses $\mathrm{Hg}(\mathrm{II}), \mathrm{ZntR}$ regulates $\mathrm{Zn}$ (II), $\mathrm{Cd}(\mathrm{II})$ and $\mathrm{Pb}(\mathrm{II}), \mathrm{PbrR}$ and $\mathrm{CadR}$ regulate $\mathrm{Pb}(\mathrm{II})$ and $\mathrm{Cd}(\mathrm{II})$, respectively, while CoaR is responsible for $\mathrm{Co}(\mathrm{II})$ regulation. Monovalent transition metal ions, $\mathrm{Cu}(\mathrm{I}), \mathrm{Ag}(\mathrm{I})$ and $\mathrm{Au}(\mathrm{I})$ are regulated by $\mathrm{CueR}$, but $\mathrm{Au}(\mathrm{I})$ is also sensed by the GolS metalloregulator. Characteristics of these proteins will be discussed further on in Chapter 2.3. and 2.4. The MerR family 
proteins share extensive similarities in their amino acid sequence and also in their overall fold. These regulators possess a $N$-terminal, winged helix DNA binding domain, followed by a 35 amino acid long dimerization domain, a leucine helix zipper which forms an antiparallel coiled coil structure with the helix of the other monomer. The $C$-terminal sequences, however, are more diverse than the other segments of the protein. Domain swapping experiments leading to MerR/ZntR hybrid proteins showed that the $C$-terminal region is responsible for the recognition of the effector metal ion.[8] In contrast to repressors and derepressors, both the apo- and the holo-forms of the activators bind to their cognate operator DNA between the -35 and -10 RNA polymerase (RNAP) recognition hexamers, with similar affinities. The recognition hexamers have an unusually long spacing, 19 base pair (bp) for CueR, $20 \mathrm{bp}$ for MerR and ZntR rather than the $16-18 \mathrm{bp}$ spacing found in most prokaryotic promoters. [9] Because of the long spacing, the binding of the apo-protein causes the distortion of the DNA chain inhibiting the interaction of the $\sigma^{70}$ subunit of the RNAP with the promoter. If the cognate metal ion binds to the protein the conformation changes leading to a significant unwinding and distortion of the DNA. In this activator complex the distance between the -35 and -10 elements is becoming optimal for the binding of the RNAP, and ultimately the RNAP transcribes the downstream genes.[2, 9, 10] The spacer size of the promoter elements is essential for the proper regulation of the MerR proteins. A shortened spacing causes the promoter to be highly active under all conditions, whereas a promoter with a longer spacing cannot be induced.[11]

This brief overview of metalloregulator families shows the diversity, and at the same time, the similarities of these proteins. In some cases, proteins from different families regulate the expression of genes with identical function in different organisms, for example M. tuberculosis CsoR, E. coli CueR and also E. hirae CopY regulates the expression of $\mathrm{Cu}(\mathrm{I})$ specific P-type ATPases. In other cases regulators from distinct structural families, like NikR and Zur, operate in the same organism (E. coli).[2] The selective and sensitive metal ion recognition of metalloregulators attracts wide interest due to its potential medical and environmental applications. Importantly, biophysical and structural studies of purified metalloregulatory proteins may provide insight into what governs their selectivity, the allosteric signal propagation and other details of their mechanism of operation. [4] 


\subsection{Copper homeostasis in Escherichia coli}

One of the best studied Gram-negative bacterium is the E. coli, its copper homeostasis is displayed schematically in Figure 2. E. coli possibly takes up copper ions via non-specific porin channels: $\mathrm{Cu}(\mathrm{II}) / \mathrm{Cu}(\mathrm{I})$ ions enter the periplasm first, but only $\mathrm{Cu}(\mathrm{I})$ is able to cross the inner membrane.

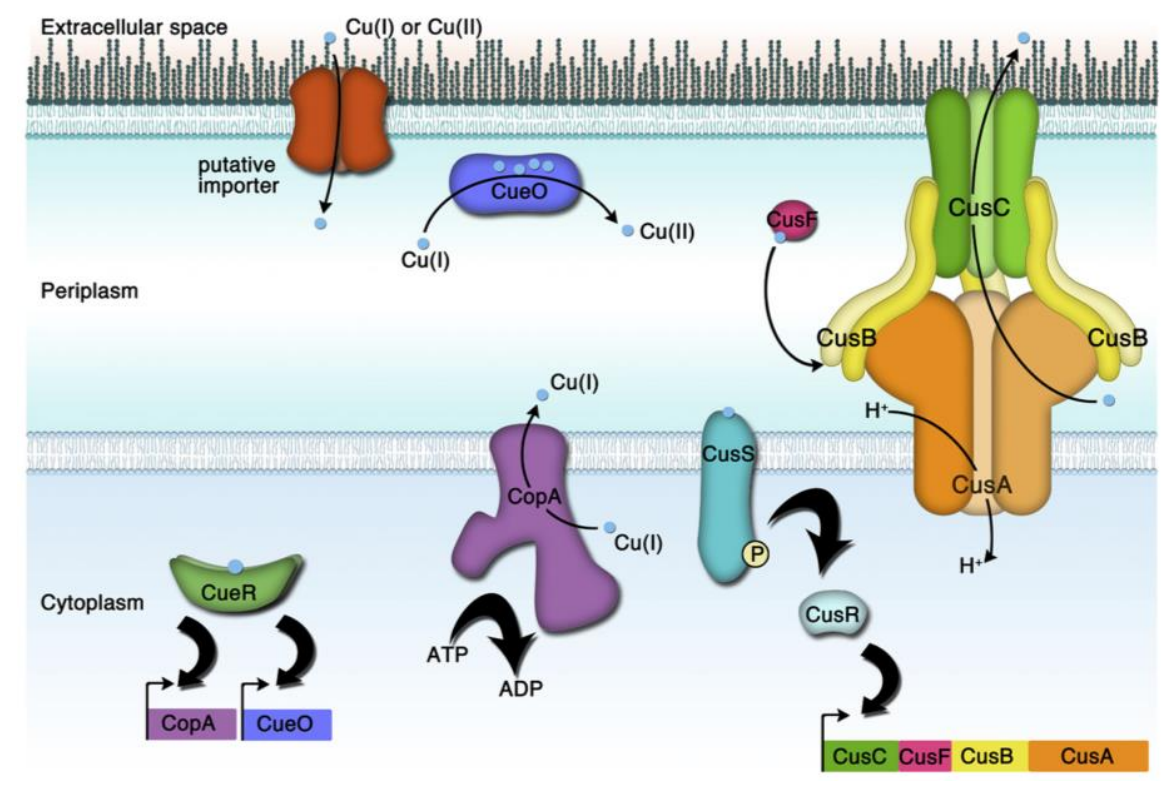

Figure 2: Copper responsive regulatory systems in E. coli.[12]

E. coli utilizes two resistance systems to cope with unfavourably high copper ion concentrations. One of these is the cus multicomponent efflux system containing the sensory-regulatory cusRS and the efflux cusCFBA elements. CusS is a membrane-anchored sensor kinase, while CusR is the cognate response regulator. Upon copper ion binding, the sensor kinase is autophosphorylated. Then the kinase transfers the phosphate group to the regulatory protein which in turn activates the transcription of the $c u s C F B A$ genes. Finally, the expressed proteins associate in a copper transporter complex which uses proton-motive force for pumping $\mathrm{Cu}(\mathrm{I})$ ions out. The CusCFBA system is especially important for cell viability at high copper concentrations and under anaerobic conditions. However, to achieve a complete copper tolerance an additional strategy is required which activates copper detoxification processes even at moderate excess of the metal ion. In E. coli, the cue system, which includes $\mathrm{CueR}$, CopA and $\mathrm{CueO}$ proteins, serves this role. CueR functions both as a sensor and a regulator. Apo-CueR is bound to the promoter region of the DNA, and upon $\mathrm{Cu}(\mathrm{I})$ binding, it activates the transcription of the copA and the сиеO genes. CopA is a P-type ATPase which is a principal component of the resistant processes, it uses energy 
from ATP hydrolysis in order to transport ions against the concentration gradient. $\mathrm{CueO}$ is a periplasmic multicopper oxidase that converts $\mathrm{Cu}(\mathrm{I})$ to less harmful $\mathrm{Cu}(\mathrm{II})$. $[13,14]$ Both of the cus and the cue systems regulate the homeostatic processes at the level of transcription.

\subsection{Features of the CueR protein}

The gene of CueR metalloregulator was first identified in E. coli K-12 as the open reading frame $y b b l .[15]$ Later it was found in many prokaryotes and some eukaryotes (the $y b b l$ gene is designated as cueR - $\mathrm{Cu}$ export Regulator). CueR is responsible for the maintenance of the cellular copper-homeostasis.[15] Based on its gene sequence it was classified as a member of the MerR family.[15] Furthermore, CueR also shares the homodimeric structure and the common fold characteristic for the MerR family. The main structural units are the $N$-terminal DNA binding domain, the dimerization helix, the $C$-terminal metal binding loop, continued in a short helix and a disordered $C$ terminus (Figure 3).[16, 17] Similarly to homologous proteins, metal ion binding occurs via well conserved cysteines of the $C$-terminal loop (Figure 4).

C112 and C120 of the metal binding loop are essential for the regulatory activity of the protein, since their mutation to serine residue $(\mathrm{C} 112 \mathrm{~S}$ and/or C120S) abolishes the transcriptional-activation response in vitro [18] and in vivo [19]. Structural studies with single-crystal X-ray diffraction analysis (SC-XRD) and with extended Xray absorption fine structure spectroscopy (EXAFS) showed that inducer metal ions coordinate in a linear bis-cysteinate
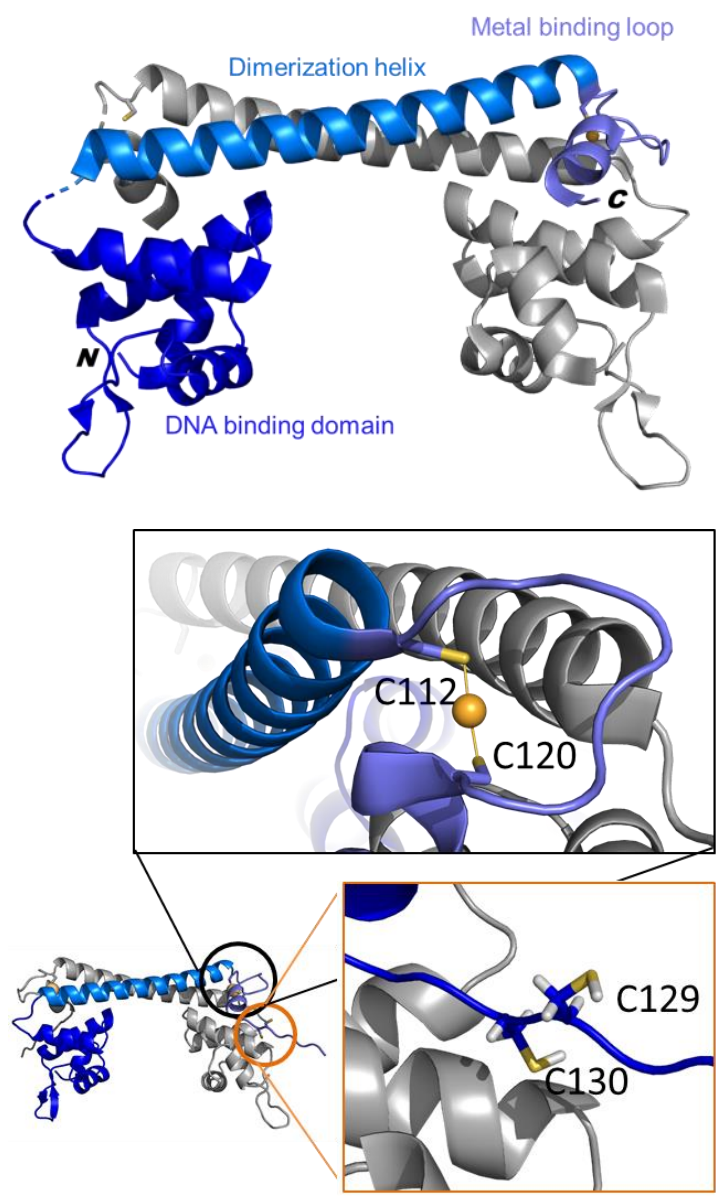

Figure 3: The potential metal binding residues and their position in the CueR protein (PDB id.: 1Q05 [16]-modified). fashion with a $\mathrm{S}-\mathrm{Cu}-\mathrm{S}$ bond angle of $176^{\circ}$ 
(Figure 3). [16, 18] CueR displays a very high affinity to $\mathrm{Cu}(\mathrm{I})$ with $K_{\mathrm{d}}=1-2 \times 10^{--21} \mathrm{M}$, in vitro.[16] There is no solved crystal structure available for the apo-protein (without DNA), therefore there is no data about how the metal ion coordination itself affects the structure of the protein, but double electron-electron resonance spectroscopy (DEER) showed that the $\mathrm{Cu}(\mathrm{I})$ binding at the $C$-terminal part of the protein has an influence on the $N$-terminal DNA binding domain and rigidifies the overall structure of the protein.[20]

A CueR (E. coli) monomer contains further two cysteines, C129 and C130, within a $\mathrm{C}$-terminal $\mathrm{CCHH}$ motif. These residues are well conserved among the CueR variants (Figure 4) suggesting that they may play a role in the operation of the protein. Despite their weak $\mathrm{Cu}(\mathrm{I})$ coordinating ability,[18] these residues were shown to be non-essential for the transcriptional activation, since their mutation did not abolish the activity in vitro.[18, 19] In the crystal structures of CueR[16] these residues are not visible due to the disordered structure of the $C$-terminus. An in vivo mutagenesis study was carried out to investigate the role of these amino acids and the overall CCHH motif.[19] The double mutation of histidine $(\mathrm{H} 131 \mathrm{~N} / \mathrm{H} 132 \mathrm{~N})$ or cysteine residues (C129S/C130S) slightly changed the sensitivity towards the cognate metal ions. Furthermore, truncation from G128, i.e. removing the $\mathrm{CCHH}$ motif, resulted in an attenuated $\mathrm{Cu}(\mathrm{I})$ response of the protein.[19] Based on the flexibility and the weak $\mathrm{Cu}(\mathrm{I})$ binding feature of this region, a metal ion chauffeuring function was suggested by which the $\mathrm{Cu}(\mathrm{I})$ coordination from the solution into the metal binding loop is facilitated.[18] It is still unexplored whether the $\mathrm{CCHH}$ fragment, which has otherwise no direct influence on the transcriptional activity of CueR, plays any role in the operation of the protein.

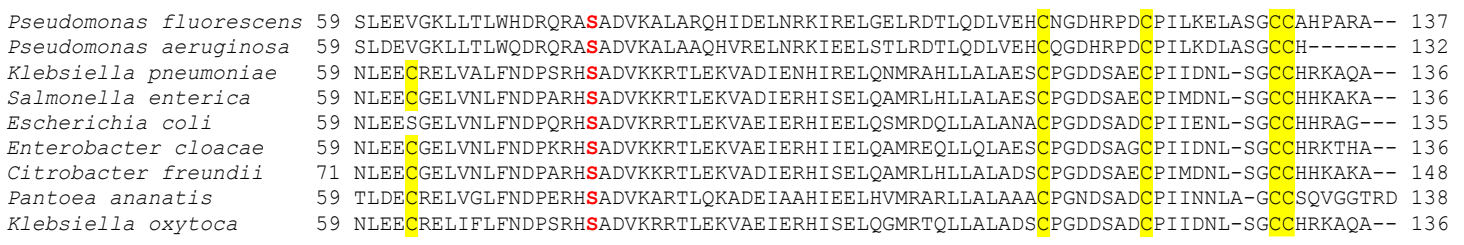

Figure 4: Alignment of CueR protein sequences from various organisms. Cysteines are highlighted with yellow background and the $S 77$ residue is typed in red letters.

Besides the cognate metal ion coordinating features, the DNA binding of CueR is also well characterized. The protein recognizes pseudo palindromic sites of the PcopA promoter which has an unusually long $(19 \mathrm{bp})$ spacer region between the -35 and -10 elements (Figure 5). Since the CueR is a transcriptional activator, both the apo- and the 
holo-forms can bind to the specific recognition sites of the DNA with almost the same affinity. The binding affinities were determined with two methods. Stoyanov et al. determined dissociation

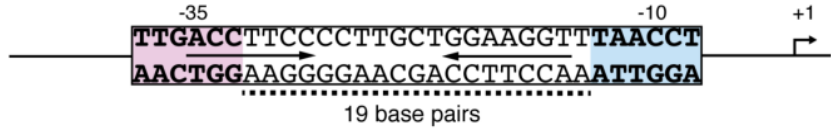

Figure 5: The E. coli PcopA sequence. -35 and -10 promoter elements separated by 19 bp highlighted with pink and blue colours, the CueR recognition site marked with arrows and +1 means the starting point of transcription. From [17], reprinted with permission from $A A A S$.

constants as $K_{\mathrm{d}(\mathrm{apo}-\mathrm{CueR})}=17( \pm 2)$

$\mathrm{nM}, K_{\mathrm{d}(\mathrm{Cu}(\mathrm{I})-\mathrm{CueR})}=25( \pm 7) \mathrm{nM}$ and $K_{\mathrm{d}(\mathrm{Ag}(\mathrm{I})-\mathrm{CueR})}=15( \pm 1.2) \mathrm{nM}$ with a gel shift assay,[15] while another group determined slightly bigger affinities, $K_{\mathrm{d}(\text { apo-CueR) }}=6( \pm 2) \mathrm{nM}$ and $K_{\mathrm{d}(\mathrm{Cu}(\mathrm{I})-\mathrm{CueR})^{\prime}}=1.9( \pm 0.8) \mathrm{nM}$ with a fluorescence anisotropy titration study.[21] In addition to the specific interaction with the recognition sites, CueR binds DNA non-specifically, as well. There is no structural evidence yet (e.g. crystal structure of CueR with non-specific DNA fragment), but based on single molecule fluorescence resonance energy transfer (smFRET) experiments the non-specific binding differs from the binding of a specific DNA, it takes place most probably without the distortion of the DNA.[22] By utilizing stroboscopic single-molecule tracking (SMT) method, the diffusion states of apo- or holoCueR were determined in vivo. These values confirmed that CueR exists in three forms in the cell: freely diffusing $\left(\mathrm{D}_{\mathrm{FD}}=3.7 \mu \mathrm{m}^{2} \mathrm{~s}^{-1}\right)$, specifically bound to the recognition sites $\left(\mathrm{D}_{\mathrm{SB}}\right.$ $\left.=0.04 \mu \mathrm{m}^{2} \mathrm{~s}^{-1}\right)$ or non-specifically bound and moving on the chromosome $\left(\mathrm{D}_{\mathrm{NB}}=0.7 \mu \mathrm{m}^{2} \mathrm{~s}^{-}\right.$ 1).[23] Non-specific interactions with DNA allow the CueR protein to slide along the chromosome and find specific sites easier because of the reduced dimensionality of the searching.[21, 23]

The molecular details of the allosteric structural changes induced by a cognate metal ion are hypothesised from the crystal structures of the DNA complex formed with the repressor (i.e. C112S, C120S and C129 - G135 deleted apo-CueR variant) and the activator (i.e. $\mathrm{Ag}(\mathrm{I})-\mathrm{CueR}$ ) forms of CueR.[17] Basically, the same protein-DNA interactions can be observed in both the repressor and the activator complex. CueR binds to the phosphate groups of the DNA backbone via an R-clamp consisting of three arginine resides (R18, R31 and R37) from the DNA binding domain. Mutagenesis and functional assays revealed that all three arginines are required for transcription activation. Moreover, direct base contacts via H-bonds are formed with Y36 and K15 by inserting into the minor and the major groove, respectively. These residues may confer the DNA-binding site specificity of the protein. A van der Waals contact is also formed by F19 which is a conserved residue in the 
MerR family.[17] The allosteric switch initiated when the cognate metal ion stabilizes the conformation of the loop by binding to the cysteine residues. This triggers displacement of residues included in the H-bond network. For instance, R75 provides a direct and essential allosteric link between the DNA binding domain and the metal-binding domain. In the apoCueR the side chain of R75 forms a H-bond with the backbone carbonyl oxygen of A118 of the metal binding domain, and upon metal ion binding to the loop, the position of R75 is changed forming $\mathrm{H}$ bonds with the backbone carbonyl oxygen atoms of D72 and F70 residues of the DNA binding domain. The R75A mutation decreases transcription activation in vivo consistent with the loss of the H-bond network.[17] The activator form is further stabilized by the docking of the $C$-terminal helix via residues I122, I123, L126 into the opened hydrophobic pocket formed by residues of the dimerization helix and the DNA binding domain (Figure 6). The existence of such an allosteric signal of the $C$-terminal helix towards the DNA-binding domain was confirmed by establishing a $\mathrm{Cu}(\mathrm{I})$-independent constitutive activator (T84V/N125L/C112S/C120S) and a constitutive repressor (truncation from I122) mutants of CueR, as well.[17]

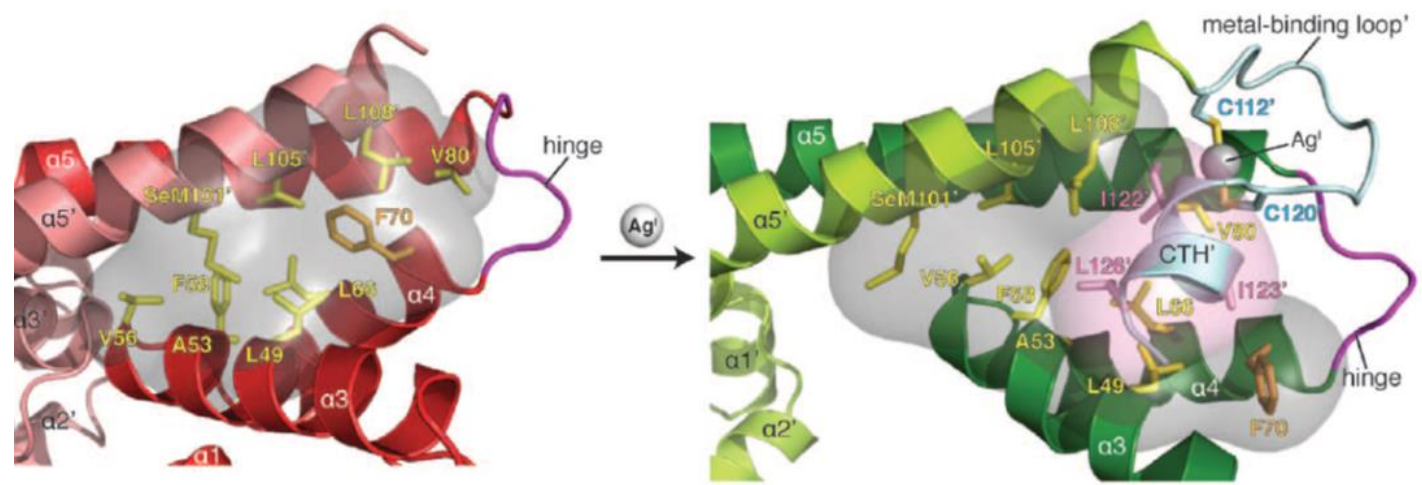

Figure 6: Transformation of the C-terminal helix in the repressor (red) and activator (green) CueR. The surface of the C-terminal helix is coloured in pink. The hydrophobic residues forming the cavity are coloured in yellow, and their surface is shown in grey. From [17], reprinted with permission from AAAS.

The relatively small changes in the structure cause a slight „scissors” motion of the dimeric protein (decreasing the dihedral angle by $\sim 33^{\circ}$ ) and a more significant difference in the DNA conformation (Figure 7). The pseudo angle of the DNA (the angle between the center-of mass of the central $7 \mathrm{bp}$ and the $7 \mathrm{bp}$ on either sides) was defined in the repressor complex as $\theta_{\mathrm{R}}=171^{\circ}$ and in the activator complex as $\theta_{\mathrm{A}}=135^{\circ}$. The apo-CueR slightly distorts the DNA (the angle in an ideal B-DNA is $180^{\circ}$ ), and the holo-CueR kinks it by further $36^{\circ}$. Such bending of the DNA shortens the space between the promoter elements 
( -35 and -10 sites) and the distance becomes close to that of a $17 \mathrm{bp}$ consensus promoter. Furthermore, the activator CueR also twists the DNA resulting in the re-orientation of the two promoter elements. By these changes the minor groove becomes wider than the major groove.[17]

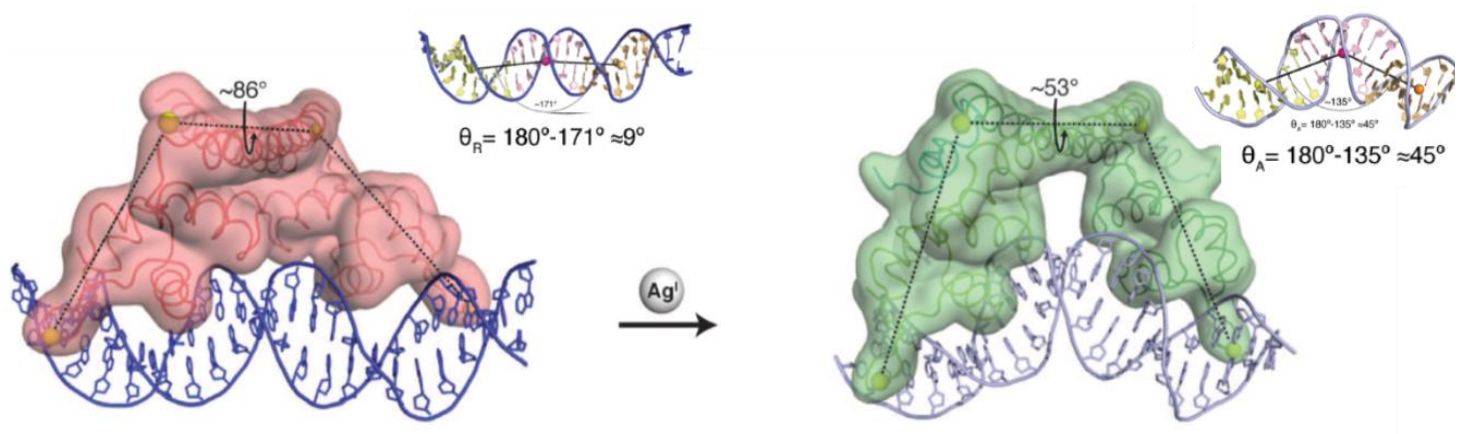

Figure 7: The slight ,scissors" motion of the repressor (pink) and activator (green) forms upon metal binding resulting in kinked and undertwisted DNA. From [17], reprinted with permission from $A A A S$.

The repressor and activator complexes were modelled onto Taq RNA polymerase. The results of these models show that CueR and the RNAP can bind on opposite faces of the DNA without steric penalties (Figure 8). The interaction of the -35 element of the repressor complex with the $\sigma 4$ domain of RNAP forces away the -10 element from the $\sigma 2$ domain which prevents contacts of RNAP with the promoter, therefore the transcription is not possible. However, the major kink and slight twist in the DNA of the activator complex brings the -10 element close to the $\sigma 2$ domain which allows the RNA polymerase to bind and start the transcription.[17]

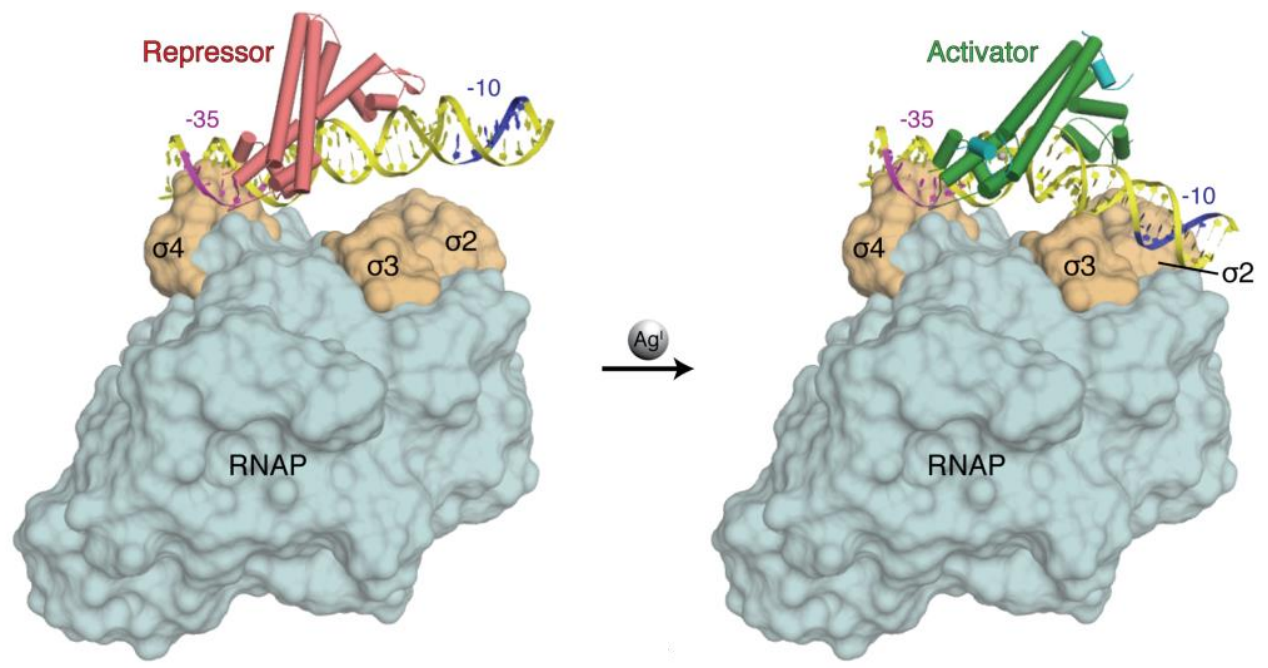

Figure 8: Repressor (pink) and activator (green) CueR-DNA complexes superimposed to the Taq RNAP. Core promoter elements, -35 and -10, are coloured in magenta and blue, respectively. From [17], reprinted with permission from AAAS. 
After understanding the difference between the repressor and the activator conformations of the CueR-DNA complexes, the next question is how CueR can switch the transcription event on and off while staying bound to a single site of the DNA. Regulation of this switch is essential for the cells. Under normal conditions, the expression of metal resistance genes would be an energy wasting process, moreover it would lead to copper deficiency. However, to avoid toxic effects of an increased copper level, the transcription should be activated immediately, and maintained until the homeostasis is in balance again. This transcriptional switching event is supposed to occur by a continuous exchange of the apo- and holo-forms of the CueR on the recognition site of the DNA. For the activation of the transcription, the holo-CueR may exchange the apo-form on the promoter, instead of a direct metallation of the promoter-bound apo-protein, since the probability of the metal ion binding to the freely diffusing copies of apo-CueR is higher.[23] Similarly, the repression of the transcription via exchanging the holo-form on the promoter by an apo-CueR is more probable than by the release of the tightly bound metal ions.[23] There is no evidence that CueR undergoes thiol ligand exchange reactions with, for instance metallothioneins or copper chaperones.[22] In vitro[20, 22] and in vivo[23, 24] experiments supported an exchange mechanism which requires well-tuned binding and unbinding of the dimeric protein to/from the promoter. Generally, the DNA binding is characterized by single-step kinetics, therefore it is directly influenced by the concentration of the holo- or apo-CueR, that is the binding rate increases with an increasing protein concentration.[23] The copy number of CueR in E. coli under normal conditions was determined to be $\sim 60,[18]$ and under $\mathrm{Cu}(\mathrm{I})$ stress the copy number increases, [23] however, it is not known whether or how the CueR expression is regulated.[15] DEER experiments showed that there is a continuous exchange between the apo-CueR, $\mathrm{Cu}(\mathrm{I})-\mathrm{CueR}$ and $\mathrm{Cu}(\mathrm{I})-\mathrm{CueR}-\mathrm{DNA}$ forms in solution, and increasing $\mathrm{Cu}(\mathrm{I})$ concentration shifts the equilibrium towards the $\mathrm{Cu}(\mathrm{I})$-CueR-DNA form.[20] On the contrary, unbinding of the protein from the DNA is an unimolecular process, thus its kinetics should be independent of the protein concentration.[22] In vitro smFRET[22] and in vivo SMT[23] studies revealed that the unbinding of CueR unexpectedly depends on the protein concentration, i.e. the free CueR proteins facilitate the unbinding of the bound protein from the DNA. This is proposed to take place via the formation of a ternary complex, where one of the two DNA-binding domains of the homodimeric CueR detaches allowing another CueR molecule to bind. This ternary complex can then either fall apart, that is called an assisted-dissociation pathway, or undergo a swap of the two proteins, named as direct-substitution pathway (Figure 9).[24] 
In support of this model, the binding affinity of apo-CueR to a DNA containing only the half of the dyad-symmetric recognition sequence was determined as $K_{\mathrm{d}} \sim 0.7 \mu \mathrm{M}$ showing that CueR can indeed bind with only one DNA binding domain.[21] The facilitated unbinding pathways were only observed when the CueR was bound to a specific recognition site.[22]

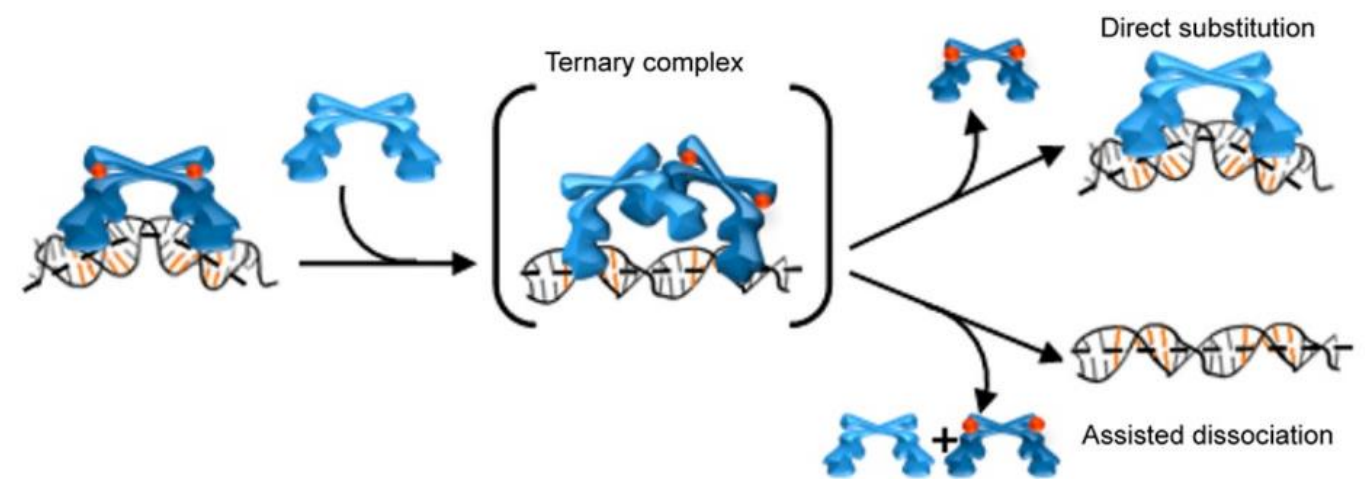

Figure 9: Proposed mechanism of direct-substitution and assisted dissociation pathways for the unbinding of CueR from a specific DNA-binding site involving a ternary $(C u e R)_{2}-D N A$ complex as an intermediate. Reprinted with permission from [24]. Copyright (2018) American Chemical Society.

In vivo SMT experiments also provided an explanation of how the cell might control the transcriptional switching during the growth cycle by showing that the chromosome organization (condensation) also modulates the unbinding of CueR form the DNA, interestingly in the opposite ways for the apo- and the holo-forms.[23] In cells with a condensed chromosome the apparent unbinding rate constant of the apo-CueR is smaller, while that of the holo-CueR is larger than in cells with a loose chromosome. Under optimal growth conditions, cells divide frequently, and dividing cells have a highly condensed chromosome, therefore the unbinding of apo-CueR from the promoter is slower. This results in the repression of the expression, by which the cell saves energy for division. On the other hand, under metal stress condition the cells barely divide, therefore their chromosome is less condensed. From a loose chromosome the apo-CueR unbinds quickly, increasing the probability of holo-CueR binding which facilitates the activation of transcription. At the same time, the unbinding of holo-CueR is slow which keeps the activation lasting longer and ultimately defending the cell against the $\mathrm{Cu}(\mathrm{I})$ ion excess caused stress.[23]

CueR possesses high metal ion selectivity in order to achieve an adequate regulation. According to in vitro assays CueR activates the transcription only in the presence of single-charged transition metal ions, as $\mathrm{Cu}(\mathrm{I}), \mathrm{Ag}(\mathrm{I})$ and $\mathrm{Au}(\mathrm{I})$, while double- 
charged metal ions, like $\mathrm{Hg}(\mathrm{II})$ and $\mathrm{Zn}(\mathrm{II})$, do not initiate the activation (Figure 10).[16] This is especially remarkable considering the well-known preference of $\mathrm{Hg}(\mathrm{II})$ ions for bisthiolate coordination environment.[25] This selectivity was explained by electrostatic- and hydrogen-bonding interactions. The $\mathrm{S}-\mathrm{Cu}-\mathrm{S}$ center formally has a net negative charge which is proposed to be neutralized by the positively charged end of the helix dipole and by two H-bonds originating from the $C$-terminal helix. Furthermore, a fairly distant residue, $\mathrm{K} 81$, might additionally contribute charge neutralization on C112.[16] The metal ion selectivity of CueR has also attracted attention as a probe for improving

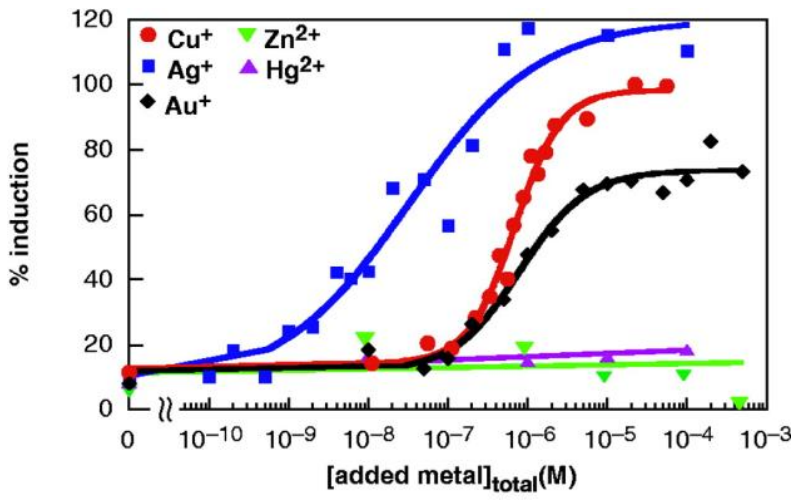

Figure 10: Metal selectivity and sensitivity of CueR in transcriptional regulation of copA in vitro. From [16]. Reprinted with permission from AAAS. computational methods aiming to estimate the absolute binding affinity of metal ions to a given protein.[26] It was shown that the metal binding loop of CueR is flexible enough to accommodate a $\mathrm{Hg}(\mathrm{II})$, and even a $\mathrm{Zn}(\mathrm{II})$ ion with a tetrahedral coordination geometry involving two water molecules. The calculated binding affinities followed the $\mathrm{Hg}(\mathrm{II})>\mathrm{Au}(\mathrm{I})>\mathrm{Ag}(\mathrm{I}) \sim \mathrm{Cu}(\mathrm{I})>\mathrm{Zn}$ (II) order. The affinities of monovalent metal ions were the highest if one or both cysteines (C112, C120) were deprotonated, however, divalent ions showed preference for the fully deprotonated cysteine ligands. The lack of transcriptional response of CueR for $\mathrm{Hg}(\mathrm{II})$ despite the high binding affinity was also explained by the strong competition with other thiol-containing molecules (e.g. glutathione) present in the cell, which may prevent the $\mathrm{Hg}$ (II) binding of CueR.[26] Understanding the metal ion selectivity of CueR was also approached via investigating the $\mathrm{Ag}(\mathrm{I}), \mathrm{Zn}(\mathrm{II})$ and $\mathrm{Hg}(\mathrm{II})$ binding of model peptides of the metal ion binding loop of CueR from E. coli and Vibrio cholerae.[27] Characterization of these peptides in the presence of the different metal ions and at different $\mathrm{pH}$ values revealed that one of the cysteines displays a unique $\mathrm{p} K_{\mathrm{a}} \sim 6.5$ for deprotonation constant in the presence of $\operatorname{Ag}(\mathrm{I})$ ion while the other cysteine residue is deprotonated and coordinated to $\operatorname{Ag}(\mathrm{I})$ already under acidic conditions. Spectroscopic data, especially those of UV-pH titrations, suggested that the second cysteine may also coordinate to $\mathrm{Ag}(\mathrm{I})$ below neutral $\mathrm{pH}$ as a protonated thiol. On the contrary to these findings, the deprotonation and coordination of both cysteines occurs at $\mathrm{pH}<6$ in the presence of $\mathrm{Hg}$ (II) and $\mathrm{Zn}$ (II) ions. With quantum- 
chemical methods a possible consequence of the protonation of C112 was suggested. When C112 protonates the backbone carbonyl oxygen atom of the S77 residue of the other monomer is "pulled" towards the metal site by a H-bond, and this small reorganization may trigger the allosteric changes in the overall structure of the CueR dimer. Since such a protonation induced switching possibly occurs only in the monovalent metal ion bound CueR, this might explain the metal ion selectivity of the protein.[27]

Although CueR is one of the most thoroughly characterized proteins in the MerR family, structural and biochemical characterization of the $\mathrm{Hg}(\mathrm{II})$-bound CueR was not carried out so far. Furthermore, despite the above elaborated findings, the mechanism of how CueR discriminates between mono and divalent metal ions is still not fully understood.

\subsection{CueR related homologs}

A careful analysis of the characteristic features of homologous proteins from the MerR family could be beneficial for the better understanding of the operation of CueR. The archetype MerR protein recognizes submicromolar $\mathrm{Hg}(\mathrm{II})$, even in the presence of millimolar concentrations of competing small molecular thiol ligands, and activates the expression of mercury binding (MerC, MerP and MerT), mercurial lysate (MerB) and mercury reductase (MerA) proteins. From the crystal structures of Bacillus megaterium MerR[28] and Tn501 MerR from Pseudomonas aeruginosa[29], it is known that $\mathrm{Hg}(\mathrm{II})$ binds in a planar trigonal geometry to the S-atoms of three conserved cysteine residues: one cysteine from one monomer (C82 of Tn501 MerR) and two cysteines from the other monomer $(\mathrm{C} 117$,

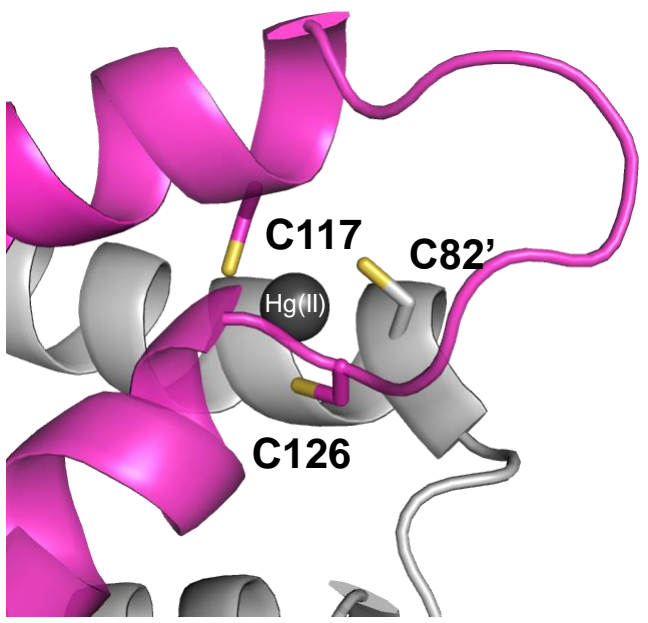

Figure 11: The coordination of $\mathrm{Hg}(\mathrm{II})$ to Tn501 MerR, PDB id.: 5CRL [29] C126 of Tn501 MerR) (Figure 11). These latter residues are located in the flexible metalbinding loop in positions corresponding to residues C112 and C120 of CueR (Figure 12). Mutation of any of these cysteines dramatically decreases the affinity of the protein for $\mathrm{Hg}(\mathrm{II})$. In spite of the planar trigonal coordination geometry being unusual for $\mathrm{Hg}(\mathrm{II})$, the association constant of Tn501 MerR for mercury(II) was estimated, via a competition study with $L$-cysteine, to be on the order of $10^{47}$.[29] In vitro studies showed that $\mathrm{Cd}(\mathrm{II}), \mathrm{Zn}(\mathrm{II})$, 
$\operatorname{Ag}(\mathrm{I}), \mathrm{Au}(\mathrm{I})$ and $\mathrm{Au}(\mathrm{III})$ ions in a two- or three-orders of magnitude higher concentration compared to $\mathrm{Hg}$ (II) can partially trigger the transcription activation.[30] However, the concentration of these metal ions in vivo is never as high as was in the in vitro experiments, thereby MerR does not activate the transcription by the intracellular level of $\mathrm{Ag}(\mathrm{I}), \mathrm{Au}(\mathrm{I})$, or $\mathrm{Zn}(\mathrm{II}) \cdot[29]$

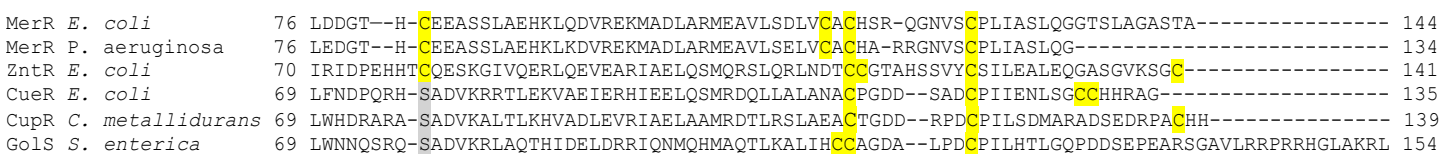

Figure 12: Sequence alignment of members from the MerR family. The cysteine residues are highlighted with yellow background.

Another representative regulator of the MerR family recognizing divalent metal ions is $\mathrm{ZntR}$. This protein regulates the $z n t A$ gene encoding a $\mathrm{Zn}(\mathrm{II})$-translocating P-type ATPase. Besides $\mathrm{Zn}$ (II), Cd(II) and $\mathrm{Hg}$ (II) ions also induce the expression of ZntA. [8] The induction by $\mathrm{Cd}(\mathrm{II})$ can be considered to be functional, since ZntA plays a role in $\mathrm{Cd}(\mathrm{II})$ resistance processes. However, the induction by $\mathrm{Hg}(\mathrm{II})$ is considered biologically irrelevant, because it is a result of the high similarities of the metal binding domain of MerR and ZntR (Figure 12).[8] The ZntR protein possesses a femtomolar sensitivity towards $\mathrm{Zn}(\mathrm{II}),[31]$ and the $K_{\mathrm{d}}$ was determined as $1.1 \times 10^{-15} \mathrm{M}[32]$. This high affinity ensures that the ZntR protein can successfully compete with endogenous $\mathrm{Zn}(\mathrm{II})$-binding proteins of the cell. The crystal structure of holo-ZntR[16] revealed that one metal binding domain of $\mathrm{ZntR}$ coordinates two $\mathrm{Zn}(\mathrm{II})$ ions (Figure 13): one $\mathrm{Zn}(\mathrm{II})$ is coordinated by $\mathrm{C} 114$ and $\mathrm{C} 124$ from one monomer and by $\mathrm{C} 79$ of the other monomer, the

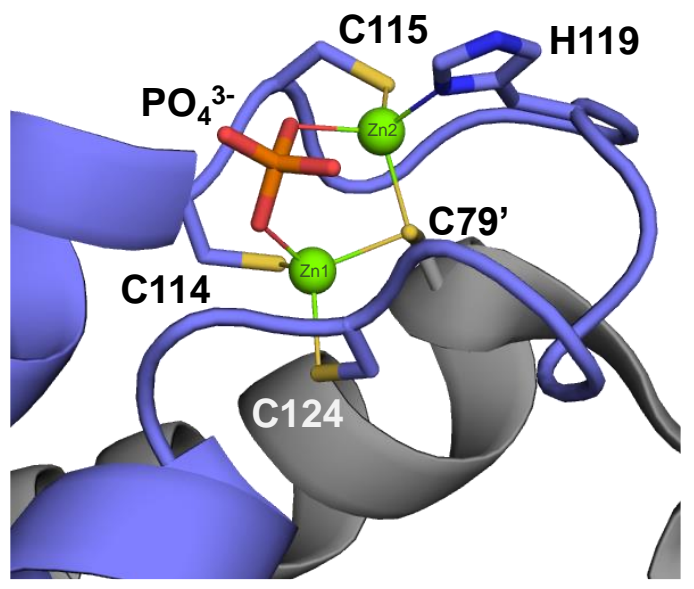

Figure 13: The coordination of Zn(II) ions to E. coli ZntR, PDB id.: 1Q09.[16] other $\mathrm{Zn}(\mathrm{II})$ is coordinated by $\mathrm{C} 115$ and $\mathrm{H} 119$ of one monomer and $\mathrm{C} 79$ of the other monomer. Both $\mathrm{Zn}(\mathrm{II})$ ions are bound in a tetrahedral coordination environment, and $\mathrm{C} 79$ acts as a bridging ligand to the two $\mathrm{Zn}(\mathrm{II})$ ions.[16]

CupR and GolS of the MerR metalloregulators sense monovalent metal ions. CupR (Ralstonia metallidurans) was shown to play role in gold stress sensing, although $\mathrm{Cu}(\mathrm{I})$ excess also increases the transcription level of the CupR regulated genes in vivo.[33] 
Biochemical characterization of the CupR protein showed that a monomer can bind one or two $\mathrm{Cu}(\mathrm{I})$ ions with slightly different affinities: $K_{\mathrm{d} / \mathrm{Cu}(\mathrm{I}) 1}=7.7 \times 10^{-17} \mathrm{M}$ and $K_{\mathrm{d} / \mathrm{Cu}(\mathrm{I}) 2}=$ $6.3 \times 10^{-19} \mathrm{M}$, or one $\mathrm{Au}(\mathrm{I})$ ion with $K_{\mathrm{d} / \mathrm{Au}(\mathrm{I})}=7.2 \times 10^{-35} \mathrm{M}$. X-ray absorption spectroscopy (XAS) and EXAFS measurements showed that one $\mathrm{Cu}(\mathrm{I})$ ion may be coordinated by three ligands which are the two conserved cysteines, C112 and C120, and possibly the third C137 residue of the $C$-terminal $\mathrm{CHH}$ motif. Aiming to characterize the role of this $\mathrm{CHH}$ motif, a $C$-terminally truncated mutant (deletion from C137) was also investigated. The deletion of the cysteine containing terminus prevented the binding of the second $\mathrm{Cu}(\mathrm{I})$ ion, meanwhile the affinity towards the first $\mathrm{Cu}(\mathrm{I})$ was preserved $\left(K_{\mathrm{d} / \mathrm{Cu}(\mathrm{I})}{ }^{\prime}=2.1 \times 10^{-18} \mathrm{M}\right)$, however the $K_{\mathrm{d}}$ value for $\mathrm{Au}(\mathrm{I})$ increased $\left.\left(K_{\mathrm{d} / \mathrm{Au}(\mathrm{I})}\right)^{\prime}=1.0 \times 10^{-32} \mathrm{M}\right)$. [33] Thus, the $\mathrm{CHH}$ motif was assumed to play an important role in the $\mathrm{Au}(\mathrm{I})$ recognition of CupR.[33]

GolS (Salmonella typhimurium) shows high sequence similarity with CueR, and like CupR, it regulates $\mathrm{Au}(\mathrm{I})$ resistance genes. The regulated golT and golB genes encode a P-type ATPase and a chaperone.[34] GolS lacks the $C$-terminal cysteine-histidine rich motif which is otherwise present in CueR and CupR. Interestingly, in GolS the metalbinding loop was showed to be responsible for $\mathrm{Au}(\mathrm{I})$ selectivity: replacing the metalbinding loop of the GolS with the loop-segment of CueR (I109 - C120) increased the in vitro sensitivity to $\mathrm{Cu}(\mathrm{I})$.[34] In a later study, such loop-replacement was utilized to establish a GolS based, broad-spectrum whole-cell biosensor for metal ions.[35]

Noticeably, in the MerR proteins an amino acid at the $N$-terminal end of the dimerization helix indicates if the regulator protein recognizes mono or divalent metal ion(s) (Figure 12). A serine is found at this position in all MerR homologs that are responsive to single charged ions (e.g. S77 in CueR, CupR and GolS), whereas a cysteine is present in homologs that respond to double charged ions (e.g. C82 in MerR and C79 in ZntR).[16, 36] The S77 residue of CueR was found to interact with the C112 and D115 residues of the metal binding loop.[16] All these three residues appear to be well conserved in $\mathrm{M}(\mathrm{I})$ ion regulators. On the contrary, in $\mathrm{M}(\mathrm{II})$-sensitive regulators the cysteine at this position participates directly in metal ion binding.[36] The role of S77 was investigated with whole cell bacterial sensors. These sensors are genetically modified bacteria developed for producing fluorescent signal recognized by GolS. In vivo experiments showed that the replacement of S77 by a cysteine in both GolS and CueR yields an inducible response in the presence of $\mathrm{Hg}(\mathrm{II})$ ions, indicating that the S77C substitution provides a third S ligand to coordinate divalent metal ions. Other mutations were also 
investigated: S77A substitution did not modify the response to monovalent metal ions, however the replacement of S77 by threonine, proline, glutamic acid, or lysine rendered inactive sensors. Thereby, this particular serine residue seems to be a key element to the selectivity of monovalent metal ion sensitive MerR family member proteins.[36]

\subsection{Basis of metal ion selectivity in metalloregulators}

The outstanding metal ion selectivity of bacterial metalloregulatory proteins is the key element for the proper regulation of metal homeostatic processes. Studies aiming at the understanding of the sophisticated mechanisms, ensuring the recognition of the "right" metal ions, became an active area of investigation. Several profound work were carried out about this field discovering the ways how these proteins achieve selectivity. [2, 5, 37]

A challenge is immediately imposed by the natural order of stability for divalent metal ions which follows a universal order, also known as the Irving-Williams series, $\mathrm{Mg}(\mathrm{II})<\mathrm{Ca}(\mathrm{II})<\mathrm{Mn}(\mathrm{II})<\mathrm{Fe}$ (II) $<\mathrm{Co}$ (II) $<\mathrm{Ni}$ (II) $<\mathrm{Cu}(\mathrm{II})>\mathrm{Zn}($ II) (Figure 14). This actually means that if these metal ions were present in the cytosol in the same amount and with the same availability, all the proteins would bind $\mathrm{Cu}(\mathrm{II})$. In the reducing intracellular environment, the cuprous $(\mathrm{Cu}(\mathrm{I}))$ form of the copper is predominant which is also a highly competitive metal ion, as are several toxic metal ions, for example $\mathrm{Cd}(\mathrm{II}), \mathrm{Hg}(\mathrm{II})$ and $\operatorname{Ag}(\mathrm{I})$.[37] In fact, the intracellular amount of metal ions is so limited that there is a competition between proteins and other molecules for binding metal ions rather than between metal ions for binding to a protein. Therefore, the relative affinities of proteins determine which protein binds a specific metal ion.[37] Among metalloregulators affinity of the sensory protein for the cognate metal ion correlates with the concentration of "free" metal ion in the cytosol (Figure 14). For example, the $\mathrm{Mn}(\mathrm{II})$ binding affinity of MntR is characterized by a $K_{\mathrm{d}}=10^{-5} \mathrm{M}$ matching the estimated $\sim 10 \mu \mathrm{M}$ cytoplasmic manganese concentration. Similarly, the $K_{\mathrm{d}}=10^{-12} \mathrm{M}$ represents the affinity of NikR for Ni(II), $K_{\mathrm{d}}=$ $10^{-15} \mathrm{M}$ of $\mathrm{ZntR}$ and Zur for $\mathrm{Zn}(\mathrm{II})$ and $K_{\mathrm{d}}=10^{-21} \mathrm{M}$ of CueR for $\mathrm{Cu}(\mathrm{I})$ implies that the cytoplasmic concentration of these metal ions decrease in this order, therefore the amount of unbound $\mathrm{Cu}(\mathrm{I})$ and $\mathrm{Zn}(\mathrm{II})$ ions in the cytoplasm is vanishingly small (Figure 14). By restricting the effective concentration of the most competitive metal ions $(e . g$. $\mathrm{Cu}(\mathrm{I}))$, the less-competitive metal ions (e.g. $\mathrm{Mg}(\mathrm{II}), \mathrm{Mn}(\mathrm{II})$ ) can bind to the weak metal binding sites.[5, 37] 


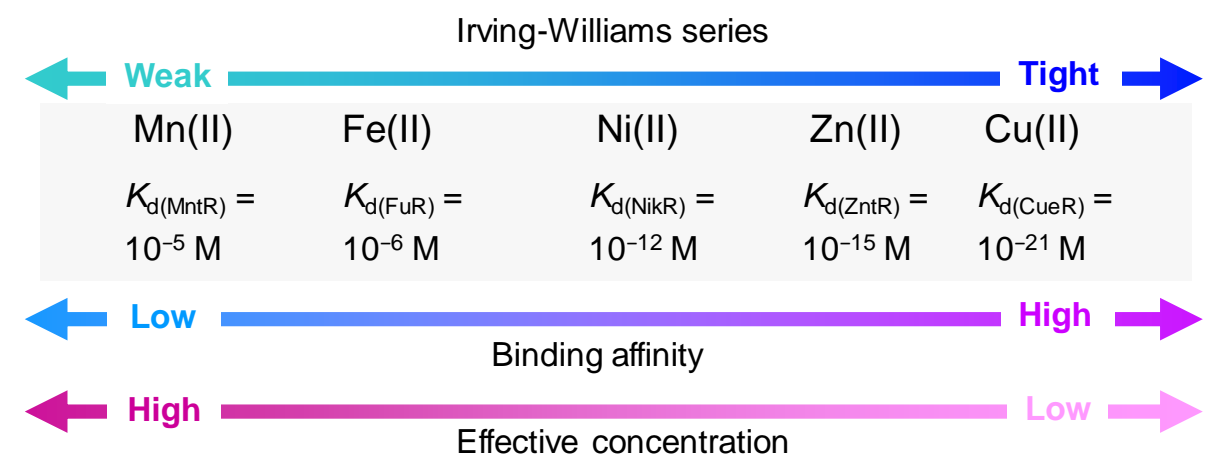

Figure 14: Comparing the tendency of affinity of metalloregulators, the Irving-William series and the cytoplasmic concentration of metal ions.

In some cases, binding of a metal ion to the adequate protein is assisted by metallochaperones or small molecule metal ion chelators. Their function is to provide the metal ion in such a way that it can be readily transferred to the acceptor protein. Such intermolecular metal-ligand exchange happens only if the appropriate interactions are formed, and therefore the selectivity of these interactions determines the selective metal ion binding of the acceptor protein.[2] For instance, the CopZ chaperone ensures the coordination of $\mathrm{Cu}(\mathrm{I})$ ions to $\mathrm{CopY}$ in E. hirae.[2]

A further possibility for achieving selectivity originates from the regulatory mechanisms of the metalloregulators. Generally, the quaternary structure and the DNA binding affinity of the protein are altered when the metalloregulator turns the transcription on or off. Upon cognate metal ion binding, the local re-arrangement of charges and donor ligands occurs which leads to the functional conformation of the protein. For instance, in repressors the coordination of cognate metal ion allosterically induces the high DNA affinity conformation of the regulatory protein which ultimately results in the binding of the protein to the operator DNA and the repression of the transcription. Accordingly, the selectivity does not strictly follow the metal binding preferences of the proteins. Noncognate, "wrong", metal ions might bind more tightly to the metalloregulator than the cognate ones, but with a different coordination geometry that is inappropriate for triggering of the required structural change.[2, 5, 38, 39] As an example, MntR possesses a weaker affinity for the inducer metal ion $\mathrm{Mn}$ (II) than for $\mathrm{Ni}$ (II), $\mathrm{Zn}$ (II) or $\mathrm{Co}$ (II) but only $\mathrm{Mn}$ (II) can trigger the appropriate structural change leading to strong interaction between MntR and DNA.[40] Another representative example is the repressor protein NmtR which recognizes only $\mathrm{Ni}$ (II) and $\mathrm{Co}(\mathrm{II})$ in vivo, but has a higher affinity for $\mathrm{Zn}$ (II) compared to the inducer metal ions. $\mathrm{Ni}(\mathrm{II})$ is bound in a distorted octahedral fashion while $\mathrm{Co}(\mathrm{II})$ is 
coordinated by five or six ligands in the protein. $\mathrm{Zn}(\mathrm{II})$, however, accommodates a tetrahedral coordination environment, indicating that a higher coordination number is essential to promote the conformational change necessary for the protein function. [41] The coordination geometry is important also in a $\mathrm{Cu}(\mathrm{I})$-sensing transcriptional repressor, $\mathrm{CsoR}$, coordinating $\mathrm{Cu}(\mathrm{I})$ ions in a trigonal fashion. It was shown that CsoR also binds $\mathrm{Ni}(\mathrm{II})$ and $\mathrm{Zn}$ (II) with very high affinity but in a non-trigonal coordination geometry preventing the protein to bind DNA in vitro.[2] Similarly, if NikR binds the inducer metal ion Ni(II), an $\alpha$-helical segment of the protein is optimally positioned for DNA binding. Despite the fact that NikR is capable of binding other metal ions, such as $\mathrm{Co}(\mathrm{II}), \mathrm{Zn}(\mathrm{II})$ and $\mathrm{Cd}(\mathrm{II})$, this helix is positioned properly only if the metal ion adopts a square planar geometry at the binding site.[6] The above examples also demonstrate that studying the interaction of metalloregulatory proteins with non-cognate metal ions might provide a deeper insight into the mechanisms of metal ion selection and the regulation steps of the transcription.[2]

In sum, metalloregulatory proteins evolved many advanced strategies to selectively regulate transcription. The determination of all factors that contribute to the selection of cognate metal ions of individual proteins is rather challenging, but studies for elucidating these strategies will continue to yield insight into the sophisticated chemistry that has evolved in cells.[42]

\subsection{An application of metalloregulators: Whole cell based}

\section{biosensors}

Toxic metal contamination caused by the industrial and agricultural activity has become a serious environmental issue due to the accumulation and harmful effects in living organisms. The negative impact of these pollutants raised a demand for fast and simple analytical methods for sensing and quantifying of these constituents. Metal ions are traditionally identified and quantified from environmental samples with conventional, robust analytical methods such as atomic absorption spectroscopy, inductively coupled plasma atomic emission spectroscopy or mass spectrometry. Although the currently used instruments are highly sensitive and provide accurate information on the sample composition, they are expensive and the preparatory procedures required for such complex samples make the analysis time consuming. The need for selective and sensitive detection of metal ions has drawn attention to genetically engineered microorganisms that can be used as whole cell based biosensors (WCB) to detect and determine the bioavailable 
fraction of toxic compounds. These allow to perform low-cost, simple and rapid assays, even in situ, moreover, they may provide relevant information on the toxicity and biological effects of the analysed components. Therefore they are promising alternatives or complements of the routinely used instrumental techniques.[43-46]

The design of WCBs targeting heavy metal ions is generally based on the fusion of a promoter DNA sequence that is induced by the targeted metal ion, to the gene of a reporter protein. In this way natural regulatory elements are used to produce easily detectable and quantitatively measurable output signal if the inducer ion is present (Figure 15).[44] Several reporter systems are currently available. According to the type of the output signal microbial biosensors are classified into electrochemical[45] and optical groups.[46]

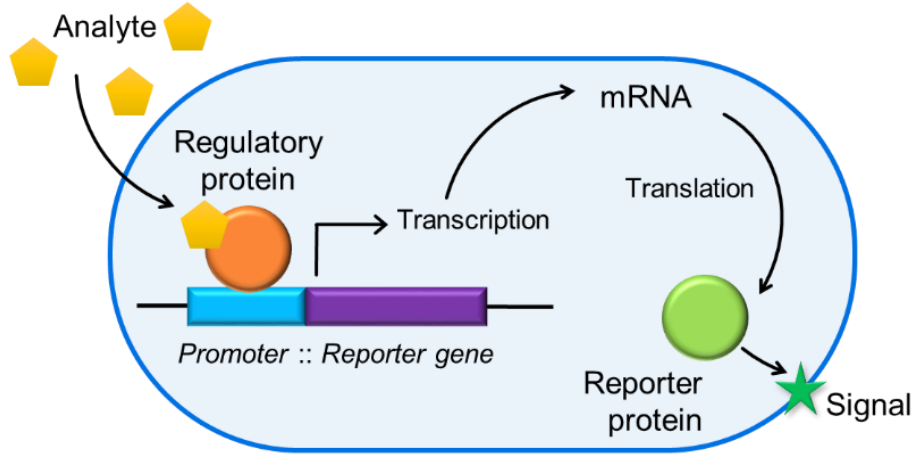

Figure 15: Schematic representation of a whole cell based biosensor. The regulatory protein detects the inducer analyte at the cytoplasm and induces the transcription of the reporter gene. The expressed reporter protein gives a detectable signal.

The majority of optical microbial metal ion biosensors are based on luminescent or fluorescent outputs.[47] Firefly luciferase (lucFF from Photinus pyralis) and bacterial luciferases (luxCDABE from the marine bacteria Vibrio fischeri and Vibrio harveyi or the terrestrial bacterium Photorhabdus luminescens) are the mostly used reporter proteins.[48] The bioluminescent reaction, catalysed by bacterial luciferase, requires the following substrates: (i) oxygen, provided by the surrounding environment, (ii) the reduced flavine mononucleotide, originated from the bacterial metabolism, and (iii) a long chain aldehyde, such as decanal, produced by enzymes (a fatty acid reductase, a synthetase, and a transferase) coded by the luxCDE genes.[49] Because all of these compounds are produced in the cell, no extra substrate addition is needed before the measurement. However, the reaction requires energy from cell metabolism, therefore, not only the amount of luciferase protein, but the metabolic state of the microorganism can have an effect on the light emission.[48] 
Another extensively used reporter is the Green Fluorescent Protein (GFP) isolated from jellyfish Aequorea Victoria and its mutants with improved characteristics. The GFP variants have different excitation and emission maxima and higher quantum yields compared to the wild type (WT) protein.[48] Moreover, some mutations improved the folding and expression properties of the protein. For instance, exchanging the S65 residue to threonine (S65T) accelerated the formation of the internal fluorophore moiety, and the mutation of F64 to leucine (F64L) alleviates the temperature sensitivity of the protein. These optimized features are combined in the GFP variant known as enhanced GFP (EGFP) (Figure 16).[52] Other fluorescent proteins, characterized by shifted excitation and emission wavelength values, are named after the colour of the emitted light, such as blue, cyan and yellow fluorescent protein. The fluorescence of these proteins can be measured without adding cofactors or substrates, furthermore, they do not participate in cell metabolism, and they are fluorescent also in nonviable cells, therefore, the toxic effects of metal ions do not influence the output signal, in contrast to luciferases.[48] An often mentioned disadvantage of GFPs, as a reporter protein, is the delay between protein expression and the appearance of fluorescence.[46]

A

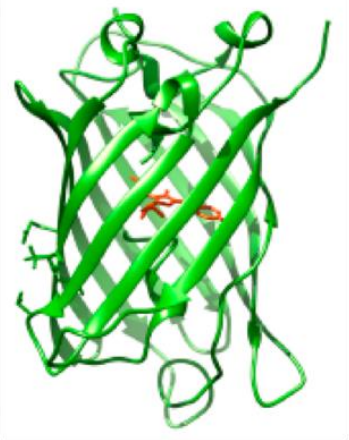

B

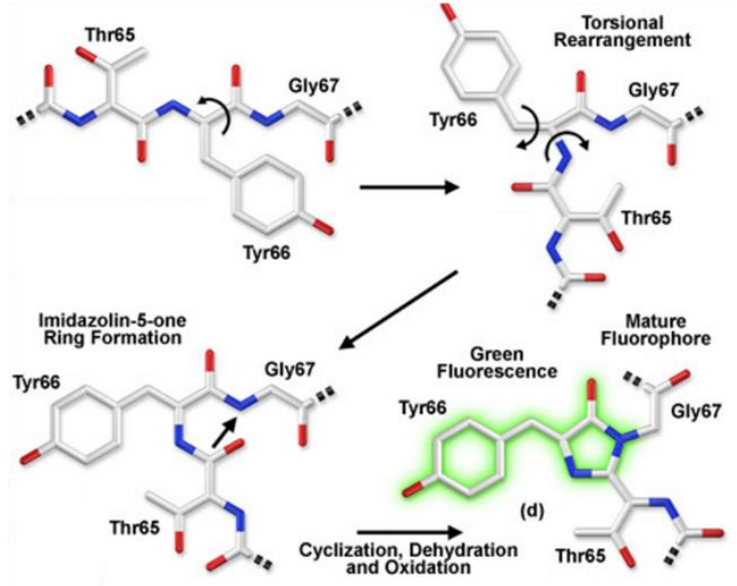

Figure 16: (A) The crystal structure of EGFP (PDB id.: 4EUL). [50] The fluorophore moiety is coloured in red. (B) The spontaneous maturation of the fluorophore moiety of EGFP. The first step of the maturation is the torsional rearrangement of the tripeptide sequence of T65-Y66-G67 providing optimal structure for a nucleophilic attack that leads to a cyclization. Following the oxidation of the tyrosine by molecular oxygen, the fluorophore is formed.[51]

The third possibility for indicating the presence of the inducer analyte by optical WCBs is based on colorimetric response. For example, a red pigment, deinoxanthin carotenoid (synthesised by the crtI gene) is produced in a cadmium biosensor causing a colour change of the cells, which is detectable through visualization.[53] This type of 
reporting signal is particularly promising since it is simple and does not requires expensive technology for detection.[47]

In the past decades several optical WCBs have been developed to detect heavy metal or metalloid ions such as $\mathrm{As}(\mathrm{III})[54,55], \mathrm{Hg}(\mathrm{II})[56], \mathrm{Cd}(\mathrm{II})[55,57,58], \mathrm{Cr}(\mathrm{III})[59]$, $\mathrm{Pb}(\mathrm{II})[60], \mathrm{Ni}(\mathrm{II})[61], \mathrm{Cu}(\mathrm{II})[62-66]($ Table 2) and $\mathrm{Zn}(\mathrm{II})[64]$.

Table 2: Characteristics of electrochemical and optical $\mathrm{Cu}(\mathrm{II})$ biosensors reported in the literature.

\begin{tabular}{|c|c|c|c|c|c|}
\hline Host & Reporter & Regulation & Inducer & LOD & Ref. \\
\hline $\begin{array}{l}\text { Saccharomyces } \\
\text { cerevisiae yeast }\end{array}$ & lacZ & Ace1/cupl & $\mathrm{Cu}(\mathrm{II})$ & $0.2 \mathrm{ppm}$ & {$[62]$} \\
\hline $\begin{array}{c}\text { Pseudomonas } \\
\text { fluorescens }\end{array}$ & $\operatorname{lux} A B$ & $\begin{array}{c}\text { CopRS/copA } \\
B C D\end{array}$ & $\begin{array}{c}\mathrm{Cu}(\mathrm{II}), \\
\operatorname{Ag}(\mathrm{I})\end{array}$ & $0.3 \mathrm{ppm}$ & [63] \\
\hline E. coli XL1-Blue & $\begin{array}{c}\text { RFP, OmpC } \\
\text { Cu binding } \\
\text { protein }\end{array}$ & CusSR/cus & $\mathrm{Cu}(\mathrm{II})$ & $26 \mu \mathrm{M}$ & [64] \\
\hline E. coli $\mathrm{DH} 1$ & luxCDABE & CueR/copA & $\begin{array}{c}\text { Cu(II), } \\
\operatorname{Ag}(\text { I), } \\
\text { Hg(II), } \\
\text { Cd(II) }\end{array}$ & $\begin{array}{c}50 \mu \mathrm{M} \\
0.5 \mu \mathrm{M} \\
5 \mu \mathrm{M} \\
0.05 \mu \mathrm{M}\end{array}$ & {$[65]$} \\
\hline E. coli MG1655 & luxCDABE & CueR/copA & $\begin{array}{c}\mathrm{Cu}(\mathrm{II}), \\
\operatorname{Ag}(\mathrm{I})\end{array}$ & $\begin{array}{l}0.3 \mu \mathrm{M} \\
0.1 \mu \mathrm{M}\end{array}$ & [66] \\
\hline E. coli $\mathrm{W} 3110$ & luxCDABE & $\mathrm{CueR} / \operatorname{cop} A$ & $\begin{array}{c}\text { Cu(II), } \\
\operatorname{Ag}(\text { I) } \\
\operatorname{Au}(\text { III })\end{array}$ & $\begin{array}{c}60 \mu \mathrm{M} \\
0.75 \mu \mathrm{M} \\
40 \mu \mathrm{M}\end{array}$ & {$[71]$} \\
\hline $\begin{array}{c}\text { E. coli } \Delta \text { copA } \\
\text { W3110 }\end{array}$ & luxCDABE & Cue R/copA & $\begin{array}{c}\mathrm{Cu}(\text { II), } \\
\operatorname{Ag}(\mathbf{I}) \\
\mathrm{Au}(\text { III) }\end{array}$ & $\begin{array}{l}4 \mu \mathrm{M} \\
0.1 \mu \mathrm{M} \\
30 \mu \mathrm{M}\end{array}$ & [71] \\
\hline E. coli $\mathrm{K} 12$ & $\begin{array}{c}\text { super folded } \\
\text { GFP }\end{array}$ & CueR/copA & $\mathrm{Cu}(\mathrm{II})$ & $\sim 75 \mathrm{ppm}$ & {$[72,73]$} \\
\hline
\end{tabular}

Bioreporter assays, generally carried out in these studies, are generally easily adaptable to a multi-well format allowing high-throughput sample screening.[67] The engineered microorganism can be either in liquid or immobilised phase in WBCs. Photomultiplier tube (PMT) detectors connected via fiber optics are mainly used as physical transducers in these devices.[49] A representative example is a sensor that has been fabricated by immobilizing living, $\mathrm{Hg}$ (II)-signalling cells onto the end surface of an optical fiber, allowing the transmission of the induced fluorescence of Enhanced cyan fluorescent protein with minimal loss.[68] In another construction, the combination of the bacterial immobilization methodology with the sensitivity of a PMT detector resulted in convenient and simple WCB with a high sensitivity to detect pollutants (heavy metals, organic chemicals and solvents) in water samples.[69] As another example, a portable kit, 
consisting of three parts: a freeze-dried biosensing strain, a compact light-proof chamber and a luminometer, has also been commercialized.[70] As more and more WCBs have been established a new way of biosensor design was suggested to encourage constructing microbial biosensors with a real-world application potential moving out from the proof of concept' phase.[47] On the other hand, despite 20 years of research, there is certainly room for improvement in terms of the technical aspects of WCB engineering. Unsolved fundamental questions concerning the proper assembly of genetic circuits, such as the sources and means of reduction of the expression noise and the properties of the regulatory cascades used in signal enhancement, still exist.[67] A large number of studies published in 2017 and 2018 emphasize the actuality and necessity of further investigations of microbial biosensors.

Since bacteria have evolved intrinsic resistance mechanisms to deal with high, toxic concentrations of metal ions, the majority of biosensing constructs are currently expressed in variants of E. coli. This results more robust biosensors that are less affected by environmental variables and are able to operate under toxic conditions.[47] In recent works the importance of choosing a suitable microbial chassis is highlighted by investigating the performance of $\mathrm{Cd}(\mathrm{II})$ or $\mathrm{As}(\mathrm{III})$ sensing modules transferred into four different bacterial species: Escherichia coli DH5 $\alpha$, Pseudomonas aeruginosa, Shewanella oneidensis and wild type Enterobacter spp.[56, 67] In the case of Cd(II) sensors the P. aeruginosa and Enterobacter spp. constructs had the lowest limit of detection[57], while the lowest concentration of As(III) could be detected by the E. coli DH5 $\alpha$ and Enterobacter spp. systems.[74] Differences could be observed even in the time required for a significant response to a given As(III) concentration: in the case of Enterobacter spp. this was only 20 min, whereas E. coli DH5a responded within 40 min. [74] The differences noted in these studies may be linked to the differences between bacterial species, as well as growth rate and native heavy metal resistance mechanisms, including metal uptake systems and the native transcriptional machinery.[74]

Metal ion resistance operons and metalloregulatory proteins are utilized in metal ion sensing WCBs. Most commonly, derepressor or activator proteins are utilized, since the general aim is to initiate the transcription when the concentration of the metal ion is increased. As mentioned above, the chosen reporter gene is cloned downstream of the appropriate promoter (Figure 15).[75] The induction of the reporter protein occurs at molecular level, providing a potential for genetic manipulation to improve sensitivity and specificity.[76] 
A good example for such an improvement is a $\mathrm{Cd}(\mathrm{II})$ sensor, where the sensitivity for $\mathrm{Cd}(\mathrm{II})$ detection showed 20-fold increase by applying a toggle gene circuit.[76] This construct consisted of the $c a d R$ promoter $(\mathrm{P} c a d R)$ fused to $l a c I^{q}$ and $g f p$ genes, and the $t a c$ promoter (Ptac) upstream to the $c a d R$ gene transcribed divergently in the same plasmid (Figure 17). Both CadR and LacI function as repressors inhibiting the transcription of genes fused to the $c a d R$ and tac promoters. In this system, $\mathrm{Cd}(\mathrm{II})$ binding to the $\mathrm{CadR}$ protein launches the expression of LacI and GFP, then the LacI protein represses the tac promoter which ultimately inhibits the transcription of the cadR gene. Consequently, the

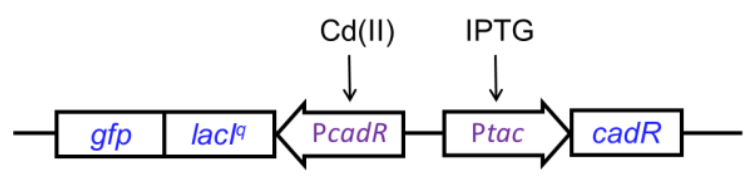

Figure 17: Scheme of the CadR based toggle gene circuit construction. $C d(I I)$ and IPTG induce the cadR and tac promoters, respectively.[76] production of the CadR sensory protein dampens while the GFP reports the presence of Cd(II). Moreover, the toggle circuit allows to switch "off" the biosensor by adding IPTG (Isopropyl $\beta$-D-1-thiogalactopyranoside). In that case, the overexpression of the CadR protein starts. The expressed CadR represses the PcadR, thus inhibiting the transcription of the $g f p$ reporter gene. This research demonstrates well the value of synthetic biology in WCB design and development.[76]

An interesting improving approach is exemplified by a GolS metalloregulatory protein based $\mathrm{Au}(\mathrm{I})$ sensor, published in two comprehensive papers. [35, 77] A fluorescent Salmonella typhimurium $\mathrm{Au}(\mathrm{I})$ - selective biosensor was constructed using a plasmid carrying the $g f p$ reporter gene fused downstream to the GolS-regulated golB promoter (PgolB::gfp). The biosensory system was also introduced into E. coli that does not possess genomic gol locus. Therefore, E. coli was co-transformed with the reporter PgolB::gfp plasmid and a plasmid including the golS sequence. Although the fluorescence increased after adding $\mathrm{Au}(\mathrm{I})$, the increase was modest compared to the $\mathrm{Au}(\mathrm{I})$-induced fluorescence observed in the original Salmonella host. Since the concentration of the overexpressed GolS protein in E. coli is much higher than the concentration of GolS expressed from its chromosomal single-copy gene in Salmonella, it was assumed that the performance of the biosensor was restrained because of the increased amount of regulatory protein present in the cell. To eliminate the different availability of the metalloregulator, the authors introduced the golS gene into the chromosome of E. coli. This transgenic strain was transformed with the PgolB::gfp reporter plasmid. By this, the expression level of GFP in E. coli became similar to the response observed in S. typhimurium. From these results the 
authors concluded that the regulatory protein has to be expressed from a single chromosomal copy for the optimal functioning of the biosensor.[77]

The $\mathrm{Au}(\mathrm{I})$ biosensor platform was modified to expand the spectrum of the detectable metal ions. Since the selectivity of the biosensor depends on the applied metallore gulatory protein, the modification of this module is required. Therefore, a S77C single amino acid substitution has been carried out in the GolS sequence. Based on the previous study,[77] this modification was introduced into the chromosomal copy of the golS gene, and at the same time the zntA gene was deleted both in the S. typhimurium and the E. coli-based systems. After this, the engineered hosts were transformed with the PgolB::gfp reporter plasmid to screen the response to various metal salts. The fluorescence increased in the presence of $\mathrm{Au}(\mathrm{I}), \mathrm{Hg}(\mathrm{II}), \mathrm{Pb}(\mathrm{II})$ and $\mathrm{Cd}(\mathrm{II})$, but not in the presence of $\mathrm{Cu}(\mathrm{II})$ and $\mathrm{Zn}(\mathrm{II})$ ions. Comparing the dose/response curves obtained with the two types of bacterial species, it was found that the expression level of GFP was lower in E. coli than in the original host, but the sensitivity and global performance were fairly similar. Because of the potential application of this non-selective biosensor for reporting the presence of toxic metal ions in water samples, the E. coli biosensor platform was tested in artificially contaminated water samples. In such samples, containing more than one inducer ions, the response was clearly additive, moreover, no interference between metal ions could be observed. In order to broaden the spectrum of detectable toxic metal ions, the gol $_{S 77 C}$ was further engineered by replacing the metal binding loop of $\mathrm{GolS}_{\mathrm{S} 77 \mathrm{C}}$ by the loop of the $\mathrm{Cu}(\mathrm{I}) / \mathrm{Ag}(\mathrm{I}) / \mathrm{Au}(\mathrm{I})$ sensor CueR protein (the segment between $\mathrm{C} 112$ and $\mathrm{C} 120$ ). This variant was named GolS $577 \mathrm{C}+\mathrm{L}$. In this strain the reporter gene was induced in the presence of either $\mathrm{Cu}(\mathrm{II}) / \mathrm{Cu}$ (I) or $\mathrm{Ag}(\mathrm{I})$, meanwhile the original response to $\mathrm{Au}(\mathrm{I})$ and $\mathrm{Hg}(\mathrm{II})$ was preserved.[35] This work shows that both site-directed mutagenesis and motif swapping can be employed to change metal ion preference of metalloregulatory proteins that makes the development of new generations of biosensors possible.[78] 


\section{AIMS AND OBJECTIVES}

In living organisms, highly specialized processes have been evolved to secure metal ion homeostasis and to protect the cell from harmful effects. In prokaryotes these processes are managed by metal ion selective metalloregulatory proteins at the level of transcription.[3-5] The copper efflux regulator CueR is a representative example of such transcriptional factors that operate via an activation type mechanism. Even though the CueR metalloprotein is well described in the literature, there are still open questions concerning its transcription regulatory mechanism:

(i) Most importantly, how CueR discriminates so successfully between mono and divalent metal ions in the transcription activation process.

(ii) Furthermore, whether or not the $C$-terminal $\mathrm{CCHH}$ fragment, which has otherwise no direct influence on the transcriptional activity of CueR,[18] plays any role in the operation of the protein.

The main goal of this $\mathrm{PhD}$ work was to answer these questions by acquiring data about the details of the selective metal ion recognition of CueR.

In order to achieve this, in the first stage of the project we planned to obtain the CueR protein in large amount and high purity for subsequent experiments. Therefore, we designed a Purification procedure to produce the wild type E. coli CueR without any affinity tag. As a complement to the results obtained with the WT CueR, we aimed to generate two mutant proteins (by the truncation of seven residues from the $C$-terminus $\Delta \mathrm{C} 7-\mathrm{CueR}$; and the mutation of S77 to cysteine in the truncated variant - S77C- $\Delta \mathrm{C} 7$ CueR), as well.

In the second, substantial part of this research, we focused mainly at WT CueR aiming to CHARACTERIZE its metal ion binding and structural properties. As a part of the characterization, our goal was to gather more information about how various factors, such as the $\mathrm{pH}$, temperature, the presence of metal ions and/or DNA, affect the secondary structure and the overall stability of the protein. Furthermore, we focused on the metal ion selectivity of the WT CueR investigating the mutant proteins as well, in order to assist the interpretation of the obtained data. We planned to investigate the interaction of $\mathrm{Hg}(\mathrm{II})$, $\mathrm{Cd}(\mathrm{II})$ and $\mathrm{Ag}(\mathrm{I})$ ions in details in order to explore how cognate and non-cognate metal ions are bound by $\mathrm{CueR}$ and to study the potential metal binding role of the $C$-terminal $\mathrm{CCHH}$ motif. 
We attempted to achieve these objectives by applying several instrumental techniques, including (i) mass spectrometry for identifying the proteins and their metal ionbound forms; (ii) circular dichroism spectroscopy for obtaining information on the secondary structure of the proteins; (iii) UV and (iv) perturbed angular correlation of $\gamma$-rays spectroscopies for monitoring the local environment of the metal ions bound to the protein.

Since, the metal ion selective operation of CueR has a Potential ApPlication in the construction of metal-ion selective sensors, we attempted to establish a reporter system based on the green fluorescent protein overexpressed under the control of CueR. We intended to apply the tools of the recombinant DNA technology to construct the appropriate genes expressing the proteins needed for a functional sensor. Such a reporter system, as a convenient tool for monitoring and comparing the biological function of WT CueR and its mutants, could further our understanding on the metal ion recognition mechanism of this fascinating metalloregulatory protein. 


\section{METHODS}

\subsection{Recombinant DNA technology}

The construction of new DNA molecules and their introduction into host cells is referred to as cloning or recombinant DNA technology. DNA manipulation is widely used for example to produce recombinant proteins or to construct genetically modified cells for analytical applications (e.g. whole cell based biosensors).

Usually, the cloning process for producing a recombinant protein starts with the amplification of the gene of the target protein by performing a polymerase chain reaction (PCR). The reaction mixture includes the following components: template DNA containing the gene of the target protein, a thermostable DNA polymerase (e.g. Taq polymerase DNA polymerase I from Thermus aquaticus), short oligonucleotides (forward and reverse primers) that are necessary for the polymerase to start the synthesis and a mixture of deoxynucleoside-triphosphate $(\mathrm{dNTP})$ building blocks. A reaction cycle consists of three discrete step (Figure 17). It starts with the denaturation step where the mixture is heated up to $\sim 95{ }^{\circ} \mathrm{C}$ to implement the dissociation of the double stranded DNA template into two single strands. Next, in the

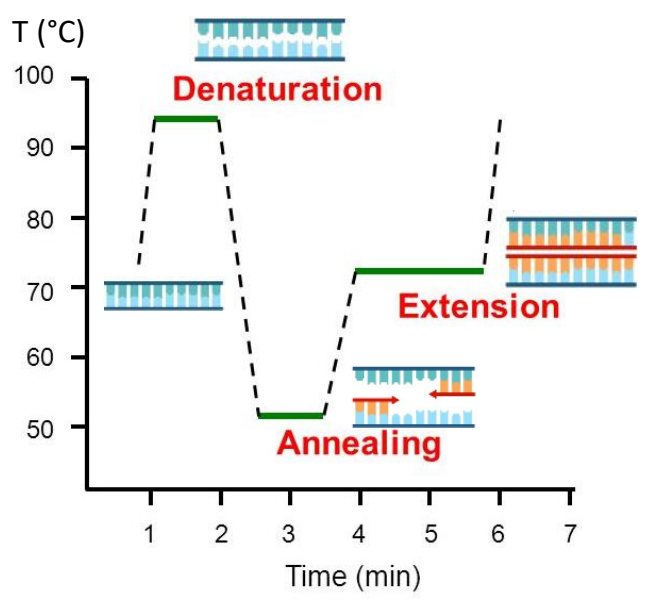

Figure 17: Steps of a PCR cycle showed as a function of time and temperature. annealing step, the temperature is decreased to the melting point of the primers, that is usually in between $50-60{ }^{\circ} \mathrm{C}$. The hybridization of the primers to the complementary sequence of the template DNA occurs in this temperature range. Finally, in the next, extension step, the temperature is increased up to the optimal working temperature $(\sim 68-$ $72{ }^{\circ} \mathrm{C}$ ) of the applied polymerase. At this point the polymerase elongates the primer in 5 , $\rightarrow 3$ ' direction. The newly synthetized complementary chain and the template DNA form a double stranded DNA that serves as a template in the next cycle. A PCR cycle is repeated several ( 25 - 30) times yielding an exponential amplification of the DNA segment assigned by the primers. PCR can also be used for introducing mutations into the original DNA sequence.[79]

In the cloning process genetically engineered plasmids are used as carrier DNAs. These plasmids are a few thousand base pair long circular DNAs optimized specifically for 
gene manipulation and protein overexpression.

Depending on the type of the plasmid (e.g. cloning, expression, reporter or viral plasmid), they may possess different regions, however, all must have an origin of replication (ori), selectable marker genes and at least one restriction enzyme recognition site. The ori is essential for the propagation of the plasmid in

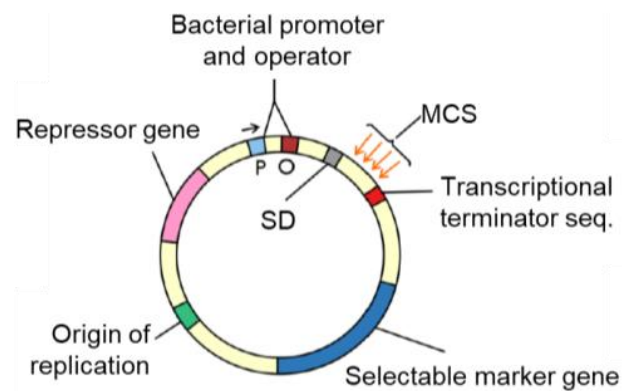

Figure 18: Schematic map of an expression plasmid. the cell. The selectable marker genes are most preferably antibiotic resistance genes that allow the selection of cells containing the plasmid. Plasmids usually have numerous unique restriction sites within a so called multi cloning site. This site provides a convenient platform for inserting and removing gene segments (Figure 18). Moreover, expression plasmids also contain a suitable operon for protein expression from the inserted gene. The elements of the operon are an inducible promoter (e.g. Plac) containing the RNAP recognition site, the Shine-Dalgarno (SD) sequence coding for a ribosomal binding site and a $\mathrm{G}-\mathrm{C}$ rich, palindromic sequence which terminates the transcription by forming a hairpin structure. Furthermore, expression plasmids contain a gene of a regulator protein (e.g. LacI) which recognises the operator and controls the transcription (Figure 18).[79]

For inserting a DNA fragment into a plasmid both the target gene segment (e.g. amplified PCR product) and the carrier plasmid should be digested with restriction enzyme(s). Restriction endonucleases recognize a specific $4-$ 8 bp long palindromic sequence and cleave the DNA by catalysing the hydrolysis of the phosphodiester bonds of the DNA backbone. Then, the linearized plasmid and the insert DNA can be connected by a ligase enzyme which catalyses the formation of phosphodiester bonds. Ligation results in a closed, circular recombinant DNA. In most cases two different restriction enzymes are used in order to control the orientation of the inserted gene (Figure 19).[79]

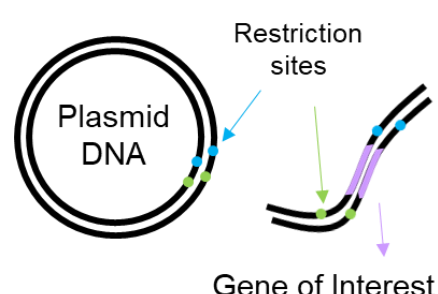

Gene of Interest

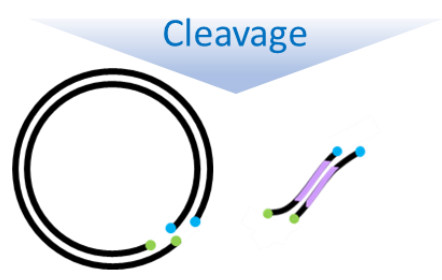

\section{Ligation}

Recombinant DNA

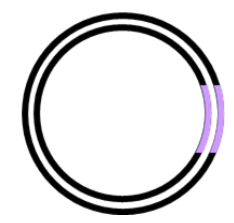

Figure 19: Workflow of cloning. 
For subsequent experiments, such as protein expression, plasmid amplification and purification, the recombinant DNA is introduced into a suitable host cell. Generally, such transformation of the host is carried out with the application of a high electric force field (i.e. electroporation) or with mild heat shock. Successfully transformed cells are antibiotic resistant, provided by the recombinant plasmid, thereby they can be selected on antibiotics containing agar plates. As a host organism E. coli is widely used because of several advantages, such as the easy to culturing in a sterile manner and in large volumes, short doubling time, easy transformation with plasmid DNA, relatively cheap growth media and effective proteins overexpression. Various genetically modified strains of E. coli are commercially available to serve all kinds of molecular biological purposes. For example, the cell growth rate of E. coli Mach1 strain is relatively quick, therefore it is preferentially used for cloning purposes or for the preparation of plasmids. On the other hand, the BL21(DE3) strain is optimized for expressing recombinant proteins. BL21(DE3) is deficient in several proteases and it carries the gene of $\mathrm{T} 7$ polymerase (from the $\mathrm{T} 7$ bacteriophage) which transcribes only the inserted genes downstream of a T7 promoter.[80]

With the tools of recombinant DNA technology genetically modified proteins can also be produced. There are several possibilities to introduce modifications into the DNA sequence.[81] For instance, modified DNA fragments can be produced and amplified in a PCR reaction by using carefully designed primer(s) in the reaction mixture. The primer should contain the desired mutation and should have a long enough complementary part in order to stick to the template DNA during annealing. Then, the modified fragment is inserted into a plasmid. Another example for DNA mutation is the non-overlapping primers

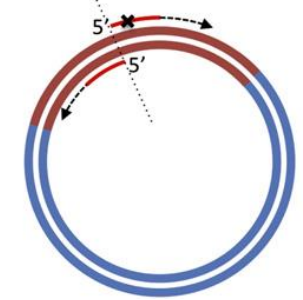

Figure 20: Scheme of Quick change with nonoverlapping primers. The $X$ mark showing the modification.[81] technique of the so called Quik Change method. In this method the whole plasmid is amplified in a PCR reaction using a "silent" primer and another one which contains the mutation (Figure 20). The product of this reaction is a linear, double stranded DNA (dsDNA) which can be circularized by ligation after phosphorylating the 5 ' -end of the DNA with a kinase enzyme. This method requires a DNA polymerase which can synthetize long (few kbp) DNA strands quickly and precisely (e.g. KOD FX).[81]

As a final step after cloning and/or sequence modification experiments, it is essential to verify the nucleotide sequence and test the functioning of the expression system. 
In this work, recombinant DNA technology was used to construct plasmids containing the gene of the wild type E. coli CueR protein or its variants, see Appendix A.2. for the experimental details. DNA cloning was also performed for establishing a fluorescent reporter system, see Appendix A.10. for the detailed experimental conditions.

\subsection{Recombinant protein expression and purification}

In order to successfully study the structure and/or function of any protein it is necessary to purify the target molecule. One approach is to isolate the protein conventionally by obtaining the source cell or tissue from the host organism. This is often a challenging task, especially when a protein is present at low concentration, e.g. a few dozens of molecules per cell. The other approach is to use recombinant DNA technology to produce modified cells with which a high protein expression level is possible (Figure 21). After transforming the host cells with an expression plasmid coding for the target protein, the modified cells are cultivated in the appropriate growth medium (Figure 21). For example, Luria-Bertani (LB) broth is a nutrition-rich medium, while M9 is a minimized salt containing medium for bacterial growth.[80]

When the cultivation is in the log phase, i.e. phase of exponential growth of the cell number, the expression of the target protein from the recombinant plasmid is induced by adding IPTG to the suspension. IPTG binds to

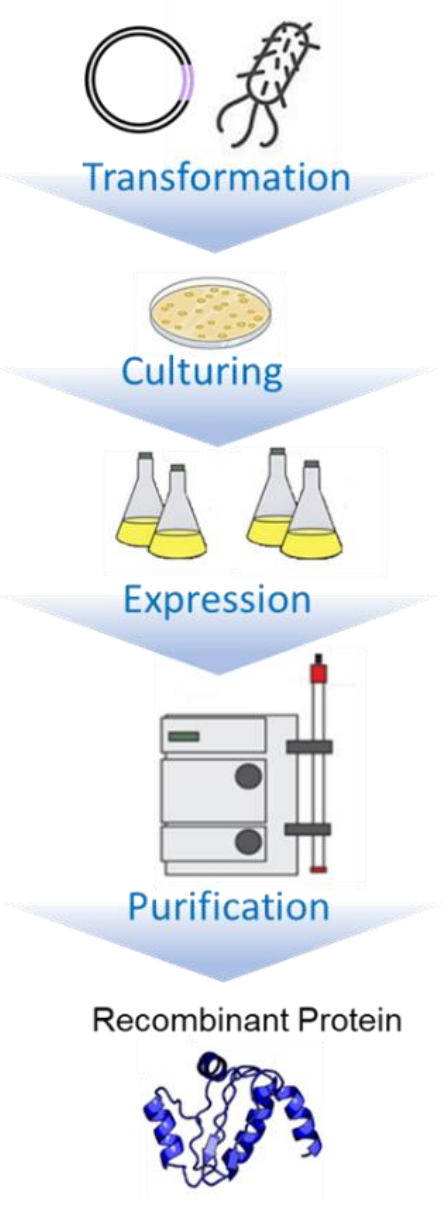

Figure 21: Workflow of recombinant protein production. the LacI repressor, and in this complex LacI is incapable to bind to the lac operator of the plasmid. As the repressor dissociates from the DNA, the transcription of downstream genes occurs which ultimately results in the expression of the recombinant protein. The expression is a critical step; improper circumstances (incubation temperature and time, concentration of IPTG etc.) cause misfolding, aggregation or a low amount of the protein. After the induction period, the cells are usually harvested, i.e. separated from the medium, and then disrupted in order to release the cytoplasmic contents. There are several methods 
for the extraction, for example sonication - using ultrasound frequency waves, enzymatic digestion with lysozyme, chemical lysis with detergents or the freeze-and-thaw technique. To avoid denaturation and proteolytic digestion of the proteins, the extraction should be carried out as gently and quickly as possible, and in cold temperature or on ice in the presence of suitable buffer to maintain $\mathrm{pH}$ and ionic strength. Then, the soluble fraction of proteins is separated from membrane and cell debris by centrifugation.[80]

Cell extracts contain thousands of unwanted proteins which are removed during the purification step. For separating proteins mainly Fast Protein Liquid Chromatography (FPLC) is used. In FPLC the mobile phase is a buffered, aqueous solution, while the stationary phase consists of cross-linked agarose beads (size of $\mu \mathrm{m}$ ) packed into a cylindrical column. In contrast to HPLC the applied pressure is relatively low (5 bar), but the flow rate is relatively high $(1-5 \mathrm{ml} / \mathrm{min})$. The separation is based on the differences in physical properties of the proteins, such as charge, molecular mass, hydrophobicity and ligand affinity. The detector system of an FPLC usually measures the UV absorbance at given wavelengths, and in most cases the $\mathrm{pH}$ and the ionic strength (conductivity), as well. [80, 82]
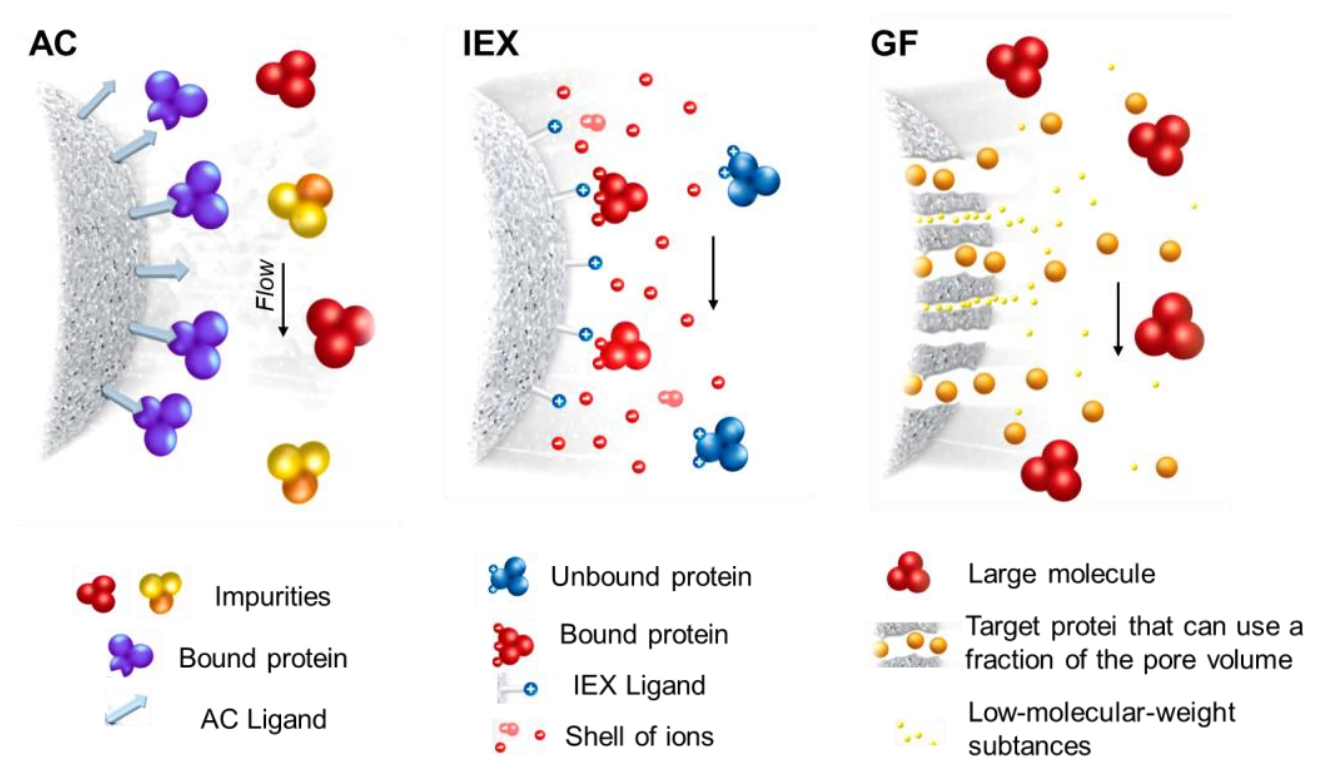

Figure 22: Schematic illustration of the separation principles in AC, IEX and GF chromatographic methods.[82]

In affinity chromatography (AC), proteins are separated on the basis of a reversible interaction between the target protein and a specific ligand attached to the resin. The interaction can be bio-specific (e.g. antibody-antigen interaction), non-biospecific (e.g. histidine containing proteins and metal ions) or it can be group specific (e.g. DNA binding 
protein and heparin). Most commonly, affinity chromatography is used to separate affinitytagged (His-tag, glutathione S-transferase, maltose binding protein etc.) proteins. After loading the sample onto the column, the target protein binds to the complementary ligand on the matrix, while other unbound proteins and materials are washed out of the column (Figure 22). Then, bound proteins are eluted with a competitive ligand or by changing $\mathrm{pH}$ or ionic strength resulting in a purified and concentrated form of the target protein. Characteristics of AC are the high selectivity, high resolution and high capacity, furthermore, the elution can be performed under mild conditions.[82]

In ion exchange (IEX), proteins are separated with differences in surface charge, based on the interaction of a charged protein and an oppositely charged chromatography medium. The net charge of a protein varies according to the $\mathrm{pH}$ of the surrounding environment and the isoelectric point, $\mathrm{p} I$, of the protein. Generally, proteins are loaded onto the column at low ionic strength, and their elution is performed by increasing salt concentration or changing the $\mathrm{pH}$ in a gradient or stepwise manner. During IEX purification the bound proteins are concentrated on the column, therefore the target protein is eluted in high concentration. Features of IEX are the high resolution and high loading capacity. Furthermore, high flow rates can be applied owing to the fast binding kinetics. IEX is ideal to apply as a first step for capturing the target protein from a large-volume sample with bulk impurities, but it can be used as an intermediate or final step, as well.[82]

The principle of gel filtration (GF), also called size exclusion chromatography, is the separation of substances based on differences in their molecular size. It is a non-binding method. Proteins are always eluted in an isocratic elution. Large molecules cannot enter the pores of the column beads, therefore their retention time is short. In contrast, small substances enter and spend time in the entire pore volume of beads, thus their retention time is relatively long, therefore they are the last to leave the column. GF can be used for purification purposes or for exchanging buffers, including desalting under mild conditions. However, a GF purification always requires a small volume, a highly concentrated sample and results in a diluted sample. An advantage of GF is that the buffer composition can be varied and selected according to requirements of further purification, analysis or storage. However, $25-150 \mathrm{mM}$ salt is recommended in the buffer, in order to eliminate weak electrostatic interactions between the proteins and the matrix. Generally, GF is used for protein samples that have passed one or several initial purification steps and are purified from bulk impurities.[82] 
Strategy for purification of a recombinant protein is always optimized according to the physical properties and the subsequent use of the target protein. The first step of optimization is the sample preparation with an aim to release and stabilize the target protein and adjust the conditions to fit the first chromatographic step. Then, three stages of the purification procedure should be designed: capture, intermediate purification and polishing stages (Figure 23). The aim of the capture stage is to isolate, concentrate and stabilize the target protein. Next, in the intermediate purification step, most of the bulk impurities (other proteins, nucleic acids, endotoxins etc.) are removed. Finally, in the final polishing stage, the remaining trace amounts of impurities are removed and the target protein is prepared for usage or storage. The purification strategy and the number of steps should depend on the purity requirements and the aimed

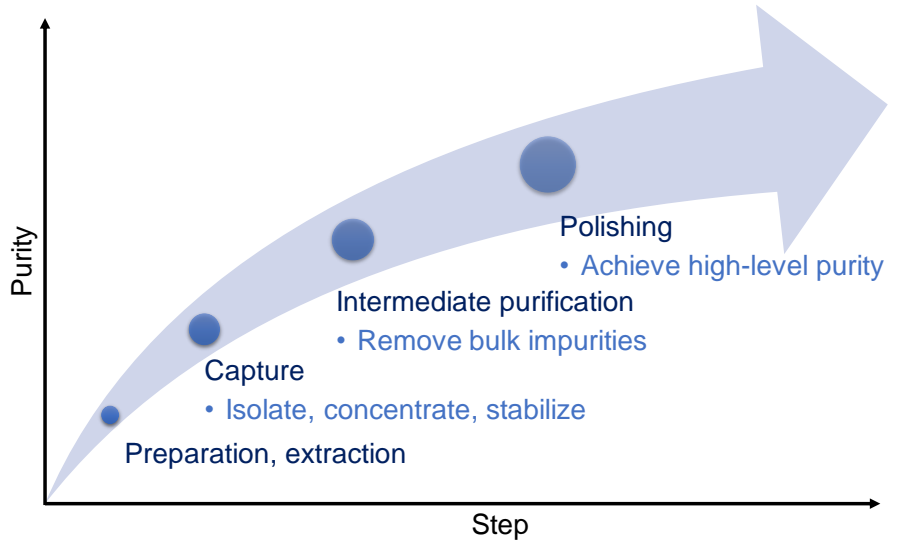

Figure 23: The three stages of a purification strategy. General aim is to increase the purity by additional purification steps.[82] overall protein recovery. For example, the amount and purity requirements of common applications follow the order below: MS analysis < functional studies < structural studies $<<$ therapeutic usage. Usually, increasing the number of steps decreases the overall recovery, extends the purification time, but increases the purity.[82]

See Appendix A.2. for the experimental details for the expression and purification of the WT and mutant CueR proteins.

\subsection{Gel electrophoresis}

Gel electrophoresis is a widely used method to analyse protein or DNA samples by separating them according to their size/molecular mass $\left(M_{\mathrm{w}}\right)$. Charged compounds (ions) migrate in a conducting medium under the force of an electric field towards the oppositely charged electrode. The velocity of the migration depends on the size, overall charge and molecular shape of the substances, if the temperature and strength of electric field are kept constant. In gel electrophoresis a porous gel provides the matrix for the separation. In principle, molecules with larger overall negative or positive charge, with a smaller size and 
with a more compact shape (more globular) migrate faster through the gel. Usually, during the sample preparation process the charge and the shape of the molecules become uniform, therefore the compounds are separated solely on the basis of their size. By changing the concentration of the gel the resolution can be adjusted: higher gel concentrations result in smaller pore sizes, therefore the separation of low molecular weight molecules is more effective.[80]

Typically, a cross-linked polyacrylamide gel is used for analysing protein samples. Usually, the protein sample is treated with the anionic detergent sodium dodecyl sulphate (SDS) and with a reducing agent ( $\beta$-mercaptoethanol, dithiothreitol (DTT)) at a high temperature $\left(\sim 95^{\circ} \mathrm{C}\right)$. By this, all proteins in the sample acquire a defolded, rod-like shape and an excess of negative charge. Thereby, proteins are separated based on their size by sodium dodecyl sulphate polyacrylamide gel electrophoresis (SDS-PAGE). After the electrophoresis protein bands are made visible with Coomassie Brilliant Blue (CBB) or $\mathrm{AgNO}_{3}$ staining with a detection limit of $100 \mathrm{ng}$ and $1 \mathrm{ng}$ protein, respectively.

For DNA (or RNA) analysis agarose gels are used as a matrix. Compared to proteins, the sample preparation of DNA is simpler, since the shape and the charge of the molecules are more uniform. Usually, DNA molecules are visualized by staining with ethidium bromide (EtBr) which intercalates into the DNA and forms a fluorescent complex. $\mathrm{EtBr}$ is carcinogenic, therefore other similar, but safer alternatives (SYBR Green, GelRed) were developed for staining DNA.

Electrophoretic mobility shift assay (EMSA) is a rapid and sensitive technique to monitor the binding of proteins to nucleic acids. EMSA is based on the slower movement of the protein-nucleic acid complex trough the gel compared to free DNA or RNA, owing to its different size, charge and shape. EMSA can be utilized for determining the stoichiometry, affinity and kinetics of the binding of the protein. Moreover, distinguishing a specific and nonspecific binding is also possible (Figure 24). If the binding is specific, the band related to the

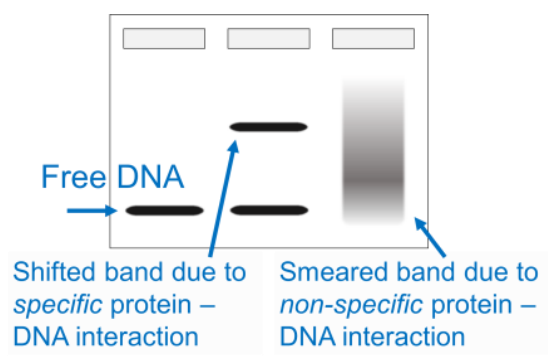

Figure 24: Scheme of electrophoretic band 'shift up' due to specific and nonspecific interactions between the protein and DNA. complex 'shifts upwards' (i.e. migrates slower) in the gel. However, if the binding is not specific, the band smears. The possibility of using both purified proteins and crude cell extracts makes EMSA a popular technique. as a separation media both agarose and "native" (i.e. SDS free) polyacrylamide gels are used. 
Usually, the nucleic acids used in EMSA are radiolabeled with ${ }^{32} \mathrm{P}$ or stained with EtBr.[83, 84]

Electrophoretic techniques were applied in several cases throughout this research work. We used agarose GE and SDS-PAGE to follow steps of DNA cloning and protein purification procedures, respectively. The DNA binding capability of the purified WT and mutant CueR proteins were investigated by EMSA using agarose gel and EtBr staining. The experimental details of SDS-PAGE and agarose GE are found in Appendix A.3. and EMSA in Appendix A.4.

\subsection{Protein and metal ion quantification}

Accurate determination of protein concentration is crucial for carrying out and evaluate protein-related experiments. Several methods and protein assays are available with their advantages and limitations. Measuring the ultraviolet (UV) absorption of the protein solution is probably the most common method, since it is very quick and simple. However, the inaccuracy of the determination is relatively high due to the absorption of other components in the sample. It is important to mention that the structure of the protein, the

$\mathrm{pH}$ and the ionic strength may affect the recorded spectrum. Generally, the absorbance at $280 \mathrm{~nm}$, related to the absorbance of aromatic amino acids, such as tyrosine and tryptophan, and disulphide bridges, is used for calculating the concentration. If the protein does not contain such chromophores, the concentration can be determined by measuring the absorbance of peptides bonds at $\sim 205 \mathrm{~nm}$. The relationship between the concentration of the absorbing compound $(c)$ and the absorbance $(A)$ is described by the Beer-Lambert law:

$$
A_{\lambda}=\varepsilon_{\lambda} c l,
$$

where $\varepsilon$ is the extinction coefficient at a selected wavelength and $l$ is the path length. The extinction coefficient of proteins varies on a wide scale depending on the primary structure. It is possible to calculate a theoretical extinction coefficient, but it is more accurate to determine it by measuring a pure sample with a known concentration.[85]

Amino acid analysis (AAA) is often regarded as the most accurate method for determining protein concentration. The first step of amino acid analysis is the hydrolysis of the peptide bonds in an oxygen-free environment with a $6 \mathrm{M} \mathrm{HCl}$ solution at $110{ }^{\circ} \mathrm{C}$ for $18-24 \mathrm{~h}$. Then, the liberated amino acids are separated by ion-exchange chromatography, post-column detected and quantified. Some amino acids can be recovered quantitatively 
after the hydrolysis (e.g. glycine, alanine, leucine, phenylalanine, histidine, arginine), thereby an accurate concentration can be given.[86]

In this work, the concentration of CueR was determined from the $A_{280}$. of the solutions.

The concentration of $\mathrm{Ag}(\mathrm{I})$ and $\mathrm{Cd}(\mathrm{II})$ solutions was determined by argentometric and complexometric titrations, respectively. $\mathrm{AgClO}_{4}$ solutions were prepared with a concentration of $\sim 0.05 \mathrm{M}$, and a $\mathrm{KCl}$ solution of known concentration was titrated by the $\mathrm{Ag}(\mathrm{I})$ solution. Chloride ions react with $\mathrm{Ag}(\mathrm{I})$ ions to give a $\mathrm{AgCl}$ precipitation. Fluorescein was used as an indicator and the end-point was marked by the formation of a pink, coagulated precipitate in the yellowish suspension. $\mathrm{Cd}\left(\mathrm{ClO}_{4}\right)_{2}$ solutions were prepared with a concentration of $\sim 0.025 \mathrm{M}$ and titrated by an ethylenediaminetetraacetic acid (EDTA) titrant of known concentration in the presence of hexamethylenetetramine buffer and methylthymol blue indicator. $\mathrm{Hg}(\mathrm{II})$ solutions were prepared by dissolving precise weights of high purity $\mathrm{HgCl}_{2}$ to the final concentration of $\sim 0.025 \mathrm{M}$.

\subsection{Protein identification and characterization by mass spectrometry}

Mass Spectrometry (MS) is a powerful analytical method invented in the early years of the XX century. It plays significant role in protein-related sciences since 1990s by the development of "soft" ionization techniques. Further improvements of the instruments and coupling MS with chromatographic technique made this method an indispensable analytical tool in proteomics.

The first step during a mass spectrometric measurement is the formation of gasphased molecule-ions in the ion source. In protein sciences, the commonly used "soft" ionization techniques are the matrix assisted laser desorption ionization (MALDI) and the electrospray ionization (ESI). The ions formed in the ion source are accelerated and formed into a coherent ion beam by ion optics. Next, the ions are separated according to their massto-charge ratio $(\mathrm{m} / \mathrm{z})$ by a mass analyzer. Mass analyzers are, for example, quadrupole, time-of-flight (TOF), iontrap, linear iontrap, fourier transform ion cyclotron resonance (FTICR) and orbitrap. As the ion beam reaches the detector it is converted and enhanced into an electric signal which is transmitted to the computer controlling the instrument. The data output is a mass spectrum displaying the relative abundance or intensity of detected ions as a function of $\mathrm{m} / z$. 
Electrospray is a "soft" ionization technique for producing gas-phase ions from non-volatile, solution-phased samples even in polar solvents, without fragmentation. The analyte is forced through a capillary into a high-voltage $(2-5 \mathrm{kV})$ electric field. Nitrogen or carbon dioxide can be used as inert gas for nebulizing the fluid, focusing the dispersion and as a drying gas. The applied electric force generates charged droplets in the aerosol. The size of these droplets is decreasing upon the evaporation of the solvent, and the heated capillary facilitates more intensive evaporation. The loss of the solvent increases the repulsive forces

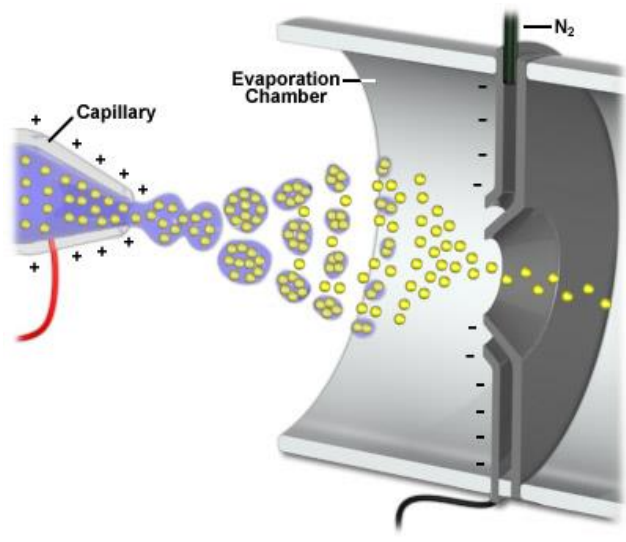

Figure 25: The sample injection and ionization in Electrospray Ionization technique. between the excess charges, forcing the unstable droplets to disintegrate into smaller and stable ones. This process is also called "Coulombic explosion". Finally, all the macroscopic solvent droplets evaporate and gas-phased molecule-ions of the analyte are obtained (Figure 25). A unique feature of ESI is that the ionization process often leads to the formation of multiply charged ions, $[\mathrm{M}+\mathrm{nH}]^{\mathrm{n}+}$. This has facilitated the use of general mass spectrometers for the analysis of large-sized, intact biopolymers, particularly proteins. ESI is also widely used for investigating noncovalent associations of macromolecules or small ligands. The deconvolution (i.e. transformation) of the multiply charged ion envelope results in the molecular mass of the neutral $(z=0)$ or the singly charged $[\mathrm{M}+\mathrm{H}]^{+}$ molecule.[87]

The orbitrap analyzer is a relatively new development, firstly presented in 1999 and commercialized in 2005 by Thermo Fisher Scientific.[88] The orbitrap is an electrostatic ion trap consisting of a spindle-like central and a barrel-shape outer electrode (Figure 26). Ions formed during the ionization are collected in a specialized compartment called the C-trap and then an ion pocket is injected into the orbitrap as high-speed pulses. In between the two electrodes of the orbitrap the ions follow a complex, nearly circular, spiral trajectory which is composed of two components: a rotary motion around the inner electrode and an axial oscillation along the same electrode. The voltage applied between the two electrodes generates a strictly linear electric field along the longitudinal axis, thus the oscillation of the ions becomes purely harmonic. This axial periodic oscillation is proportional to the $\mathrm{m} / \mathrm{z}$. Due to the movement of ions, a current image is generated which 
is detected by the outer electrode. Then, the signal is interpreted by using Fouriertransformation into a mass spectrum. The resolution of orbitrap has a maximum of 240000 at $m / z$ 400. This is much higher than other analyzers (e.g. Time-of flight, Quadrupole) can achieve, except for only the FT-ICR analyzer. On the other hand, orbitraps are much less expensive than FTICR systems, because there is no need for a superconducting magnet. Other advantages of oritrap are the high accuracy and a wide

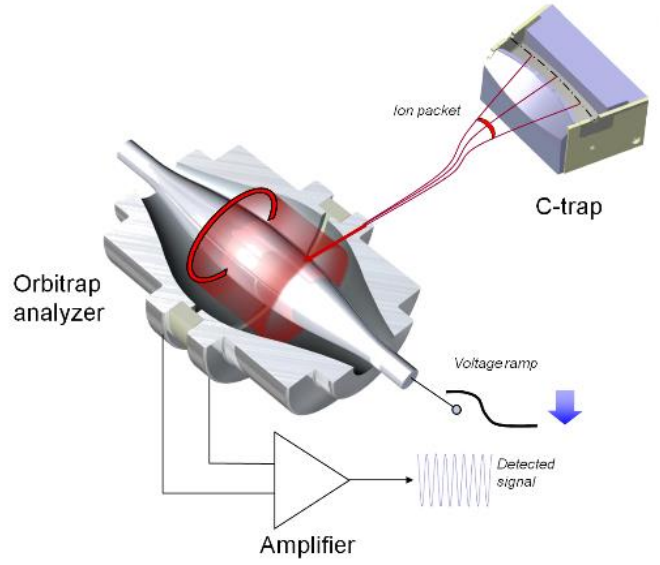

Figure 26: The operating principle of the Orbitrap analyzer. Reprinted with permission from [88]. Copyright (2013) American Chemical Society. dynamic range $\left(>10^{3}\right)$. A disadvantage is that the number of ions that can be held in the trap is limited and this may affect on the detection of minor sample components.[87, 88]

Mass spectrometry is becoming an important tool in biochemistry for characterizing and the quality control of recombinant proteins and other macromolecules. Among others, rapid identification, analysis of the post-translational modifications (PTMs), examination of covalent and non-covalent interactions and the primary structure determination of proteins are all possible by mass spectrometry. A one-step mass measurement provides the molecular weight of the intact protein. However, the experimental molecular weight can be different from the predicted mass because of the $N$ - and $C$-terminal processing, PTMs and chemical modifications (the latter reactions mainly occur during the purification processes). Thus, the mass of the intact protein itself is insufficient for precise identification and characterization, therefore, it is crucial to examine the exact amino acid sequence with peptide mass fingerprint or tandem MS methods.

Peptide Mass Fingerprint (PMF) is a widely used approach for rapid identification of a protein component from protein solutions, from cell lysates or tissues after a separation with 1 or $2 \mathrm{D}$ electrophoresis. Initially, the isolated protein is enzymatically digested by a sequence specific protease, such as trypsin. Then the produced peptide mixture is introduced into a mass spectrometer. The observed masses are compared to the predicted masses of peptides, from the theoretical digestion of proteins, taken from a database. The fast and accurate MS analysis and the modern databases provide reliable protein identifications.[89] 
Tandem mass spectrometry (or MS/MS) is applied in biochemistry for analyzing protein samples without separating the individual components or for obtaining more information about the integrity of a purified protein sample. During an MS/MS experiment a molecule-ion (called precursor ion) with specific $\mathrm{m} / \mathrm{z}$ ratio is isolated first, then fragmented for further analysis in a second mass spectrometric measurement. This procedure can be repeated in $\mathrm{MS}^{\mathrm{n}}$ experiments, where $\mathrm{n}$ means the number of mass analysis steps.

Collision-induced dissociation (CID) is the most widely applied fragmentation method for proteome identification (Figure 27). There are two possibilities for performing low-energy CID fragmentation: beam-type (or tandem-in-space) and ion trap (or tandemin-time) CID. In the first case, the instrument has more than one mass analyzer and the different stages of the analysis are accomplished separately. The tandem-in-time CID is performed in ion traps. The precursor ion is selected first by its $m / z$ value and then fragmented via resonance-activation. The $\mathrm{m} / \mathrm{z}$ values of the fragment ions usually differ from the selected $\mathrm{m} / \mathrm{z}$, thereby they are not activated and fragmented further. Accordingly, this kind of CID results in the breaking of only one covalent bond without forming any internal or immonium ions making the data interpretation easier. ESI ionization is advantageous in CID tandem MS experiments, because higher charge state of the precursor ion increases the probability of the decomposition.[90, 91]

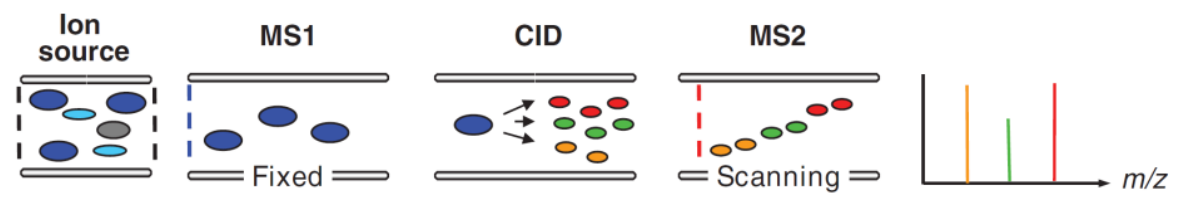

Figure 27: Principle of MS/MS measurements applying CID fragmentation.[91]

In CID, proteins are fragmented mostly along the peptide bond and form different types of ions. The nomenclature defines two sets of ions according to the terminus that remains in the ion: $a$-, $b$ - and $c$-ions contain the $N$-terminus, the $x$-, $y$ - and $z$-ions contain the $C$-terminus. Numerical subscripts represent the number of amino acid residues present in the product ion, and the numbering starts from the terminal amino acid (Figure 28). 

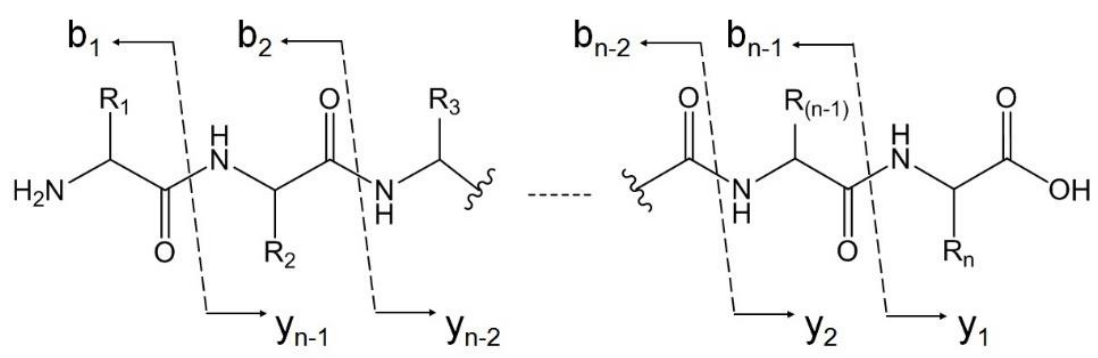

Figure 28: The nomenclature of product ions generated under low-energy CID.

The product ion spectrum is systematically evaluated. $b$ - and $y$-ion series are identified by comparison with the calculated $\mathrm{m} / \mathrm{z}$ values generated from the amino acid sequence of the target protein. While the excepted $\mathrm{m} / \mathrm{z}$ ratios are generated easily by computer programs (e.g. Protein Prospector (C) The Regents of the University of California), the relative intensity of the fragment ions is unequal and somewhat unpredictable.

In this work, the molecular mass of the purified proteins was determined with an Orbitrap Elite (Thermo Scientific) mass spectrometer coupled with electrospray ion source from acidified and desalted samples. CID fragmentation was used to investigate the integrity of the WT CueR protein. Furthermore, native ESI-MS was also applied to study protein-metal ion interactions at $\mathrm{pH}$ 7.5. See experimental details in Appendix A.5. PMF was applied to identify proteins from the SDS-PAGE gels during the optimization of the protein purification (Appendix A.6.).

\subsection{UV spectroscopy for studying metal ion-thiolate interactions}

Absorption of ultraviolet or visible (UV-Vis) electromagnetic radiation causes electronic transitions of a molecule, which means that electrons are excited from a lower energy to a higher energy molecular orbital (MO). UV-Vis spectroscopy is a method to study these transitions. The absorption spectrum provides both qualitative and quantitative information, based on the positions of the absorption peaks $\left(\lambda_{\max }\right)$ and the intensity of the bands $\left(A_{\lambda}, \varepsilon_{\lambda}\right)$, respectively.

UV-Vis spectroscopy is an essential method in chemistry; among several applications it is often used to characterize transition metal complexes. Charge transfer (CT) bands are a result of an electronic transition, but in this case the change in the electron distribution occurs between the metal ion and the ligands. These electronic transitions are formally allowed by selection rules (i.e. spin rule, Laporte's rule) and therefore CT bands are intense (typical $\varepsilon$ is a few $10000 \mathrm{dm}^{3} \mathrm{~mol}^{-1} \mathrm{~cm}^{-1}$ ) and are usually present in the UV 
region of the spectrum. Ligand-to-metal CT (LMCT) transitions happens if the molecular orbitals of the ligands are filled and there are empty orbitals at the metal ion at the same energy level, hence transition may occur from the ligand based orbitals to the empty metal d-orbitals. Metal-to-ligand CT occurs if the ligand possesses low-lying empty orbitals and the metal is in a low oxidation state (i.e. electron rich). The spectral characteristics of CT absorption bands are highly dependent on the metal ion, ligands and the geometry of the complex.

In the present work, UV-Vis spectroscopy was applied to observe metal ion protein complex formation by monitoring the $\mathrm{S}^{2-}$ thiolate $\rightarrow \mathrm{M}^{2+}$ LMCT transitions (Appendix A.7.).

\subsection{Circular dichroism spectroscopy}

Circular dichroism (CD) spectroscopy is based on the phenomenon that optically active substances absorb the right and left circularly polarised light differently. Thus, after left and right circularly polarized light passes through the sample, owing to the non-equal absorption of the two components, elliptically polarized light is detected. A CD spectrum is usually reported in ellipticity $(\theta)$ given in degrees as a function of wavelength $(\lambda)$. The ellipticity is directly proportional to the differential absorption $(\Delta A)$ of the two circularly polarized light components: $\theta=32.98 \Delta A$. Applying the Lambert-Beer law, the difference in molar extinction coefficients $\left(\Delta \varepsilon=\varepsilon_{\mathrm{L}}-\varepsilon_{\mathrm{R}}\right)$, called as the molar circular dichroism or delta epsilon, can be calculated in units of $\mathrm{M}^{-1} \mathrm{~cm}^{-1}$ by the following equation:

$$
\Delta \varepsilon=\frac{\Delta A}{l c N}
$$

$l$ is the path length, $c$ is the concentration, $N$ is the number of amino acids - in case the optically active substance is a protein.

The far UV CD spectra (below $240 \mathrm{~nm}$ ) of proteins is characteristic for their secondary structure composition (Figure 29). The two main transition in this region are: the $n \rightarrow \pi^{*}$ transition centred around $220 \mathrm{~nm}$ and the more intense $\pi \rightarrow \pi^{*}$ transition around $190 \mathrm{~nm}$. To obtain an estimate of the secondary structure composition from the $\mathrm{CD}$

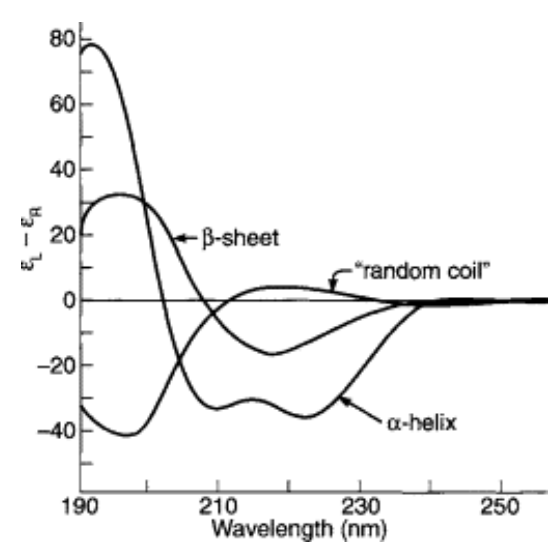

Figure 29: Circular dichroism spectra for polypeptides with different conformations. [92] 
spectrum, the molar circular dichroism spectrum is analysed with various algorithms, which employ distinct data sets of reference proteins (with resolved crystal structures, and thus with known secondary structure).[93, 94] The most widely used algorithms are SELCON, CONTIN, CDSSTR, that are also collected in the CDPro[95] software package, CDNN[96], CCA+[97] and BeStSel[98].

Temperature-dependent CD spectra of proteins provide information about the thermal stability of the molecules. Temperature scans can be used to determine the denaturation temperature $\left(\mathrm{T}_{\mathrm{m}}\right)$ in the absence or presence of various ligands. Temperature-dependence is commonly presented by a thermal denaturation curve (Figure 30) that is the

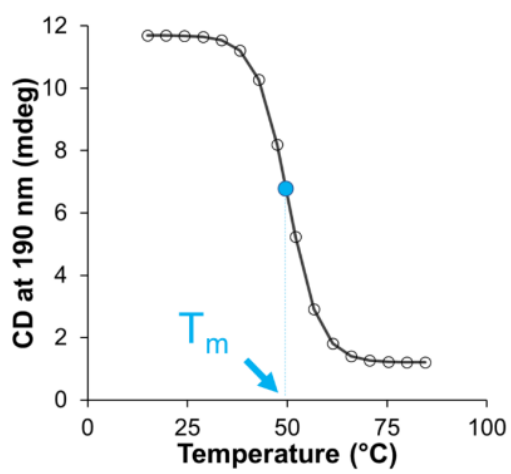

Figure 30: A typical protein denaturation curve obtained with temperature dependent $C D$ measurements. $T_{m}$ indicates the denaturation temperature. ellipticity measured at a certain wavelength displayed as a function of the temperature. If the temperature increases, the H-bonds maintaining the secondary structure elements break, thus the protein defolds and the intensity of the CD signal decreases.

CD spectroscopy was used for validating the proper fold of the purified proteins and for monitoring the changes in the secondary structure upon changing the $\mathrm{pH}$ or adding metal ions and/or DNA to the proteins. Denaturation curves of WT CueR were recorded in order to investigate the effect of the presence of metal ions and/or DNA on the thermal stability of the protein. The experimental conditions of CD measurements are collected in Appendix A.8.

\subsection{Fluorescence measurements: fluorescent spectroscopy and microscopy}

The phenomenon of fluorescence is widely applied in biological and chemical sciences, and it is regularly used also for cellular and molecular imaging. Fluorescence is a type of photoluminescence, i.e. absorbing electromagnetic radiation results in an electronically excited state of a substance and it relax by the emission of a photon. Depending on the nature of the excited state, the emitted luminescence can be classified into two categories: fluorescence and phosphorescence. The two processes are illustrated by the Jablonski diagram (Figure 31). The singlet ground, first, and second electronic states 
are represented by the $S_{0}, S_{1}$, and $S_{2}$ levels, respectively. The vibrational energy levels of these electronic states are denoted by $0,1,2$, etc. By absorbing light, an electron of the fluorophore is usually excited to a higher vibrational level of either $S_{1}$ or $\mathrm{S}_{2}$, then in a rapid $\left(\sim 10^{-12} \mathrm{~s}\right)$

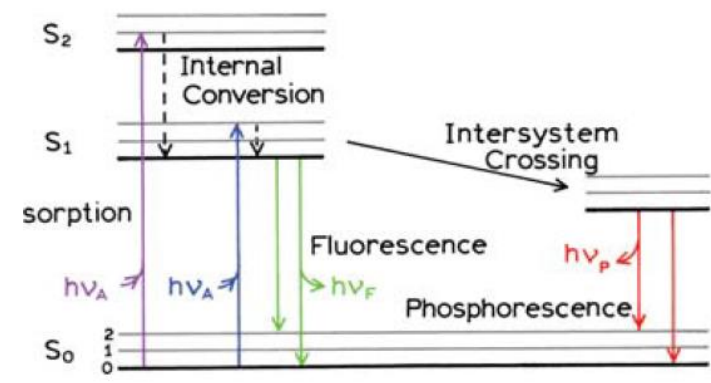

Figure 31: Jablonski diagram of absorption and emission via fluorescence and phosphorescence. [99] relaxation, called internal conversion, the electron reaches the lowest vibrational level of $S_{1}$. The electron in its excited singlet state has an opposite spin relative to the second electron in the ground-state orbital. Consequently, return to the ground state is spin allowed and occurs rapidly by emission of a photon, that is called fluorescence. A typical fluorescence lifetime is near $10 \mathrm{~ns}$. An interesting consequence of this process is that the emission spectrum is typically a mirror image of the absorption spectrum. Another possibility is that the fluorophore in the $S_{1}$ state undergoes a spin conversion, called intersystem crossing, to the first triplet state, $T_{1}$. Transition from $T_{1}$ to the $S_{0}$ state is forbidden because the electron in the excited orbital has the same spin orientation as the ground-state electron, therefore the emission rate is slow (lifetimes are typically milliseconds to seconds). This process is named phosphorescence.[99]

Fluorescence typically occurs from aromatic, planar or cyclic molecules with several $\pi$-bonds. Such molecules are called fluorophores. The spectral data of fluorophores are generally presented as emission spectra, i.e. a plot of the fluorescence intensity versus wavelength. Fluorophores are characterized by the wavelength of the excitation and emission maxima, quantum yield (i.e. the number of emitted photons relative to the number of absorbed photons) and the fluorescence lifetime.[99]

Fluorescent molecules can be also classified into intrinsic or extrinsic fluorophores. Intrinsic fluorophores are those that occur naturally, for example the indole group of tryptophan or the GFP. Fluorescent proteins, such as EGFP, contain a highly fluorescent moiety that is formed spontaneously upon protein folding. The fluorophore is protected by a barrel of $\beta$-sheet, see Figure 16 in paragraph 2.6. In general, GFPs have a good photostability and display high quantum yields, see in Table 3 the spectral properties of EGFP.[50] Fluorescent proteins can be expressed in cells individually or as a fusion-tag of target proteins. Extrinsic fluorophores are dyes, also called probes, added to a sample in order to produce fluorescence with the desired spectral properties. A wide variety of 
extrinsic fluorophores have been developed for labelling macromolecules, for instance the non-fluorescent DNA. Examples of fluorescent DNA dyes are ethidium bromide and 4',6diamidino-2-phenolindole (DAPI). When bound to dsDNA, the emission maxima of DAPI is at $461 \mathrm{~nm}$ (blue) (Table 3).[100] DAPI is extensively used to stain cells in fluorescent microscopy.

Table 3: Spectral properties of EGFP and DAPI in complex with DNA.

\begin{tabular}{l|c|c}
\hline & EGFP & DAPI-dsDNA \\
\hline$\lambda_{\text {Ex }}(\mathrm{nm})$ & 488 & 358 \\
\hline$\lambda_{\text {Em }}(\mathrm{nm})$ & 507 & 461 \\
\hline Quantum yield & 0.60 & 0.92 \\
\hline$\varepsilon \times 10^{-4}\left(\mathrm{M}^{-1} \mathrm{~cm}^{-1}\right)$ & 5.50 & 2.36 \\
\hline $\mathrm{t}_{\text {maturation }}(\mathrm{min})$ & 25 & - \\
\hline
\end{tabular}

Fluorescence spectroscopy (also called as fluorimetry) is used for measuring and characterizing fluorescent samples. The sample is illuminated, i.e. excited, with a continuous beam of light at an optimal wavelength $\left(\lambda_{\mathrm{Ex}}\right)$ and the intensity at the wavelength of the emission maxima of the emission band $\left(\lambda_{\mathrm{Em}}\right)$ or the emission spectrum is recorded. The detector is placed perpendicular to the light-source to avoid any interference from the transmitted excitation light. Recently, high-throughput and rapid fluorescence intensity measurements are performed with plate readers (or microplate readers). For such measurements only a few hundreds of $\mu \mathrm{L}$ sample is required that is loaded into wells of a microplate. In plate readers not only the excitation light, but the emitted light is also filtered by a monochromator. The emitted light is directed towards the detector optics by a mirror moved above the wells.[101]

Fluorescence is widely applied in microscopy as well, since its selectivity increases the contrast between the signal and background during the imaging. Numerous probes are commercially available for labelling biological systems making the simultaneous imaging of different cell compartments or molecular components possible. Intrinsic fluorophores are used for labelling proteins and tracking them in living cells. By the innovations of laser scanning confocal microscopes the quality of the images is highly improved, since it is possible to filter out the exciting light without blocking the emitted fluorescence, thereby only the fluorescent objects are visible. In modern fluorescence microscopes, the objective is used both to illuminate and to image the specimen (so-called epi-illumination). The 
operating principle is the following: a beam of light with a narrow bandwidth is transmitted by an excitation filter and directed to the specimen by a dichroic mirror. This beam of light selectively excites a particular fluorophore of the sample. Then, the fluorescence is collected by the objective and sent through the dichroic mirror and the barrier filter to the eye or camera port above. The dichroic mirror and the two filters are very wavelength selective and placed in the

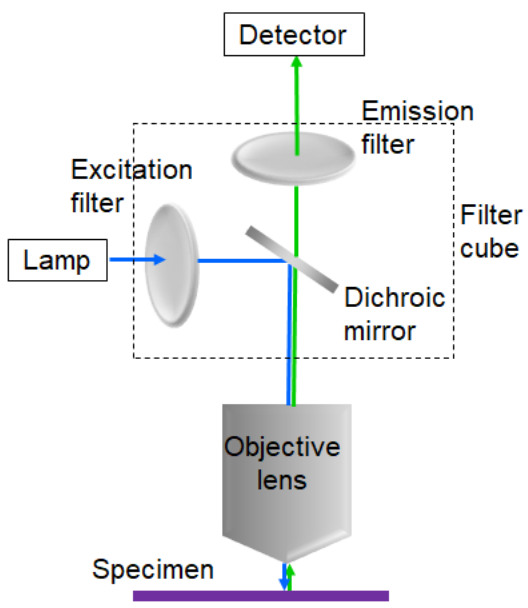

Figure 32: Components and light paths of a fluorescence microscope. so-called filter cube (Figure 32). Samples are usually stained and then fixed on a slide with a mounting medium that reduces photo-bleaching (i.e. continuous decrease in the fluorescence intensity of a sample).[102]

In the present work, the function of the reporter system was studied with fluorescent microscope and microplate reader based on the expression of the fluorescent protein. The detailed experimental description of the sample preparation, the imaging and the fluorescent intensity measurements is detailed in Appendix A.11.

\subsection{Perturbed angular correlations of $\gamma$-rays spectroscopy}

Perturbed angular correlations (PAC) of $\gamma$-rays spectroscopy is a rather exotic spectroscopic method used for exploring structure and dynamics of the metal binding sites of proteins. Great advantages of this metal site specific spectroscopy are the high sensitivity to the changes in the very local surrounding of a metal ion, and the possibility of carrying out the measurements in solution phase at low concentrations $(<\mathrm{nM}) .[103-105]$

In PAC spectroscopy, radioactive isotopes that decay by the successive emission of two $\gamma$-rays are used. In this work, three radioactive probes, ${ }^{111 \mathrm{~m}} \mathrm{Cd},{ }^{111} \mathrm{Ag}$ and ${ }^{199} \mathrm{~m} \mathrm{Hg}$, were utilized. A few parameters and the decay schemes of the isotopes are presented in Table 4 and Figure 33. The data interpretation of ${ }^{111 \mathrm{~m}} \mathrm{Cd}$ and ${ }^{199 \mathrm{~m}} \mathrm{Hg}$ PAC spectra is usually straightforward, because there is no element transformation during the nuclear decay. The metastable isotopes possess relatively short half-lives $\left(t_{1 / 2} \sim 40-50 \mathrm{~min}\right)$, therefore the data collection takes only a few hours. However, the decay scheme of ${ }^{111} \mathrm{Ag}$ is more complex: ${ }^{111} \mathrm{Ag}$ decays by $\beta^{-}$emission to ${ }^{111} \mathrm{Cd}$, with a $\sim 5 \%$ probability to the excited state of the 
${ }^{111} \mathrm{Cd}$ nucleus $(I=3 / 2)$. Only $4 \%$ of the nuclei in this state decay by emitting two consecutive $\gamma$-rays (Figure 33). Because of the element and oxidation state change from $\mathrm{Ag}(\mathrm{I})$ to $\mathrm{Cd}(\mathrm{II})$, the data interpretation of ${ }^{111} \mathrm{Ag}$ PAC spectra is more complicated. Nevertheless, ${ }^{111} \mathrm{Ag}$ PAC can be used not only to study the structure, but also the flexibility of the metal site. The half-life of ${ }^{111} \mathrm{Ag}$ is 7.45 days, thereby obtaining a ${ }^{111} \mathrm{Ag}$ PAC spectrum takes from few days up to few weeks. Generally, the lifetime of the intermediate state of PAC isotopes is in a ns- $\mu$ s range, consequently, PAC spectroscopy can be used to characterize dynamics of the metal binding sites at this timescale.[103-105]
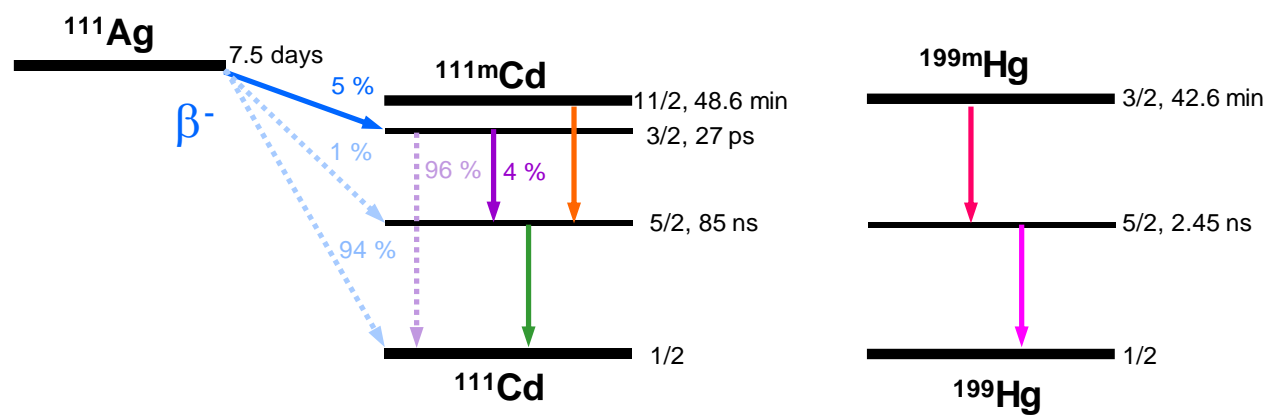

Figure 33: Decay schemes of ${ }^{111} \mathrm{Ag},{ }^{111 m} \mathrm{Cd}$ and ${ }^{199 m} \mathrm{Hg}$ including information about the nuclear spin and the half-life of the energy levels. The solid arrows indicate the $\gamma-\gamma$ cascade used in PAC spectroscopy.[103-105]

Table 4: Characteristic parameters of PAC isotopes used in this work. [103-105] IT: isomeric transition, $\beta^{-}$: emission of an electron and an antineutrino in a process that transforms a neutron to a proton.

\begin{tabular}{c|c|c|c|c|c|c|c}
\hline $\begin{array}{c}\text { Parent } \\
\text { isotope }\end{array}$ & Half-life & $\begin{array}{c}\text { Type of } \\
\text { decay }\end{array}$ & $\begin{array}{c}\text { Probe } \\
\text { isotope }\end{array}$ & $\begin{array}{c}\text { Half-life of } \\
\text { intermediate } \\
\text { nuclear state }\end{array}$ & $\boldsymbol{I}$ & $\begin{array}{c}\mathbf{E}\left(\gamma_{1}\right) \\
(\mathbf{k e V})\end{array}$ & $\begin{array}{c}\mathbf{E}\left(\gamma_{2}\right) \\
(\mathbf{k e V})\end{array}$ \\
\hline${ }^{111 \mathrm{~m} \mathrm{Cd}}$ & $48.54 \mathrm{~min}$ & $\mathrm{IT}$ & ${ }^{111} \mathrm{Cd}$ & $85.0 \mathrm{~ns}$ & $5 / 2$ & 150.82 & 245.42 \\
${ }^{111} \mathrm{Ag}$ & 7.45 days & $\beta^{-}$ & ${ }^{111} \mathrm{Cd}$ & $85.0 \mathrm{~ns}$ & $5 / 2$ & 96.73 & 245.42 \\
${ }^{199 \mathrm{~m}} \mathrm{Hg}$ & $42.6 \mathrm{~min}$ & $\mathrm{IT}$ & ${ }^{199} \mathrm{Hg}$ & $2.45 \mathrm{~ns}$ & $5 / 2$ & 374.10 & 158.38 \\
\hline
\end{tabular}

PAC spectroscopy is based on the principle that the total angular momentum is conserved during the nuclear decay, i.e. the consecutive $\gamma$-rays are not emitted in random directions. The direction of the emission of the first $\gamma$-ray depends on the orientation of the nuclear spin $(I)$, and the second $\gamma$-ray is emitted at a given angle with respect to the first. In other words, there is an angular correlation between the two emitted $\gamma$-rays. If the 
radioactive nucleus interacts with the surrounding charge distribution while it is in the intermediate nuclear energy level, the angular correlation of the $\gamma$ rays is perturbed.

In PAC spectroscopy, the so-called nuclear quadrupole interaction (NQI) is measured. NQI refers to the interaction between the electric quadrupole moment of the PAC isotope nucleus (Q) and the electric field gradient (EFG) originated from the
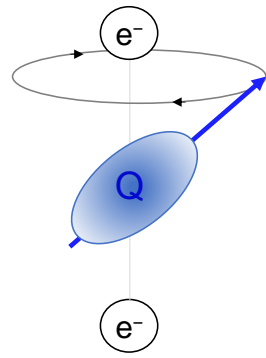

Figure 34 Schematic representation of the precession of a non-spherical nucleus in between two negative charges. surrounding charges within a few Ångströms. When a spinning non-spherical charge distribution is placed between two negative charges, the energy of the system depends on the orientation of the angular momentum (I) (Figure 34). In the quantum mechanical representation, the angular momentum cannot point into arbitrary direction, but only certain directions are available along the axis defined by the external charges. Thereby, the electric field gradient causes a hyperfine energy splitting of the intermediate energy level into sublevels (three sublevels if $I=5 / 2)($ Figure 35). The energy differences between the three sublevels are characterised by three frequencies $\omega_{1}$, $\omega_{2}$, and $\omega_{3}$, where $\omega_{3}=\omega_{1}+\omega_{2}$. In addition, if the energy splitting occurs in an axially symmetric EFG, the relation between $\omega_{1}$ and $\omega_{2}$ is $\omega_{2}=2 \omega_{1}$, whereas if it occurs in an EFG with maximum asymmetry, $\omega_{2}=\omega_{1}$. The three frequencies and their correlation are manifested in the pattern of a PAC spectrum as a fingerprint of the local charge distribution, i.e. the local structure around the

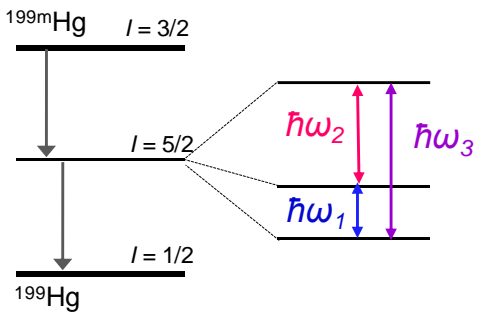

Figure 35: Energy splitting of the intermediate level of ${ }^{199 m} \mathrm{Hg}(I=5 / 2)$ due to a nuclear quadrupole interaction (NQI) in an axially symmetric EFG.[103] radioactive isotope (Figure 36).[103-105]

As it was mentioned before, the direction of a second emitted $\gamma$-ray is determined by the first which is a function of the nuclear spin states. Due to the hyperfine interaction elaborated before, the most probable direction of the emission of the second $\gamma$-ray changes. For nuclei with an intermediate level of $I=5 / 2$ in a randomly oriented, but identical, static $\mathrm{EFG}$, the perturbation function is given as:

$$
G_{22}(t)=a_{0}+a_{1} \cos \left(\omega_{1} t\right)+a_{2} \cos \left(\omega_{2} t\right)+a_{3} \cos \left(\omega_{3} t\right)
$$


The amplitudes of the peaks in the Fourier transformed PAC spectra, corresponding to the three frequencies described above, follow the relation: $a_{1} \geq a_{2}>a_{3}$ (Figure 36). However, if more than one NQI (that is more than one coordination geometry) is present, the magnitudes of amplitudes do not follow this order, e.g. $a_{2}$ might be equal or even larger than $a_{1}$. Moreover, the frequencies and the amplitudes depend on the strength of the NQI, represented by the parameter $\omega_{0}$ (or $v_{\mathrm{Q}}=$ $\left.1 / 6 \omega_{0}\right)$, and the asymmetry parameter $\eta$ of the EFG (with a value between 0 and 1 , where 1 corresponds to the highest degree of asymmetry). The fitting of the Fourier transformed PAC spectra provides the $\omega_{0}$ and $\eta$ values, and through these, valuable information about the coordination environment of the PAC

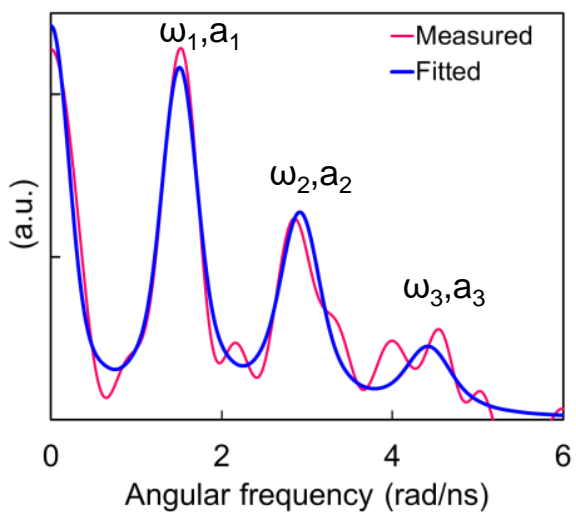

Figure 36: A Fourier transformed PAC spectrum and its fitting showing a typical

$P A C$ pattern defined by the three frequencies. Notice that $\omega_{3}=\omega_{1}+\omega_{2}$ and $\mathrm{a}_{1}>\mathrm{a}_{2}>\mathrm{a}_{3}$. isotope.[103-105]

In a non-static EFG, the perturbation function changes in a characteristic way and provides information on the conformational dynamics of the probed molecule, if the rotational diffusion (Brownian motion) of the molecules is limited. This can be achieved by freezing the sample or by adding sucrose (typically $55 \mathrm{w} / \mathrm{w} \%$ ) to the sample and perform the experiment at ca. $1{ }^{\circ} \mathrm{C} .[103-105]$

With the aim to understand better the metal ion coordination characteristics of CueR several PAC experiments were carried out with the WT and the $\triangle \mathrm{C} 7$ - and S77C- $\Delta \mathrm{C} 7-\mathrm{Cu} R$ variants. ${ }^{199 \mathrm{~m}} \mathrm{Hg}$ PAC measurements were performed at the ISOLDE beam line at CERN, while ${ }^{111 \mathrm{~m}} \mathrm{Cd}$ and ${ }^{111} \mathrm{Ag}$ PAC experiments were carried out at the University of Copenhagen. The production of the radioactive isotopes and the sample preparation and measurement conditions are described in more detail in Appendix A.9.1 and A.9.2. 


\section{RESULTS AND DISCUSSION}

\subsection{Production of the CueR protein and its mutants}

In order to execute studies on the metal binding features of CueR it was necessary to produce the protein by overexpressing and purifying it. Therefore, we optimized an advanced procedure for purifying the WT CueR without any affinity tag from E. coli.

Two other proteins were also produced in this work, both of these are variants of the CueR protein. First, a truncated variant, hereafter named as $\triangle \mathrm{C} 7-\mathrm{CueR}$, was obtained by the deletion of $7 \mathrm{C}$-terminal amino acids (starting from G128), containing a $\mathrm{CCHH}$ segment (Figure 37). The $\Delta \mathrm{C} 7-\mathrm{CueR}$ protein possesses only one metal binding site formed by residues $\mathrm{C} 112$ and $\mathrm{C} 120$ and thus it displays the coordination properties of solely the metal ion binding loop of CueR. Accordingly, comparison of the metal ion binding features of this protein with those of the WT CueR may help to understand the function of the CCHH motif. Next, a single S77C mutation was introduced into the sequence of the truncated CueR (Figure 37), hereafter named as S77C- $\triangle \mathrm{C} 7-\mathrm{CueR}$. Based on studies carried out with the GolS protein[36], the mutation of this particular S77 residue to cysteine may change the metal binding features of the protein by providing a third thiolate ligand to coordinate metal ions.

The complete sequences of these proteins can be found in Appendix A1.1.

$$
\begin{array}{lll}
\text { WTCueR } & 74-\text { RQSADVKRLAQTHIDELDRRIQNMQHMAQTLKALANACPGDDSADCPIIENLSGCCHHRAG } & -135 \\
\Delta \text { C7-CueR } & 74-\text { RQSADVKRLAQTHIDELDRRIQNMQHMAQTLKALANACPGDDSADCPIIENLSG } & -128 \\
\text { S77C- } \Delta \text { C7-CueR } & 74-\text { RQCADVKRLAQTHIDELDRRIQNMQHMAQTLKALANACPGDDSADCPIIENLSG } & -128
\end{array}
$$

Figure 37: Comparison of the C-terminal amino acid sequence of the WT, $\triangle C 7$ - and $S 77 C-\triangle C 7$ CueR proteins. The differences and the cysteines are highlighted in red and in yellow colour, respectively.

\subsubsection{Cloning and introducing mutations}

The gene of the wild type CueR in a pET-24a plasmid was kindly provided by prof. Alfonso Mondragon (Department of Molecular Biosciences, Northwestern University, Evanston, Illinois, USA).[106] The DNA segment, encoding CueR, was re-cloned into a pET-21a plasmid.

The gene of $C$-terminally truncated CueR protein was constructed using a conventional restriction enzyme digestion/ligation cloning method. As a first step, the shortened gene was amplified from pET-21a-CueR plasmid in a PCR, then cloned into pET-21a plasmid. 
The single amino acid mutation, exchanging the S77 amino acid to cysteine, was carried out with Quik change ${ }^{\mathrm{TM}}$ protocol[81] on the previously obtained pET-21a- $\Delta \mathrm{C} 7-$ CueR plasmid.

\subsubsection{Building up the purification procedure of the WT CueR protein: difficulties and their solutions}

WT CueR is made up of 135 amino acids. The average molecular weight of the apoprotein is $15235.1 \mathrm{Da}$, and the theoretical $\mathrm{p} I$ is 5.72 . This would allow for applying cation exchange at $\mathrm{pH} 3.0$ being a great advantage in the purification process of an air-sensitive protein. The $\mathrm{p} K_{\mathrm{a}}$ of cysteine thiols is ca. 8.4.[107] A lower $\mathrm{pH}$, ensuring the protonated state of cysteines, should decelerate the oxidation leading to the formation of intra- and/or intermolecular disulfide bonds and thus, to the potential formation of polymeric aggregates. However, it turned out that CueR in its highly positively charged form under acidic condition binds tightly to the negatively charged DNA that leads to the precipitation of the protein-DNA complex. Streptomycin sulfate, a water soluble antibiotic binding to the bacterial ribosome, is a widely used agent to precipitate nucleic acids. In our experiment streptomycin sulfate caused not only the removal of nucleic acids, but most of the CueR protein disappeared from the solution, too. This necessitated a change of the purification strategy.

In order to perform anion exchange the increase of the $\mathrm{pH}$ was required. Taking into account the acid-base properties of the cysteine thiol groups, $\mathrm{pH}=7.5$ was chosen for this procedure. $\mathrm{Na}_{2} \mathrm{~S}_{2} \mathrm{O}_{4}$ was added to the samples before and after the lysis of cells to prevent the oxidation of CueR. Anion exchange alone was not enough to obtain an adequately purified CueR (see later in Figure 41, lane 2). Therefore, the samples were loaded on a gel filtration column, preceded by a concentration step. However, precipitation was observed during the

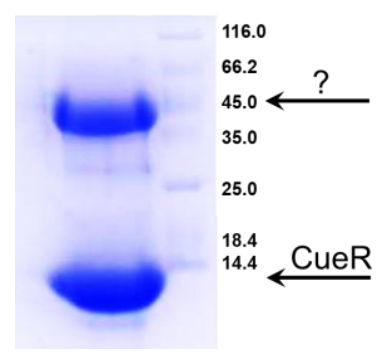

Figure 38: SDS-PAGE image of the precipitated proteins with the molecular weight standard given in $k D a$. ultrafiltration step. This experiment was repeated in the presence of DTT as a reducing agent and argon-flushed buffers but the precipitation could not be avoided. The precipitated proteins were analyzed with SDSPAGE showing two clear bands on the gel: a $\sim 15 \mathrm{kDa}$ size protein expected to be CueR, and an unknown protein with a size of $\sim 45 \mathrm{kDa}$ (Figure 38). The latter protein appeared 
in all fractions of the previous purification steps (even in gel filtration experiment separating the molecules based on their size) together with the target CueR molecule.

The two bands were cut from the gel and analyzed with peptide mass fingerprinting. As a result of this procedure the 15 and $45 \mathrm{kDa}$ proteins were identified as the CueR (CUER_ECOLI) and an Elongation factor of E. coli (EFTU1_ECOLI), respectively (Appendix A.6.2.). The most intense peaks of the mass spectra obtained from the bottom and upper protein bands matched to CueR with $44 \%$, and to the Elongation factor with 58 $\%$ sequence coverage, respectively. Thus, CueR co-precipitated with another nucleic acid binding protein, an elongation factor, suggesting that $\mathrm{CueR}$ interacted with this elongation factor through DNA. Therefore, we expected that the precipitation of CueR might have been prevented by digesting DNA with DNaseI enzyme before the first chromatographic step. Indeed, precipitation was not observed during the subsequent anion exchange and gel filtration purification steps after digesting DNA with DNaseI. However, the purity of the CueR containing fractions collected from the gel filtration column was found to be insufficient.

In order to achieve a better separation, we started a new purification procedure by loading the DNaseI digested mixture directly onto an anion exchange column. After this step affinity chromatography purification by a Heparin column and a subsequent anion exchange were introduced. The glycosaminoglycan heparin mimics the polyanionic structure of nucleic acids. Consequently, nucleic acid binding proteins, such as CueR show a strong affinity to heparin, too. One may notice that heparin carries negative charges, and thus it can also work as a cation exchange column. However, in our system the positively charged proteins were removed in the flow-through fraction of the preceding anion exchange step. Anion exchange was introduced as the third chromatographic step in the protocol. This was necessary because $\mathrm{a} \sim 31 \mathrm{kDa}$ protein contamination appeared in the collected fractions, in addition to CueR, when gel filtration was applied directly after affinity chromatography (Figure 39). 

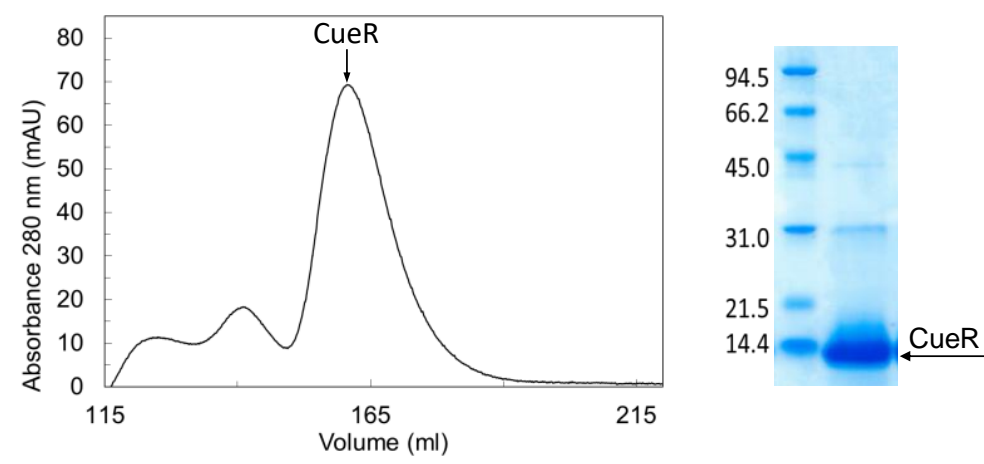

Figure 39: Chromatogram of gel filtration and SDS-PAGE analysis of the combined and concentrated CueR containing fractions obtained in a procedure without performing a second anion exchange between the affinity chromatography and gel filtration steps.

The separation of CueR from the $\sim 31 \mathrm{kDa}$ protein was successful in the purification process complemented with this second anion exchange, introduced between the affinity purification and gel filtration steps. A Source 30 Q 16/13 column was selected, with a higher resolution as compared to that of Sepharose FF. The anion exchange at this step was performed at $\mathrm{pH}=7.0$ (Figure $40 \mathrm{C}$ ). The final gel filtration produced a single, well separated peak (Figure $44 \mathrm{D})$.
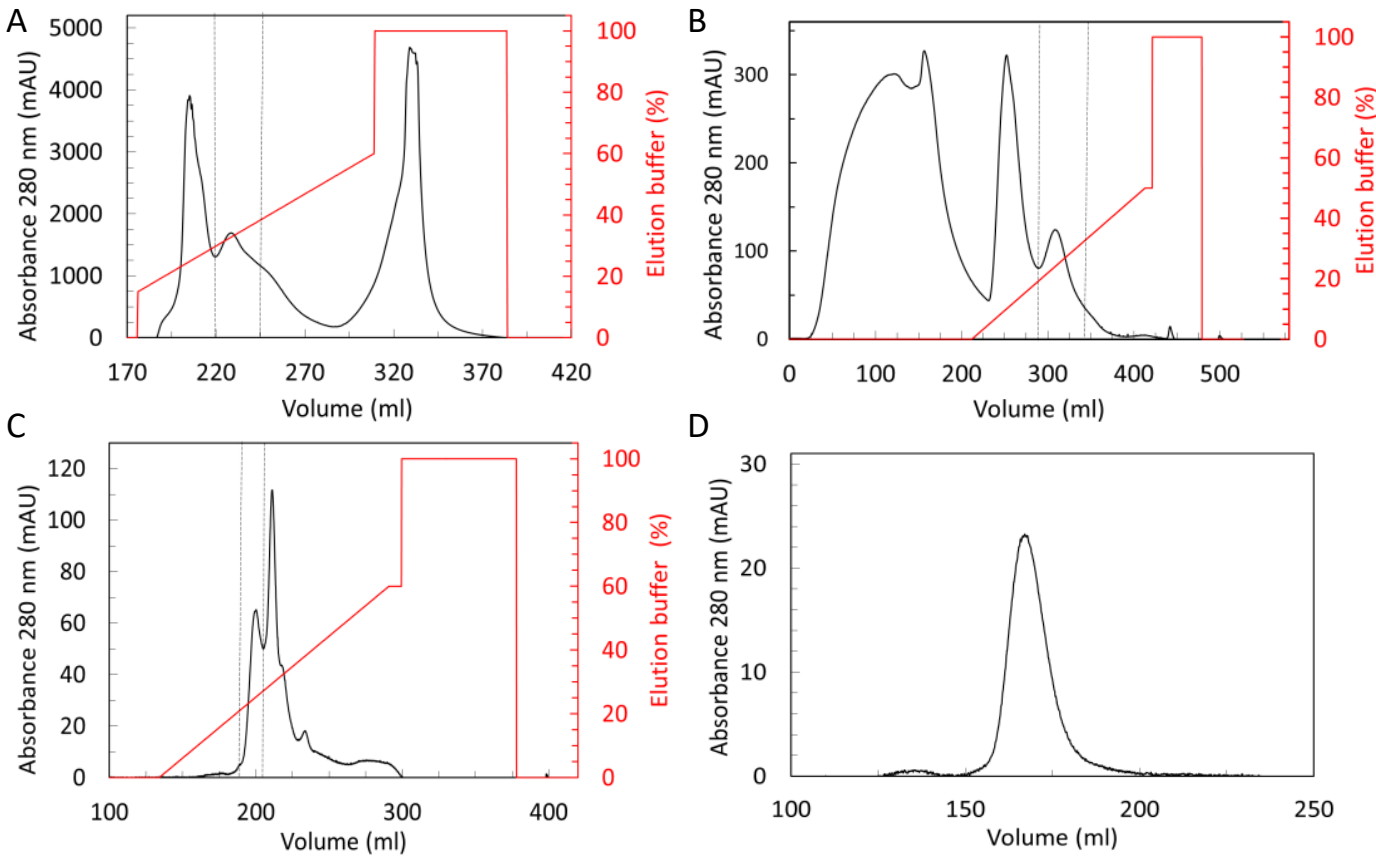

Figure 40: Representative chromatograms of the various purification steps (dotted lines denote the collected fractions). The dashed lines show the percentage of the applied, high ionic strength buffer during the elution. (A) first anion exchange on a Sepharose FF 16/10 column; (B) affinity purification on a Heparin FF 16/10; (C) second anion exchange on Source 30 Q 16/13; (D) gel filtration on HiLoad Superdex 75 26/600 with isocratic elution. 


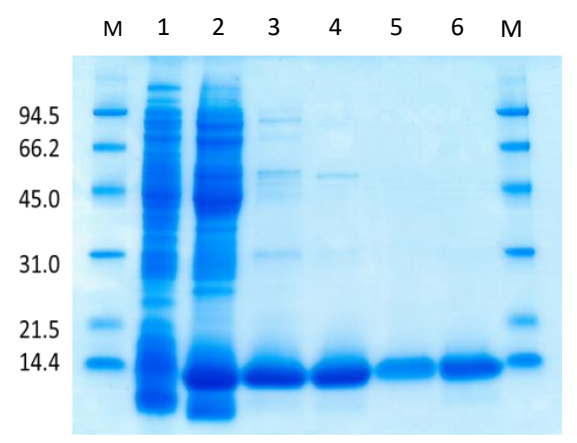

Figure 41: SDS-PAGE analysis performed at the various stages of the purification. M: molecular weight standard given in $\mathrm{kDa} ; 1$ : supernatant, 2: sample after the first anion exchange; 3: sample after affinity purification; 4: sample after the second anion exchange;5: sample after gel filtration; 6: final concentrated sample.

Finally, pure CueR fractions were obtained in the four-step chromatographic procedure (Figure 40), preceded by the digestion of the DNA, as it was reflected by the SDS-PAGE analysis (Figure 41). The average yield was $4 \mathrm{mg}$ protein per $1 \mathrm{~L}$ culture.

\subsubsection{Optimizing the procedure for purifying mutant Cue R proteins}

The modifications introduced into the amino acid sequence of the CueR, i.e. truncation and S77C point mutation, led only to minor changes in some physical properties. Thereby, the purification of the mutant proteins could be performed similarly as described previously for the WT protein.

The removed segment (CCHHRAG) contains a positively charged arginine, hence the $\mathrm{p} I$ of the $\Delta \mathrm{C} 7-\mathrm{CueR}$ protein is slightly decreased $(\mathrm{p} I=5.2)$ compared to the WT protein. This resulted in a little altered elution time from the anion exchange and the Heparin columns. Furthermore, the $\Delta \mathrm{C} 7-\mathrm{CueR}$ protein contains only 2 cysteines that made the protein less air sensitive compared to the WT protein. High purity samples could be obtained even by eliminating

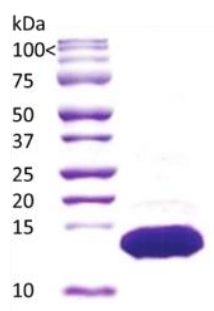

Figure 42: $S D S-P A G E$ analysis of the purified and up-concentrated $\triangle C 7$-CueR protein. the second anion exchange step (Figure 42).

However, the S77C mutation increased the number of cysteines to 3. Most likely, the odd number of cysteines fostered the formation of intermolecular disulfide bonds leading to formation of polymeric forms. This was evidenced by SDS-PAGE analysis of the fractions obtained from the gel filtration step (Figure 43) in which the S77C protein was present in all fractions of the isocratic elution. To avoid the formation of polymers, a reducing agent (DTT) was added to the sample and to the elution buffer prior the gel 
filtration step. In this way, the S77C protein could be successfully separated from the other proteins (Figure 43).
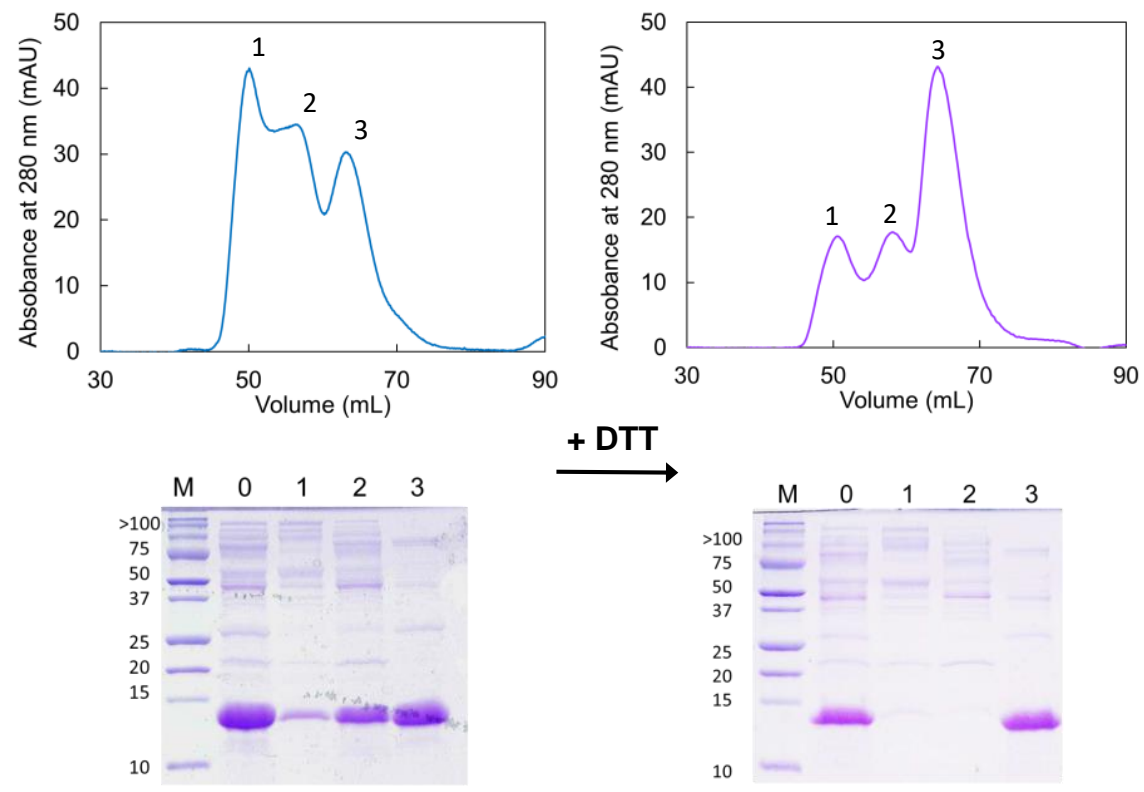

Figure 43: Chromatogram and SDS-PAGE analysis of fractions obtained from gel filtration of $S 77 C-\triangle C 7$ protein samples in the absence (left) and presence (right) of DTT reducing agent. M: molecular weight standard given in $\mathrm{kDa}$; 0 : sample before gel filtration; 1-3: samples corresponding to peaks on the chromatogram.

\subsubsection{Validating the obtained proteins with MS, CD and EMSA}

The purified protein samples were analyzed with mass spectrometry. The deconvoluted monoisotopic molecular masses of the singly charged $\left(\mathrm{MH}^{+}\right)$intact proteins correspond well to the theoretically calculated protonated monoisotopic masses, see in Table 5.

Table 5: The theoretical and experimental masses of the purified proteins.

\begin{tabular}{l|l|l}
\hline Protein & Theoretical mass & Experimental mass \\
\hline WT CueR & $15226.605 \mathrm{Da}$ & $15226.61 \mathrm{Da}$ \\
$\Delta \mathrm{C} 7-\mathrm{CueR}$ & $14462.309 \mathrm{Da}$ & $14462.29 \mathrm{Da}$ \\
S77C- $\Delta$ C7-CueR & $14478.286 \mathrm{Da}$ & $14478.31 \mathrm{Da}$ \\
\hline
\end{tabular}

In order to investigate the oxidation state of the cysteine residues, a CID experiment was performed with WT CueR. The ion deserved at $897 \mathrm{~m} / \mathrm{z}(\mathrm{z}=17)$ was chosen for fragmentation in the ion trap. The most abundant fragment at $789.66 \mathrm{~m} / \mathrm{z}(\mathrm{z}=3)$ was further fragmented and identified as the $C$-terminal PGDDSADCPIIENLSGCCHHRAG part of 
the protein (Figure 44). Analysis of the $\mathrm{MS}^{3}$ spectrum showed that the majority of the peaks corresponding to sequences containing various number of cysteines e.g. the $\mathrm{y}_{10}$ $[\text { LSGCCHHRAG }]^{+}, \mathrm{y}_{7}:$ [CCHHRAG $^{+}$and $\mathrm{y}_{6}:$ [CHHRAG $^{+}$display masses expected from the reduced forms. Signals of fragments with a disulfide bridge typically between C129 and C130 represent only a small fraction of the CueR molecules. The fact that during iontrap CID experiment the protein was broken between C112 and P113 indicates that C112 is not linked to the other cysteine residue $(\mathrm{C} 120)$ of the metal ion binding loop through an intramolecular disulfide bridge. All in all, from the $\mathrm{MS}^{3}$ experiment we have a clear evidence that all of the four cysteines can be kept in their reduced form in the large majority of the protein molecules.
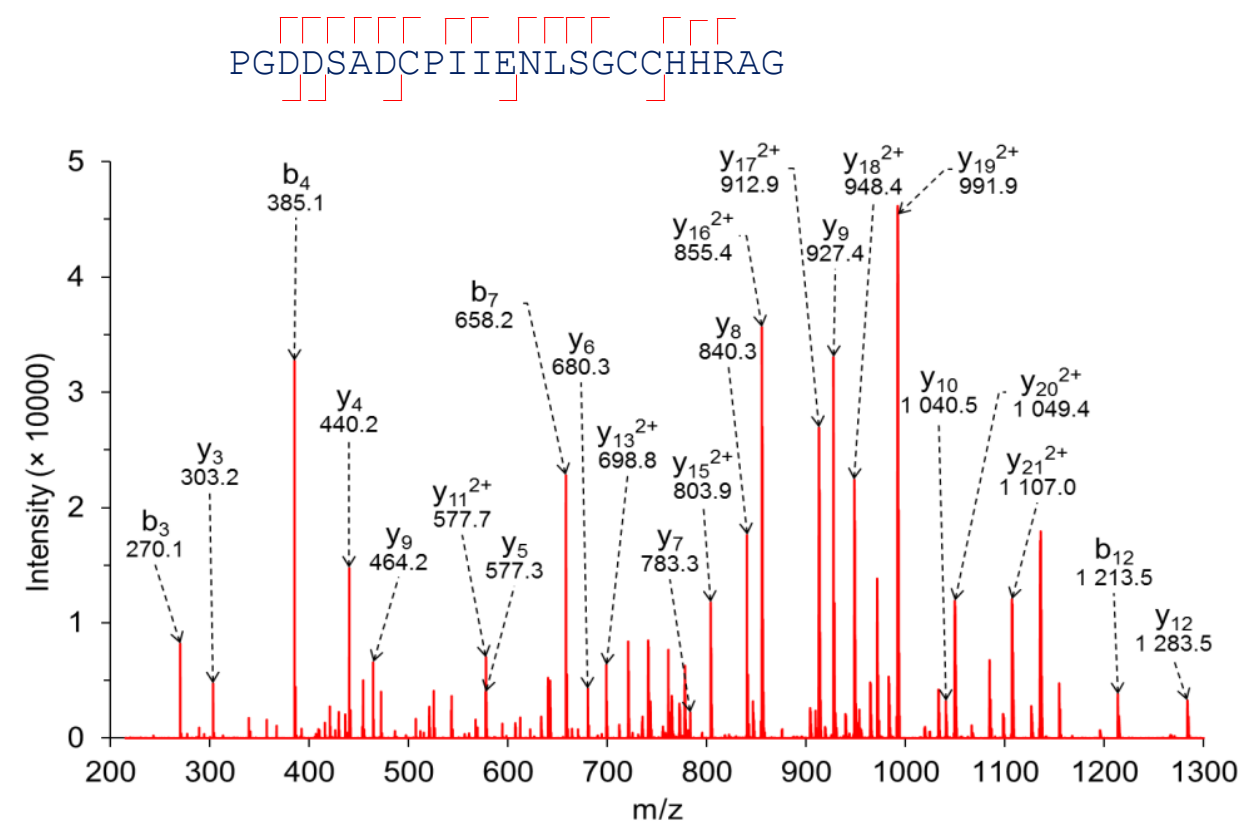

Figure 44: $M S^{3}$ CID spectrum of CueR showing fragments of [PGDDSADCPIIENLSGCCHHRAG $]^{3+}$ from the C-terminal part of the protein.

The solution structure of the proteins was tested by CD spectroscopy. The recorded spectra (Figure 45) are characteristic for proteins that are rich in $\alpha$-helices, in agreement with the crystal structures of the apo- and metal-bound forms of CueR (PDB id: 1Q05, 1Q06, 1Q07,[16] 4WLW, 4WLS[17]) (Table 6). The evaluation of the CD spectra by BeStSel[98] program yielded $~ 43 \% \alpha$-helical content (Figure 45). The CD spectra of the WT and modified CueR proteins are nearly identical (Figure 45), which means that the modifications did not change significantly the secondary structure of the protein. 
A

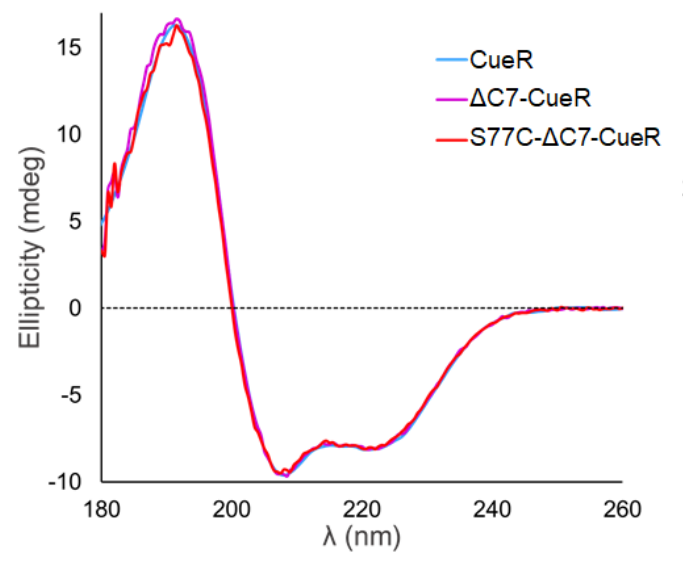

B

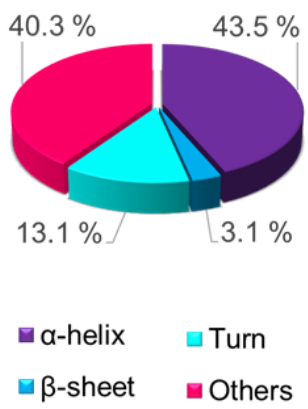

Figure 45: (A) CD spectra of the WT, $\triangle C 7$ - and $S 77 C-\triangle C 7-C u e R$ proteins $\left(c_{\text {protein }}=\right.$ $25 \mu M$ ) recorded in a $0.2 \mathrm{~mm}$ quartz cell; (B) Secondary structure composition of WT CueR calculated with BeStSel[98].

Table 6: The secondary structure element composition of CueR, determined by the DSSP[108] and BeStSel[98] programs from the crystal structures. Data obtained by the two programs were found to be identical considering the relationship between various subgroups of the secondary structure components. [98]

\begin{tabular}{c|c|c|c|c|c}
\hline Crystal structure & PDB id. & $\boldsymbol{\alpha}$-helix & $\boldsymbol{\beta}$-sheet & Turn & Others \\
\hline $\begin{array}{c}\mathrm{Cu}(\mathrm{I})-\mathrm{Ag}(\mathrm{I})-\text { and } \\
\mathrm{Au}(\mathrm{I})-\mathrm{CueR}\end{array}$ & $\begin{array}{c}1 \mathrm{Q} 05,1 \mathrm{Q} 06, \\
1 \mathrm{Q} 07\end{array}$ & $63 \%$ & $3 \%$ & $6 \%$ & $28 \%$ \\
\hline $\mathrm{Ag}(\mathrm{I})-\mathrm{CueR}+\mathrm{DNA}$ & $4 \mathrm{WLW}$ & $59 \%$ & $3 \%$ & $9 \%$ & $29 \%$ \\
\hline $\mathrm{CueR}+\mathrm{DNA}$ & $4 \mathrm{WLS}$ & $62 \%$ & $0 \%$ & $9 \%$ & $29 \%$ \\
\hline
\end{tabular}

Moreover, EMSA clearly showed that the specific 35 bp long DNA fragment (the PcopA promoter region) is shifted in the gel in the presence of the proteins (Figure 46), while the band of a non-specific DNA fragment smears as a result of non-specific DNAprotein interactions. This undoubtedly verifies the proper folding and functioning of the proteins. These findings also suggest that the mutations do not alter either the DNA binding ability or specific DNA sequence recognition of the proteins (Figure 46). 
A

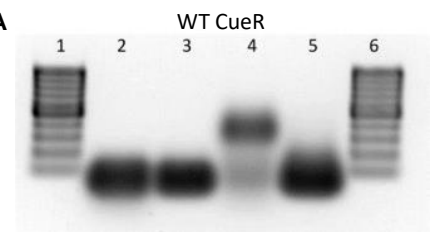

B

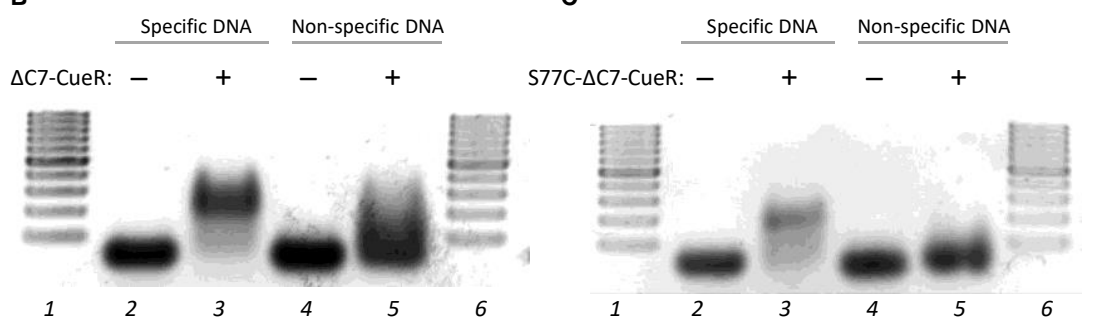

Figure 46: EMSA analysis of WT CueR (A), $\triangle C 7-C u e R(B), S 77 C-\triangle C 7-C u e R(C)$ and 35 bp specific and non-specific DNA fragments. Lane 1 and 6 contain the $100 \mathrm{bp}$ DNA ladder (GeneRuler, Thermo) for comparison in all cases.

(A) The free specific and non-specific DNA samples are in lanes 2 and 3 respectively. Lane 4 shows the effect of WT CueR on the specific DNA while lane 5 represents the effect of CueR on the nonspecific DNA.

$(B, C)$ The protein-free specific and non-specific DNA samples are in lanes 2 and 4, respectively, while protein-DNA mixtures are in lanes 3 and 6.

As a conclusion, the purification of the proteins was successful, and the proteins were ready to be subjected to subsequent characterization experiments. In order to adjust protein - metal ion ratio accurately, the molar absorption of CueR was determined as $\varepsilon_{280}$ $=5488 \mathrm{M}^{-1} \mathrm{~cm}^{-1}$ by amino acid analysis. The AAA was carried out at the department of Systems Biology, at Technical University of Denmark. Since neither of the mutations changed the number of chromophores (possessing absorbance at $280 \mathrm{~nm}$ ) in the protein, the value was accepted as a molar absorbance of the two mutant proteins, as well.

\subsection{The effect of $p H$, metal ions and DNA on secondary structure} of WT CueR

A variety of factors influence the conformation and folding of proteins in solution phase, some due to specific interactions. In case of $\mathrm{CueR}$, important factors are associated with the metal ion and DNA binding function. Furthermore, $\mathrm{pH}$ might also influence the structure through hydrogen bonding and/or charge-charge interactions. The protonation of a cysteine in the metal binding loop was already proposed to participate in the mechanism of the protein.[27] The effect of $\mathrm{pH}$, temperature, and the presence of binding partners on the secondary structure of CueR was studied here, in order to gain more information about the behaviour of this protein in solution. 


\subsubsection{Structural switch of CueR induced by pH change}

$\mathrm{CD}$ spectra of CueR were recorded in the $\mathrm{pH}$ range of $6.0-7.5$ (Figure 47). The structure of CueR above $\mathrm{pH} 7.0$ is rich in helices. Below $\mathrm{pH} 7.0$, a clear change in the shape of the spectra was observed (Figure 47A). This change reflects the dramatic increase in the fraction of $\beta$-sheets and turns, in parallel with the decrease of the $\alpha$-helical content, which approaches $0 \%$ by $\mathrm{pH} 6.0$. At the same time, the fraction of 'other' secondary structure elements is unaffected by the $\mathrm{pH}$ (Figure 47B). The conformation change within a narrow $\mathrm{pH}$ range is not unique, but rather rare among proteins. Such phenomena may trigger or influence various biochemical processes, for instance, the formation of $\beta$-sheet rich structures in prion proteins [109-112], the binding of metal ions or small molecules to proteins[113-116], protein interactions with membranes[117-121] or activity of enzymes[122-127]. Nevertheless, similar observation has not been reported so far for metalloregulatory proteins.
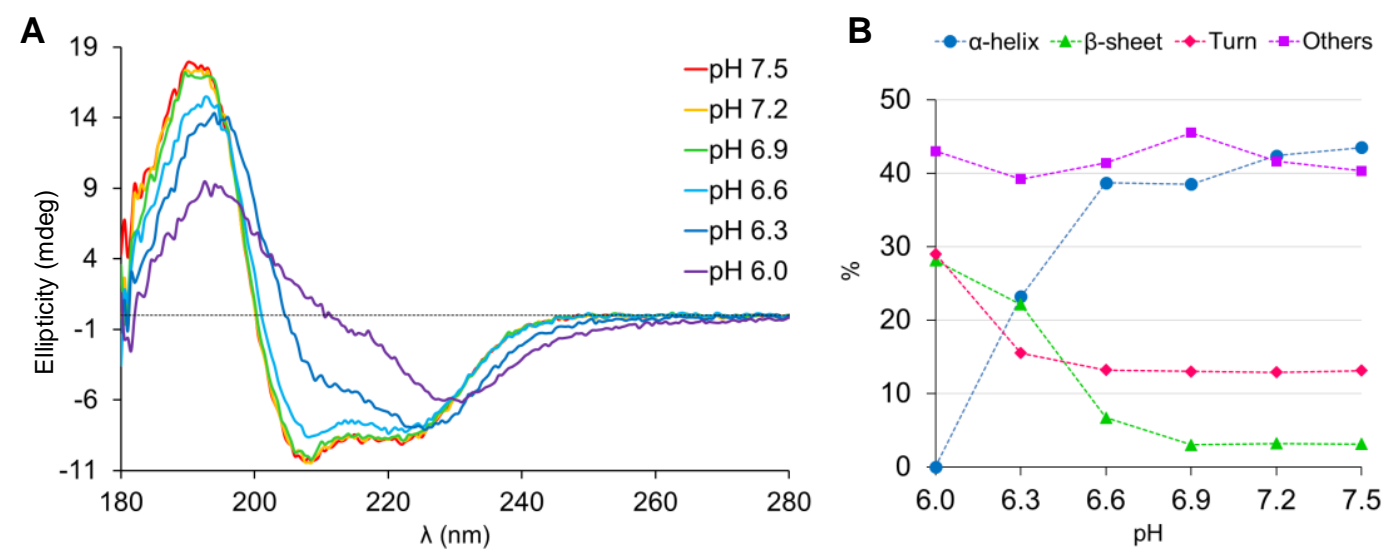

Figure 47: (A) pH-dependent changes in the CD spectrum of WT CueR; (B) The secondary structure composition of the CueR protein calculated by BeStSel. The spectra were recorded in a $0.2 \mathrm{~mm}$ quartz cell, in a mixture of Tris and MES buffers, $c_{\text {CueR }}=20.7 \mu \mathrm{M}$.

The effect of $\mathrm{pH}$ on the CueR structure can most probably be attributed to the protonation/deprotonation of ionizable amino acid residues. CueR has 20 negatively (Asp + Glu) and 16 positively (Arg + Lys) charged amino acids, as well as 4 cysteine and 5 histidine residues (Figure 48). Considering the consensus $\mathrm{p} K_{a}$ values for the side chains of amino acids,[128, 129] the protonation/deprotonation of histidines has the highest probability to occur in the $\mathrm{pH}$ range of $7.0-6.0$.

It is important to note that the $\mathrm{p} K_{a}$ values of ionizable residues in folded proteins may be strongly influenced by their local environment via charge-charge and charge-dipole 
interactions (H-bonding, helix dipoles) and the Born effect (dehydration).[124, 127, 130, 131] Moreover, the protonation/deprotonation of the titratable residues may cause conformational changes resulting in different $\mathrm{p} K_{a}$ values of a given amino acid in the two different microenvironments. Such complex behavior, supplemented with the polyelectrolyte effect and further technical difficulties make it impossible to determine the precise $\mathrm{p} K_{a}$ values for all individual groups of a protein.

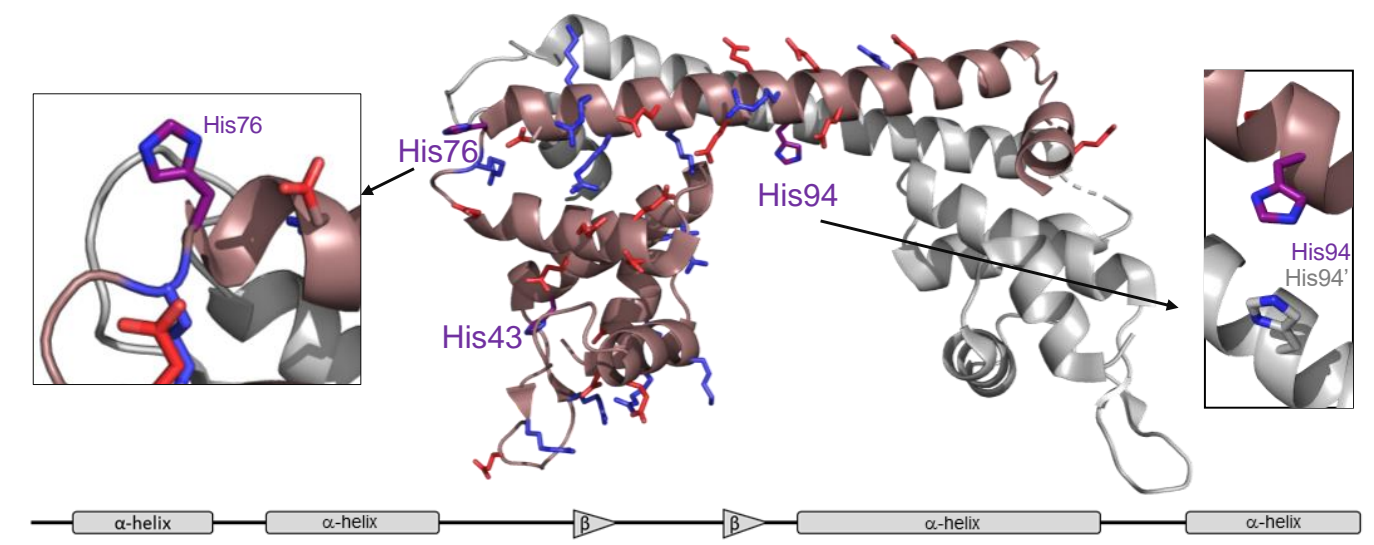

MNISDVAKITGLTSKAIRFYEEKGLVTPPMRSENGYRTYTQQHLNELTLLRQARQVGFNLEESGELVN

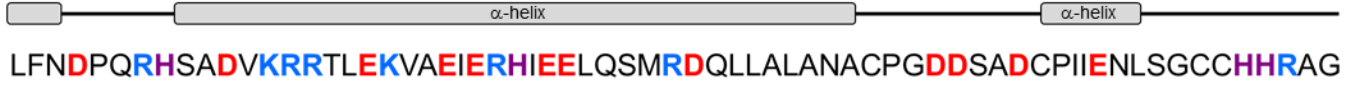

Figure 48: 3D structure representation (PDB id.: 1Q06) and the amino acid sequence of CueR highlighting the basic (blue), acidic (red) and histidine (purple) residues. In the brackets $\mathrm{H76}$ and $\mathrm{H} 94$ residues are shown enlarged.

In order to investigate how the $\mathrm{p} K_{a}$ values of the residues are influenced by the local environment in the CueR, the constants were predicted with the PROPKA program package[132](Table 7). The PROPKA considers hydrogen bonding, desolvation, and charge-charge interactions within the local protein environment $(<6.0 \AA)$ as the most important factors influencing the acid dissociation constants. The calculated $\mathrm{p} K_{a}$ values, in support of the hypothesis above, indicate that the three histidines, H43, H76 and H94, could mainly contribute to the change in the protonation state of the protein within $\mathrm{pH} 7.0-6.0$. In addition, PROPKA calculated the pI values of the protein in its folded and unfolded state: $\mathrm{p} I^{\text {folded }}=5.32, \mathrm{p} I^{\text {unfolded }}=5.5$. This suggests that the protonation processes are more favorable for the unfolded state, supporting that the protonation of the histidine residues could significantly influence on the secondary structure.

By taking a closer look at the positions of these amino acids (Figure 48), H76 and H94 are suspected to be accountable for inducing the conformational switch of protein. The $\mathrm{p} K_{a}$ of $\mathrm{H} 76$ residue is slightly higher than the model value in both $\mathrm{A}$ and $\mathrm{B}$ chains, 
respectively, possibly because of involvement in charge-charge interactions. Furthermore, $\mathrm{H} 76$ is exceptional, because it is the first amino acid of the dimerization helix. The ability of the $N$-terminal His amino acid to induce helical fold has been found to decrease with its protonation.[133] Thus, we suggest that the protonation of H76 not only affects the chargecharge interactions, but may also result in the destabilization of the helical structure toward the $C$-terminus. H94 is also particular due to its position: $\mathrm{H} 94$ residues of the two protein chains are facing each other in the coiled-coil region, thereby, giving a possibility for the formation of a charge-charge type interaction. The concurrent protonation of both H94 residues at the center of the dimerization helix would result in a repulsion between the two chains, similarly to that observed in a triple stranded coiled-coil.[134]

The PROPKA calculation revealed that the $\mathrm{pH}$ of optimum stability of the dimeric CueR is 7.8 with a calculated free energy of $-7.2 \mathrm{kcal} / \mathrm{mol}$ at $298 \mathrm{~K}$.

Table 7: The $p K_{a}$ values estimated by PROPKA program[132] for the A-and B-chain of the Ag(I)-bound CueR protein (PDB file 1Q06).

\begin{tabular}{|c|c|c|c|c|c|c|c|c|c|}
\hline \multicolumn{2}{|c|}{ Residue } & \multirow{2}{*}{$\begin{array}{c}\text { A-chain } \\
\text { p } \boldsymbol{K}_{\boldsymbol{a}} \\
3.59\end{array}$} & \multirow{2}{*}{$\begin{array}{c}\text { B-chain } \\
\text { p } \boldsymbol{K}_{\boldsymbol{a}} \\
2.64\end{array}$} & \multirow{2}{*}{$\begin{array}{c}\begin{array}{c}\mathbf{p} K_{a-} \\
\text { model }\end{array} \\
3.8\end{array}$} & \multicolumn{2}{|c|}{ Residue } & \multirow{2}{*}{$\begin{array}{c}\text { A-chain } \\
\text { p } \boldsymbol{K}_{\boldsymbol{a}} \\
9.67\end{array}$} & \multirow{2}{*}{$\begin{array}{c}\text { B-chain } \\
\text { p } \boldsymbol{K}_{\boldsymbol{a}} \\
9.41\end{array}$} & \multirow{2}{*}{$\begin{array}{c}\mathrm{pK}_{a-} \\
\text { model } \\
9\end{array}$} \\
\hline Asp & 5 & & & & Cys & 112 & & & \\
\hline Asp & 72 & 3.36 & 3.29 & 3.8 & Cys & 120 & 10.07 & 10.84 & 9 \\
\hline Asp & 79 & 3.03 & 3.12 & 3.8 & Tyr & 20 & 10.52 & 10.78 & 10 \\
\hline Asp & 103 & 3.13 & 2.76 & 3.8 & Tyr & 36 & 10.06 & 10.09 & 10 \\
\hline Asp & 115 & nd & 1.79 & 3.8 & Tyr & 39 & 11.66 & 11.54 & 10 \\
\hline Asp & 116 & nd & 3.64 & 3.8 & Lys & 8 & 10.5 & 10.55 & 10.5 \\
\hline Asp & 119 & nd & 3.89 & 3.8 & Lys & 15 & 10.43 & 10.36 & 10.5 \\
\hline Glu & 21 & 3.78 & 3.43 & 4.5 & Lys & 23 & 10.34 & 10.72 & 10.5 \\
\hline Glu & 22 & 3.99 & 4.15 & 4.5 & Lys & 81 & 10.42 & 10.32 & 10.5 \\
\hline Glu & 33 & 3.93 & 4.56 & 4.5 & Lys & 87 & 11.16 & 11.09 & 10.5 \\
\hline Glu & 46 & 3.55 & 4.23 & 4.5 & Arg & 18 & 12.93 & 12.16 & 12.5 \\
\hline Glu & 61 & 4.94 & 4.88 & 4.5 & Arg & 31 & 12.12 & 12.59 & 12.5 \\
\hline Glu & 62 & 3.4 & 3.29 & 4.5 & Arg & 37 & 13.62 & 13.37 & 12.5 \\
\hline Glu & 65 & 3.87 & 3.86 & 4.5 & Arg & 51 & 12.2 & 11.92 & 12.5 \\
\hline Glu & 86 & 4.59 & 4.08 & 4.5 & Arg & 54 & 12.48 & 12.27 & 12.5 \\
\hline Glu & 90 & 4.16 & 4.56 & 4.5 & Arg & 75 & 12.08 & nd & 12.5 \\
\hline Glu & 92 & 4.41 & 4.63 & 4.5 & Arg & 82 & 13.08 & 12.43 & 12.5 \\
\hline Glu & 96 & 4.85 & 4.66 & 4.5 & Arg & 83 & 13.31 & 13.66 & 12.5 \\
\hline Glu & 97 & 4.51 & 4.57 & 4.5 & Arg & 93 & 12.5 & 13.03 & 12.5 \\
\hline Glu & 124 & 4.68 & 4.74 & 4.5 & Arg & 102 & 13.21 & 14.12 & 12.5 \\
\hline His & 43 & 5.73 & 5.54 & 6.5 & N-term & 1 & 7.79 & 7.84 & 8 \\
\hline His & 76 & 6.71 & 7.03 & 6.5 & C-term & 127 & 3.77 & 3.54 & 3.2 \\
\hline His & 94 & 6.43 & 5.78 & 6.5 & & & & & \\
\hline
\end{tabular}




\subsubsection{The effect of metal ions on the secondary structure of Cue $R$}

As an important factor in the function of CueR, the effect of the metal ion coordination was also examined with respect to the secondary structure. CD spectra were recorded in the presence of one equivalent of mono- or divalent metal ions at $\mathrm{pH}$ 7.5. The presence of $\mathrm{Hg}(\mathrm{II}), \mathrm{Zn}(\mathrm{II})$ or $\mathrm{Cd}(\mathrm{II})$ does not alter the $\mathrm{CD}$ spectrum compared to the apoprotein (Figure 49). In previous works carried out on the metal site model peptides it was shown that these non-cognate metal ions can coordinate to the cysteines of the peptide models.[27, 135-137] We assume that the binding of these metal ions to CueR occurs in a coordination mode that does not trigger the formation of the $C$-terminal helix. Consequently, the secondary structure composition (Figure 49) of the apo- and the noncognate metal ion bound CueR are rather similar.

In contrast, the presence of $\operatorname{Ag}(\mathrm{I})$ ions significantly affects the shape and intensity of the spectrum (Figure 49), the $\alpha$-helical content increases by $10 \%$ (Table 8). This may reflect the stabilization of the metal binding loop and the formation of the $C$-terminal helix, which ultimately leads to the formation of the activator conformation as it was observed by X-ray crystallographic studies.[17]

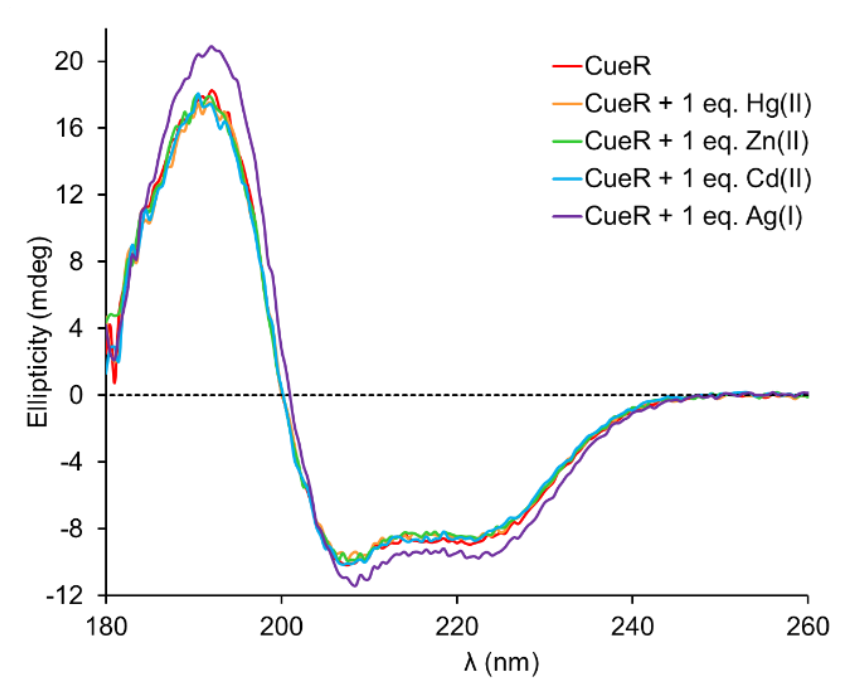

Figure 49: $C D$ spectra of the CueR protein in the presence of one equivalent of $H g(I I), C d(I I), Z n(I I)$ or $A g(I)$ ions per protein monomer. $l=0.2 \mathrm{~mm}, c_{C u e R}=20.7 \mu M$. 
Table 8: The secondary structure composition of CueR in the presence and absence of $\mathrm{Ag}(\mathrm{I}) / \mathrm{Hg}(\mathrm{II})$ ions determined by the BeStSel and CDNN programs.

\begin{tabular}{c|c|cccc}
\hline Sample & Program & $\boldsymbol{\alpha}$-helix & $\boldsymbol{\beta}$-sheet & Turn & Others \\
\hline \multirow{2}{*}{ apo- CueR } & BeStSel & $46 \%$ & $3 \%$ & $13 \%$ & $38 \%$ \\
\cline { 2 - 6 } & CDNN & $52 \%$ & $9 \%$ & $14 \%$ & $19 \%$ \\
\hline \multirow{2}{*}{$\mathrm{Ag}(\mathrm{I})-\mathrm{CueR}$} & $\mathrm{BeStSel}$ & $56 \%$ & $0 \%$ & $13 \%$ & $32 \%$ \\
\cline { 2 - 6 } & $\mathrm{CDNN}$ & $61 \%$ & $6 \%$ & $13 \%$ & $16 \%$ \\
\hline \multirow{2}{*}{$\mathrm{Hg}(\mathrm{II})-\mathrm{Cu} \mathrm{Cu}$} & $\mathrm{BeStSel}$ & $42 \%$ & $3 \%$ & $13 \%$ & $42 \%$ \\
\cline { 2 - 6 } & $\mathrm{CDNN}$ & $50 \%$ & $9 \%$ & $14 \%$ & $21 \%$ \\
\hline
\end{tabular}

Another important question is whether metal ions affect the conformational switch of the apo-protein observed at $\mathrm{pH}$ below 7.0. Hence, the CD spectra of the CueR protein was recorded at pH 6.0 in the presence of 1 equivalent $\mathrm{Ag}(\mathrm{I})$ or $\mathrm{Hg}(\mathrm{II})$ ions (Figure 50). The spectrum obtained in the absence of $\mathrm{Ag}(\mathrm{I})$ at $\mathrm{pH} 6.0$ is clearly different but resembles the one at $\mathrm{pH} 7.5$, suggesting a partial stabilization of the helix-rich overall structure (Figure 50). It has to be mentioned, however, that at an extended time scale (incubation for hours) the spectrum of the $\operatorname{Ag}(\mathrm{I})$-containing sample approaches the one that is characteristic at $\mathrm{pH} 6.0$ for the apo-form. In contrast to the $\mathrm{Ag}(\mathrm{I})$ ions, no significant spectral difference is seen in the CD spectra recorded in the presence and absence of $\mathrm{Hg}$ (II) ions at $\mathrm{pH} 6.0$ (Figure 50), indicating that the binding of $\mathrm{Hg}(\mathrm{II})$ has no such stabilizing effect on the helical structure of CueR.

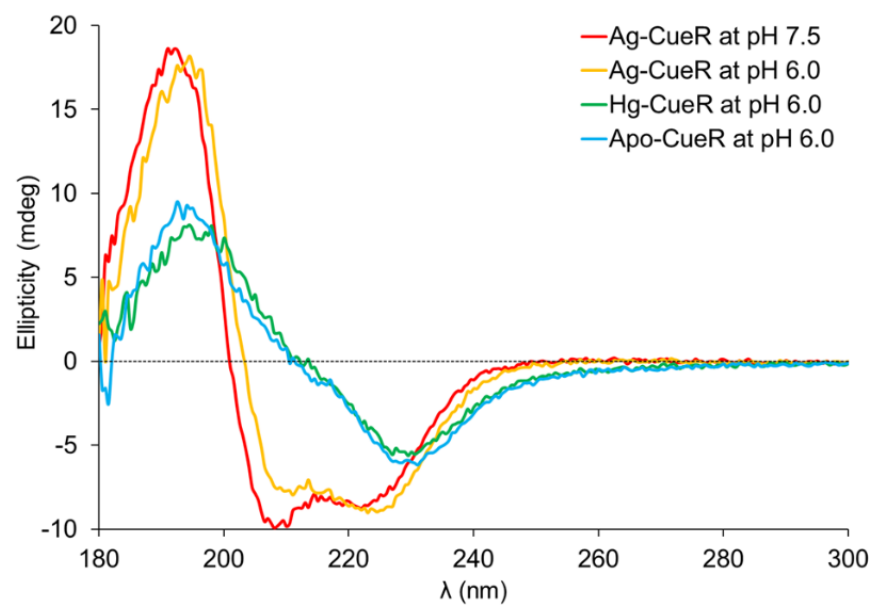

Figure 50: CD spectra of the CueR protein in the presence of one equivalent $A g(I)$ at $p H$ 7.5 (red) and after decreasing the $\mathrm{pH}$ to 6.0 (yellow). The spectrum recorded in the presence of one equivalent $\mathrm{Hg}(\mathrm{II})$ ions at $\mathrm{pH} 6.0$ is shown in green. For comparison, the spectrum of apo-CueR at pH 6.0 is also presented (blue). $l=0.2 \mathrm{~mm}, c_{\text {CueR }}=20.7 \mu \mathrm{M}$. 


\subsubsection{Locking the secondary structure of CueR by DNA binding}

The dependence of the secondary structure was also investigated for another crucial determinant in the function of CueR, namely the effect of DNA binding. The CD spectrum of CueR was recorded in the presence of half equivalent of PcopA DNA at pH 7.5 (Figure $51)$.

When DNA is present, the addition of metal ions has no effect on the secondary structure of the protein (Figure 51). Thus, CueR is likely to find a very stable secondary structure in its complex with DNA. Indeed, the transcriptional regulation by CueR occurs primarily via changes in the tertiary structure,[17] which cannot be detected by far UV CD spectroscopy.

The effects of decreasing the $\mathrm{pH}$ was further examined. With the DNA and $\operatorname{Ag}(\mathrm{I})$ or $\mathrm{Hg}(\mathrm{II})$ present in the solution no spectral changes were observed at $\mathrm{pH} 6.0$ as compared to the spectra recorded at $\mathrm{pH} 7.5$ (Figure 51). This suggests that the DNA locks the CueR in the $\alpha$-helical rich structure and protects the protein from the structural transformation triggered by the $\mathrm{pH}$ changes in its environment. Based on these results, we recommend to carry out experiments with CueR at a pH lower than 7.0 only in the presence of DNA.

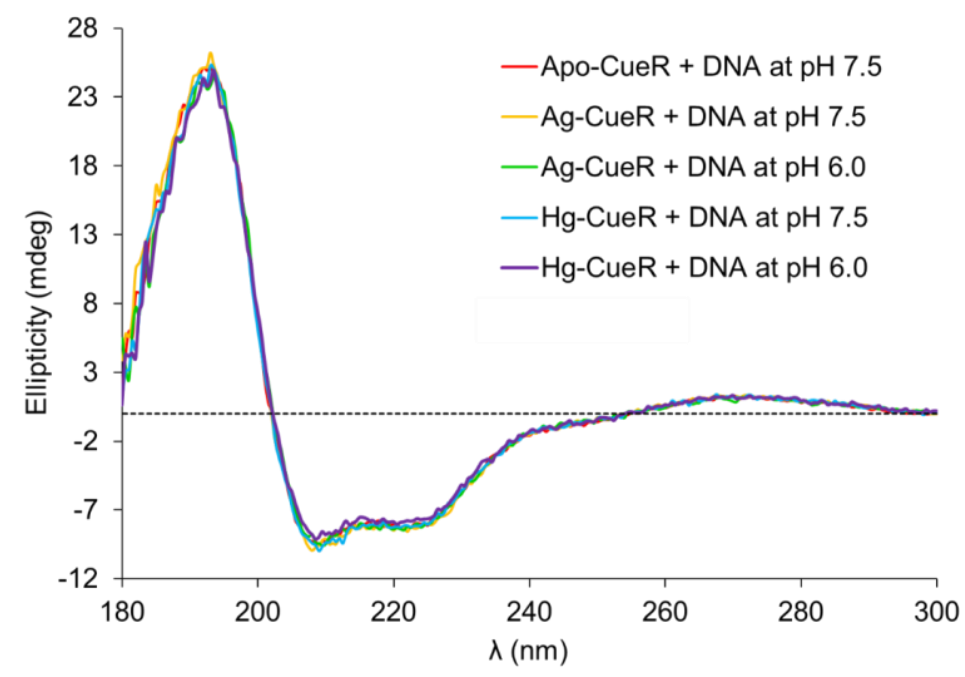

Figure 51: The CD spectra of CueR in the presence of 0.5 equivalent DNA at $p H 7.5$ and in the presence both $0.5 \mathrm{eq}$. DNA and $1.0 \mathrm{eq}$. $\mathrm{Ag}(\mathrm{I}) / \mathrm{Hg}(\mathrm{II})$ ions at $\mathrm{pH} 7.5$ and $\mathrm{pH}=6.0$.

$$
l=0.2 \mathrm{~mm}, c_{\text {CueR }}=20.7 \mu \mathrm{M} \text {. }
$$

\subsubsection{Denaturation curves of Cue $R$ by increasing temperature}

The temperature dependence of the $\mathrm{CD}$ spectra of CueR were recorded in the presence of metal ions and DNA in comparison with the apo-protein (Figure 52). The apoand $\mathrm{Hg}(\mathrm{II})$-bound CueR display two melting points, at a temperature of less than $50^{\circ} \mathrm{C}$ and 
at $\sim 65^{\circ} \mathrm{C}$, indicating that the defolding occurs in two distinct steps. Based on the extent of the change in the CD intensity at $193 \mathrm{~nm}$, it is difficult to assign the denaturation processes to individual domains of the protein, but most probably the helixes of the DNA-binding domain unfold at a lower temperature, whereas the coiled-coil structure formed by the dimerization helixes unfold separately at a higher temperature. Interestingly, in the presence of $\operatorname{Ag}(\mathrm{I})$ the melting occurs in one step (Figure 52A). Based on the proposed assignment of the melting temperatures above, the lack of the structural change at $\mathrm{T}<50$ ${ }^{\circ} \mathrm{C}$ is likely due to stabilization of the DNA binding domain. A similar observation was reported upon $\mathrm{Cu}(\mathrm{I})$ binding in solution: DEER experiments showed that the coordination of $\mathrm{Cu}(\mathrm{I})$ ions to the $\mathrm{C}$-terminal part of the protein influences the conformation of the $\mathrm{N}$ terminal DNA binding domain and rigidifies the overall structure of the protein.[20] The fact that the DNA binding domain is stabilized by only the cognate $\operatorname{Ag}(\mathrm{I})$ agrees well with the selective metal recognition of the CueR and the allosteric regulation mechanism. In addition, the DNA binding domain is also stabilized through the interactions with DNA, as indicated by the absence of the first denaturation process in the melting curve of the CueRDNA complex (Figure 52B).
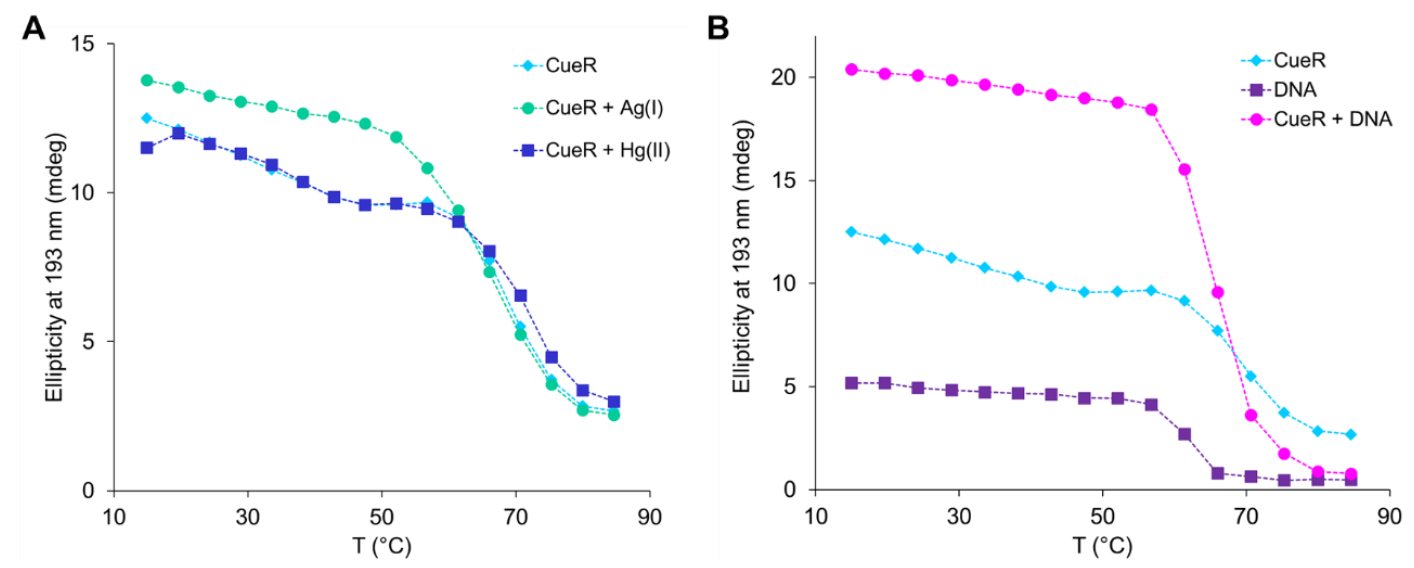

Figure 52: (A) The effect of $\mathrm{Ag}(\mathrm{I})$ and $\mathrm{Hg}(\mathrm{II})$ ions on the denaturation process of CueR. (B) Comparison of the melting curves of DNA, CueR and the protein-DNA complex. $l=0.1 \mathrm{~mm}$, $c_{\text {CueR }}=27 \mu M, c_{\text {metal ion }}=27 \mu M, c_{D N A}=13.5 \mu M$

\subsection{Metal ion recognition - Characterization of metal ion binding properties}

Despite the thorough studies undertaken with CueR, the details of the mechanism how this metalloregulatory protein discriminates between mono- and divalent metal ions and the possible role of the $\mathrm{CCHH}$ motif have not been clarified, yet. With the aim of 
characterizing the metal ion binding properties of CueR and exploring the function of the $\mathrm{CCHH}$ motif, we studied the interaction of the WT and mutant proteins with $\mathrm{Hg}(\mathrm{II}), \mathrm{Cd}(\mathrm{II})$ and $\operatorname{Ag}(\mathrm{I})$.

\subsubsection{Investigation of the $\mathrm{Hg}(I I)$ binding of $W T$ and $\triangle C 7-C u e R$ with mass} spectrometry

Surprisingly, $\mathrm{Hg}(\mathrm{II})$ does not trigger the activation of transcription by CueR,[16] in spite of its well-known preference for a bis-thiolate coordination environment. According to studies performed with model peptides the metal binding loop of CueR $[27,135]$ and other short two cysteine containing peptides[138], as well as QM/MM calculations[26] $\mathrm{Hg}(\mathrm{II})$ ions may be coordinated to the cysteines of the metal binding loop and CCHH motif more efficiently than the cognate $\operatorname{Ag}(\mathrm{I})$ ions.

$\mathrm{Hg}(\mathrm{II})$ binding to the wild type and truncated CueR variant was studied by ESI-MS (Figure 53). In the absence of $\mathrm{Hg}(\mathrm{II})$ ions, the predominant peaks appearing in the deconvoluted mass spectra of the WT and $\Delta \mathrm{C} 7-\mathrm{CueR}$ proteins correspond to the mass of the reduced, monomeric apo-forms (15235.6 Da and 14770.4 Da, respectively) (Figure 53). The addition of 0.2 or 0.5 equivalent of $\mathrm{Hg}(\mathrm{II})$ to either protein results in similar changes: the relative abundance of the apo-forms gradually decreases, meanwhile new peaks, with an increased $m / z$ value, emerge and become predominant. These new peaks correspond to a protein species binding a single $\mathrm{Hg}(\mathrm{II})$ ion (see Appendix A.5.3. for isotopic envelops Figure A1 and A2). In the presence of one equivalent of $\mathrm{Hg}(\mathrm{II})$ the signal of the metal ion free proteins nearly disappears while the peaks of the $\mathrm{Hg}-\mathrm{CueR} / \mathrm{Hg}-\Delta \mathrm{C} 7-\mathrm{CueR}$ complexes dominate. The spectrum recorded for the sample containing WT CueR and two equivalents of $\mathrm{Hg}(\mathrm{II})$ is fundamentally different from those obtained under equimolar or sub-equimolar conditions. The new signal observed at $m / z=15632.5$ can be unambiguously assigned to the $\mathrm{Hg}_{2}$-CueR complex. Indeed, the same peak is present already in the spectrum recorded at one equivalent $\mathrm{Hg}$ (II) per CueR but with a significantly smaller intensity. Signals of a similar adduct, carrying two $\mathrm{Hg}$ (II) ions could not be detected for the truncated protein at any $\mathrm{Hg}(\mathrm{II})$ :protein ratio (Figure 53.).

These ESI-MS spectra provide rather interesting, albeit qualitative information, concerning the stoichiometry of the $\mathrm{Hg}(\mathrm{II})$-bound protein complexes and also about the $\mathrm{Hg}(\mathrm{II})$-binding affinities. The disappearance of the signals of the apo-forms in the presence of 1.0 equivalent of $\mathrm{Hg}(\mathrm{II})$ implies that $\mathrm{Hg}(\mathrm{II})$ ions display a high affinity to both proteins. Comparison of the spectra obtained for the two proteins at twofold $\mathrm{Hg}$ (II)-excess per 
proteins clearly demonstrate the availability of two binding sites for $\mathrm{Hg}$ (II) ions in the WT CueR. These are most likely the metal ion binding loop formed by $\mathrm{C} 112$ and $\mathrm{C} 120$, and the $C$-terminal CCHH motif. Participation of the latter $\mathrm{CCHH}$ fragment in $\mathrm{Hg}(\mathrm{II})$ binding is supported by the lack of signals corresponding to a $\mathrm{Hg}_{2}-\Delta \mathrm{C} 7-\mathrm{CueR}$ complex, even at twofold $\mathrm{Hg}$ (II)-excess over the protein. The observation that signals of $\mathrm{Hg}_{2}-\mathrm{CueR}$ are already present at 1.0 equivalent of $\mathrm{Hg}(\mathrm{II})$, might suggest that there is no significant difference in the $\mathrm{Hg}(\mathrm{II})$-binding affinities of the two sites of the WT protein.
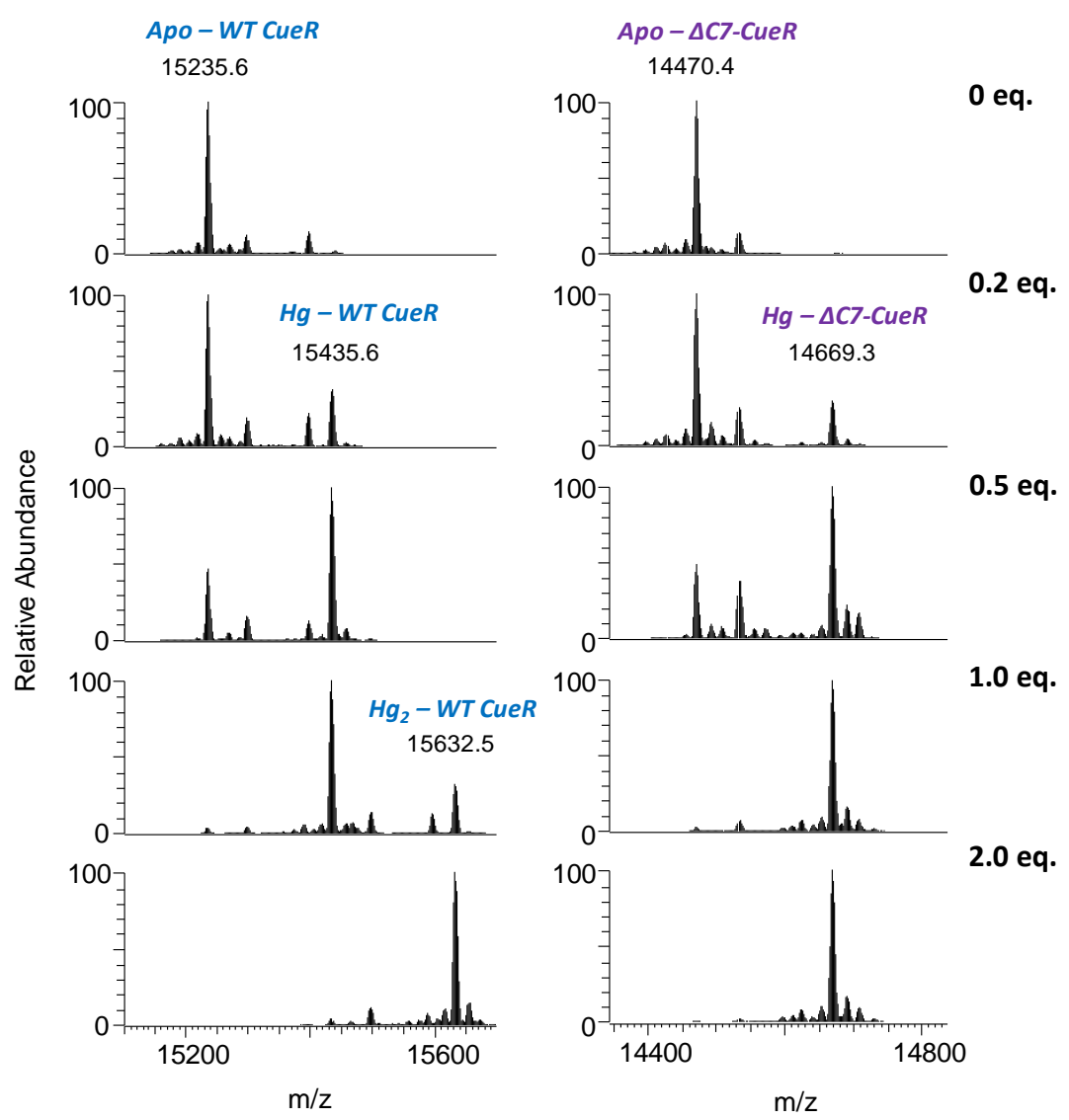

Figure 53: Deconvoluted native ESI-MS spectra of the WT and truncated CueR in the absence and presence of 0.2, 0.5, 1.0 and 2.0 equivalents of $\mathrm{Hg}(\mathrm{II})$ ions. Individual samples contained $20 \mu \mathrm{M}$ protein in a $10 \mathrm{mM} \mathrm{NH}_{4} \mathrm{HCO}_{3}$ buffer, $0.5 \mathrm{mM}$ TCEP, $\mathrm{pH}=7.5$

5.3.2. Analysis of the coordination environment of $\mathrm{Hg}(I I)$ in $W T$ and $\Delta C 7$ Cue R with ${ }^{199 m} \mathrm{Hg}$ PAC

${ }^{199} \mathrm{~m} H g$ PAC experiments were performed on the $\mathrm{Hg}(\mathrm{II})-\mathrm{CueR}$ and $\mathrm{Hg}(\mathrm{II})-\Delta \mathrm{C} 7-$ CueR systems in the presence of DNA, at pH 6.0 and 8.0, at different $\mathrm{Hg}$ (II) to protein ratios $(0.2: 1,1: 1$ and $2: 1)$, in order to elucidate the $\mathrm{Hg}(\mathrm{II})$ coordination to CueR (Figure 54, Fitted parameters for the spectra are included in Appendix A.9.3. Table A7 and A8). 
At $\mathrm{pH} 6.0$ at $\mathrm{Hg}(\mathrm{II}): \mathrm{CueR}$ of 0.2 and 1.0 , the signals agree well with a $\mathrm{HgS}_{2}$ coordination geometry, i.e. coordination of $\mathrm{Hg}(\mathrm{II})$ by two cysteinates. This also holds for $\mathrm{Hg}(\mathrm{II})$ :CueR of 2.0, although a slightly larger linewidth is observed, in particular for the first peak at $\sim 1.4 \mathrm{rad} / \mathrm{ns}$ (Figure 54). This presumably reflects the occupation of two $\mathrm{HgS}_{2}$ sites, and it can originate either from minor differences in the structures of the two sites, or from metal site dynamics at the nanosecond time scale becoming more pronounced upon binding of the second $\mathrm{Hg}(\mathrm{II})$.
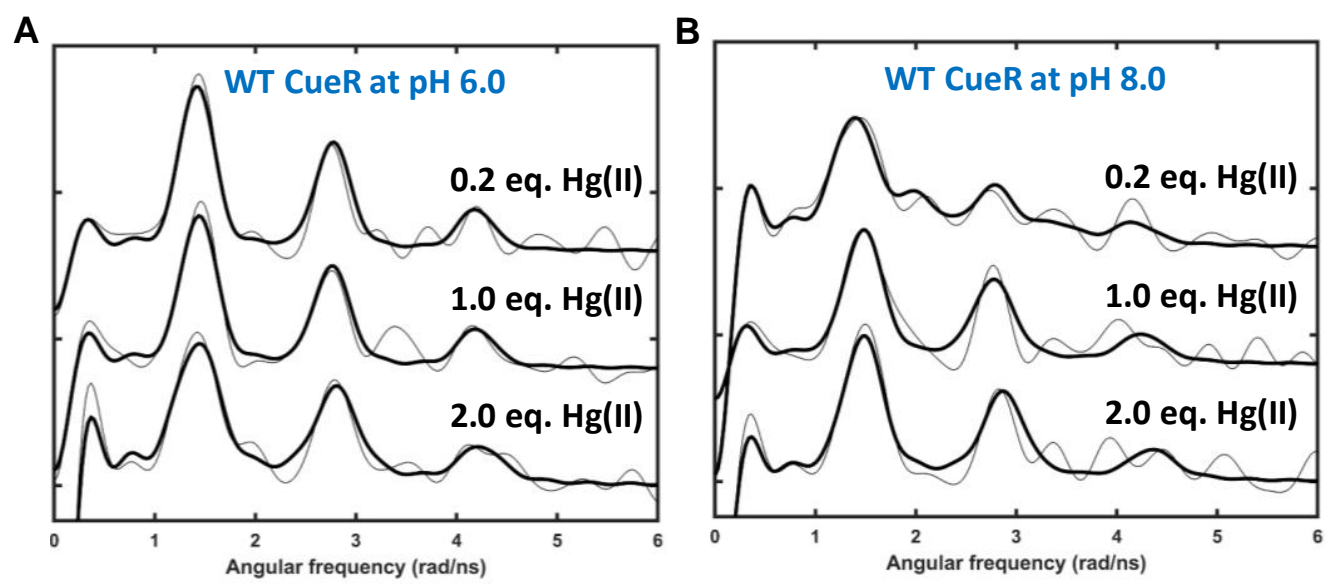

Figure 54: Experimental and fitted ${ }^{199 m} \mathrm{Hg} P A C$ spectra of WT CueR in the presence of DNA with 0.2, 1.0 and 2.0 equivalents of $\mathrm{Hg}(\mathrm{II})$ at $\mathrm{pH} 6.0(\mathrm{~A})$ and at $\mathrm{pH} 8.0(\mathrm{~B}) . c_{W T \text { СиeR }}=12 \mu \mathrm{M}$, $c_{D N A}=6 \mu M$.

The spectrum recorded with 0.2 equivalent of $\mathrm{Hg}(\mathrm{II})$ per $\mathrm{CueR}$ at $\mathrm{pH} 8.0$ is more complex than that of the identical sample at $\mathrm{pH} 6.0$ (Figure 54). Qualitatively, the first peak is shifted to a slightly lower frequency and exhibits a considerable broadening, while the second peak $(\sim 2.8 \mathrm{rad} / \mathrm{ns})$ is attenuated to the extent that it barely rises above the noise level. A reliable analysis of the data requires the inclusion of two NQIs. One of these is very similar to that observed in the spectra at $\mathrm{pH}$ 6.0, most likely reflecting a $\mathrm{HgS}_{2}$ structure. The other NQI has a higher asymmetry parameter and a lower frequency (Table A7), indicating a higher coordination number than 2 . The lower frequency agrees well with a trigonal planar $\mathrm{HgS}_{3}$ structure, but the relatively high asymmetry parameter rules out this possibility. However, in the simple angular overlap mode (AOM)[139], a T shaped $\mathrm{HgS}_{3}$ coordination geometry gives the same frequency as a trigonal planar structure, but an asymmetry parameter of 1 . Thus, a $\mathrm{T}$ shaped $\mathrm{HgS}_{3}$ structure with the equatorial ligand in a slightly longer $\mathrm{Hg}-\mathrm{S}$ distance seems to be a plausible structural interpretation of the low frequency signal. Such structures have also been observed in smaller inorganic $\mathrm{Hg}(\mathrm{II})$ containing compounds.[140] The increased availability of deprotonated cysteines with 
increasing $\mathrm{pH}$ agrees well with this change in speciation observed at $\mathrm{pH} 6.0$ and $\mathrm{pH}$ 8.0, and is paralleled by a change from $\mathrm{HgS}_{2}$ to $\mathrm{HgS}_{3}$ coordination.[141] It is also conceivable that the spectrum at 0.2 equivalent of $\mathrm{Hg}$ (II) reflects intermediate (nanosecond) exchange between $\mathrm{HgS}_{2}$ and $\mathrm{HgS}_{3}$ structures. It cannot be excluded that the data recorded at 1.0 equivalent of $\mathrm{Hg}(\mathrm{II})$ also contains signals reflecting both of these species, but the reduced chi-square does not improve significantly upon including a second NQI. Consequently, we have only included the high frequency NQI $\left(\sim \mathrm{HgS}_{2}\right)$ in the analysis. For the experiment with 2.0 equivalents of $\mathrm{Hg}(\mathrm{II})$ the signal may be satisfactorily fitted with just one (high frequency) NQI, presumably reflecting $\mathrm{HgS}_{2}$ structure for both $\mathrm{Hg}(\mathrm{II})$ bound to CueR .

Most interestingly, the ${ }^{199} \mathrm{~m} H \mathrm{PAC}$ spectrum recorded at $\mathrm{pH} 8.0$ with $0.2 \mathrm{eq} . \mathrm{Hg}$ (II) for $\Delta \mathrm{C} 7-\mathrm{CueR}$ exhibits a signal reflecting only a $\mathrm{HgS}_{2}$ type species (Figure 55). The fact that the $\Delta \mathrm{C} 7-\mathrm{CueR} \mathrm{Hg}(\mathrm{II})$ site exhibits such a structure strongly supports the interpretation presented above for the WT CueR: if $\mathrm{HgS}_{3}$ is formed by the occupation of the functional site, a third thiolate is recruited from the $\mathrm{CCHH}$ motif, or vice-versa, $\mathrm{Hg}(\mathrm{II})$ binds to the $\mathrm{CCHH}$ motif and recruits one of the cysteines from the functional binding site. With 2.0 equivalents of $\mathrm{Hg}(\mathrm{II})$ per $\Delta \mathrm{C} 7-\mathrm{CueR}$ at $\mathrm{pH} 8.0$, the signal changes as compared to experiments with $\leq 1$ equivalent $\mathrm{Hg}^{\mathrm{II}}$, presumably because the functional metal site is filled, and the additional $\mathrm{Hg}$ (II)

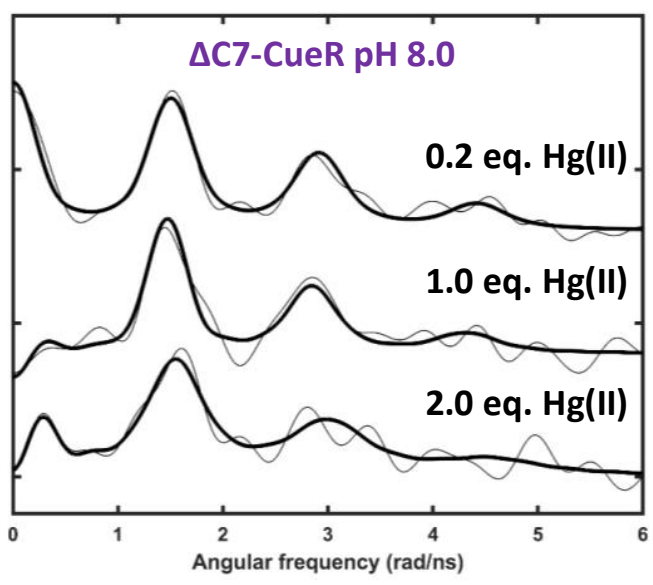

Figure 55: Experimental and fitted ${ }^{199 m} \mathrm{Hg}$ $P A C$ spectra of $\triangle C 7-C u e R$ in the presence of 0.5 eq. DNA with $0.2,1.0$ and 2.0 equivalents of $\mathrm{Hg}(\mathrm{II})$ at $\mathrm{pH}$ 8.0. $\mathrm{c}_{\triangle C 7-\mathrm{CueR}}=$ $8.4 \mu M$. accommodates a coordination geometry other than linear $\mathrm{HgS}_{2}$ originated from weak or non-specific $\mathrm{Hg}(\mathrm{II})$ adducts. This agrees well with the ESI-MS data, where no $\mathrm{Hg}_{2}-\Delta \mathrm{C} 7-$ CueR was observed.

\subsubsection{Characterization of the Hg(II) binding to WT and $\triangle C 7-C u e R$ with UV spectroscopy}

In order to characterize further the metal site coordination geometries, the UV absorption of WT and $\triangle \mathrm{C} 7-\mathrm{CueR}$ was monitored in titration with $\mathrm{Hg}(\mathrm{II})$ ions (Figure 56A). 

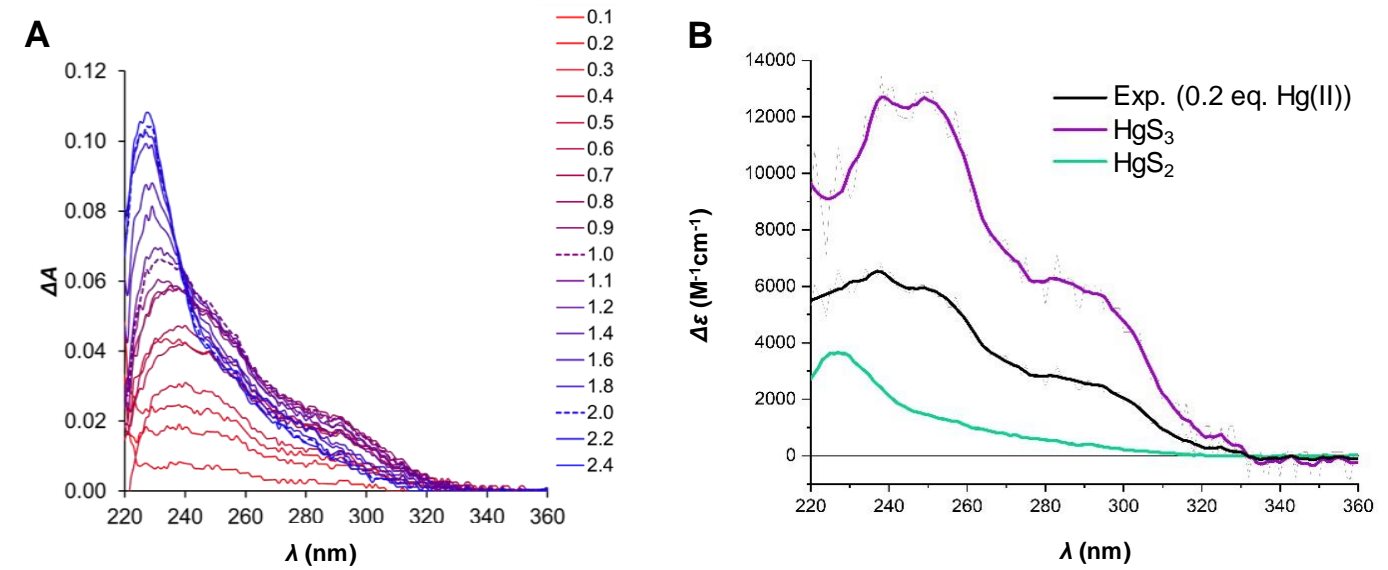

Figure 56: (A) UV absorption difference spectra of WT CueR titrated with Hg(II) ions (0.1 - 2.4 equivalents). Spectra recorded in the presence of 1.0 and 2.0 equivalents of $\mathrm{Hg}(\mathrm{II})$ are shown with dashed lines. $\mathrm{pH}=7.5, c_{W T}$ CueR $=14 \mu \mathrm{M}$. (B) Estimated molar absorbance for the $\mathrm{HgS}_{2}$ and $\mathrm{HgS}_{3}$ species derived from the UV absorption spectrum of WT CueR recorded with 0.2 and 2.0 eq. $\mathrm{Hg}(\mathrm{II})$ (details of the calculation are provided in the text).

$\mathrm{Hg}(\mathrm{II})$-thiolate complexes possess characteristic CT bands in the region of 230 $300 \mathrm{~nm}$. With the help of experimental data on $\mathrm{Hg}(\mathrm{SEt})_{2}$ and $\left[\mathrm{Et}_{4} \mathrm{~N}\right]\left[\mathrm{Hg}(\mathrm{SBut})_{3}\right]$ model compounds, the UV-absorption properties of linearly and trigonal planar coordinated $\mathrm{Hg}(\mathrm{II})$, respectively, were characterized.[142] Linearly coordinated $\mathrm{Hg}$ (II)-thiolate species display a transition at $\sim 230 \mathrm{~nm}$.[143] The increase of the coordination number shifts the absorption bands towards longer wavelengths.[144, 145] The spectrum of a trigonal $\mathrm{Hg}(\mathrm{II})$ tris(thiolate) complex has a characteristic absorption maximum at $245 \mathrm{~nm}$ with a distinct shoulder at $290 \mathrm{~nm}$.[143] Qualitatively, the absorption difference spectra of WT CueR at subequimolar $\mathrm{Hg}(\mathrm{II})$ :protein ratios exhibit a characteristic absorption at $\sim 290 \mathrm{~nm}$ reflecting the presence of a $\mathrm{HgS}_{3}$ structure (Figure 56), in agreement with the ${ }^{199 \mathrm{~m}} \mathrm{Hg}$ PAC data.

The ${ }^{199} \mathrm{~m} H g$ PAC data indicate $\sim 40 \% \mathrm{HgS}_{3}$ and $\sim 60 \% \mathrm{HgS}_{2}$ at 0.2 eq. $\mathrm{Hg}$ (II). The recorded spectrum with 2.0 eq. $\mathrm{Hg}$ (II) per WT CueR was used to determine the molar absorption of the $\mathrm{HgS}_{2}$ species (green curve in Figure 56B). Next, we predicted the pure $\mathrm{HgS}_{3}$ molar spectrum (purple curve in Figure 56B) by assuming that the experimentally determined spectrum is given by $0.6 \mathrm{HgS}_{2}+0.4 \mathrm{HgS}_{3}$, as suggested by the relative population of the two species by the ${ }^{199} \mathrm{mHg}$ PAC results. The UV absorption spectra derived in this manner for $\mathrm{HgS}_{2}$ and $\mathrm{HgS}_{3}$ agree well with those reported in the literature (Table 9).[144] 
Table 9: Spectroscopic properties of the $\mathrm{HgS}_{2}$ and $\mathrm{Hg} \mathrm{S}_{3}$ species compared to $\mathrm{Hg}(\mathrm{II}) / \mathrm{MerR}$ and $\mathrm{Hg}(\mathrm{II}) / \mathrm{L} 16 \mathrm{C}$ complexes

\begin{tabular}{lll}
\hline Sample & $\boldsymbol{\lambda}(\mathbf{n m})$ & $\boldsymbol{\varepsilon}\left(\mathbf{c m}^{-\mathbf{1}} \mathbf{m M} \mathbf{- 1}\right)$ \\
\hline & 242 & 19.8 \\
$\mathrm{Hg}-\mathrm{MerR}[143]$ & 260 & 14.6 \\
& 290 & 6.45 \\
\hline 1:2 Hg/L16C[144] & 240 & 2.70 \\
\hline \multirow{3}{*}{ :3 Hg/L16C[144] } & 247 & 16.8 \\
& 265 & 10.6 \\
& 295 & 5.00 \\
$\mathrm{CueR}\left(\mathrm{HgS}_{3}\right)$ & 240 & 12.6 \\
& 250 & 12.6 \\
\hline CueR $\left(\mathrm{HgS}_{2}\right)$ & 290 & 5.82 \\
\hline
\end{tabular}

The significant difference between both the ${ }^{199} \mathrm{~m} H g$ PAC and the UV absorption spectra recorded with 1.0 eq. $\mathrm{Hg}(\mathrm{II})$ and 0.2 eq. $\mathrm{Hg}(\mathrm{II})$ can be explained with a simple probabilistic model assuming that the two metal ion binding sites (i.e. the functional site and the $C$-terminal site) are independent. In other words, $\mathrm{Hg}(\mathrm{II})$ is distributed randomly among the 4 metal sites of a protein dimer, and the population of two adjacent sites leads to the formation of $\mathrm{HgS}_{2}$, because there are no more cysteines locally available to form $\mathrm{HgS}_{3}$. This very simple interpretation is to some extent supported by the ESI-MS data, which reflect a population of the $\mathrm{Hg}_{2}-\mathrm{CueR}$ species when $\mathrm{Hg}(\mathrm{II})$ and CueR are present in equimolar amounts. Obviously, at 2.0 eq. of $\mathrm{Hg}(\mathrm{II})$ there is no more possibility to form $\mathrm{HgS}_{3}$, because the protein is saturated with $\mathrm{Hg}(\mathrm{II})$ resulting in $\mathrm{HgS}_{2}$ structures at all four metal sites in the dimer. Similar geometrical rearrangement was observed in metallothioneins upon saturating the protein by the metal ion in a titration with $\operatorname{Hg}(\mathrm{II}) \cdot[146,147]$

The UV absorption spectra recorded for $\Delta \mathrm{C} 7-\mathrm{CueR}$ exclusively exhibit the signature of $\mathrm{HgS}_{2}$ structures (Figure 57), in accordance with the

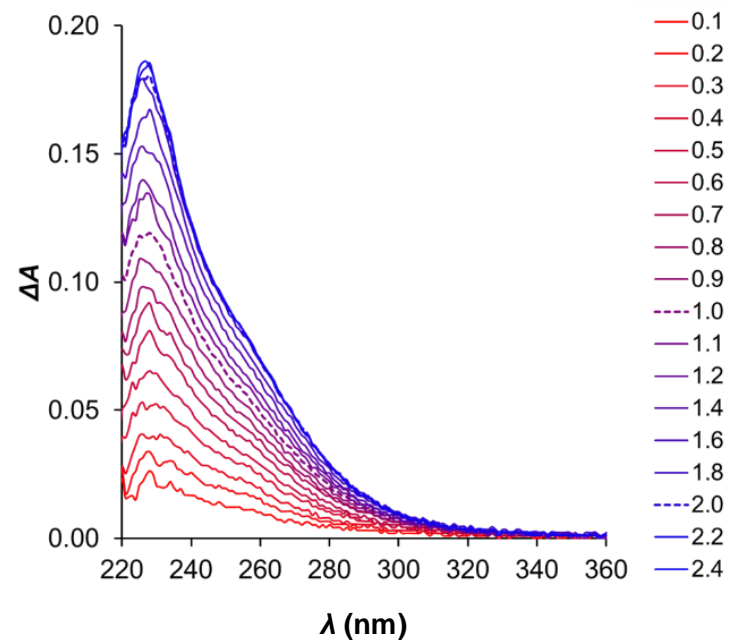

Figure 57: UV absorption difference spectra of $\triangle C 7-C u e R$ titrated with $\mathrm{Hg}(\mathrm{II})$ ions $(0.1-2.4$ equivalents). Spectra recorded in the presence of 1.0 and 2.0 equivalents of $H g(I I)$ are shown with dashed lines. $p H=7.5, c_{\triangle C 7-C u e R}=12 \mu M$. 
interpretation of the ESI-MS and ${ }^{199} \mathrm{mHg}$ PAC experimental data. Surprisingly, the absorbance for $\Delta \mathrm{C} 7-\mathrm{CueR}$ continues to increase beyond 1.0 eq. of $\mathrm{Hg}(\mathrm{II})$ and saturates only at ca. $2: 1 \mathrm{Hg}(\mathrm{II}): \triangle \mathrm{C} 7-\mathrm{CueR}$ ratio, indicating that the truncated protein can accommodate two $\mathrm{Hg}(\mathrm{II})$ ions in a $\mathrm{HgS}_{2}$ coordination environment. This may be realized if a dinuclear $\mathrm{Hg}_{2} \mathrm{~S}_{2}$ site is formed by the participation of two thiolates as bridging ligands. Interestingly, this agrees with the unexpectedly high frequency observed by PAC spectroscopy $\left(v_{\mathrm{Q}}=1.60\right.$ GHz, Table A8), which can be explained by the presence of a positive charge of the second $\mathrm{Hg}(\mathrm{II})$. The fact that the species with two $\mathrm{Hg}$ (II) bound per CueR monomer is not observed in ESI-MS implies that the binding of the second $\mathrm{Hg}(\mathrm{II})$ is relatively weak.

\subsubsection{A mechanism to prevent transcriptional activation by $\mathrm{Hg}(\mathrm{II})$ ions}

As described above, two species co-exist at $\mathrm{pH} 8.0$ at 0.2 and 1.0 equivalent of $\mathrm{Hg}(\mathrm{II})$, most likely the linear $\mathrm{HgS}_{2}$ and a $\mathrm{T}$ shaped $\mathrm{HgS}_{3}$ structure with the equatorial $\mathrm{Hg}$ $\mathrm{S}$ bond being longer than the other two (Figure 58). $\mathrm{Hg}(\mathrm{II})$ is bound by the two cysteinates of the metal binding loop of the protein and the additional thiolate is most likely recruited from the $\mathrm{CCHH}$ motif, or vice versa. The net negative charge of $\mathrm{HgS}_{3}$ may be stabilized due to the presence of lysine or arginine in the $C$-terminal fragment of CueR.
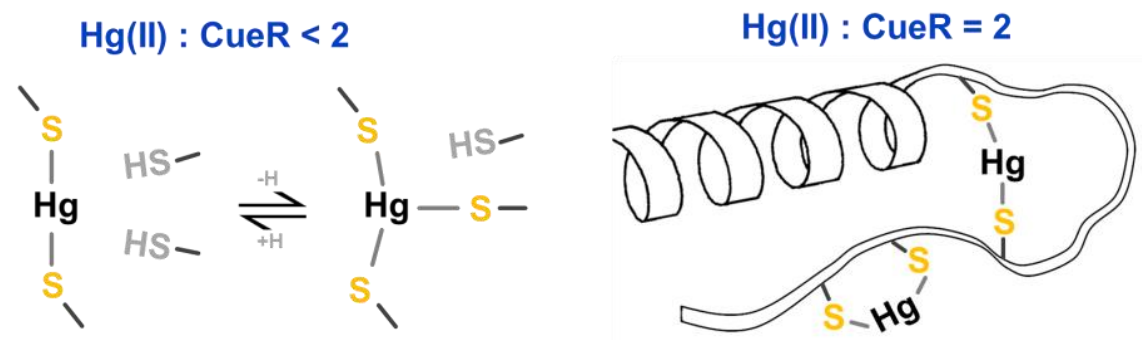

Figure 58: Model structures of $\mathrm{Hg}(\mathrm{II})$ bound to WT CueR at $\mathrm{pH}$ 8.0. Binding of $\mathrm{Hg}(\mathrm{II})$ to CueR gives rise to an equilibrium between $\mathrm{HgS}_{2}$ and $\mathrm{HgS}_{3}$ when $\mathrm{Hg}(\mathrm{II}): \mathrm{CueR}<2$, and to pure $\mathrm{HgS}_{2}$ coordination upon addition of $2 \mathrm{Hg}(\mathrm{II})$ ions per protein monomer.

This implies a mechanism where the specificity of CueR for monovalent metal ions and against divalent metal ions is achieved the coordination of an auxiliary ligand from the $\mathrm{CCHH}$ motif to divalent metal ions, besides $\mathrm{C} 112$ and $\mathrm{C} 120$ of the metal binding loop, and this prevents the docking of the $C$-terminal helix into the hydrophobic pocket,[17] and consequently inhibits the activation of transcription. That is, the $\mathrm{CCHH}$ motif is not involved in the function of CueR when sensing the monovalent metal ions, but it does take 
part in the binding of divalent metal ions, a mechanism that would account for the selectivity of CueR.

\subsubsection{Investigation of the $A g(I)$ and $C d(I I)$ binding of WT Cue R with mass} spectrometry

ESI-MS spectra were also recorded from samples of WT CueR contain increasing amounts (0.2, 0.5, 1.0 and 2.0 equivalents) of $\mathrm{Ag}(\mathrm{I})$ and $\mathrm{Cd}(\mathrm{II})$ ions (Figure 59).

The series of MS spectra obtained with Cd(II) displays a similar trend as observed with $\mathrm{Hg}(\mathrm{II})$ ions: by increasing the $\mathrm{Cd}(\mathrm{II})$ :WT CueR ratio, the relative abundance of the apo-form of the protein gradually decreases, while new peaks, with an increased $\mathrm{m} / \mathrm{z}$ value corresponding to WT CueR binding one or two Cd(II) ions(Appendix A.5.3., Figure A4), gradually emerge. Importantly, these results suggest that not only $\mathrm{Hg}$ (II) ions, but $\mathrm{Cd}$ (II) can also bind to both potential metal ion binding sites of the WT CueR with relatively high affinities.
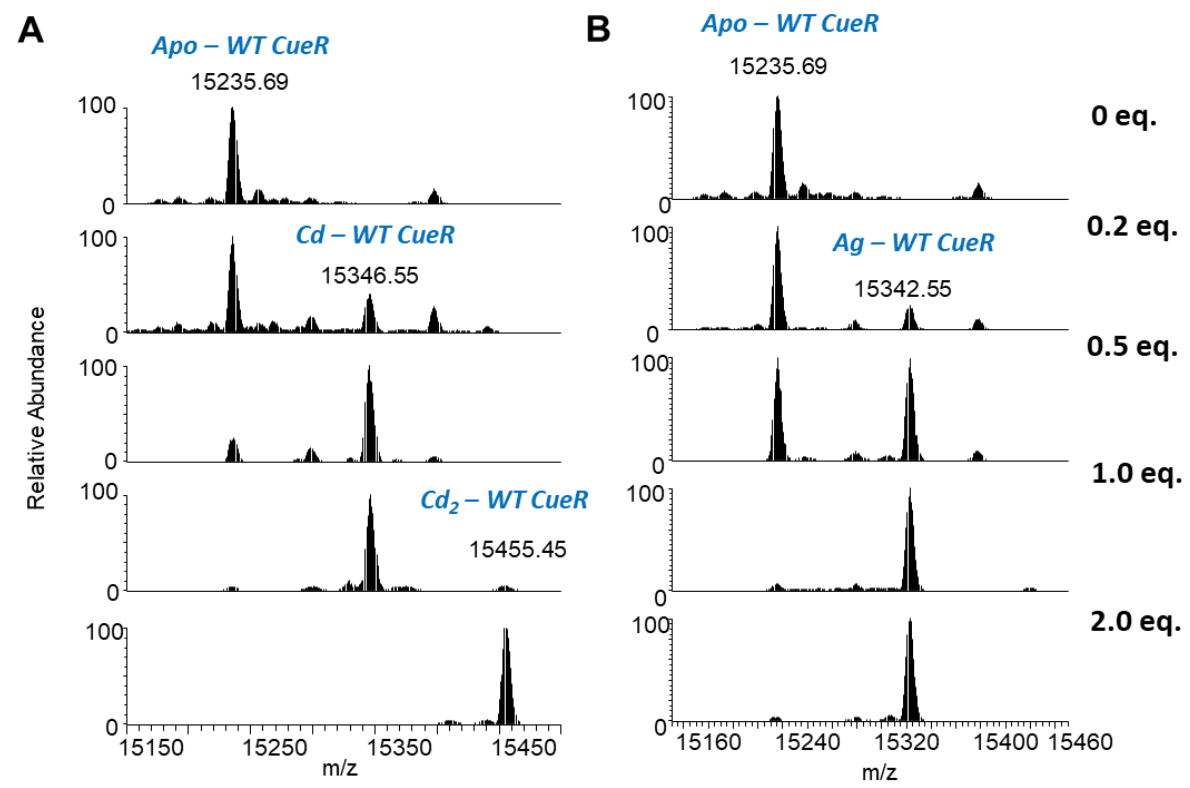

Figure 59: Deconvoluted native ESI-MS spectra of the WT CueR in the absence and presence of 0.2, 0.5, 1.0 and 2.0 equivalents of $C d(I I)(A)$ and $A g(I)$ ions (B). Spectra were recorded from individual samples buffered with $10 \mathrm{mM} \mathrm{NH}_{4} \mathrm{HCO}_{3} . c_{\text {CUeR }}=20 \mu \mathrm{M}, c_{T C E P}=0.5 \mathrm{mM}, \mathrm{pH}$ $=7.5$.

In contrast, $\operatorname{Ag}(\mathrm{I})$ binding to WT CueR occurs in a markedly different way compared to what was observed with $\mathrm{Hg}(\mathrm{II})$ or $\mathrm{Cd}(\mathrm{II})$. In line with adding up to one equivalent of $\operatorname{Ag}(\mathrm{I})$ the signal of the apo-protein nearly disappears, while the peak of the Ag-CueR complex, at $m / z=15342.6$, becomes predominant (Appendix A.5.3., Figure A4). 
Even at a $\mathrm{Ag}(\mathrm{I})$ :WT CueR 2:1 ratio, no signals corresponding to a $\mathrm{Ag}_{2}-\mathrm{CueR}$ complex can be observed. This suggest that the two metal ion binding sites of CueR possess a different affinity to $\mathrm{Ag}(\mathrm{I})$, similarly to $\mathrm{Cu}(\mathrm{I})$.[18] Based on previous structural studies[16-18], $\mathrm{Ag}(\mathrm{I})$ binds to the metal ion binding loop formed by $\mathrm{C} 112$ and $\mathrm{C} 120$ and not to the $C$-terminal CCHH motif.

\subsubsection{Characterization of $A g(I)$ binding of Cue $R$ and its variants}

${ }^{111} \mathrm{Ag}$ PAC experiments were carried out with the WT, $\Delta \mathrm{C} 7$ - and S77C- $\Delta \mathrm{C} 7-\mathrm{CueR}$ proteins in the presence of 0.5 equivalent of $\mathrm{Ag}(\mathrm{I})$ ions at $\mathrm{pH}=8.0$ in order to investigate the $\mathrm{Ag}(\mathrm{I})$ binding of CueR with a particular focus on the role of the $\mathrm{CCHH}$ motif and the effect of the presence of an additional cysteine, C77, that is missing in WT CueR but present at or near this position in several divalent metal ion sensing MerR family member metallore gulators (Figure 60, Fitted parameters are included in Appendix A.9.4. Table A9). These ${ }^{111} \mathrm{Ag}$ PAC experiments were conducted at $-196{ }^{\circ} \mathrm{C}$ to prevent or slow down the structural relaxation occurring after the decay of ${ }^{111} \mathrm{Ag}$ to ${ }^{111} \mathrm{Cd}$.

The spectrum of the WT protein displays two nuclear quadrupole interactions (NQIs) at $-196{ }^{\circ} \mathrm{C}$ characterized by a high and a low frequency signal representing two coordination geometries (discussed in details in the following subchapter, 5.3.7.). The $\triangle \mathrm{C} 7$ CueR variant exhibits essentially the same high frequency signal and a slightly different low frequency signal, demonstrating the presence of similar species to those formed with the WT protein. This is in line with the conclusions drawn from the ESI-MS experiment, that is the $C$-terminal $\mathrm{CCHH}$ motif does not participate directly in the $\operatorname{Ag}(\mathrm{I})$ binding under these conditions (metal ion:protein ratio and $\mathrm{pH}$ ) allowing the formation of the activator

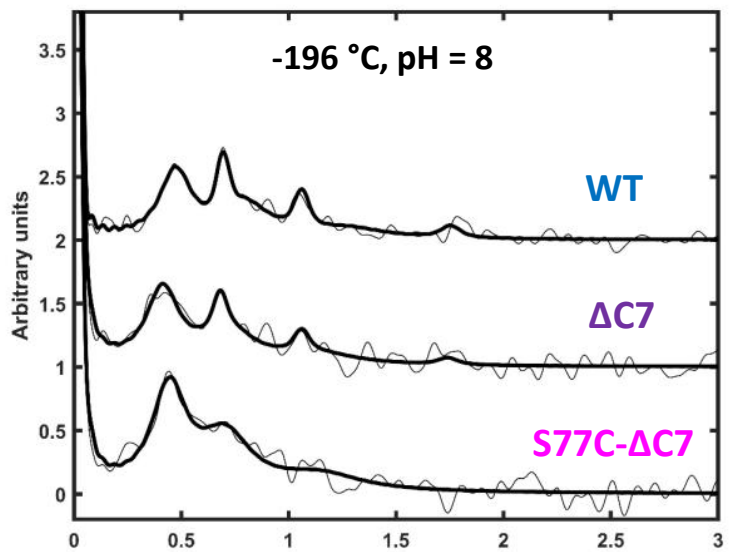

Figure 60: Experimental and fitted ${ }^{111} \mathrm{Ag} P A C$ spectra of WT, $\triangle C 7$ - and S77C- $\triangle C 7-C u e R$ in the presence of $0.5 \mathrm{eq}$. $\mathrm{Ag}(\mathrm{I})$, at $\mathrm{pH}=8.0$, at $-196^{\circ} \mathrm{C} . c_{\text {protein }}=11 \mu \mathrm{M}, \mathrm{w} / \mathrm{w} \%_{\text {sucrose }}=55 \%$ conformation of the protein.

The ${ }^{111} \mathrm{Ag}$ PAC spectrum obtained for the S77C- $\Delta \mathrm{C} 7-\mathrm{CueR}$ variant under the same experimental conditions displays a significantly different shape (Figure 60). It is 
convincible that because of the spatial proximity of $\mathrm{C} 77$ residue to the metal ion binding site, C77 residue provides an additional thiolate ligand to the coordinating metal ion similarly to the cysteine found at this position in homologous MerR proteins. [8, 16, 28, 29, 148] The PAC data imply that during the decay, the C77 coordinates to ground state $\mathrm{Cd}(\mathrm{II})$ by forming a 3-coordinate (or higher coordination number) site.

\subsubsection{Flexibility of the metal ion binding site of WT CueR}

${ }^{111} \mathrm{Ag}$ decays to ${ }^{111} \mathrm{Cd}$ by $\beta^{-}$emission and ${ }^{111} \mathrm{Ag}$ PAC spectroscopy may provide an insight into the metal site structure and dynamics occurring at the CueR metal site upon the instantaneous change of element and oxidation state from $\mathrm{Ag}(\mathrm{I})$ to $\mathrm{Cd}(\mathrm{II})$.

As it was mentioned before, in a frozen solution at $-196{ }^{\circ} \mathrm{C}$ two nuclear quadrupole interactions are observed in the ${ }^{111} \mathrm{Ag}$ PAC spectrum of WT CueR (Figure 61, Fitted parameters are included in Appendix A.9.4. Table A10). The high frequency signal, NQI $\left(\omega_{0}=0.555 \mathrm{rad} / \mathrm{ns}\right)$, is analysed unambiguously given that all three peaks characteristic of a ${ }^{111} \mathrm{Ag}$ PAC signal rise above the noise level, and they satisfy the requirement $\omega_{1}+\omega_{2}=\omega_{3}$. Semi-empirical AOM calculation[139] indicate that the ground state $\mathrm{Cd}(\mathrm{II})$ remains essentially in the $\operatorname{Ag}(\mathrm{I})$ coordination geometry, possibly establishing a long contact with the S77 carbonyl oxygen. The significant deviation of the asymmetry parameter from zero $(\eta=0.51)$ indicates that the structure is distorted, i.e. the linear coordination observed in the crystal structures is not maintained.

The other, low frequency signal, $\mathrm{NQI}_{2}\left(\omega_{0}=0.41 \mathrm{rad} / \mathrm{ns}\right)$ is more difficult to interpret unambiguously because several possible structures map into the observed frequency range. However, the lower frequency strongly indicates a coordination number higher than 2 , either as a result of coordination by a nearby amino acid residue or an extraneous ligand such as a solvent water molecule.

The ${ }^{111} \mathrm{Ag}$ PAC experiment conducted at $1{ }^{\circ} \mathrm{C}$ exclusively displays one NQI, with essentially the same parameters as the low frequency $\mathrm{NQI}_{2}$ observed at $-196{ }^{\circ} \mathrm{C}$. Consequently, this species must represent the lower free energy structure at $1{ }^{\circ} \mathrm{C}$, and the barrier to relaxation from the high frequency species to the low frequency species must be small enough to be overcome within $\sim 10 \mathrm{~ns}$ at $1{ }^{\circ} \mathrm{C}$ of the course of decay from ${ }^{111} \mathrm{Ag}$ to ${ }^{111} \mathrm{Cd}$. 


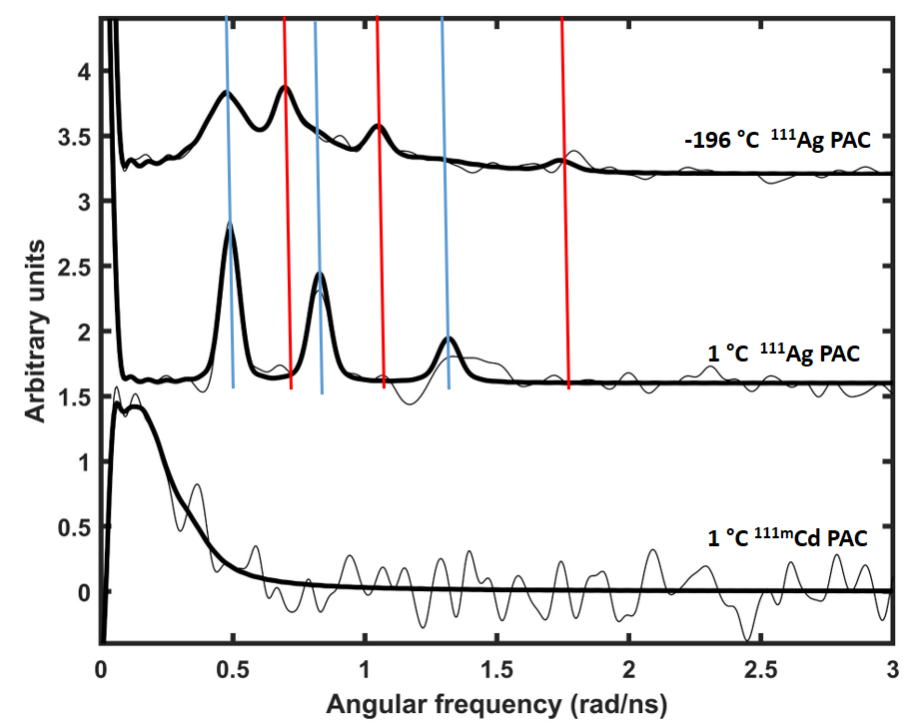

Figure 61: ${ }^{111} \mathrm{Ag}$ - and ${ }^{111 \mathrm{~m}} \mathrm{Cd}$-PAC spectra of WT CueR. At-196 ${ }^{\circ} \mathrm{C}$ two different $N Q I$ s characterized by a high frequency signal (red), $N Q I_{1}$, and a low frequency signal (blue), $\mathrm{NQI}_{2}$, are observed; At $1{ }^{\circ} \mathrm{C}$ only the low frequency signal, $\mathrm{NQI}_{2}$, is observed; Experimental and fitted data are shown by thin and thick black lines,

respectively. $c_{C u e R}=11 \mu \mathrm{M}, c_{A g(I)}=5.5 \mu \mathrm{M}, c_{C d(I I)}=11 \mu \mathrm{M}, c_{D N A}=5.5 \mu \mathrm{M}$, $w / w \%_{\text {sucrose }}=55 \%, p H=7.3$ at room temperature

${ }^{111 \mathrm{~m}} \mathrm{Cd}$ decays to the nuclear ground state of ${ }^{111} \mathrm{Cd}$, i.e. it is an isomeric transition with no change of element or oxidation state, and ${ }^{111 \mathrm{~m} C d ~ P A C}$ spectroscopy therefore reflects the thermodynamic equilibrium of Cd(II) binding to CueR. The ${ }^{111 \mathrm{~m} C d}$ PAC spectrum of CueR exhibits low frequencies reflecting a symmetric coordination, possibly distorted tetrahedral $\mathrm{CdS}_{4}$, although other coordination geometries cannot be fully excluded. It is noteworthy that the ${ }^{111 \mathrm{~m} C d}$ PAC spectrum is distinct from the ${ }^{111} \mathrm{Ag}$ PAC spectra. We may thus conclude that the ${ }^{111} \mathrm{Ag}$ PAC spectra reflect structure(s) of the $\mathrm{Ag}(\mathrm{I})$ CueR complex, and/or transient species formed at the nanosecond time scale after the decay.

In summary, $\mathrm{Cd}(\mathrm{II})$ may be trapped at low temperature in a distorted two-coordinate structure, (with an additional long contact to the S77 carbonyl oxygen), resembling the functional $\mathrm{Ag}(\mathrm{I})$-binding site of $\mathrm{CueR}$, but at $1{ }^{\circ} \mathrm{C}$ it rapidly relaxes to a transient species with higher coordination number. The equilibrium $\mathrm{Cd}$ (II) binding exhibits high symmetry with a possible distorted tetrahedral $\mathrm{CdS}_{4}$ coordination geometry. This structural flexibility of the metal ion binding site is likely to be an essential element of the protein function where the transcriptional activation is only desired for binding of the monovalent metal ions, and other, non-cognate metal ions may disrupt of the functional CueR binding site. This is, in contrast to the metal site properties reported for the small blue copper protein 
azurin where only very little structural change was observed at the metal site by ${ }^{111} \mathrm{Ag}$ PAC upon the decay from ${ }^{111} \mathrm{Ag}$ to ${ }^{111} \mathrm{Cd}$. [149] Azurin is an electron transporter, and is required to accommodate change of oxidation state between $\mathrm{Cu}(\mathrm{I})$ and $\mathrm{Cu}(\mathrm{II})$ without much structural reorganization. CueR, however, is expected to behave in the opposite way and be able to discriminate between monovalent coinage metal ions and other metal ions while binding to the same metal site. In sum, metal site rigidity/flexibility is a property which is important for the function of metalloproteins, and ${ }^{111} \mathrm{Ag}$ PAC spectroscopy maybe applied as a spectroscopic tool to probe this feature.

\subsection{Bioanalytical application}

\subsubsection{Strategy of establishing a fluorescent reporter system}

As a highly selective and sensitive protein, CueR provides a promising platform for constructing selective metal-ion sensing systems. In this work, a bacterial fluorescent reporter system was established for $\mathrm{Cu}$ (II) ions. In principle, the $\mathrm{Cu}$ (II) ions penetrate through the membrane barriers of the cell and then they are converted into $\mathrm{Cu}(\mathrm{I})$ by the reducing environment of the cytosol. In case of overaccumulation, the excess $\mathrm{Cu}(\mathrm{I})$ ions bind to CueR leading to the expression of EGFP fluorescent protein via transcription activation (Figure 62).

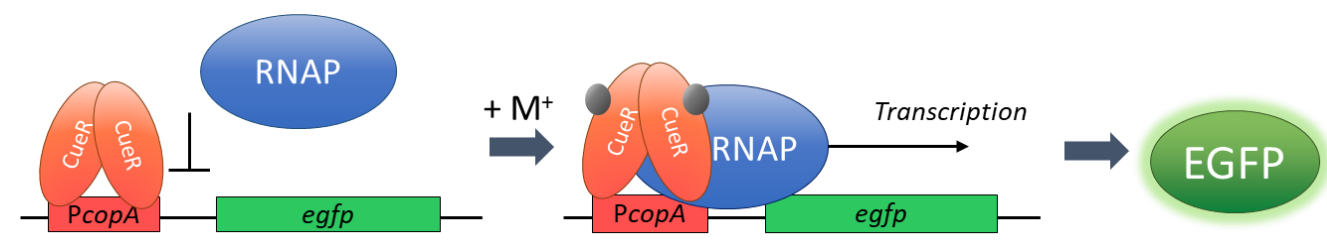

Figure 62: The scheme of CueR based fluorescent reporter system. Upon metal binding CueR activates the transcription of the egfp gene resulting in the expression of EGFP as the fluorescent reporter in the cell.

The reporter DNA segment (PcopA::egfp) was constructed by fusing the $e g f p$ gene downstream to the CueR-responsive promoter region (PcopA). The PcopA::egfp DNA segment was inserted into pUC119 high copy number plasmid resulting in its pUC119copA-EGFP derivative (Figure 63C). In a next step, the gene of the regulatory protein (i.e. cueR) was cloned into the pUC119-copA-EGFP plasmid, under the regulation of the lac promoter (Plac) of the plasmid transcribed divergently than PcopA::egfp. Thereby, this DNA construct named pUC119-CueR-copA-EGFP plasmid, encompasses both the reporter and the regulator genes (Figure 63D). After the cloning procedure, E. coli bacteria were 
transformed with pUC119-CueR-copA-EGFP reporter plasmid. The expression of the EGFP protein was qualitatively analysed with fluorescence microscopy. The chromosomal DNA of bacteria was stained with DAPI dye in order to make the presented images comparable by visualizing the number and position of the cells. In the experiments both negative and positive controls were applied. Bacteria harboring an "empty" pUC119 plasmid served as a negative control (Figure 63A), whereas, bacteria transformed with pUC119-EGFP plasmid, encompassing the egfp gene downstream to the Plac sequence, were used as positive control (Figure 63B).
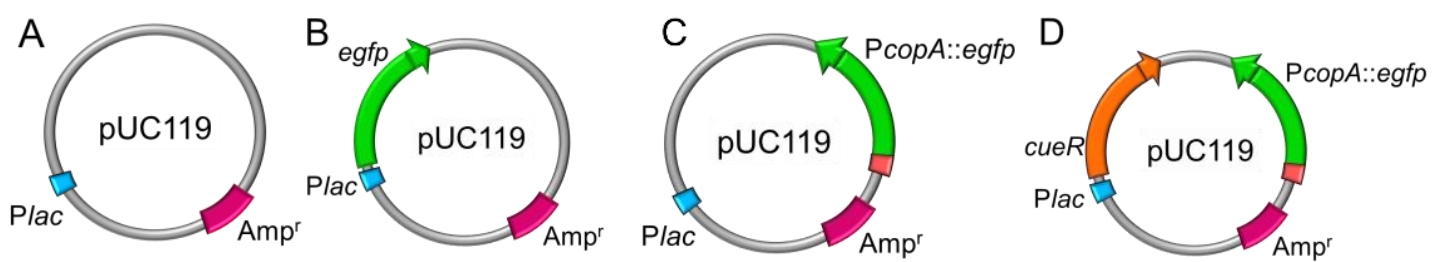

Figure 63: The pUC119 plasmid derivatives used in experiments discussed later. (A) pUC119 "empty" plasmid is a negative control, (B) pUC119-EGFP plasmid is a positive control, (C) pUC119-copA-EGFP contains the promoter-reporter sequence and (D) pUC119-CueR-copAEGFP encompasses also the cueR gene.

\subsubsection{EGFP expression in BL21(DE3) cells}

At the first stage of the experiments, the reporter system was tested in BL21(DE3) cells (Figure 64). The fluorescent images of the control samples exposed to IPTG and $\mathrm{Cu}$ (II) ions show that the background fluorescence of the cells is negligible, and the EGFP can be expressed in bacteria and visualized by microscopy (Figure 64A). Next, cells harboring the reporter pUC119-CueR-copA-EGFP plasmid were tested. IPTG was added to all sample in order to induce the expression of $\mathrm{CueR}$, whereas $\mathrm{Cu}$ (II) was added in an increasing concentration $\left(c_{\mathrm{Cu}(\mathrm{II})}=0,0.1\right.$ and $\left.1 \mathrm{mM}\right)$ to express EGFP by inducing the $\mathrm{P}$ copA promoter through the CueR protein. The fluorescent imaging clearly revealed that $1 \mathrm{mM}$ $\mathrm{Cu}$ (II) added to the LB medium of bacterial culture could activate the reporter system resulting in the overexpression of EGFP (Figure 64B). 
A
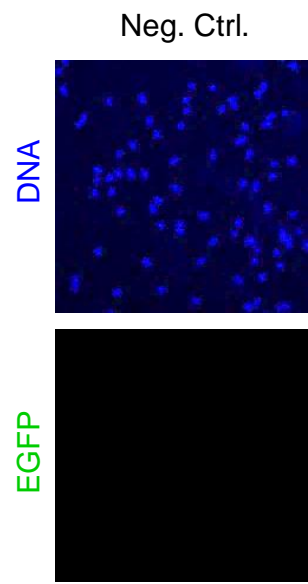

Pos. Ctrl.
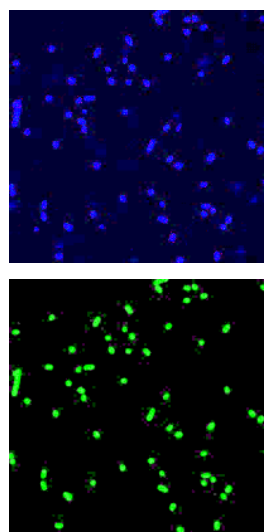

B

pUC119-CueR-copA-EGFP
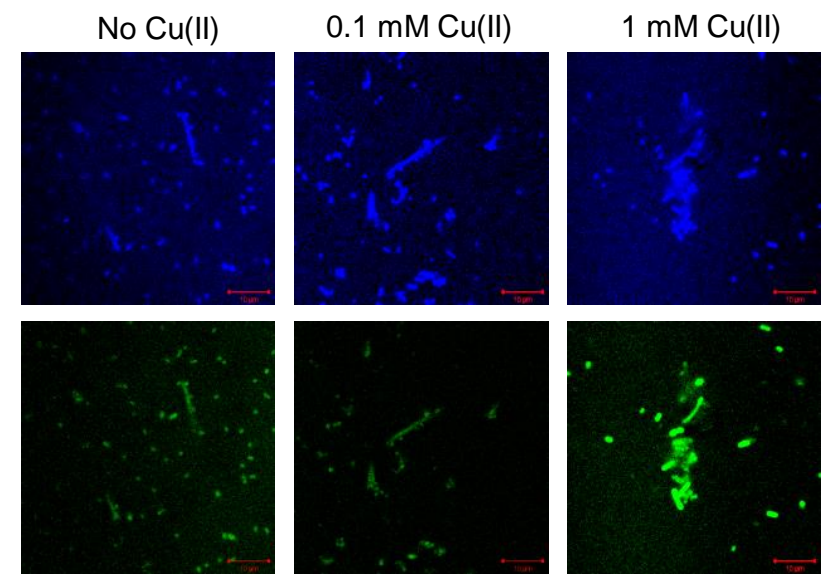

Figure 64: Fluorescent microscopic images of DAPI stained BL21(DE3) cells. (A) Images of

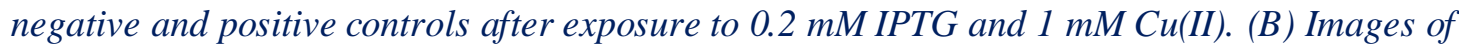
cells transformed with pUC119-CueR-copA-EGFP after exposure to $0.2 \mathrm{mM} \mathrm{IPTG}$ and increasing concentration $(0,0.1$ and $1 \mathrm{mM})$ of $\mathrm{Cu}(\mathrm{II})$ ions.

Bacterial samples were also subjected to high throughput fluorescence intensity measurement with a microplate reader in order to gain quantitative information about the EGFP expression. We observed that the added $\mathrm{Cu}$ (II) formed a fluorescent complex with a component of the cultivation medium. Therefore, the induced cells had to be washed and transferred into phosphate-buffered saline (PBS) buffer before the fluorescent measurements. By the elimination of the interfering $\mathrm{Cu}$ (II) complex, only the fluorescence of the cells was measured demonstrated by a negligible fluorescence of the negative control sample exposed to $\mathrm{Cu}(\mathrm{II})$ (Figure 65A). In order to increase the sensitivity of the experiments, cells were grown in M9 minimal medium. This medium contained the minimal amount of buffering agents, inorganic ions, nitrogen and carbon source to support microbial growth, hence, it included less potential ligands for $\mathrm{Cu}(\mathrm{II})$ binding than $\mathrm{LB}$ did. Thereby, already $10 \mu \mathrm{M}$ external $\mathrm{Cu}(\mathrm{II})$ induced the expression of EGFP in bacteria cultivated in M9. In addition, fluorescent measurements revealed that the presence of IPTG was not necessary for the reporter system to function (Figure 65A). This phenomenon was confirmed by fluorescence imaging revealing that the EGFP expression occurs with or without IPTG exposure (Figure 65B). This might be explained by the participation of the endogenous CueR in the regulation of the $\mathrm{P} \operatorname{cop} A$ promoter (assuming a tight control of the Plac). To avoid the interplay between the exogenous and the chromosomal copy of CueR, a cell line lacking the cueR was obtained for the subsequent experiments. 

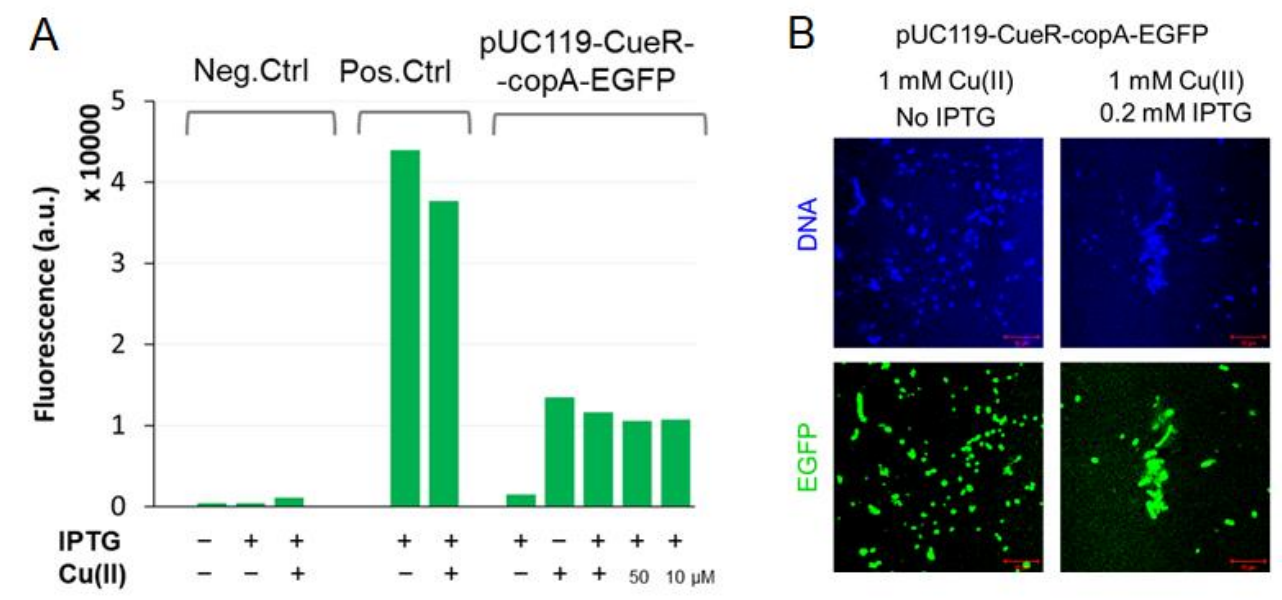

Figure 65: (A) Fluorescence of transformed BL21(DE3) cells measured in PBS with microplate reader. The presence or absence of $0.2 \mathrm{mM} \mathrm{IPTG}$ and $0.1 \mathrm{mM} \mathrm{Cu}(\mathrm{II})$ during the protein induction is marked with + and -, respectively. (B) Images of BL21(DE3) cells transformed with pUC119-CueR-copA-EGFP and exposed to $1 \mathrm{mMCu(II)}$ alone or in combination with $0.2 \mathrm{mM}$ IPTG.

\subsubsection{Experiments in CueR knock-out cells}

The $\Delta c u e R$ BW25113 CueR knock-out E. coli strain, i.e. lacking the chromosomal cueR gene, was obtained from the Keio collection. The Keio collection consists of almost four thousand variants of E. coli K-12 BW25113 strain in which the open-reading frames of non-essential genes was replaced with a kanamycin cassette. As a basis of comparison, the unmodified BW25113 strain was also acquired and investigated.

First, the BW25113 cells harbouring the positive and negative control plasmids were tested. As expected, the background fluorescence of the cells was shown to be negligible, whereas the expression of EGFP was clearly observable (Figure 66A). Next, BW25113 cells transformed with the reporter plasmid were investigated. Likewise in BL21 cells, $1 \mathrm{mM}$ added $\mathrm{Cu}$ (II) induced the expression of EGFP in the absence of IPTG (Figure 66B). It is worth mentioning that even 10 times higher concentration of $\mathrm{Zn}(\mathrm{II})$ did not result in expressing fluorescent protein owing to the selectivity of CueR (Figure 66B). 


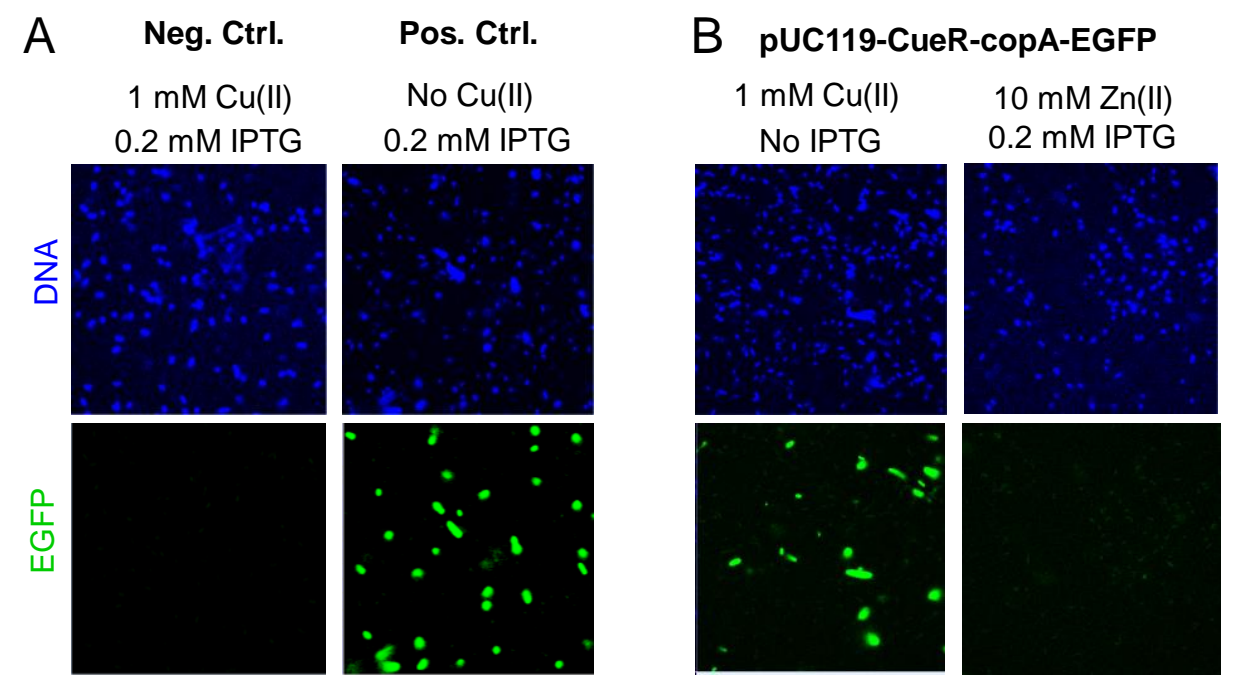

Figure 66: Fluorescent microscopic images of DAPI stained BW25113 cells. (A) Images of negative and positive controls as described in paragraph 5.4.1. (B) Images of cells transformed with pUC119-CueR-copA-EGFP and cultivated in the presence of $1 \mathrm{mM} \mathrm{Cu(II)} \mathrm{or}$ $10 \mathrm{mM} \mathrm{Zn}(\mathrm{II})$ ions.

The BW25113 and the knock-out $\triangle c u e R$ BW25113 cells were transformed with a control plasmid containing only the PcopA::egfp reporter segment (pUC119-copA-EGFP) and exposed to $\mathrm{Cu}(\mathrm{II})$ enriched environment to prove the interference of the endogenous CueR in the reporter system. Microscopic images showed that the EGFP expression was only activated in BW25113 cells possessing chromosomal copy of the cueR gene (Figure 67). In $\triangle c u e R$ BW25113 cells the transcription could not be induced by the $\mathrm{Cu}(\mathrm{II})$ ions because of the lack of a key element: the regulator protein (Figure 67B).
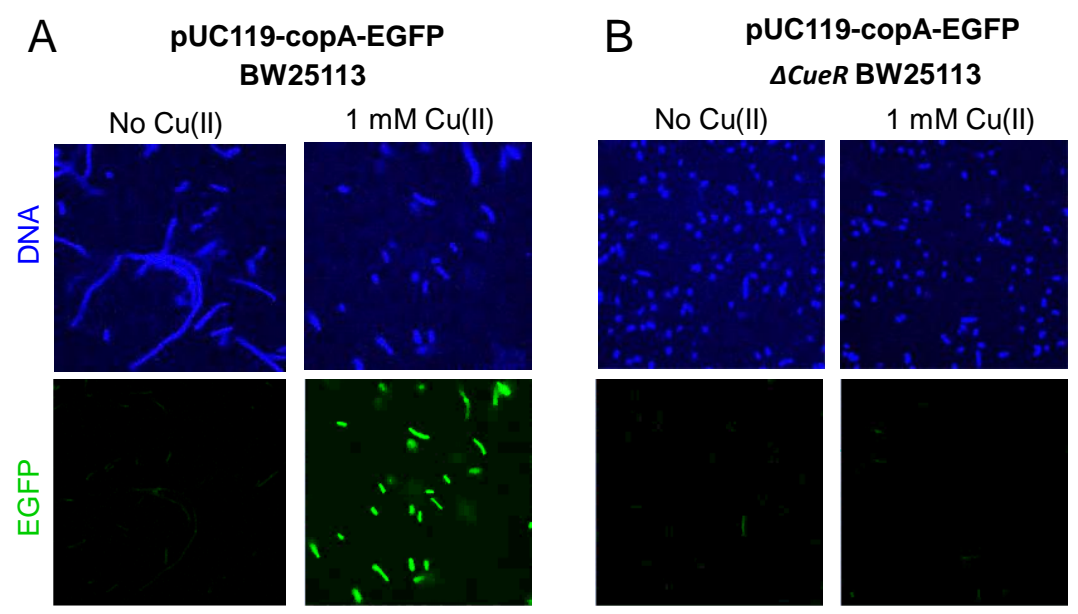

Figure 67: Fluorescent microscopic images of DAPI stained BW25113 (A) and $\triangle C u e R$ $B W 25113$ (B) cells transformed with pUC119-CueR-copA-EGFP and cultured in the absence and in the presence of $1 \mathrm{mMCu}(\mathrm{II})$. 
Finally, the reporter plasmid pUC119-CueR-copA-EGFP was tested in $\triangle c u e R$ BW25113 cells. Unfortunately, the expression of EGFP was not induced by $\mathrm{Cu}(\mathrm{II})$ ions (Figure 68B), although the plasmid encompassed the cueR gene and the EGFP was expressible in the positive control sample (Figure 68A) suggesting that the expression of the exogenous CueR was not successful. This assumption was verified by SDS-PAGE (Figure 69).
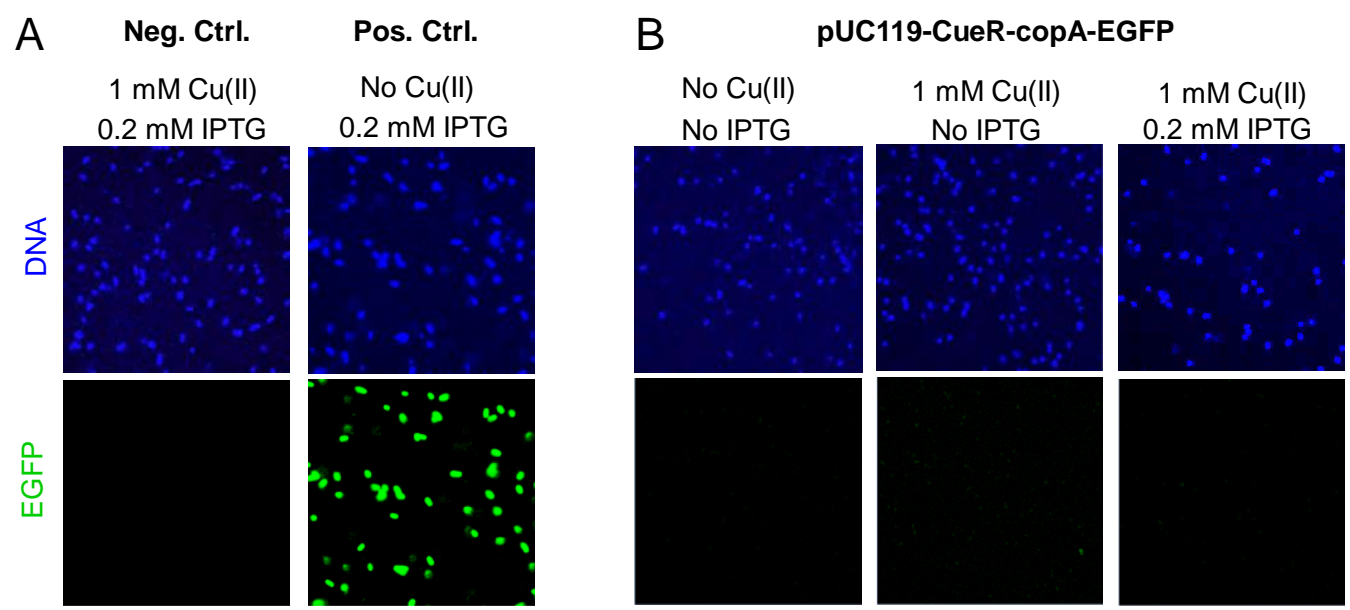

Figure 68: Fluorescent microscopic images of DAPI stained $\triangle$ CueR BW25113 cells. (A) Images of negative and positive controls. (B) Images of cells transformed with pUC119-CueRcopA-EGFP, uninduced, induced with $1 \mathrm{mM} \mathrm{Cu(II)}$ alone and in a combination with $0.2 \mathrm{mM}$ IPTG.

To understand the cause of the hindered expression of CueR, it has to be pointed out that the cueR gene was cloned into the pUC119-copA-EGFP plasmid with an upstream Shine-Dalgarno (SD) ribosomal binding site and a downstream transcriptional terminator sequence. Assuming that these extra segments disturb the transcriptional or translational process of our DNA construct, the reporter system was re-cloned eliminating the SD or both the SD and the terminator segments (Figure 69A). The expression of CueR from the original and from the re-cloned plasmids was analysed by SDS-PAGE. In accordance with microscopy, the CueR was not expressed from the original SD-cueR-Terminator unit (Figure 69B). However, the removal of the SD segment allowed the expression (Figure $69 B$ ). Based on the intensity of the protein bands on the gel, the amount of the overexpressed CueR is less than from a positive control (pET21a-CueR, used as an expression plasmid for protein production), but the low intracellular concentration of the regulator protein might be advantageous for the performance of the reporter system.[77] 
A

\begin{tabular}{l} 
A. SD-cueR-Term \\
$\qquad$\begin{tabular}{|l|l|l|}
\hline SD & cueR & Terminator \\
B. cueR-Term & cueR & Terminator \\
\hline & & \\
\hline & & \\
\hline
\end{tabular} \\
C. cueR \\
\hline
\end{tabular}

$\mathrm{B}$ $M-A B C+$ $\mathrm{kDa}$ 50 37 25 15

Figure 69: (A) Schematic representation of the gene segments cloned into pUC119-copAEGFP plasmid (B) SDS-PAGE analysis of CueR expression in BL21(DE3). Lane M contains a molecular weight standard, Lane of - and + show negative and positive control, respectively. Lane A, B and C correspond to the constructions showed on panel (A). The expected size of CueR is band pointed out by the arrow.

These results provide a solid background for further investigation related to this project will be carried out by incoming members of our laboratory. Later, we wish to use this reporter system for monitoring and comparing the biological function of WT CueR and its mutants, could further our understanding on the metal ion recognition mechanism of this fascinating metalloregulatory protein. 


\section{SUMMARY}

In living organisms, highly specialized processes have been evolved to in order to secure the metal ion homeostasis and protect the cell from harmful effects. In prokaryotes these processes are managed by metal ion selective metalloregulatory proteins at the level of transcription.[3-5] In this thesis, the CueR metalloregulatory protein was investigated. The transcriptional activation of CueR is initiated selectively by monovalent transition metal ions, $\mathrm{Cu}(\mathrm{I}), \operatorname{Ag}(\mathrm{I})$ and $\operatorname{Au}(\mathrm{I}) .[15,16,19]$ The details of the allosteric mechanism through the CueR regulate the transcription is well described in the literature,[16-18, 20, 23, 24] however, it is still unexplored how CueR discriminates so successfully between soft mono- and divalent metal ions. Therefore, aimed to get a deeper insight into the metal ion selective operation of CueR.

My $\mathrm{PhD}$ research involved the cloning and the purification of the WT E. coli CueR and two mutant $\Delta \mathrm{C} 7$ - and S77C- $\Delta \mathrm{C} 7-\mathrm{CueR}$ proteins, which were subjected to structural and metal ion binding characterization studies. Finally, a bacterial fluorescent reporter system for $\mathrm{Cu}(\mathrm{II})$ ions was established on the basis of the high selectivity and sensitivity of CueR.

In the first place, a new, chromatographic procedure for purifying the CueR protein was built up and optimized, that may also provide general guidelines for working with airsensitive DNA binding proteins. This procedure includes an enzymatic digestion of the DNA content of the lyzed cells and four subsequent chromatographic purification steps, such as anion exchange, affinity chromatography a second anion exchange and gel filtration. The integrity, the proper folding and the functioning of the purified proteins were undoubtedly verified with mass spectrometry, collision induced dissociation tandem mass spectrometry, circular dichroism spectroscopy and electrophoretic mobility shift assay. These experiments also proved that the mutations do not alter the $\alpha$-helical rich secondary structure, the DNA binding ability or the specific DNA sequence recognition of the truncated $\Delta \mathrm{C} 7$ - and the truncated and serine point mutant $\mathrm{S} 77 \mathrm{C}-\Delta \mathrm{C} 7-\mathrm{CueR}$.

Next, the effect of $\mathrm{pH}$, temperature, and the presence of specific binding partners on the secondary structure of $\mathrm{CueR}$ was studied in order to gain more information about behaviour of this protein in solution. $\mathrm{pH}$ dependent $\mathrm{CD}$ experiments revealed that decreasing the $\mathrm{pH}$ from 7.5 to 6.0 induces the transformation of the otherwise helix-rich functional structure into a $\beta$-sheet rich form. Such a conformational change within a narrow $\mathrm{pH}$ range is rather rare among proteins, and similar observation has not been reported for 
metalloregulatory proteins so far. Based on the $\mathrm{p} K_{a}$ values calculated by PROPKA program and structural considerations, $\mathrm{H} 76$ and $\mathrm{H} 94$ residues are suspected to be accountable for inducing the conformational switch of protein.

At $\mathrm{pH} 7.5$, in contrast to $\mathrm{Hg}(\mathrm{II}), \mathrm{Zn}$ (II) or $\mathrm{Cd}(\mathrm{II})$ ions, the presence of $\mathrm{Ag}(\mathrm{I})$ significantly affects the shape and intensity of the CD spectrum indicating a $10 \%$ increase in the $\alpha$-helical content. This may reflect the stabilization of the metal binding loop and the formation of the $C$-terminal helix which ultimately leads to the formation of the activator conformation.[17] The CD spectra recorded in the presence of DNA does not differ significantly from the superposition of the individual spectra of CueR and DNA, implying that the secondary structure of neither the protein, nor the DNA is amended substantially due to the interaction. Furthermore, at $\mathrm{pH} 6.0$ the $\alpha$-helical rich fold was stabilized completely in the presence of DNA. Among the examined metal ions, a partial stabilization of the helix-rich structure was observed exclusively in the presence of the cognate $\operatorname{Ag}(\mathrm{I})$ ion.

The temperature dependent CD experiments showed that the CueR unfolds in two distinct steps, the most probably the helixes of the DNA-binding domain unfold at a lower temperature $\left(T<50{ }^{\circ} \mathrm{C}\right)$, whereas the coiled-coil structure formed by the dimerization helixes unfold separately at a higher temperature $\left(T \sim 65^{\circ} \mathrm{C}\right)$. Interestingly, in the presence of the cognate $\operatorname{Ag}(\mathrm{I})$ or DNA the melting occurs in one step, presumably due to stabilization of the DNA binding domain agreeing well with the selective metal recognition of the CueR and the allosteric regulation mechanism. $[17,20]$

With the aim of characterizing the metal ion binding properties of CueR and explore the function of the $\mathrm{CCHH}$ motif, we studied the interaction of the WT and mutant proteins with $\mathrm{Hg}(\mathrm{II}), \mathrm{Cd}(\mathrm{II})$ and $\mathrm{Ag}(\mathrm{I})$ ions.

The qualitative analysis of the $\mathrm{Hg}$ (II) binding of WT and $\Delta \mathrm{C} 7-\mathrm{CueR}$ with mass spectrometry clearly demonstrated two binding sites are available for $\mathrm{Hg}$ (II) ions in the WT CueR, reasonably the metal ion binding loop formed by $\mathrm{C} 112$ and $\mathrm{C} 120$, and the $C$-terminal $\mathrm{CCHH}$ motif. The $\mathrm{Hg}(\mathrm{II})$ coordination to $\mathrm{CueR}$ was elucidated with ${ }^{199 \mathrm{~m}} \mathrm{Hg}$ PAC experiments performed on the $\mathrm{Hg}(\mathrm{II})-\mathrm{CueR}$ and $\mathrm{Hg}(\mathrm{II})-\Delta \mathrm{C} 7-\mathrm{CueR}$ systems at different $\mathrm{Hg}$ (II) to protein ratios $(0.2: 1,1: 1$ and 2:1), in the presence of DNA, at $\mathrm{pH} 6.0$ and 8.0. It was shown that with subequimolar $\mathrm{Hg}$ (II) concentrations the coordination geometry of $\mathrm{Hg}$ (II) ions in WT CueR differs at the two distinct $\mathrm{pH}$ values. At $\mathrm{pH}$ 6.0, the signals agree well with a linear $\mathrm{HgS}_{2}$ coordination geometry, whereas at $\mathrm{pH} 8.0$ two structures co-exists: 
a linear $\mathrm{HgS}_{2}$ coordination and a $\mathrm{T}$ shaped $\mathrm{HgS}_{3}$ structure. The $\mathrm{UV}$ absorption spectra series of $\mathrm{Hg}(\mathrm{II})-\mathrm{WT}$ CueR system was used to determine the molar absorption of the $\mathrm{HgS}_{2}$ and the $\mathrm{HgS}_{3}$ species. The obtained values agree well with those reported in the literature. In contrast to the WT CueR, the truncated variant coordinates only one $\mathrm{Hg}$ (II) ion per protein monomer, and the ${ }^{199} \mathrm{mg}$ PAC and the UV absorption spectra exclusively exhibit the signature of $\mathrm{HgS}_{2}$ structure. From these results it became clear that the additional thiolate in the $\mathrm{HgS}_{3}$ structure is recruited from the $\mathrm{CCHH}$ motif. This implies a mechanism where the specificity of CueR for monovalent metal ions and against divalent metal ions is achieved by coordination to divalent metal ions by the $\mathrm{CCHH}$ motif, preventing the docking of the $C$-terminal helix into the hydrophobic pocket,[17] and consequently inhibiting activation of transcription.

Additionally, the binding of $\mathrm{Ag}(\mathrm{I})$ and $\mathrm{Cd}(\mathrm{II})$ to WT CueR was investigated with ESI-MS. The MS spectra obtained with Cd(II) displays a similar trend as it was observed with $\mathrm{Hg}(\mathrm{II})$ ions: $\mathrm{Cd}(\mathrm{II})$ can also bind to the two metal ion binding sites of the WT CueR with relatively high affinities. In contrast, the cognate $\operatorname{Ag}(\mathrm{I})$ ion binds only to the metal ion binding loop of the protein, since signals corresponding to a $\mathrm{Ag}_{2}-\mathrm{CueR}$ complex could be detected.

Furthermore, ${ }^{111} \mathrm{Ag}$ PAC experiments were carried out with the WT, $\Delta \mathrm{C} 7$ - and S77C- $\Delta$ C7-CueR proteins at $-196{ }^{\circ} \mathrm{C}$ in order to prevent or slow down the structural relaxation occurring after the decay of ${ }^{111} \mathrm{Ag}$ to ${ }^{111} \mathrm{Cd}$. The PAC spectra of the WT and $\triangle \mathrm{C} 7-\mathrm{CueR}$ proteins are rather similar confirming that the $C$-terminal $\mathrm{CCHH}$ motif does not participate directly in the $\operatorname{Ag}(\mathrm{I})$ binding allowing the formation of the activator conformation of the protein. Additionally, the ${ }^{111} \mathrm{Ag}$ PAC data for the S77C- $\triangle \mathrm{C} 7-\mathrm{CueR}$ variant exhibits a significantly different signal, probably the proximal $\mathrm{C} 77$ residue provides an additional thiolate ligand to the coordinating metal ion. The PAC data imply that during the decay, the $\mathrm{C} 77$ coordinates to the ground state $\mathrm{Cd}(\mathrm{II})$ by forming a 3-coordinate (or higher coordination number) site.

${ }^{111} \mathrm{Ag}$ PAC spectroscopy provided insight to the metal site dynamics occurring at the CueR metal site upon the instantaneous change of element and oxidation state from $\mathrm{Ag}(\mathrm{I})$ to $\mathrm{Cd}(\mathrm{II}) .{ }^{111} \mathrm{Ag}$ PAC spectrum of WT CueR recorded at $-196{ }^{\circ} \mathrm{C}$ exhibits two NQIs, one agrees well with a distorted linear structure with two coordinating thiolates, whilst the other signal reflecting a higher coordination number. In contrast, at $1{ }^{\circ} \mathrm{C}$ only the latter signal is present, demonstrating that relaxation to this structure occurs within the time frame of the decay from ${ }^{111} \mathrm{Ag}$ to ${ }^{111} \mathrm{Cd}$. In addition, the ${ }^{111 \mathrm{~m}} \mathrm{Cd} \mathrm{PAC}$ spectrum of WT CueR 
reflecting dynamic and symmetric coordination, e.g. $\mathrm{CdS}_{4}$, or exchange between several species. These results indicate that the flexibility of the metal ion binding site allows of different coordination modes and geometries for the mono and divalent metal ions and thus, as an essential element of the function of the protein, ensures the monovalent metal ion selective activation of the transcription process.

Finally, a fluorescent reporter system was constructed by fusing the gene of the enhanced green fluorescent protein (EGFP) downstream to the CueR-responsive promoter region. The reporter system was tested in various E. coli strains, such as BL21(DE3), BW25113 and AcueR BW25113 CueR knock-out strains. The initial investigations revealed that $1 \mathrm{mM}$ or $10 \mu \mathrm{M}$ ambient $\mathrm{Cu}$ (II) induce the expression of EGFP in LB and M9 minimal media, respectively. On the contrary, even $10 \mathrm{mM}$ of $\mathrm{Zn}(\mathrm{II})$ did not result in expressing fluorescent protein owing to the selectivity of CueR. In addition, the interference of the endogenous CueR was also discovered and eliminated by introducing the reporter system into $\triangle c u e R$ BW25113 cells. On the basis of the presented results of this work the reporter system will be further optimized and characterized.

The results presented here may contribute to understand the details of bacterial metal ion regulatory mechanisms, and may also forward the design of molecules for selective metal ion binding/accumulation or the development of sensitive metal iondetection methods. 


\section{7. ÖSSZEFOGLALÁS}

Disszertációm a CueR fémionszabályzó fehérje szerkezetének és funkciójának jobb megértését célzó vizsgálataink eredményeit mutatja be. A CueR a sejt $\mathrm{Cu}(\mathrm{I})$ koncentrációjának csökkentésében szerepet játszó fehérjék génjének transzkripcióját szabályozza. A transzkripció aktiválása allosztérikus módon és kizárólag az egyértékü átmeneti fémionok $\mathrm{Cu}(\mathrm{I}), \operatorname{Ag}(\mathrm{I})$ és $\mathrm{Au}(\mathrm{I})$, fehérjéhez való kötődésének hatására következik be.[15, 16, 19] Az allosztérikus mechanizmus lépései jól ismertek az irodalomból, de még nem tisztázott az a kérdés, hogy a CueR fehérje hogyan képes különbséget tenni az egy- és kétértékü „szoft” fémionok között. Ezért a fehérje különböző fémionokkal történő vizsgálatát, illetve fémion-szelektív müködésének jobb megértését tüztük ki doktori munkám céljául.

A PhD kutatómunkám magában foglalta a natív E. coli CueR (WT CueR), valamint két mutáns fehérje ( $\Delta \mathrm{C} 7$ - and S77C- $\Delta \mathrm{C} 7-\mathrm{CueR})$ klónozását és tisztítását, majd a szerkezeti és fémion-kötő tulajdonságaik vizsgálatát. Ezeken felül kialakítottunk egy, a CueR fehérje szelektivitásán és érzékenységén alapuló, bakteriális fluoreszcens tesztrendszert.

A CueR tisztításához kidolgoztunk és optimalizáltunk egy kromatográfiás eljárást, amely iránymutatásul szolgálhat más, oxigén-érzékeny DNS kötő fehérjével való munkához. Ez az új eljárás tartalmazza az elroncsolt sejtekből származó DNS enzimatikus emésztését és négy kromatográfiás tisztítási lépést, sorrendben egy anioncserét, affinitás kromatográfiát, egy második anioncserét és végül egy gélszürést. A megtisztított fehérjék integritását, funkcionalitását és a megfelelő szerkezet kialakulását tömegspektrometriával, gél elektroforetikus mobilitás változás kísérletekkel és cirkuláris dikroizmus spektroszkópiával igazoltuk. Ezek az eredmények azt is bizonyították, hogy a fehérje szekvenciájában történt módosítások nem okoznak eltérést a csonkított ( $\triangle \mathrm{C} 7-\mathrm{CueR}$ ) és az S77C pont mutációt tartalmazó csonkított (S77C- $\Delta$ C7-CueR) fehérjék $\alpha$-hélixekben gazdag másodlagos szerkezetében, DNS-kötő képességében, illetve a specifikus DNS felismerésében a natív fehérjéhez képest.

Megvizsgáltuk a pH, a hőmérséklet és specifikus kötő-partnerek jelenlétének hatását a CueR másodlagos szerkezetére annak érdekében, hogy több információt nyerjünk a fehérje oldatbeli viselkedéséről. A pH-függő CD mérések azt mutatták, hogy a pH 7,5ről 6,0-ra csökkentésével a fehérje egyébként $\alpha$-hélixekben gazdag szerkezete átalakul $\beta$ redős formává. Ilyen szük pH-tartományon belül lezajló konformációs változás meglehetősen ritka jelenség a fehérjék körében, és hasonló megfigyelést fémionszabályzó 
fehérjék esetében még nem publikáltak. A PROPKA programmal meghatározott $\mathrm{p} K_{\mathrm{a}}$ értékek, valamint szerkezeti megfontolások alapján feltételezhetően a H76 és H94 aminosavak protonálódása eredményezi a fehérje szerkezetváltozását. Ezen felül azt is megfigyeltük, hogy $\mathrm{pH}=6.0$-nál a CueR $\alpha$-hélixekben gazdag szerkezete teljes mértékben stabilizálható DNS hozzáadásával, míg Ag(I) ionok hatására csak részleges a szerkezet stabilizációja.

Ellentétben a $\mathrm{Hg}(\mathrm{II}), \mathrm{Zn}(\mathrm{II})$ és $\mathrm{Cd}(\mathrm{II})$ ionokkal, $\mathrm{Ag}(\mathrm{I})$ ionok jelenléte $\mathrm{pH}=$ 7,5-nél számottevő hatással van a fehérje CD spektrumának alakjára és intenzitására. A spektrális változás az $\alpha$-hélixek mennyiségének $\sim 10 \quad \%$-os növekedését jelzi, ami nagy valószínűséggel a fémion-kötő hurok és a $C$-terminális hélix, és ezáltal az aktivátor konformáció stabilizálásához vezet.[17]

A hőmérsékletfüggő $\mathrm{CD}$ mérések azt mutatták, hogy a fehérje két lépésben denaturálódik. Feltételezhetően a DNS-kötő domén hélixei alacsonyabb hőmérsékleten ( $T$ $<50{ }^{\circ} \mathrm{C}$ ), míg a „coiled-coil” szerkezetben lévő dimerizációs hélix magasabb hőmérsékleten $\left(T \sim 65^{\circ} \mathrm{C}\right)$ denaturálódik. Érdekes módon mind $\mathrm{Ag}(\mathrm{I})$ ionok, mind $\mathrm{DNS}$ jelenlétében a fehérje „olvadása” egy lépésben játszódik le, amelynek magyarázata nagy valószínűséggel a DNS-kötő domén különböző kölcsönhatások általi stabilizációja. Ez a megfigyelés összhangban van a CueR fémion-szelektív, allosztérikus szabályozó mechanizmusával. $[17,20]$

A CueR fémion-kötő sajátságainak és a $\mathrm{CCHH}$ motívum szerepének vizsgálata céljából tanulmányoztuk a natív és a mutáns CueR fehérjék kölcsönhatását $\mathrm{Hg}(\mathrm{II}), \mathrm{Cd}(\mathrm{II})$ és $\operatorname{Ag}(\mathrm{I})$ ionokkal. A WT CueR és $\Delta \mathrm{C} 7-\mathrm{CueR}$ fehérjék növekvő $\mathrm{Hg}(\mathrm{II})$ koncentrációk mellett felvett tömegspektrumai azt bizonyították, hogy a $\mathrm{Hg}(\mathrm{II})$ a natív fehérjében két kötőhelyhez, a C112 és C120 aminosavakat magába foglaló fémion-kötő hurokhoz, illetve a $C$-terminálishoz közeli $\mathrm{CCHH}$ motívumhoz, is képes koordinálódni. $\mathrm{A} \mathrm{Hg}(\mathrm{II})$ ionok CueR-hez való kötődését a $\mathrm{Hg}(\mathrm{II})-\mathrm{WT}$ CueR és a $\mathrm{Hg}$ (II)- $\Delta$ C7-CueR rendszereken DNS jelenlétében, különböző $\mathrm{Hg}(\mathrm{II})$ - fehérje arányoknál (0.2:1, 1:1 and 2:1), $\mathrm{pH}=6,0$-n és pH = 8.0-n végzett ${ }^{199 \mathrm{~m} H g}$ PAC kísérletekkel vizsgáltuk. Az ekvimoláris összetételhez képest kisebb $\mathrm{Hg}(\mathrm{II})$ koncentrációk jelenlétében a natív fehérjéhez kötődő $\mathrm{Hg}(\mathrm{II})$ ionok különböző koordinációs geometriájú szerkezeteket alakítanak ki a két vizsgált pH-n. A pH =6,0-nál mért jelek egy lineáris, $\mathrm{HgS}_{2}$ koordinációs geometria kialakulására utalnak, míg $\mathrm{pH}=8,0$ nál egy lineáris $\mathrm{HgS}_{2}$ és egy $\mathrm{T}$-alakú $\mathrm{HgS}_{3}$ geometriájú részecske egyidejüleg van jelen a rendszerben. A Hg(II)-WT CueR rendszerben mért UV abszorpciós spektrumsorozatból 
meghatároztuk a fehérjével kialakuló $\mathrm{HgS}_{2}$ és $\mathrm{HgS}_{3}$ szerkezetek moláris abszorbanciáját. A meghatározott értékek jó egyezést mutatnak az irodalomban ugyanilyen koordinációs környezetü $\mathrm{Hg}(\mathrm{II})$-centrumokra közölt adatokkal. Ellentétben a natív fehérjével, a $\mathrm{Hg}$ (II)$\triangle$ C7-CueR rendszerben elvégzett ${ }^{199} \mathrm{~m} H \mathrm{PAC}$ és UV abszorpciós mérések kizárólag a lineáris $\mathrm{HgS}_{2}$ koordinációs geometria kialakulását mutatták. Ezek az eredmények azt igazolják, hogy a WT CueR fehérjével kialakuló $\mathrm{HgS}_{3}$ szerkezetben a harmadik tiolátcsoport a $\mathrm{CCHH}$ motívum valamelyik ciszteinjétől származik. Ebből pedig arra a következtethetünk, hogy a CueR egyértékü fémionokra vonatkozó szelektivitásának oka lehet a $\mathrm{CCHH}$ motívum kétértékü fémionok koordinációjában való részvétele, ami sztérikusan megakadályozza a $C$-terminális hélix bekötődését a hidrofób zsebbe,[17] és ezáltal gátolja a transzkripció folyamatának aktiválását.

$\mathrm{Az} \operatorname{Ag}(\mathrm{I})$ és $\mathrm{Cd}(\mathrm{II})$ ionok WT CueR fehérjéhez való kötődését szintén megvizsgáltuk ESI-MS spektrometriával. A Cd(II) jelenlétében felvett spektrumok hasonló tendenciát mutattak, mint a $\mathrm{Hg}(\mathrm{II})$ ionokkal mértek: a $\mathrm{Cd}(\mathrm{II})$ ionok is képesek a natív fehérje mindkét potenciális kötőhelyéhez kötődni meglehetősen nagy affinitással. Ezzel ellentétben az $\operatorname{Ag}(\mathrm{I})$ ionok csak a fémionkötő hurokhoz kötődnek, amit az MS spektrumokon az $\mathrm{Ag}_{2}-\mathrm{CueR}$ komplexnek megfelelő jelek hiánya mutatott.

${ }^{111} \mathrm{Ag}$ PAC spektroszkópiával is tanulmányoztuk a WT CueR, a $\Delta \mathrm{C} 7-\mathrm{CueR}$ és az S77C- $\Delta$ C7-CueR fehérjék kölcsönhatását $\mathrm{Ag}(\mathrm{I})$ ionokkal. A méréseket $-196{ }^{\circ} \mathrm{C}$-on végeztük annak érdekében, hogy megakadályozzuk vagy lelassítsuk a ${ }^{111} \mathrm{Ag}$ anyaizotóp ${ }^{111} \mathrm{Cd}$ izotóppá történő radioaktív bomlását kísérő szerkezeti relaxációt. A natív és a $\Delta \mathrm{C} 7$ CueR fehérjékkel mért ${ }^{111} \mathrm{Ag}$ spektrumok nagyon hasonlóak, ami igazolja, hogy a $C$ terminális $\mathrm{CCHH}$ motívum nem játszik közvetlen szerepet az $\mathrm{Ag}(\mathrm{I})$ megkötésében, és ez lehetővé teszi az aktivátor konformáció kialakulását. Az S77C- $\Delta \mathrm{C} 7-\mathrm{CueR}$ fehérje ${ }^{111} \mathrm{Ag}$ PAC spektruma az előzőktől jelentősen eltér, melynek oka feltehetőleg az, hogy a térben a közeli C77 oldallánca egy további tiolát donorcsoportot szolgáltat a koordinálódó fémion számára. A PAC mérésekből nyert adatok azt sugallják, hogy a C77 koordinálódik a radioaktív bomlás során keletkező alapállapotú Cd(II) ionhoz, ezzel hármas, vagy nagyobb koordinációs-számú komplexeket hozva létre.

A ${ }^{111} \mathrm{Ag}$ PAC spektroszkópiai mérések kiváló betekintést nyújtottak a CueR fémionkötő helyén lejátszódó folyamatok dinamikájába, melyek az $\operatorname{Ag}(\mathrm{I})-\mathrm{Cd}(\mathrm{II})$ átalakulással járó pillanatszerü elemátalakulást és oxidációs szám változást kísérik. A natív fehérje $-196{ }^{\circ} \mathrm{C}-\mathrm{n}$ felvett ${ }^{111} \mathrm{Ag}$ PAC spektruma két nukleáris kvadrupól kölcsönhatást 
(NQI) jelez. Ezek egyike egy torzult lineáris szerkezethez rendelhető, amelyben két tiolátcsoport kötődése mellett a nagyobb távolságra lévő S77 karbonilcsoport oxigénje is kapcsolódhat a fémionhoz, míg a másik NQI egy nagyobb koordinációs számú szerkezetre jellemző. Ezzel szemben az $1{ }^{\circ} \mathrm{C}-n$ mért PAC spektrum csak az utóbbi szerkezetre jellemző csúcsokat tartalmaz, ami azt jelzi, hogy a ${ }^{111} \mathrm{Ag}{ }^{111} \mathrm{Cd}$-má történő bomlásának időintervallumában megtörténik a fémion-kötő hely relaxációja ebbe a szerkezetbe. A WT CueR ${ }^{111 \mathrm{~m} C d}$ PAC spektruma ugyanakkor egy szimmetrikus koordinációs geometriájú, valószínüleg torzult tetraéderes $\mathrm{CdS}_{4}$ típusú részecske jelenlétére utal. A felsorolt eredmények arra engednek következtetni, hogy a CueR fémion-kötő helyének flexibilitása eltérő koordinációs módot és geometriát tesz lehetővé az egy- és kétértékű fémionok számára, s így a fehérje müködési mechanizmusának alapvető elemeként biztosítja a transzkripció egyértékü fémionokra szelektív aktiválását.

Végül, a CueR által szabályozott DNS promóter régió és egy zöld fluoreszcens fehérje (EGFP) génjének fuzionálásával kialakítottunk egy rézionokra érzékeny fluoreszcens tesztrendszert. A tesztrendszer müködését különböző E. coli törzsekben, úgy, mint BL21(DE3), BW25113 és AcueR BW25113 CueR knock-out, vizsgáltuk. Kimutattuk, hogy LB tápoldatban $1 \mathrm{mM}$, míg M9 minimál-tápoldatban már $10 \mu \mathrm{M}$ koncentrációban jelen lévő $\mathrm{Cu}(\mathrm{II})$ ionokhatására kifejeződik az EGFP fehérje. A CueR fehérje szelektivitásának köszönhetően Zn(II) ionok jelenléte, még $10 \mathrm{mM}$ koncentrációban sem indukálja az fluoreszcens fehérje termelődését. Felismertük az endogén CueR zavaró hatását is, majd a tesztrendszer $\triangle c u e R$ BW25113 sejtekben való alkalmazásával kiküszöböltük azt. A jelen munkában bemutatott eredmények alapján a tesztrendszer további optimalizálása és jellemzése is lehetséges.

A dolgozatomban bemutatott eredmények hozzájárulnak a bakteriális fémionszabályzó mechanizmusok megértéséhez, valamint reményeink szerint elősegíthetik a fémionok szelektív megkötésére/akkumulációjára alkalmas molekulák tervezését, illetve fémionok érzékeny és szelektív kimutatására alkalmas módszerek fejlesztését. 


\section{REFERENCES}

[1] R. Crichton, Biological Inorganic Chemistry (Third Edition), Academic Press, 2019, 1-18.

[2] Z. Ma, F. E. Jacobsen, D. P. Giedroc, Coordination chemistry of bacterial metal transport and sensing, Chemical Reviews, 2009, 109, 4644-4681.

[3] A. O. Summers, Damage control: regulating defenses against toxic metals and metalloids, Current Opinion in Microbiology, 2009, 12, 138-144.

[4] H. Reyes-Caballero, G. C. Campanello, D. P. Giedroc, Metalloregulatory proteins: Metal selectivity and allosteric switching, Biophysical Chemistry, 2011, 156, 103-114.

[5] D. P. Giedroc, A. I. Arunkumar, Metal sensor proteins: nature's metalloregulated allosteric switches, Dalton Transactions, 2007, 3107-3120.

[6] C. M. Phillips, E. R. Schreiter, Y. Guo, S. C. Wang, D. B. Zamble, C. L. Drennan, Structural Basis of the Metal Specificity for Nickel Regulatory Protein NikR, Biochemistry, 2008, 47, 1938-1946.

[7] P. A. Cobine, G. N. George, C. E. Jones, W. A. Wickramasinghe, M. Solioz, C. T. Dameron, Copper Transfer from the $\mathrm{Cu}(\mathrm{I})$ Chaperone, CopZ, to the Repressor, Zn(II)CopY: Metal Coordination Environments and Protein Interactions, Biochemistry, 2002, 41, 5822-5829.

[8] K. R. Brocklehurst, J. L. Hobman, B. Lawley, L. Blank, S. J. Marshall, N. L. Brown, A. P. Morby, ZntR is a $\mathrm{Zn}(\mathrm{II})$-responsive MerR-like transcriptional regulator of zntA in Escherichia coli, Molecular Microbiology, 1999, 31, 893-902.

[9] J. L. Hobman, J. Wilkie, N. L. Brown, A Design for Life: Prokaryotic Metal-binding MerR Family Regulators, Biometals, 2005, 18, 429-436.

[10] J. V. Stoyanov, J. L. Hobman, S. P. Kidd, N. L. Brown, The MerR family of transcriptional regulators, FEMS Microbiology Reviews, 2003, 27, 145-163.

[11] J. Parkhill, N. L. Brown, Site-specific insertion and deletion mutants in the mer promoteroperator region of Tn501; the nineteen base-pair spacer is essential for normal induction of the promoter by MerR, Nucleic acids research, 1990, 18, 5157-5162.

[12] E. H. Kim, D. H. Nies, M. M. McEvoy, C. Rensing, Switch or Funnel: How RND-Type Transport Systems Control Periplas mic Metal Homeostasis, Journal of Bacteriology, 2011, 193, 2381-2387.

[13] C. Rademacher, B. Masepohl, Copper-responsive gene regulation in bacteria, Microbiology, 2012, 158, 2451-2464.

[14] K. Yamamoto, A. Ishihama, Transcriptional response of Escherichia coli to external copper, Molecular Microbiology, 2005, 56, 215-227.

[15] J. V. Stoyanov, J. L. Hobman, N. L. Brown, CueR (YbbI) of Escherichia coli is a MerR family regulator controlling expression of the copper exporter CopA, Molecular Microbiology, 2001, 39, 502-512.

[16] A. Changela, K. Chen, Y. Xue, J. Holschen, C. E. Outten, T. V. Halloran, A. Mondragón, Molecular Basis of Metal-Ion Selectivity and Zeptomolar Sensitivity by CueR, Science, 2003, 301, 1383.

[17] S. J. Philips, M. Canalizo-Hernandez, I. Yildirim, G. C. Schatz, A. Mondragón, T. V. O'Halloran, TRANSCRIPTION. Allosteric transcriptional regulation via changes in the overall topology of the core promoter, Science (New York, N.Y.), 2015, 349, 877-881. 
[18] K. Chen, S. Yuldasheva, J. E. Penner-Hahn, T. V. O'Halloran, An Atypical Linear Cu(I)-S2 Center Constitutes the High-Affinity Metal-Sensing Site in the CueR Metalloregulatory Protein, Journal of the American Chemical Society, 2003, 125, 12088-12089.

[19] J. V. Stoyanov, N. L. Brown, The Escherichia coli Copper-responsivecopA Promoter Is Activated by Gold, Journal of Biological Chemistry, 2003, 278, 1407-1410.

[20] H. Sameach, A. Narunsky, S. Azoulay-Ginsburg, L. Gevorkyan-Aiapetov, Y. Zehavi, Y. Moskovitz, T. Juven-Gershon, N. Ben-Tal, S. Ruthstein, Structural and Dynamics Characterization of the MerR Family Metalloregulator CueR in its Repression and Activation States, Structure, 2017, 25, 988-996.e983.

[21] N. M. Andoy, S. K. Sarkar, Q. Wang, D. Panda, J. J. Benítez, A. Kalininskiy, P. Chen, Single-Molecule Study of Metalloregulator CueR-DNA Interactions Using Engineered Holliday Junctions, Biophysical Journal, 2009, 97, 844-852.

[22] C. P. Joshi, D. Panda, D. J. Martell, N. M. Andoy, T.-Y. Chen, A. Gaballa, J. D. Helmann, P. Chen, Direct substitution and assisted dissociation pathways for turning off transcription by a MerR-family metalloregulator, Proceedings of the National Academy of Sciences, 2012, 109, 15121.

[23] T. Y. Chen, A. G. Santiago, W. Jung, Ł. Krzemiński, F. Yang, D. J. Martell, J. D. Helmann, P. Chen, Concentration- and chromosome-organization-dependent regulator unbinding from DNA for transcription regulation in living cells, Nature Communications, 2015, 6, 7445 .

[24] T. Y. Chen, Y. S. Cheng, P.-S. Huang, P. Chen, Facilitated Unbinding via MultivalencyEnabled Ternary Complexes: New Paradigm for Protein-DNA Interactions, Accounts of Chemical Research, 2018, 51, 860-868.

[25] D. C. Bebout, Mercury: Inorganic \& Coordination Chemistry Based in part on the article Mercury: Inorganic \& Coordination Chemistry by Gregory J. Grant which appeared in the Encyclopedia of Inorganic Chemistry, First Edition, Encyclopedia of Inorganic and Bioinorganic Chemistry, 2011.

[26] L. Rao, Q. Cui, X. Xu, Electronic Properties and Desolvation Penalties of Metal Ions Plus Protein Electrostatics Dictate the Metal Binding Affinity and Selectivity in the Copper Efflux Regulator, Journal of the American Chemical Society, 2010, 132, 18092-18102.

[27] D. Szunyogh, H. Szokolai, P. W. Thulstrup, F. H. Larsen, B. Gyurcsik, N. J. Christensen, M. Stachura, L. Hemmingsen, A. Jancsó, Specificity of the Metalloregulator CueR for Monovalent Metal Ions: Possible Functional Role of a Coordinated Thiol?, Angewandte Chemie International Edition, 2015, 54, 15756-15761.

[28] C. C. Chang, L. Y. Lin, X. W. Zou, C. C. Huang, N. L. Chan, Structural basis of the mercury(II)-mediated conformational switching of the dual-function transcriptional regulator MerR, Nucleic acids research, 2015, 43, 7612-7623.

[29] D. Wang, S. Huang, P. Liu, X. Liu, Y. He, W. Chen, Q. Hu, T. Wei, J. Gan, J. Ma, H. Chen, Structural Analysis of the $\mathrm{Hg}(\mathrm{II})$-Regulatory Protein Tn501 MerR from Pseudomonas aeruginosa, Scientific Reports, 2016, 6, 33391.

[30] D. M. Ralston, T. V. Halloran, Ultrasensitivity and heavy-metal selectivity of the allosterically modulated MerR transcription complex, Proceedings of the National Academy of Sciences, 1990, 87, 3846.

[31] C. E. Outten, Halloran, V. Thomas, Femtomolar Sensitivity of Metalloregulatory Proteins Controlling Zinc Homeostasis, Science, 2001, 292, 2488.

[32] Y. Hitomi, C. E. Outten, T. V. O'Halloran, Extreme Zinc-Binding Thermodynamics of the Metal Sensor/Regulator Protein, ZntR, Journal of the American Chemical Society, 2001, $123,8614-8615$. 
[33] X. Jian, E. C. Wasinger, J. V. Lockard, L. X. Chen, C. He, Highly Sensitive and Selective Gold(I) Recognition by a Metalloregulator in Ralstonia metallidurans, Journal of the American Chemical Society, 2009, 131, 10869-10871.

[34] S. K. Checa, M. Espariz, M. E. P. Audero, P. E. Botta, S. V. Spinelli, F. C. Soncini, Bacterial sensing of and resistance to gold salts, Molecular Microbiology, 2007, 63, 13071318.

[35] S. Cerminati, F. C. Soncini, S. K. Checa, A sensitive whole-cell biosensor for the simultaneous detection of a broad-spectrum of toxic heavy metal ions, Chemical Communications, 2015, 51, 5917-5920.

[36] M. M. Ibáñez, S. K. Checa, F. C. Soncini, A Single Serine Residue Determines Selectivity to Monovalent Metal Ions in Metalloregulators of the MerR Family, Journal of Bacteriology, 2015, 197, 1606.

[37] K. J. Waldron, N. J. Robinson, How do bacterial cells ensure that metalloproteins get the correct metal?, Nature Reviews Microbiology, 2009, 7, 25.

[38] S. Tottey, D. R. Harvie, N. J. Robinson, Understanding How Cells Allocate Metals Using Metal Sensors and Metallochaperones, Accounts of Chemical Research, 2005, 38, 775-783.

[39] M. A. Pennella, D. P. Giedroc, Structural Determinants of Metal Selectivity in Prokaryotic Metal-responsive Transcriptional Regulators, Biometals, 2005, 18, 413-428.

[40] M. V. Golynskiy, W. A. Gunderson, M. P. Hendrich, S. M. Cohen, Metal Binding Studies and EPR Spectroscopy of the Manganese Transport Regulator MntR, Biochemistry, 2006, $45,15359-15372$.

[41] J. S. Cavet, W. Meng, M. A. Pennella, R. J. Appelhoff, D. P. Giedroc, N. J. Robinson, A Nickel-Cobalt-sensing ArsR-SmtB Family Repressor: CONTRIBUTIONS OF CYTOSOL AND EFFECTOR BINDING SITES TO METAL SELECTIVITY, Journal of Biological Chemistry, 2002, 277, 38441-38448.

[42] P. R. Chen, C. He, Selective recognition of metal ions by metalloregulatory proteins, Current Opinion in Chemical Biology, 2008, 12, 214-221.

[43] K. Yagi, Applications of whole-cell bacterial sensors in biotechnology and environmental science, Applied Microbiology and Biotechnology, 2007, 73, 1251-1258.

[44] S. Magrisso, Y. Erel, S. Belkin, Microbial reporters of metal bioavailability, Microbial Biotechnology, 2008, 1, 320-330.

[45] F. Lagarde, N. Jaffrezic-Renault, Cell-based electrochemical biosensors for water quality assessment, Analytical and Bioanalytical Chemistry, 2011, 400, 947.

[46] Y. Lei, W. Chen, A. Mulchandani, Microbial biosensors, Analytica Chimica Acta, 2006, $568,200-210$.

[47] L. T. Bereza-Malcolm, G. Mann, A. E. Franks, Environmental Sensing of Heavy Metals Through Whole Cell Microbial Biosensors: A Synthetic Biology Approach, ACS Synthetic Biology, 2015, 4, 535-546.

[48] K. Hakkila, M. Maksimow, M. Karp, M. Virta, Reporter Genes lucFF, luxCDABE, gfp, and dsred Have Different Characteristics in Whole-Cell Bacterial Sensors, Analytical Biochemistry, 2002, 301, 235-242.

[49] T. Charrier, M. J. Durand, M. Affi, S. Jouanneau, H. Gezekel, G. Thouand, in Biosensors (Ed.: P. A. Serra), InTech, Rijeka, 2010, p. Ch. 11.

[50] J. A. J. Arpino, P. J. Rizkallah, D. D. Jones, Crystal Structure of Enhanced Green Fluorescent Protein to $1.35 \AA$ Resolution Reveals Alternative Conformations for Glu222, PLOS ONE, 2012, 7, e47132. 
[51] N. C. Shaner, G. H. Patterson, M. W. Davidson, Advances in fluorescent protein technology, Journal of Cell Science, 2007, 120, 4247.

[52] J. Lippincott-Schwartz, G. H. Patterson, Development and Use of Fluorescent Protein Markers in Living Cells, Science, 2003, 300, 87.

[53] M.-H. Joe, K.-H. Lee, S.-Y. Lim, S.-H. Im, H.-P. Song, I. S. Lee, D.-H. Kim, Pigmentbased whole-cell biosensor system for cadmium detection using genetically engineered Deinococcus radiodurans, Bioprocess and Biosystems Engineering, 2012, 35, 265-272.

[54] F. F. Roberto, J. M. Barnes, D. F. Bruhn, Evaluation of a GFP reporter gene construct for environmental arsenic detection, Talanta, 2002, 58, 181-188.

[55] Y. Yoon, S. Kim, Y. Chae, S. W. Kim, Y. Kang, G. An, S.-W. Jeong, Y.-J. An, Simultaneous detection of bioavailable arsenic and cadmium in contaminated soils using dual-sensing bioreporters, Applied Microbiology and Biotechnology, 2016, 100, 37133722 .

[56] M. Virta, J. Lampinen, M. Karp, A Luminescence-Based Mercury Biosensor, Analytical Chemistry, 1995, 67, 667-669.

[57] L. Bereza-Malcolm, S. Aracic, R. Kannan, G. Mann, A. E. Franks, Functional characterization of Gram-negative bacteria from different genera as multiplex cadmium biosensors, Biosensors and Bioelectronics, 2017, 94, 380-387.

[58] C. E. Raja, G. S. Selvam, Construction of green fluorescent protein based bacterial biosensor for heavy metal remediation, International Journal of Environmental Science \& Technology, 2011, 8, 793-798.

[59] R. Branco, A. Cristóvão, P. V. Morais, Highly Sensitive, Highly Specific Whole-Cell Bioreporters for the Detection of Chromate in Environmental Samples, PLOS ONE, 2013, 8 , e54005.

[60] L. Bereza-Malcolm, S. Aracic, E. A. Franks, Development and Application of a Synthetically-Derived Lead Biosensor Construct for Use in Gram-Negative Bacteria, Sensors, 2016, 16.

[61] L. Peca, P. B. Kós, Z. Máté, A. Farsang, I. Vass, Construction of bioluminescent cyanobacterial reporter strains for detection of nickel, cobalt and zinc, FEMS Microbiology Letters, 2008, 289, 258-264.

[62] K. Tag, K. Riedel, H.-J. Bauer, G. Hanke, K. H. R. Baronian, G. Kunze, Amperometric detection of $\mathrm{Cu} 2+$ by yeast biosensors using flow injection analysis (FIA), Sensors and Actuators B: Chemical, 2007, 122, 403-409.

[63] A. Tom-Petersen, C. Hosbond, O. Nybroe, Identification of copper-induced genes in Pseudomonas fluorescens and use of a reporter strain to monitor bioavailable copper in soil, FEMS Microbiology Ecology, 2001, 38, 59-67.

[64] S. Ravikumar, I. Ganesh, I.-k. Yoo, S. H. Hong, Construction of a bacterial biosensor for zinc and copper and its application to the development of multifunctional heavy metal adsorption bacteria, Process Biochemistry, 2012, 47, 758-765.

[65] T. Charrier, M.-J. Durand, S. Jouanneau, M. Dion, M. Pernetti, D. Poncelet, G. Thouand, A multi-channel bioluminescent bacterial biosensor for the on-line detection of metals and toxicity. Part I: design and optimization of bioluminescent bacterial strains, Analytical and Bioanalytical Chemistry, 2011, 400, 1051-1060.

[66] K. Riether, M. A. Dollard, P. Billard, Assessment of heavy metal bioavailability using Escherichia coli zntAp::lux and copAp::lux-based biosensors, Applied Microbiology and Biotechnology, 2001, 57, 712-716. 
[67] J. R. van der Meer, S. Belkin, Where microbiology meets microengineering: design and applications of reporter bacteria, Nature Reviews Microbiology, 2010, 8, 511.

[68] I. Biran, D. M. Rissin, E. Z. Ron, D. R. Walt, Optical imaging fiber-based live bacterial cell array biosensor, Analytical Biochemistry, 2003, 315, 106-113.

[69] E. Eltzov, A. Yehuda, R. S. Marks, Creation of a new portable biosensor for water toxicity determination, Sensors and Actuators B: Chemical, 2015, 221, 1044-1054.

[70] S. H. Choi, M. B. Gu, A portable toxicity biosensor using freeze-dried recombinant bioluminescent bacteria, Biosensors and Bioelectronics, 2002, 17, 433-440.

[71] J. V. Stoyanov, D. Magnani, M. Solioz, Measurement of cytoplas mic copper, silver, and gold with a lux biosensor shows copper and silver, but not gold, efflux by the CopA ATPase of Escherichia coli, FEBS Letters, 2003, 546, 391-394.

[72] iGEM, http://2015.igem.org/Team:Bielefeld-CeBiTec/Project/HeavyMetals (2019, May 29).

[73] iGEM, http://parts.igem.org/Part:BBa_K1758320 (2019, May 29).

[74] L. Bereza-Malcolm, S. Aracic, G. Mann, A. E. Franks, The development and analyses of several Gram-negative arsenic biosensors using a synthetic biology approach, Sensors and Actuators B: Chemical, 2018, 256, 117-125.

[75] R. Fernandez-López, R. Ruiz, F. de la Cruz, G. Moncalián, Transcription factor-based biosensors enlightened by the analyte, Frontiers in Microbiology, 2015, 6, 648.

[76] C. H. Wu, D. Le, A. Mulchandani, W. Chen, Optimization of a whole-cell cadmium sensor with a toggle gene circuit, Biotechnology Progress, 2009, 25, 898-903.

[77] S. Cerminati, F. C. Soncini, S. K. Checa, Selective detection of gold using genetically engineered bacterial reporters, Biotechnology and Bioengineering, 2011, 108, 2553-2560.

[78] S. K. Checa, M. D. Zurbriggen, F. C. Soncini, Bacterial signaling systems as platforms for rational design of new generations of biosensors, Current Opinion in Biotechnology, 2012, 23, 766-772.

[79] G. M. Cooper, R. E. Hausman, The cell : a molecular approach, 2018.

[80] D. Whitford, Proteins : structure and function, J. Wiley \& Sons, Chichester, West Sussex, 2013.

[81] K. L. Tee, T. S. Wong, Polishing the craft of genetic diversity creation in directed evolution, Biotechnology Advances, 2013, 31, 1707-1721.

[82] Strategies for Protein Purification Handbook, GE Healthcare Bio-Sciences AB, 2010.

[83] M. G. Fried, Measurement of protein-DNA interaction parameters by electrophoresis mobility shift assay, Electrophoresis, 1989, 10, 366-376.

[84] L. M. Hellman, M. G. Fried, Electrophoretic mobility shift assay (EMSA) for detecting protein-nucleic acid interactions, Nature Protocols, 2007, 2, 1849.

[85] B. J. S. C. Olson, J. Markwell, Assays for Determination of Protein Concentration, Current Protocols in Protein Science, 2007, 48, 3.4.1-3.4.29.

[86] S. M. Rutherfurd, G. S. Gilani, Amino Acid Analysis, Current Protocols in Protein Science, 2009, 58, 11.19.11-11.19.37.

[87] J. Greaves, J. Roboz, Mass spectrometry for the novice, CRC ; Taylor \& Francis [distributor], Boca Raton, Fla.; London, 2011.

[88] R. A. Zubarev, A. Makarov, Orbitrap Mass Spectrometry, Analytical Chemistry, 2013, 85, 5288-5296. 
[89] R. Aebersold, D. R. Goodlett, Mass Spectrometry in Proteomics, Chemical Reviews, 2001, 101, 269-296.

[90] K. F. Medzihradszky, R. J. Chalkley, Lessons in de novo peptide sequencing by tandem mass spectrometry, Mass Spectrometry Reviews, 2015, 34, 43-63.

[91] I. A. Papayannopoulos, The interpretation of collision-induced dissociation tandem mass spectra of peptides, Mass Spectrometry Reviews, 1995, 14, 49-73.

[92] N. V. Bhagavan, in Medical Biochemistry (Fourth Edition) (Ed.: N. V. Bhagavan), Academic Press, San Diego, 2002, pp. 51-65.

[93] S. M. Kelly, T. J. Jess, N. C. Price, How to study proteins by circular dichroism, Biochimica et Biophysica Acta (BBA) - Proteins and Proteomics, 2005, 1751, 119-139.

[94] L. Whitmore, B. A. Wallace, Protein secondary structure analyses from circular dichroism spectroscopy: Methods and reference databases, Biopolymers, 2008, 89, 392-400.

[95] N. Sreerama, S. Y. Venyaminov, R. W. Woody, Estimation of the number of alpha-helical and beta-strand segments in proteins using circular dichroism spectroscopy, Protein Science : A Publication of the Protein Society, 1999, 8, 370-380.

[96] G. Böhm, R. Muhr, R. Jaenicke, Quantitative analysis of protein far UV circular dichroism spectra by neural networks, Protein Engineering, 1992, 5, 191-195.

[97] A. Perczel, K. Park, G. D. Fasman, Deconvolution of the circular dichroism spectra of proteins: The circular dichroism spectra of the antiparallel $\beta$-sheet in proteins, Proteins: Structure, Function, and Bioinformatics, 1992, 13, 57-69.

[98] A. Micsonai, F. Wien, L. Kernya, Y.-H. Lee, Y. Goto, M. Réfrégiers, J. Kardos, Accurate secondary structure prediction and fold recognition for circular dichroism spectroscopy, Proceedings of the National Academy of Sciences, 2015, 112, E3095-E3103.

[99] J. R. Lakowicz, Principles of Fluorescence Spectroscopy (Ed.: J. R. Lakowicz), Springer US, Boston, MA, 2006, pp. 1-26.

[100] J. Kapuscinski, DAPI: a DNA-Specific Fluorescent Probe, Biotechnic \& Histochemistry, 1995, 70, 220-233.

[101] J. R. Lakowicz, Principles of Fluorescence Spectroscopy (Ed.: J. R. Lakowicz), Springer US, Boston, MA, 2006, pp. 27-61.

[102] J. W. Lichtman, J.-A. Conchello, Fluorescence microscopy, Nature Methods, 2005, 2, 910919.

[103] L. Hemmingsen, K. N. Sas, E. Danielsen, Biological Applications of Perturbed Angular Correlations of $\gamma$-Ray Spectroscopy, Chemical Reviews, 2004, 104, 4027-4062.

[104] A. Jancso, J. G. Correia, A. Gottberg, J. Schell, M. Stachura, D. Szunyogh, S. Pallada, D. C. Lupascu, M. Kowalska, L. Hemmingsen, TDPAC and $\beta-N M R$ applications in chemistry and biochemistry, Journal of Physics G: Nuclear and Particle Physics, 2017, 44, 064003.

[105] S. Chakraborty, S. Pallada, J. T. Pedersen, A. Jancso, J. G. Correia, L. Hemmingsen, Nanosecond Dynamics at Protein Metal Sites: An Application of Perturbed Angular Correlation (PAC) of $\gamma$-Rays Spectroscopy, Accounts of Chemical Research, 2017, 50, 2225-2232.

[106] F. W. Outten, C. E. Outten, J. Hale, T. V. O'Halloran, Transcriptional Activation of an Escherichia coliCopper Efflux Regulon by the Chromosomal MerR Homologue, CueR, Journal of Biological Chemistry, 2000, 275, 31024-31029.

[107] R. Crichton, in Biological Inorganic Chemistry (Third Edition) (Ed.: R. Crichton), Academic Press, 2019, pp. 81-118. 
[108] W. Kabsch, C. Sander, Dictionary of protein secondary structure: Pattern recognition of hydrogen-bonded and geometrical features, Biopolymers, 1983, 22, 2577-2637.

[109] E. Langella, R. Improta, V. Barone, Checking the pH-Induced Conformational Transition of Prion Protein by Molecular Dynamics Simulations: Effect of Protonation of Histidine Residues, Biophysical Journal, 2004, 87, 3623-3632.

[110] D. O. V. Alonso, C. An, V. Daggett, Simulations of biomolecules: characterization of the early steps in the $\mathrm{pH}$-induced conformational conversion of the hamster, bovine and human forms of the prion protein, Philosophical Transactions of the Royal Society of London. Series A: Mathematical, Physical and Engineering Sciences, 2002, 360, 1165-1178.

[111] J. W. Kelly, The environmental dependency of protein folding best explains prion and amyloid diseases, Proceedings of the National Academy of Sciences, 1998, 95, 930-932.

[112] D. O. V. Alonso, S. J. DeArmond, F. E. Cohen, V. Daggett, Mapping the early steps in the $\mathrm{pH}$-induced conformational conversion of the prion protein, Proceedings of the National Academy of Sciences, 2001, 98, 2985-2989.

[113] V. Cabra, R. Arreguin, R. Vazquez-Duhalt, A. Farres, Effect of temperature and pH on the secondary structure and processes of oligomerization of $19 \mathrm{kDa}$ alpha-zein, Biochimica et Biophysica Acta (BBA) - Proteins and Proteomics, 2006, 1764, 1110-1118.

[114] S. H. Yoo, J. P. Albanesi, High capacity, low affinity Ca2+ binding of chromogranin A. Relationship between the $\mathrm{pH}$-induced conformational change and $\mathrm{Ca} 2+$ binding property, Journal of Biological Chemistry, 1991, 266, 7740-7745.

[115] R. Kun, M. Szekeres, I. Dékány, Isothermal titration calorimetric studies of the $\mathrm{pH}$ induced conformational changes of bovine serum albumin, Journal of Thermal Analysis and Calorimetry, 2009, 96, 1009-1017.

[116] N. Leloup, P. Lössl, D. H. Meijer, M. Brennich, A. J. R. Heck, D. M. E. Thies-Weesie, B. J. C. Janssen, Low $\mathrm{pH}$-induced conformational change and dimerization of sortilin triggers endocytosed ligand release, Nature Communications, 2017, 8, 1708.

[117] A. Bañares-Hidalgo, J. Pérez-Gil, P. Estrada, Acidic pH triggers conformational changes at the NH2-terminal propeptide of the precursor of pulmonary surfactant protein $\mathrm{B}$ to form a coiled coil structure, Biochimica et Biophysica Acta (BBA) - Biomembranes, 2014, 1838, 1738-1751.

[118] A. Puhar, E. A. Johnson, O. Rossetto, C. Montecucco, Comparison of the pH-induced conformational change of different clostridial neurotoxins, Biochemical and Biophysical Research Communications, 2004, 319, 66-71.

[119] P. A. Nguyen, C. S. Soto, A. Polishchuk, G. A. Caputo, C. D. Tatko, C. Ma, Y. Ohigashi, L. H. Pinto, W. F. DeGrado, K. P. Howard, pH-Induced Conformational Change of the Influenza M2 Protein C-Terminal Domain, Biochemistry, 2008, 47, 9934-9936.

[120] S. Kannan, R. Shankar, P. Kolandaivel, Insights into structural and inhibitory mechanisms of low pH-induced conformational change of influenza HA2 protein: a computational approach, Journal of Molecular Modeling, 2019, 25, 99.

[121] J. S. Harrison, C. D. Higgins, M. J. O’Meara, J. F. Koellhoffer, B. A. Kuhlman, J. R. Lai, Role of Electrostatic Repulsion in Controlling pH-Dependent Conformational Changes of Viral Fusion Proteins, Structure, 2013, 21, 1085-1096.

[122] V. Mishra, A. Kumar, V. Ali, K. Y. J. Zhang, T. Nozaki, Characterization of pH-induced transitions of Entamoeba histolytica d-phosphoglycerate dehydrogenase, International Journal of Biological Macromolecules, 2015, 79, 284-289.

[123] E. R. Georgieva, A. J. Narvaez, N. Hedin, A. Gräslund, Secondary structure conversions of Mycobacterium tuberculosis ribonucleotide reductase protein $\mathrm{R} 2$ under varying $\mathrm{pH}$ and temperature conditions, Biophysical Chemistry, 2008, 137, 43-48. 
[124] N. V. Di Russo, D. A. Estrin, M. A. Martí, A. E. Roitberg, pH-Dependent Conformational Changes in Proteins and Their Effect on Experimental pK(a)s: The Case of Nitrophorin 4, PLoS Computational Biology, 2012, 8, e1002761.

[125] H. Nar, A. Messerschmidt, R. Huber, M. van de Kamp, G. W. Canters, Crystal structure analysis of oxidized Pseudomonas aeruginosa azurin at $\mathrm{pH} 5 \cdot 5$ and $\mathrm{pH} 9 \cdot 0$ : $\mathrm{A} \mathrm{pH}$-induced conformational transition involves a peptide bond flip, Journal of Molecular Biology, 1991, $221,765-772$.

[126] A. B. Carius, P. Rogne, M. Duchoslav, M. Wolf-Watz, G. Samuelsson, T. Shutova, Dynamic $\mathrm{pH}$-induced conformational changes of the $\mathrm{PsbO}$ protein in the fluctuating acidity of the thylakoid lumen, Physiologia Plantarum, 2019, 166, 288-299.

[127] K. J. Yeo, Y.-S. Hong, J.-G. Jee, J. K. Lee, H. J. Kim, J.-W. Park, E.-H. Kim, E. Hwang, S.-Y. Kim, E.-G. Lee, O. Kwon, H.-K. Cheong, Mechanism of the pH-Induced Conformational Change in the Sensor Domain of the DraK Histidine Kinase via the E83, E105, and E107 Residues, PLOS ONE, 2014, 9, e107168.

[128] R. L. Thurlkill, G. R. Grimsley, J. M. Scholtz, C. N. Pace, pK values of the ionizable groups of proteins, Protein Science, 2006, 15, 1214-1218.

[129] G. R. Grimsley, J. M. Scholtz, C. N. Pace, A summary of the measured pK values of the ionizable groups in folded proteins, Protein Science : A Publication of the Protein Society, 2009, 18, 247-251.

[130] D. E. Anderson, W. J. Becktel, F. W. Dahlquist, pH-Induced denaturation of proteins: a single salt bridge contributes $3-5 \mathrm{kcal} / \mathrm{mol}$ to the free energy of folding of T4 lysozyme, Biochemistry, 1990, 29, 2403-2408.

[131] P. T. Chivers, K. E. Prehoda, B. F. Volkman, B.-M. Kim, J. L. Markley, R. T. Raines, Microscopic pKa Values of Escherichia coli Thioredoxin, Biochemistry, 1997, 36, 1498514991.

[132] H. Li, A. D. Robertson, J. H. Jensen, Very fast empirical prediction and rationalization of protein pKa values, Proteins: Structure, Function, and Bioinformatics, 2005, 61, 704-721.

[133] D. A. E. Cochran, S. Penel, A. J. Doig, Effect of the N1 residue on the stability of the $\alpha$ helix for all 20 amino acids, Protein Science, 2001, 10, 463-470.

[134] W. Kiyoko, M. Toshihisa, O. Jun-ichi, T. Toshiki, ph-Induced Conformational Change in An A- Helical Coiled-Coil is Controlled by His Residues in the Hydrophobic Core, Protein \& Peptide Letters, 2003, 10, 27-33.

[135] D. Szunyogh, B. Gyurcsik, F. H. Larsen, M. Stachura, P. W. Thulstrup, L. Hemmingsen, A. Jancsó, ZnII and HgII binding to a designed peptide that accommodates different coordination geometries, Dalton Transactions, 2015, 44, 12576-12588.

[136] A. Jancsó, B. Gyurcsik, E. Mesterházy, R. Berkecz, Competition of zinc(II) with cadmium(II) or mercury(II) in binding to a 12-mer peptide, Journal of Inorganic Biochemistry, 2013, 126, 96-103.

[137] A. Jancsó, D. Szunyogh, F. H. Larsen, P. W. Thulstrup, N. J. Christensen, B. Gyurcsik, L. Hemmingsen, Towards the role of metal ions in the structural variability of proteins: CdII speciation of a metal ion binding loop motif, Metallomics, 2011, 3, 1331-1339.

[138] T. M. DeSilva, G. Veglia, F. Porcelli, A. M. Prantner, S. J. Opella, Selectivity in heavy metal- binding to peptides and proteins, Biopolymers, 2002, 64, 189-197.

[139] R. Bauer, S. J. Jensen, B. Schmidt-Nielsen, The angular overlap model applied to the calculation of nuclear quadrupole interactions, Hyperfine Interactions, 1988, 39, 203-234.

[140] A. Manceau, K. L. Nagy, Relationships between $\mathrm{Hg}(\mathrm{ii})-\mathrm{S}$ bond distance and $\mathrm{Hg}$ (ii) coordination in thiolates, Dalton Transactions, 2008, 1421-1425. 
[141] O. Iranzo, P. W. Thulstrup, S.-b. Ryu, L. Hemmingsen, V. L. Pecoraro, The Application of 199Hg NMR and 199mHg Perturbed Angular Correlation (PAC) Spectroscopy to Define the Biological Chemistry of HgII: A Case Study with Designed Two- and Three-Stranded Coiled Coils, Chemistry - A European Journal, 2007, 13, 9178-9190.

[142] J. G. Wright, M. J. Natan, F. M. MacDonnel, D. M. Ralston, T. V. O'Halloran, Mercury(II)-Thiolate Chemistry and the Mechanism of the Heavy Metal Biosensor MerR, Progress in Inorganic Chemistry, 1990.

[143] S. P. Watton, J. G. Wright, F. M. MacDonnell, J. W. Bryson, M. Sabat, T. V. O'Halloran, Trigonal mercuric complex of an aliphatic thiolate: a spectroscopic and structural model for the receptor site in the mercury(II) biosensor MerR, Journal of the American Chemical Society, 1990, 112, 2824-2826.

[144] G. R. Dieckmann, D. K. McRorie, D. L. Tierney, L. M. Utschig, C. P. Singer, T. V. O'Halloran, J. E. Penner-Hahn, W. F. DeGrado, V. L. Pecoraro, De Novo Design of Mercury-Binding Two- and Three-Helical Bundles, Journal of the American Chemical Society, 1997, 119, 6195-6196.

[145] F. Jalilehvand, B. O. Leung, M. Izadifard, E. Damian, Mercury(II) Cysteine Complexes in Alkaline Aqueous Solution, Inorganic Chemistry, 2006, 45, 66-73.

[146] E. Freisinger, Spectroscopic characterization of a fruit-specific metallothionein: M. acuminata MT3, Inorganica Chimica Acta, 2007, 360, 369-380.

[147] O. Schicht, E. Freisinger, Spectroscopic characterization of Cicer arietinum metallothionein 1, Inorganica Chimica Acta, 2009, 362, 714-724.

[148] X. Liu, Q. Hu, J. Yang, S. Huang, T. Wei, W. Chen, Y. He, D. Wang, Z. Liu, K. Wang, J. Gan, H. Chen, Selective cadmium regulation mediated by a cooperative binding mechanism in CadR, Proceedings of the National Academy of Sciences, 2019, 116, 20398.

[149] R. Bauer, E. Danielsen, L. Hemmingsen, M. J. Bjerrum, Ö. Hansson, K. Singh, Interplay between Oxidation State and Coordination Geometry of Metal Ions in Azurin, Journal of the American Chemical Society, 1997, 119, 157-162.

[150] M. Loos, C. Gerber, F. Corona, J. Hollender, H. Singer, Accelerated Isotope Fine Structure Calculation Using Pruned Transition Trees, Analytical Chemistry, 2015, 87, 5738-5744.

[151] T. Butz, S. Saibene, T. Fraenzke, M. Weber, A "TDPAC-camera", Nuclear Instruments and Methods in Physics Research Section A: Accelerators, Spectrometers, Detectors and Associated Equipment, 1989, 284, 417-421. 


\section{ACKNOWLEDGEMENT}

I wish to express my deepest gratitude to my supervisors, Dr. Attila Jancsó and Dr. Gyurcsik Béla. Their knowledge, expertise, consistent support and guidance assisted my scientific development since my second undergraduate year. I could not have asked for better mentors for my $\mathrm{PhD}$ project. I also thank them for the opportunities to travel and work abroad, and thereby becoming a part of the international scientific community.

I am thankful to Dr. Gábor Galbács and Dr. Tamás Kiss, as the current and the former Head of Department, for allowing me to carry out my $\mathrm{PhD}$ work in their laboratories.

I would like to say special thanks to Dr. Lars Hemmingsen for welcoming me as a guest PhD student at University of Copenhagen. His way of thinking about science always inspired me. I am also very grateful for his effective work and help in publishing papers.

I am thankful for our collaborators for the possibility to work in their excellent laboratories and for their professional help: Dr. Peter Waaben Thulstrup, Marianne Lund Jensen (University of Copenhagen, Denmark), Dr. Hans Erik Mølager Christensen, Dr. Michael Jensen (Technical University of Denmark), Dr. Kyosuke Nagata, Dr. Kohsuke Kato, Dr. Atsushi Kawaguchi, Dr. Masamitsu Noby Asaka, (University of Tsukuba, Japan), Dr. Éva Hunyadi-Gulyás, Dr. Valéria Bugris, Dr. Veronika Harmat (Biological Research Centre, Hungary), Dr. Juliana Schell (CERN, Switzerland), Dr. Nadica Ivošević DeNardis, Dr. Tea Mišić Radić (Ruđer Bošković Institute, Croatia), Dr. Nykola Jones, Dr. Søren Vrønning Hoffmann (University of Aarhus, Denmark), Dr. Beáta G. Vértessy (Budapest University of Technology and Economics, Hungary).

I owe many thanks to my love, family and friends for their continuous support, patience and inspiration that I was given during all these years.

Finally, thank you for the actual and former lab members, fellows in the $\mathrm{PhD}$ room, for the refreshing laughs and chats.

I would like to greatly acknowledge the financial support from the Hungarian National Research, Development and Innovation Office (GINOP-2.3.2-15-2016-00038 and K_16/120130), the New National Excellence Program of the Ministry of Human Capacities (NTP-EFÖ-P-15-0304-A, NTP-NFTÖ-16-0185 and NTP-NFTÖ-18-B-0137), the Balassi Institute in the „Campus Hungary” and „Campus Mundi” Program, the COST Action CA15126 ARBRE MOBIEU, the Japan Society for the Promotion of Science (JSPS) and the European Union's Horizon 2020 Framework research and innovation (ENSAR2 and CALIPSOplus). 


\section{Publication list}

Identification number in the Hungarian Collection of Scientific

Publications (MTMT): 10054977

\section{Publications related to the dissertation}

1. R.K. Balogh, B. Gyurcsik, É. Hunyadi-Gulyás, H.E.M. Christensen, A. Jancsó: Advanced purification strategy for CueR, a cysteine containing copper(I) and DNA binding protein. Protein Expression and Purification, 123, 90-96 (2016). DOI:10.1016/j.pep.2016.03.012 $\mathrm{IF}=1.29$

2. R.K. Balogh, B. Gyurcsik, É. Hunyadi-Gulyás, J. Schell, P.W. Thulstrup, L. Hemmingsen, A. Jancsó: C-terminal cysteines of CueR act as auxiliary metal site ligands upon $\mathrm{Hg}^{\mathrm{II}}$ binding - A mechanism to prevent transcriptional activation by divalent metal ions? Chemistry - A European Journal, 25, 15030-15035 (2019) DOI: $10.1002 /$ chem. 201902940 $\mathrm{IF}=5.16$

3. R.K. Balogh, B. Gyurcsik, M. Jensen, P.W. Thulstrup, U. Köster, N.J. Christensen, F.J. Mørch, M.L. Jensen, A. Jancsó, L. Hemmingsen: Flexibility of the CueR metal site probed by instantaneous change of element and oxidation state from $\mathrm{Ag}^{\mathrm{I}}$ to $\mathrm{Cd}^{\mathrm{II}}$. Chemistry - A European Journal, Accepted (2020)

$\mathrm{IF}=5.16$

$\Sigma \mathrm{IF}=11.61$

\section{Further publications}

4. E. Németh, R.K. Balogh, K. Borsos, A. Czene, P.W. Thulstrup, B. Gyurcsik: Intrinsic protein disorder could be overlooked in cocrystallization conditions - An SRCD case study. Protein Science, 25, 1977-1988 (2016). DOI: 10.1002/pro.3010 $\mathrm{IF}=2.42$

5. K. Kowalski, J. Skiba, Q. Yuan, A. Hildebrandt, H. Lang, D. Trzybiński, K. Woźniak, R.K. Balogh, B. Gyurcsik, and V. Vrček: Ferrocenyl GNA nucleosides: a bridge between organic and organometallic xeno-nucleic acids. ChemPlusChem, 83, 77-86 (2018) DOI: 10.1002/cplu.201700551 $\mathrm{IF}=3.44$ 
6. N. Ivošević DeNardis, J. Pečar Ilić, I. Ružić, N. Novosel, T. Mišić Radić, A. Weber, D. Kasum, Z. Pavlinska, R.K. Balogh, B. Hajdu, A. Marček Chorvátová, B. Gyurcsik: Algal cell response to laboratory-induced cadmium stress: a multimethod approach. European Biophysics Journal, 48, 231-248 (2019). DOI: 10.1007/s00249-019-01347-6

$\mathrm{IF}=2.53$

7. H.A.H. Abd Elhameed, B. Hajdu, R.K. Balogh, E. Hermann, É. Hunyadi-Gulyás, B. Gyurcsik: Purification of proteins with native terminal sequences using a Ni(II)cleavable C-terminal hexahistidine affinity tag. Protein Expression and Purification, 159, 53-59 (2019) DOI: 10.1016/j.pep.2019.03.009

$\mathrm{IF}=1.29$

$\Sigma \Sigma \mathrm{IF}=21.29$

\section{Poster presentations at international conferences}

1. R. Balogh, A. Jancsó, B. Gyurcsik, H.E.M Christensen: Synthesis, purification and metal ion binding studies on native and modified CueR metalloregulatory proteins. REGIONAL CONFERENCE: "Heavy metal as contaminants of the environments"- HuRo conference, Timisoara, Romania, 17 May 2013

2. R. Balogh, A. Jancsó, B. Gyurcsik, H.E.M Christensen: Synthesis, purification and metal ion binding studies on native and modified CueR metalloregulatory proteins. 13th Edition of Academic Days Timisoara, Timisoara, Romania,13-14 June 2013

3. R.K. Balogh, K. Borsos, A. Czene, E. Németh, B. Gyurcsik: Induced Folding of NColE7 Metallonuclease Monitored by SRCD. 590. WE-Heraeus-Seminar on Synchrotron Radiation Circular Dichroism (SRCD) Spectroscopy, Bad Honnef, Germany, 17-20 May 2015

4. R.K. Balogh, A. Jancsó, B. Gyurcsik, H.E.M. Christensen, É. Hunyadi-Gulyás: Strategies for purification of a cysteine containing DNA binding protein. 13th European Biological Inorganic Chemistry Conference, Budapest, Hungary, 28 August - 1 September 2016

5. R.K. Balogh, A. Jancsó, B. Gyurcsik, E. Németh: A study on the secondary structure of the metalloregulatory protein CueR: effect of $\mathrm{pH}$, metal ions and DNA. $14^{\text {th }}$ International Symposium on Applied Bioinorganic Chemistry (ISABC), Toulouse, France, 7-10 June 2017 
6. R.K. Balogh, A. Jancsó, B. Gyurcsik, E. Németh: pH induced structural switch of CueR metalloregulatory protein. 19 $9^{\text {th }}$ International Union of Pure and Applied Biology (IUPAB) Congress and $11^{\text {th }}$ European Biophysical Societies' Association (EBSA) Congress, Edinburgh, Scotland, 16-20 July 2017

7. R.K. Balogh, E. Mesterházy, K. Kato, K. Nagata, A. Jancsó ,B. Gyurcsik: Detection of toxic metal ions by the CueR metalloregulator. 14 ${ }^{\text {th }}$ European Biological Inorganic Chemistry Conference, Birmingham, United Kingdom, 26-30 August 2018

8. R.K. Balogh, E. Mesterházy, K. Kato, K. Nagata, A. Jancsó ,B. Gyurcsik: Detection of toxic metal ions by the CueR metalloregulator. COST-sponsored ARBREMOBIEU plenary meeting, Zagreb, Croatia, 18-20 March 2019

9. R.K. Balogh, Béla Gyurcsik, Éva Hunyadi-Gulyás, Peter W. Thulstrup, Lars Hemmingsen, Attila Jancsó: Investigation of $\mathrm{Hg}(\mathrm{II})$ binding of CueR protein: a possible role of $\mathrm{C}$-terminal cysteines in selective operation of the protein, Interlaken, Switzerland, 11-16 August 2019

\section{Oral presentations at international conferences}

1. R.K. Balogh, H.E.M. Christensen, M.N. Asaka, K. Kato, K. Nagata, B. Gyurcsik, A. Jancsó: The potential application of CueR protein in selective detection of toxic metal ions. XXV. International Conference on Coordination and Bioinorganic Chemistry - The $50^{\text {th }}$ Anniversary of ICCBIC, Smolenice, Slovakia, 31 May - 5 June 2015

2. R.K. Balogh, Béla Gyurcsik, Attila Jancsó: Transcriptional activator CueR protein: purification and characterization, $9^{\text {th }}$ Chemistry Towards Biology (CTB), Budapest, Hungary, 24-27 September 2018

\section{Oral presentations at Hungarian conferences}

1. Balogh R.K., Mesterházy E., Gyurcsik B., Jancsó A., H.E.M. Christensen, M.N. Asaka, K. Kato, K. Nagata; Réz(I)ionok szelektív kimutatása a CueR fémszabályzó fehérje segítségével. XXXVIII. Kémiai Előadói Napok, Szeged, 2015. október 2628.

2. Balogh R.K., Gyurcsik B., Jancsó A.: A CueR fehérje másodlagos szerkezetének vizsgálata cirkuláris dikroizmus spektroszkópiával. XXXIX. Kémiai Előadói Napok, Szeged, 2016. október 17-19.

3. Balogh R.K., Jancsó A., Gyurcsik B., Németh E.: Egy transzkripciós aktivátor fehérje $\mathrm{pH}$ indukált szerkezetváltozásának tanulmányozása. 51. Komplexkémiai Kollokvium, Balatonvilágos, 2017 május 29-31. 


\section{APPENDIX}

A.1. Sequences of protein and DNA and strains of bacteria A1.1. Protein sequences

wild type (WT) CueR: MNISDVAKITGLTSKAIRFYEEKGLVTPPMRSENGYRTYTQ $\triangle \mathrm{C} 7$-CueR: MNISDVAKITGLTSKAIRFYEEKGLVTPPMRSENGYRTYTQ S77C- $\triangle$ C7-CueR: $\quad$ MNISDVAKITGLTSKAIRFYEEKGLVTPPMRSENGYRTYTQ

QHLNELTLLRQARQVGFNLEESGELVNLFNDPQRHSADVKRRTLEKVAEIERHIE QHLNELTLLRQARQVGFNLEESGELVNLFNDPQRHSADVKRRTLEKVAEIERHIE QHLNELTLLRQARQVGFNLEESGELVNLFNDPQRHCADVKRRTLEKVAEIERHIE

ELQSMRDQLLALANACPGDDSADCPIIENLSGCCHHRAG ELQSMRDQLLALANACPGDDSADCPIIENLSG - - - - ELQSMRDQLLALANACPGDDSADCPIIENLSG - - - - - -

\section{A1.2. DNA sequences}

PcopA dsDNA: specific double strand DNA fragment including the recognition site of CueR protein i.e., the promoter sequence of copA gene:

5' - AAAGGTTAAACCTTCCAGCAAGGGGAAGGTCAAGA - 3'

Non-specific DNA segment:

5' - GCTGTACATATCGGTAGATTTCGATCGGTAGATGA - 3' 
Table A1: E. coli genotypes.

\begin{tabular}{|c|c|}
\hline Strain of $E$. coli & Features \\
\hline DH10B & 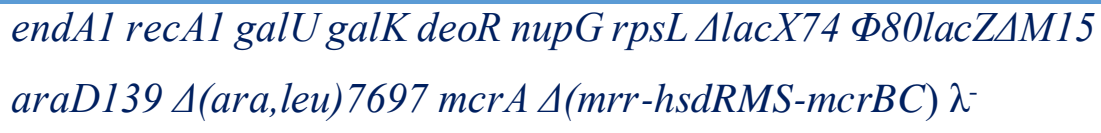 \\
\hline BL21(DE3) & ompT gal [dcm] [lon] hsd $S_{B}$ \\
\hline Mach1 & $\begin{array}{l}\text { ArecA1398 endA1 fhuA } \Phi 804(\text { lac }) M 15 \text { A(lac)X74 hsdR(rK- } \\
m K+)\end{array}$ \\
\hline BW25113 & 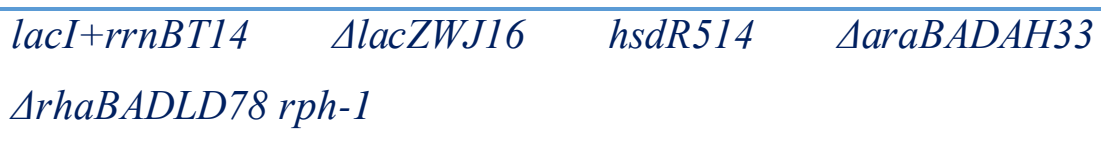 \\
\hline BW25113 $\Delta$ CueR & 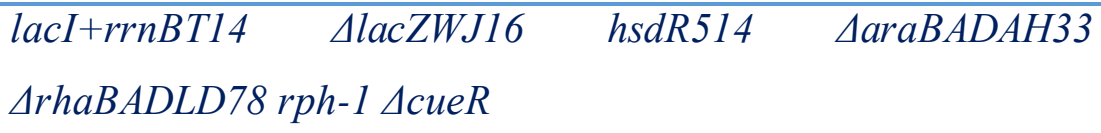 \\
\hline
\end{tabular}

A.2. Cloning, expression and purification of CueR and its mutants A.2.1. Plasmid construction for protein expression

The gene of E. coli CueR was kindly provided by prof. Alfonso Mondragon (Department of Molecular Biosciences, Northwestern University, Evanston, Illinois, USA).[106] The cueR gene was recloned into a pET-21a (Amp ${ }^{\mathrm{R}}$ ) plasmid (Novagen). The gene was amplified by PCR using T7 sequencing (T7-F forward and T7-T2 reverse, see sequences in Table A2) primers, then cloned between NdeI and BamHI sites to create pET21a-CueR. A stop codon prior to the BamHI cleavage site assured the expression of the protein without any additional amino acids.

Table A2: Sequence of primers used in cloning.

\begin{tabular}{c|c}
\hline Name & Sequence $\mathbf{( 5}^{\prime} \mathbf{-} \mathbf{3}^{\prime}$ ) \\
\hline T7-F & TAATACGACTCACTATAGGG \\
T7-T2 & GCTAGTTATTGCTCAGCGG \\
Tr-CueR-R & TCGGATCCTCAGCCGGAGAGATTTTC \\
S77C-F & GCCGACGTCAAACGGCG \\
S77C-R & GCAGTGCCGCTGCGGGTC \\
\hline
\end{tabular}

The gene of $C$-terminally truncated CueR protein was constructed using a conventional restriction enzyme digestion/ligation cloning method. As a first step, the 
shortened gene was amplified from pET-21a-CueR plasmid with T7-F forward and TrCueR-R reverse primers in PCR (Table A2). The PCR reaction mixture contained the followings: $29 \mu \mathrm{L}$ sterile MilliQ water, $5 \mu \mathrm{L} 10 \times$ Taq buffer (Thermo Scientific), $5 \mu \mathrm{L}$ dNTP mix (Thermo Scientific), $0.5 \mu \mathrm{L}$ solution of pET-21-CueR plasmid, $5-5 \mu \mathrm{L}$ of the primers $\left(c_{\text {primer }}=10 \mu \mathrm{M}\right), 0.5 \mu \mathrm{L}$ Taq polymerase. The DNA was amplified by using following settings: initial denaturation at $94{ }^{\circ} \mathrm{C}$ for $2 \mathrm{~min}$, denaturation at $94{ }^{\circ} \mathrm{C}$ for $15 \mathrm{sec}$, annealing at $53{ }^{\circ} \mathrm{C}$ for $1 \mathrm{~min}$ and extension at $72{ }^{\circ} \mathrm{C}$ for $1 \mathrm{~min}$, the cycle repeated 30 times from the second step. The DNA fragment and pET-21a plasmid were digested by NdeI and BamHI (Fermentas) restriction enzymes at $37^{\circ} \mathrm{C}, 2 \mathrm{~h}$. The reaction mixtures were prepared as the following table shows (Table A3).

Table A3: Reaction mixture of DNA digestion with NdeI and BamHI restriction enzymes.

\begin{tabular}{l|c|c}
\hline Components & plasmid & insert \\
\hline sterile MilliQ water $(\mu \mathrm{L})$ & 26 & 1 \\
10x Orange Buffer (Thermo Scientific) $(\mu \mathrm{L})$ & 4 & 2 \\
Plasmid DNA $(\sim 200 \mathrm{ng} / \mu \mathrm{L})(\mu \mathrm{L})$ & 8 & 15 \\
NdeI 10 U/ $\mu \mathrm{L}($ Thermo Scientific) $(\mu \mathrm{L})$ & 1 & 1 \\
BamHI 10 U/ $\mu \mathrm{L}$ (Thermo Scientific) $(\mu \mathrm{L})$ & 1 & 1 \\
\hline
\end{tabular}

After a subsequent purification the digested insert and plasmid were mixed at 1:5 molar ratio in the ligation mixture and ligated by T7 Ligase (NEB) at RT for 30 min, then incubated overnight at $4{ }^{\circ} \mathrm{C} .30 \mu \mathrm{L}$ of Mach1 competent cells were transformed with $10 \mu \mathrm{L}$ ligation mixture and spread onto ampicillin containing LB plates. The obtained pET-21a$\Delta$ C7-CueR plasmid was purified with EZ-10 Spin Column Plasmid DNA Kit following the protocol for purification of low copy plasmid DNA.

The single amino acid mutation of the S77 amino acid to cysteine, was carried out with Quik change protocol on the previously obtained pET-21a- $\Delta$ C7-CueR plasmid. The reverse primer contained the mutation: as the serine codon (agc) was exchanged to cysteine codon (tgc). The two strands of the pET-21a-S77C- $\Delta \mathrm{C} 7-\mathrm{CueR}$ plasmid were amplified in a PCR using S77C-F, S77C-R primers (Table A2) and KOD-FX DNA polymerase (denaturation at $94{ }^{\circ} \mathrm{C}$ for $2 \mathrm{~min}$, annealing at $58{ }^{\circ} \mathrm{C}$ for $30 \mathrm{sec}$, extension at $68^{\circ} \mathrm{C}$ for 7 min, 30 cycles). The linear dsDNA was purified and treated with T4 polynucleotide kinase $\left(37^{\circ} \mathrm{C}, 1 \mathrm{~h}\right.$ in the presence of $1 \mathrm{mM}$ ATP $)$. Then plasmids were circulated by ligating with 
Ligation High (RT, $1 \mathrm{~h}$ ). $100 \mu \mathrm{L}$ of Mach1 competent cells were transformed with the ligation mixture.

All three plasmids (pET-21a-CueR, pET-21a- $\Delta$ C7-CueR, pET-21a-S77C- $\Delta$ C7CueR) were sequenced to confirm the success of cloning.

\section{A.2.2. Protein purification}

E. coli BL21 (DE3) bacteria expressing the wild type CueR from the pET-21a-CueR expression vector were first grown in $50 \mathrm{~mL} \mathrm{LB} / \mathrm{Amp}+$ medium (including $0.1 \mathrm{mg} / \mathrm{mL}$ ampicillin at final concentration) at $37^{\circ} \mathrm{C}$ for $\sim 4$ hours until $\mathrm{OD}_{600}=0.6-1.0$ was reached. This pre-culture was sedimented by centrifugation at $4{ }^{\circ} \mathrm{C}$ and $18000 \times \mathrm{g}$ for $10 \mathrm{~min}$. The cells were re-suspended in $50 \mathrm{~mL}$ fresh $\mathrm{LB} / \mathrm{Amp}+$ medium, and $6.5 \mathrm{ml}$ of this culture was used to inoculate $650 \mathrm{~mL} \mathrm{LB} / \mathrm{Amp}+$ medium. When $\mathrm{OD}_{600}$ of $0.4-0.6$ was attained, the protein expression was induced by the addition of IPTG to a final concentration of $0.1 \mathrm{mM}$. The cultures were incubated overnight at $20^{\circ} \mathrm{C}$ to avoid aggregation otherwise observed at $37{ }^{\circ} \mathrm{C}$. The cells were harvested by centrifugation at $4{ }^{\circ} \mathrm{C}$ and then suspended in $40 \mathrm{~mL}$ of $20 \mathrm{mM}$ Tris/ $\mathrm{HCl}$ buffer, $\mathrm{pH}$ 7.5. $\mathrm{Na}_{2} \mathrm{~S}_{2} \mathrm{O}_{4}$ was added to the sample before and after cell lysis to a final concentration of $2 \mathrm{mM}$. The cells were lysed by sonication and the extract was centrifuged at $4{ }^{\circ} \mathrm{C}$ and $18000 \times \mathrm{g}$ for $20 \mathrm{~min}$. Nucleic acids in the supernatant were digested at $R T$ for 1.5 hours in the presence of DNase I $(25 \mu \mathrm{g} / \mathrm{mL})$ and $\mathrm{MgCl}_{2}(2 \mathrm{mM})$. The sample was diluted with $20 \mathrm{mM}$ Tris/ $\mathrm{HCl}, \mathrm{pH} 7.5$ to a conductivity of $2.3 \mathrm{mS} / \mathrm{cm}$ and filtered through a $0.45 \mu \mathrm{m}$ GHP Acrodisc ${ }^{\circledR}$ GF $25 \mathrm{~mm}$ Syringe Filter (Life Sciences).

After the preparatory procedures, the WT CueR protein was purified in four chromatographic steps in the order of anion exchange, affinity chromatography, a second anion exchange and finally a gel filtration. Between each purification step the pooled fractions were ultrafiltrated three times in a Millipore 5124 Amicon Stirred Cell Model $8400,400 \mathrm{~mL}\left(\mathrm{~N}_{2}\right.$ gas, PLBC 3000 membrane) with the binding buffer used in the following purification step.

First, the filtered solution was loaded onto a HiLoad Sepharose Fast Flow Q 16/10 column, which had been equilibrated with 5 column volume (CV) of $20 \mathrm{mM}$ Tris/ $\mathrm{HCl}, \mathrm{pH}$ 7.5 (Buffer A). The bound proteins were eluted with a linear gradient of $20 \mathrm{mM}$ Tris/HCl, $1 \mathrm{M} \mathrm{NaCl}, \mathrm{pH} 7.5$ (Buffer B) from $15 \%$ to $60 \%$ in $6 \mathrm{CV}$. The CueR containing fractions were collected and diluted with $20 \mathrm{mM}$ Tris/ $\mathrm{HCl}, \mathrm{pH} 7.5$ to a conductivity of $7 \mathrm{mS} / \mathrm{cm}$.

In the second step the sample was filtered and loaded onto a HiPerp Heparin FF $16 / 10$ column, preequilibrated with a $20 \mathrm{mM}$ Tris/ $\mathrm{HCl}, 50 \mathrm{mM} \mathrm{NaCl}, \mathrm{pH} 7.5$ buffer. The 
bound protein was eluted with a linear gradient of $20 \mathrm{mM}$ Tris/ $\mathrm{HCl}, 1 \mathrm{M} \mathrm{NaCl}, \mathrm{pH} 7.5$ from $0 \%$ to $50 \%$ in $10 \mathrm{CV}$.

Following affinity chromatography, the fractions containing CueR were pooled and diluted 3 times with $20 \mathrm{mM}$ Tris/HCl, $\mathrm{pH}$ 7.5. The ultrafiltered sample was loaded onto a Source 30 Q 16/13 column, preequilibrated with $5 \mathrm{CV}$ of $20 \mathrm{mM}$ Tris/ $\mathrm{HCl}, \mathrm{pH}$ 7.5. The bound protein was eluted with linear gradient of $20 \mathrm{mM}$ Tris/ $\mathrm{HCl}, 1 \mathrm{M} \mathrm{NaCl}, \mathrm{pH} 7.0$ from $0 \%$ to $60 \%$ in $6 \mathrm{CV}$. The CueR fractions were collected and filtered again.

Finally, the sample was loaded onto a HiLoad Superdex 75 26/60 column, preequilibrated with a buffer required for the subsequent application (Tris or HEPES containing also $1 \mathrm{mM}$ DTT/ $1 \mathrm{mM}$ TCEP as reducing agents). Proteins were eluted with isocratic elution and then concentrated by ultrafiltration.

The expression and purification procedures of the mutant CueR proteins were performed as described previously for the WT protein, except that the second anion exchange step was eliminated. In addition, to achieve proper separation of S77C- $\Delta \mathrm{C} 7-$ CueR by gel filtration, the addition of reducing agent ( 2 mM DTT) to sample and the buffer was required.

\section{A.3. Gel electrophoresis}

\section{A.3.1. SDS-PAGE}

Protein samples were analyzed with SDS-PAGE. Polyacrylamide gels were either commercially available Any $\mathrm{kD}^{\mathrm{TM}}$ Mini-PROTEAN ${ }^{\circledR} \mathrm{TGX}^{\mathrm{TM}}$ (Bio-Rad) or hand casted gels. The casted gels contained 3 layers: separating, spacer and stacking, each was prepared as Table A4 shows.

Table A4: Ingredients for the three layers of a casted polyacrylamide gel.

\begin{tabular}{l|c|c|c}
\hline \multicolumn{1}{c|}{ Solution } & Separating & Spacer & Stacking \\
\hline $30 \%$ acrylamide/bis-acrylamide, 29:1 & 3.3 & 0.5 & 0.33 \\
solution (BioRad) $(\mathrm{mL})$ & & & \\
\hline 3 M Tris, 0.3 \% SDS, $\mathrm{pH}=8.5$ buffer $(\mathrm{mL})$ & 2 & 0.5 & 0.625 \\
\hline $33 \%$ glycerol solution $(\mathrm{mL})$ & 0.7 & - & - \\
\hline MilliQ water $(\mathrm{mL})$ & - & 0.5 & 1.55 \\
\hline $10 \%$ ammonium persulfate solution $(\mu \mathrm{L})$ & 25 & 12 & 25 \\
\hline Tetramethylethylenediamine solution $(\mu \mathrm{L})$ & 2 & 2 & 2 \\
\hline
\end{tabular}


For running the gels separate anode buffer $(0.2 \mathrm{M}$ Tris, $\mathrm{pH}=8.9)$ and cathode buffer (0.1 M Tris, $0.1 \mathrm{M}$ tricine, $0.1 \% w / V$ SDS, $\mathrm{pH}=8.25)$ were prepared and applied. The gels were run with $30-60 \mathrm{~mA}$ for $1-2 \mathrm{~h}$. After electrophoresis, gels were stained with Coomassie Brilliant Blue solution (0.2 g CBB, 10\% V/V acetic acid, $50 \% \mathrm{~V} / \mathrm{V}$ methanol) for $1 \mathrm{~h}$ and destained with a destaining solution (10\% $\mathrm{V} / \mathrm{V}$ acetic acid, $30 \% \mathrm{~V} / \mathrm{V}$ methanol) overnight.

\section{A.3.2. Agarose gel electrophoresis}

For casting $1 \% \mathrm{w} / \mathrm{V}$ agarose gels, $1.2 \mathrm{~g}$ agarose was mixed in $120 \mathrm{ml}$ Tris-acetateEDTA (TAE) buffer (40 mM Tris, $20 \mathrm{mM}$ acetic acid, and $1 \mathrm{mM}$ EDTA pH 8.0) and dissolved by heating in a microwave oven. After the solution was cooled down to $\sim 60{ }^{\circ} \mathrm{C}$, EtBr was added to a final concentration of $0.5 \mathrm{ng} / \mu \mathrm{l}$.

DNA samples were mixed with $6 \times$ Loading Dye $(10 \mathrm{mM}$ Tris-HCl, $\mathrm{pH} 7.6,0.03$ $\%$ bromophenol blue, $0.03 \%$ xylene cyanol FF, $60 \%$ glycerol, 60 mM EDTA - Thermo Scientific). The electrophoresis was carried out with $100 \mathrm{~V}$ for $30-60$ minutes.

\section{A.4. Functionality test of purified proteins with EMSA}

The DNA binding capability of CueR and its variants were evidenced by electrophoretic gel mobility shift assay. The volume of the protein-DNA reaction mixture was $5 \mu \mathrm{L}$ by mixing $1 \mu \mathrm{L} 50 \mu \mathrm{M}$ DNA solution (in $20 \mathrm{mM}$ Tris/HClO4, $0.1 \mathrm{mM} \mathrm{NaClO} 4$, pH 8.0 buffer) with $4 \mu \mathrm{L} 100 \mu \mathrm{M}$ Protein solution (in $20 \mathrm{mM}$ Tris/HCl, $1 \mathrm{mM}$ DTT, pH 7.5

buffer). After 4 hours incubation at $37{ }^{\circ} \mathrm{C}$ this solution was mixed with $1 \mu \mathrm{L} 6 \times$ Loading Dye (10 mM Tris-HCl, pH 7.6, $0.03 \%$ bromophenol blue, $0.03 \%$ xylene cyanol FF, $60 \%$ glycerol, $60 \mathrm{mM}$ EDTA - Thermo Scientific) to load it onto $2 \%(2.0 \mathrm{~g} / 100 \mathrm{~mL})$ agarose gel and then run for 30 minutes applying $100 \mathrm{~V}$. After the electrophoresis, the gel was submerged into $1 \mu \mathrm{g} / \mathrm{mL}$ ethidium bromide solution for $20 \mathrm{~min}$, and washed two times with water for $10 \mathrm{~min}$. The sequences of the applied DNA segments can be found in Appendix 1.2 .

\section{A.5. Mass spectrometric measurements}

Mass spectrometric experiments were performed on an LTQ-Orbitrap Elite (Thermo Scientific) mass spectrometer coupled with a TriVersa NanoMate (Advion) chip- 
based electrospray ion source. The capillary voltage was $1.3-1.4 \mathrm{keV}$ and the source temperature was $300^{\circ} \mathrm{C}$. We used Xcalibur 2.2 (Thermo) software for data evaluation and deconvolution.

\section{A.5.1. Sample preparation for intact mass measurements}

The purified protein sample was acidified with $10 \% \mathrm{~V} / \mathrm{V}$ formic acid to $\mathrm{pH} \sim 2$ in order to encourage positive ion formation. Then, the sample was desalted by C18 Zip-tip (Millipore) purification, eluted into $0.1 \% \mathrm{~V} / \mathrm{V}$ formic acid, $50 \% \mathrm{~V} / \mathrm{V}$ acetonitrile solvent.

\section{A.5.2. Sample preparation for native $M S$}

Native mass spectra were measured from samples containing WT or $\Delta \mathrm{C} 7-\mathrm{CueR}$ at a protein concentration of $20 \mu \mathrm{M}\left(10 \mathrm{mM}\right.$ ammonium bicarbonate/ $\mathrm{NH}_{3}, 0.5 \mathrm{mM}$ TCEP, $\mathrm{pH}$ 7.5). $0.2,0.5,1.0$ and 2.0 equivalents of $\mathrm{Hg}(\mathrm{II}) / \mathrm{Ag}(\mathrm{I}) / \mathrm{Cd}(\mathrm{II})$ was added to individual samples from a $\mathrm{HgCl}_{2} / \mathrm{AgClO}_{4} / \mathrm{Cd}\left(\mathrm{ClO}_{4}\right)_{2}$ stock solution $\left(c_{\mathrm{Hg}(\mathrm{II})}=c_{\mathrm{Ag}(\mathrm{I})}=c_{\mathrm{Cd}(\mathrm{II})}=250 \mu \mathrm{M}\right)$. 
Apo-CueR

Exp.
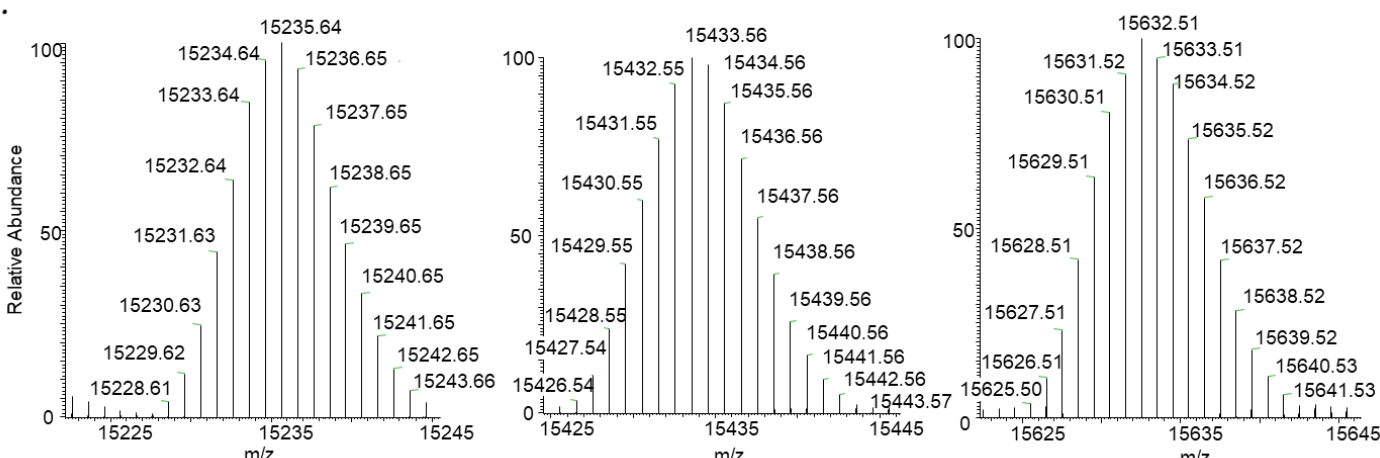

Calc.

\begin{tabular}{|c|c|c|}
\hline \multirow{2}{*}{$\begin{array}{l}\text { Elemental } \\
\text { Composition: }\end{array}$} & \multicolumn{2}{|c|}{ C652 H1055 N198 O209 S7 } \\
\hline & $\mathrm{m} / \mathrm{z}$ & $\%$ \\
\hline & 15226.60516 & 0.10 \\
\hline & 15227.60800 & 0.84 \\
\hline & 15228.61074 & 3.58 \\
\hline & 15229.61338 & 10.31 \\
\hline & 15230.61594 & 22.67 \\
\hline & 15231.61842 & 40.57 \\
\hline & 15232.62085 & 61.47 \\
\hline & 15233.62321 & 81.04 \\
\hline & 15234.62552 & 94.83 \\
\hline & 15235.62778 & 100.00 \\
\hline & 15236.63000 & 96.15 \\
\hline & 15237.63219 & 85.11 \\
\hline & 15238.63434 & 69.88 \\
\hline & 15239.63646 & 53.58 \\
\hline & 15240.63855 & 38.56 \\
\hline & 15241.64062 & 26.18 \\
\hline & 15242.64267 & 16.83 \\
\hline & 15243.64471 & 10.27 \\
\hline & 15244.64674 & 5.97 \\
\hline & 15245.64878 & 3.32 \\
\hline & 15246.65083 & 1.76 \\
\hline & 15247.65289 & 0.89 \\
\hline & 15248.65501 & 0.42 \\
\hline & 15249.65728 & 0.19 \\
\hline & 15250.65950 & 0.08 \\
\hline & 15251.66140 & 0.03 \\
\hline & 15252.66337 & 0.01 \\
\hline & 15253.66541 & 0.00 \\
\hline
\end{tabular}

C652 H1052 N198 O209 S7 Hg1

\begin{tabular}{ll}
\hline $\mathrm{m} / \mathrm{z}$ & $\%$ \\
15419.54750 & 0.00 \\
15420.55029 & 0.00 \\
15421.55008 & 0.02 \\
15422.55168 & 0.13 \\
15423.55379 & 0.62 \\
15424.55600 & 2.13 \\
15425.55819 & 5.67 \\
15426.56033 & 12.43 \\
15427.56242 & 23.28 \\
15428.56448 & 38.19 \\
15429.56650 & 55.81 \\
15430.56851 & 73.63 \\
15431.57051 & 88.54 \\
15432.57250 & 97.83 \\
15433.57449 & 100.00 \\
15434.57648 & 95.07 \\
15435.57845 & 84.49 \\
15436.58043 & 70.49 \\
15437.58240 & 55.41 \\
15438.58436 & 41.17 \\
15439.58633 & 29.00 \\
15440.58829 & 19.42 \\
15441.59025 & 12.38 \\
15442.59222 & 7.52 \\
15443.59420 & 4.36 \\
15444.59620 & 2.40 \\
15445.59822 & 1.25 \\
15446.60029 & 0.62 \\
15447.60236 & 0.28 \\
15448.60444 & 0.11 \\
15449.60639 & 0.04 \\
15450.60850 & 0.01 \\
15451.60926 & 0.00 \\
\hline &
\end{tabular}

C652 H1051 N198 O209 S7 Hg2

\begin{tabular}{cc}
\hline $\mathrm{m} / \mathrm{z}$ & $\%$ \\
15617.50979 & 0.00 \\
15618.50994 & 0.00 \\
15619.51114 & 0.02 \\
15620.51279 & 0.11 \\
15621.51466 & 0.40 \\
15622.51658 & 1.24 \\
15623.51849 & 3.15 \\
15624.52038 & 6.91 \\
15625.52223 & 13.33 \\
15626.52407 & 23.01 \\
15627.52589 & 35.96 \\
15628.52770 & 51.40 \\
15629.52951 & 67.69 \\
15630.53132 & 82.63 \\
15631.53313 & 93.98 \\
15632.53495 & 100.00 \\
15633.53677 & 99.92 \\
15634.53860 & 94.04 \\
15635.54043 & 83.62 \\
15636.54228 & 70.42 \\
15637.54413 & 56.28 \\
15638.54599 & 42.77 \\
15639.54785 & 30.97 \\
15640.54973 & 21.39 \\
15641.55161 & 14.10 \\
15642.55350 & 8.86 \\
15643.55540 & 5.32 \\
15644.55733 & 3.03 \\
15645.55927 & 1.64 \\
15646.56122 & 0.83 \\
15647.56319 & 0.39 \\
15648.56518 & 0.17 \\
15649.56700 & 0.06 \\
15650.56912 & 0.02 \\
15651.56983 & 0.00 \\
15652.57632 & 0.00 \\
\hline &
\end{tabular}

Figure A1: Comparison of the experimental and calculated isotopic envelope of WT CueR, HgWT CueR and $\mathrm{Hg}_{2}-W T$ CueR species (calculations were executed with Protein Prospector ver. 5.22.1-UCSF). 
Apo- $\triangle$ C7CueR

Exp.

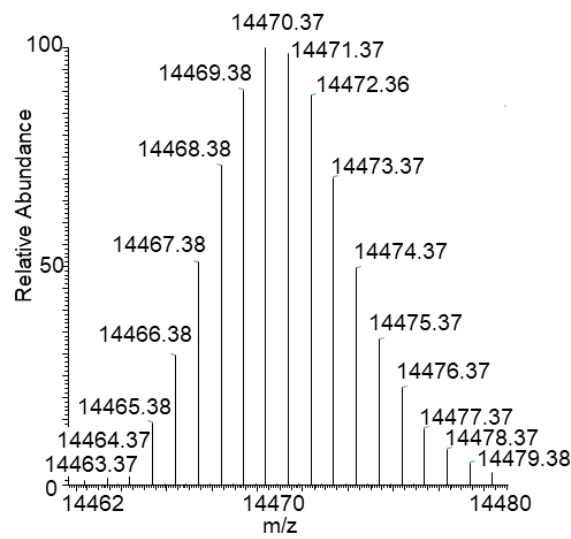

Calc.

Elemental Composition:

C623 H1011 N184 O202 S5

\begin{tabular}{cc}
\hline $\mathrm{m} / \mathrm{z}$ & $\%$ \\
14462.30928 & 0.16 \\
14463.31214 & 1.29 \\
14464.31491 & 5.20 \\
14465.31760 & 14.23 \\
14466.32023 & 29.70 \\
14467.32279 & 50.39 \\
14468.32529 & 72.34 \\
14469.32774 & 90.30 \\
14470.33015 & 100.00 \\
14471.33251 & 99.74 \\
14472.33484 & 90.67 \\
14473.33714 & 75.83 \\
14474.33941 & 58.82 \\
14475.34165 & 42.58 \\
14476.34387 & 28.93 \\
14477.34607 & 18.53 \\
14478.34826 & 11.23 \\
14479.35044 & 6.46 \\
14480.35261 & 3.54 \\
14481.35481 & 1.85 \\
14482.35702 & 0.92 \\
14483.35928 & 0.43 \\
14484.36164 & 0.19 \\
14485.36411 & 0.08 \\
14486.36650 & 0.03 \\
14487.36930 & 0.01 \\
14488.37067 & 0.00 \\
\hline & \\
& \\
140 \\
140
\end{tabular}

$\mathrm{Hg}-\triangle \mathrm{C} 7 \mathrm{CueR}$

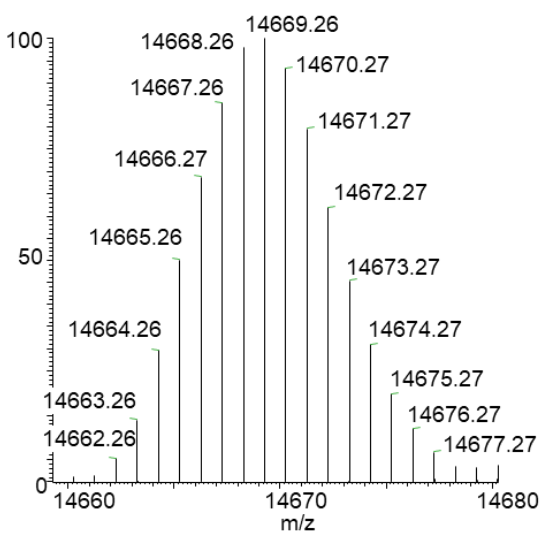

C623 H1009 N184 O202 S5 Hg1

\begin{tabular}{cc}
\hline $\mathrm{m} / \mathrm{z}$ & $\%$ \\
14656.25945 & 0.00 \\
14657.26224 & 0.00 \\
14658.26194 & 0.03 \\
14659.26358 & 0.20 \\
14660.26573 & 0.91 \\
14661.26797 & 3.00 \\
14662.27019 & 7.69 \\
14663.27236 & 16.22 \\
14664.27448 & 29.22 \\
14665.27658 & 46.06 \\
14666.27865 & 64.67 \\
14667.28072 & 81.90 \\
14668.28279 & 94.46 \\
14669.28485 & 100.00 \\
\hline 14670.28692 & 97.82 \\
14671.28900 & 88.91 \\
14672.29107 & 75.45 \\
14673.29315 & 60.04 \\
14674.29522 & 44.98 \\
14675.29730 & 31.81 \\
14676.29938 & 21.32 \\
14677.30147 & 13.56 \\
14678.30356 & 8.20 \\
14679.30566 & 4.72 \\
14680.30779 & 2.58 \\
14681.30991 & 1.34 \\
14682.31208 & 0.66 \\
14683.31434 & 0.30 \\
14684.31650 & 0.12 \\
14685.31885 & 0.04 \\
14686.32123 & 0.01 \\
14687.32309 & 0.00 \\
\hline & \\
& \\
140 \\
140
\end{tabular}

Figure A2: Comparison of the experimental and calculated isotopic envelope of $\triangle C 7-C u e R$ and Hg-AC7-CueR species (calculations were executed with Protein Prospector ver. 5.22.1-UCSF). 


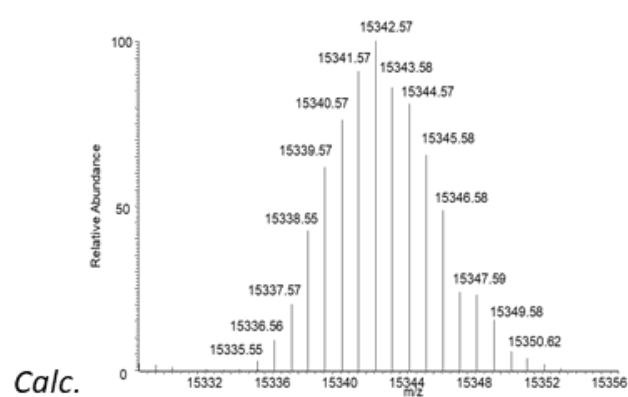

\begin{tabular}{|c|c|c|}
\hline \multirow[t]{26}{*}{$\begin{array}{l}\text { Elemental } \\
\text { Composition: }\end{array}$} & \multicolumn{2}{|c|}{ C652 H1053 N1980209S7 Ag1 } \\
\hline & $\mathrm{m} / \mathrm{z}$ & $\%$ \\
\hline & 15334.51 & 2.44 \\
\hline & 15335.51 & 7.16 \\
\hline & 15336.51 & 16.34 \\
\hline & 15337.51 & 30.71 \\
\hline & 15338.52 & 49.30 \\
\hline & 15339.52 & 69.21 \\
\hline & 15340.52 & 86.46 \\
\hline & 15341.52 & 97.40 \\
\hline & 15342.52 & 100.00 \\
\hline & 15343.53 & 94.37 \\
\hline & 15344.53 & 82.45 \\
\hline & 15345.53 & 67.09 \\
\hline & 15346.53 & 51.09 \\
\hline & 15347.53 & 36.57 \\
\hline & 15348.54 & 24.67 \\
\hline & 15349.54 & 15.73 \\
\hline & 15350.54 & 9.48 \\
\hline & 15351.54 & 5.37 \\
\hline & 15352.54 & 2.87 \\
\hline & 15353.55 & 1.40 \\
\hline & 15354.55 & 0.62 \\
\hline & 15355.55 & 0.22 \\
\hline & 15356.55 & 0.07 \\
\hline & 15357.55 & 0.01 \\
\hline
\end{tabular}

Figure A3: Comparison of the experimental and calculated isotopic envelope of Ag-WT CueR (calculations were executed with enviPat Web 2.4[150]). 

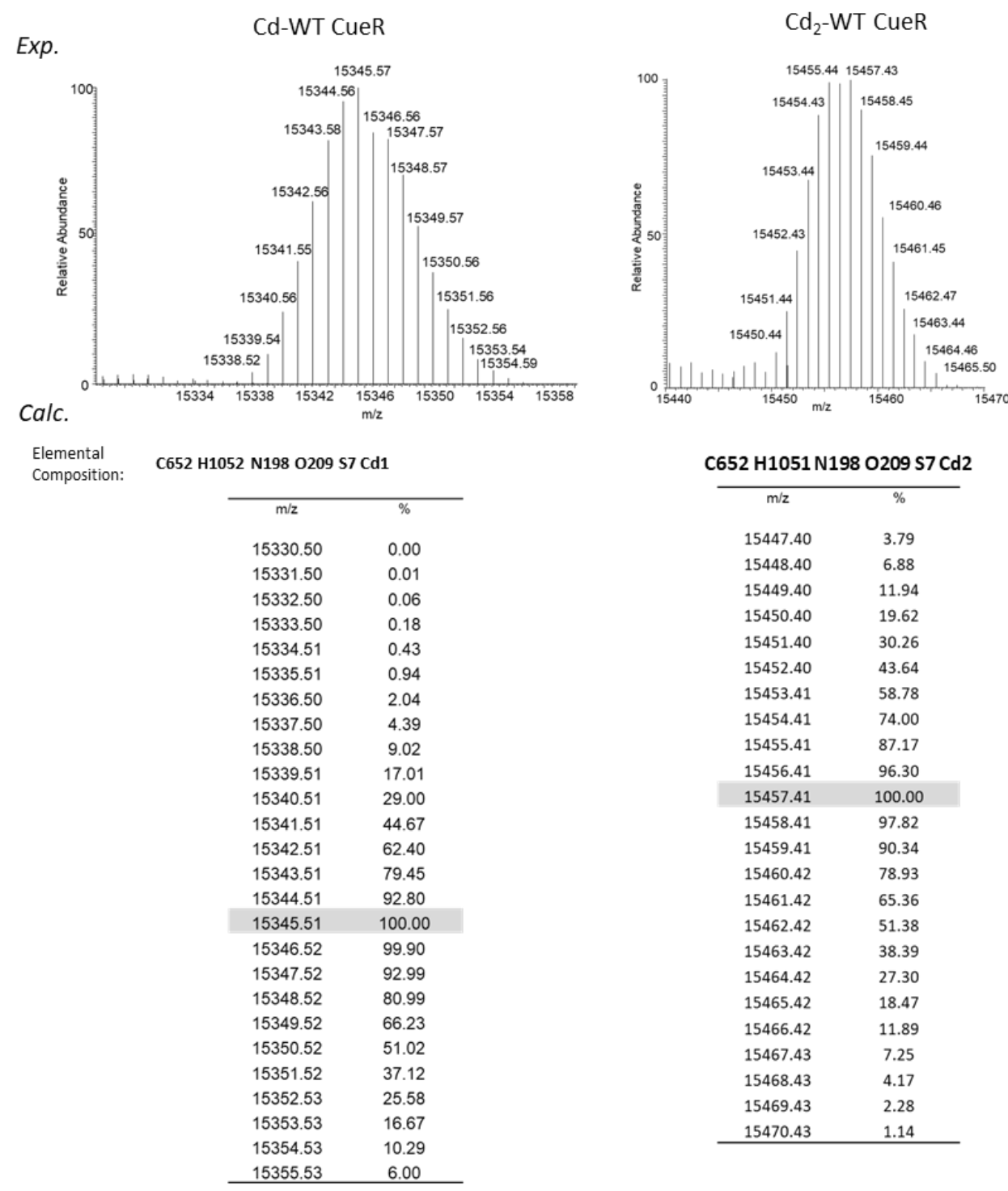

\begin{tabular}{cc} 
C652 H1051 N198 O209 S7 Cd2 \\
\hline m/z & $\%$ \\
15447.40 & 3.79 \\
15448.40 & 6.88 \\
15449.40 & 11.94 \\
15450.40 & 19.62 \\
15451.40 & 30.26 \\
15452.40 & 43.64 \\
15453.41 & 58.78 \\
15454.41 & 74.00 \\
15455.41 & 87.17 \\
15456.41 & 96.30 \\
15457.41 & 100.00 \\
15458.41 & 97.82 \\
15459.41 & 90.34 \\
15460.42 & 78.93 \\
15461.42 & 65.36 \\
15462.42 & 51.38 \\
15463.42 & 38.39 \\
15464.42 & 27.30 \\
15465.42 & 18.47 \\
15466.42 & 11.89 \\
15467.43 & 7.25 \\
15468.43 & 4.17 \\
15469.43 & 2.28 \\
15470.43 & 1.14 \\
\hline &
\end{tabular}

Figure A4: Comparison of the experimental and calculated isotopic envelope of Cd-WT CueR and $\mathrm{Cd}_{2}$-WT CueR species (calculations were executed with enviPat Web 2.4[150]).

\section{A.6. Peptide Mass fingerprint identification}

\section{A.6.1. Experimental details}

Proteins were identified by peptide mass fingerprint analysis carried out with a MALDI-TOF mass spectrometer (Bruker, Reflex III) Protein bands were cut out from the SDS-PAGE gel, and sliced into small pieces. The samples were reduced with DTT, alkylated with iodoacetamide and digested with trypsin at $37{ }^{\circ} \mathrm{C}$ for 4 hours. Extracted tryptic peptides were spotted onto the MALDI target plate using 2,5-dihydroxybenzoic acid (DHB) as a matrix and measured in positive reflectron mode. Detected peptide masses were subjected to database search against the Swissprot protein database on our in-house Mascot (Version: 2.2.07, Matrix Science) search engine. 
A.6.2. Result of PMF identification

\section{Protein\#1}

CUER_ECOLI, HTH-type transcriptional regulator CueR OS = Escherichia coli (strain K12)

Protein sequence coverage: $44 \%$

Database: SwissProt

Mass values searched: 17

Mass values matched: 9

Matched peptides shown in bold red.

1 MNISDVAKIT GLTSKAIRFY EEKGLVTPPM RSENGYRTYT QQHLNELTLL

51 RQARQVGFNL EESGELVNLF NDPQRHSADV KRRTLEKVAE IERHIEELQS

101 MRDQLLALAN ACPGDDSADC PIIENLSGCC HHRAG

Table A5: Identified peptide fragments in the PMF analysis of protein \#1

\begin{tabular}{|l|l|l|l|l|l|l|}
\hline Start & End & Observed & $\mathbf{M r}(\mathbf{e x p t})$ & $\mathbf{M r}(\mathbf{c a l c})$ & $\mathbf{p p m}$ & Peptide \\
\hline 1 & 8 & 877.6315 & 876.6243 & 876.4375 & 213 & -.MNISDVAK.I \\
\hline 24 & 31 & 870.6604 & 869.6531 & 869.4793 & 200 & K.GLVTPPMR.S \\
\hline 24 & 31 & 886.6221 & 885.6148 & 885.4742 & 159 & K.GLVTPPMR.S \\
\hline 38 & 51 & 1729.8989 & 1728.8916 & 1728.9159 & 14.0 & R.TYTQQHLNELTLLR.Q \\
\hline 55 & 75 & 2388.0908 & 2387.0836 & 2387.1394 & 23.4 & $\begin{array}{l}\text { R.QVGFNLEESGELVNLFND } \\
\text { PQR.H }\end{array}$ \\
\hline 55 & 75 & 2405.1290 & 2404.1217 & 2404.1659 & 18.4 & $\begin{array}{l}\text { R.QVGFNLEESGELVNLFND } \\
\text { PQR.H }\end{array}$ \\
\hline 94 & 102 & 1142.6092 & 1141.6019 & 1141.5550 & 41.2 & R.HIEELQSMR.D \\
\hline
\end{tabular}

\section{Protein \#2}

EFTU1_ECOLI, Elongation factor Tu 1 OS = Escherichia coli (strain K12)

Protein sequence coverage: $58 \%$

Database: SwissProt

Mass values searched: 46

Mass values matched: 22

Matched peptides shown in bold red. 
1 MSKEKFERTK PHVNVGTIGH VDHGKTTLTA AITTVLAKTY GGAARAFDQI

51 DNAPEEKARG ITINTSHVEY DTPTRHYAHV DCPGHADYVK NMITGAAQMD

101 GAILVVAATD GPMPQTREHI LLGRQVGVPY IIVFLNKCDM VDDEELLELV

151 EMEVRELLSQ YDFPGDDTPI VRGSALKALE GDAEWEAKIL ELAGFLDSYI

201 PEPERAIDKP FLLPIEDVFS ISGRGTVVTG RVERGIIKVG EEVEIVGIKE

251 TQKSTCTGVE MFRKLLDEGR AGENVGVLLR GIKREEIERG QVLAKPGTIK

301 PHTKFESEVY ILSKDEGGRH TPFFKGYRPQ FYFRTTDVTG TIELPEGVEM

351 VMPGDNIKMV VTLIHPIAMD DGLRFAIREG GRTVGAGVVA KVLG

Table A6: Identified peptide fragments in the PMF analysis of protein \#2

\begin{tabular}{|l|l|l|l|l|l|l|}
\hline Start & End & Observed & Mr(expt) & Mr(calc) & $\mathbf{p p m}$ & Peptide \\
\hline 9 & 25 & 1795.9746 & 1794.9673 & 1794.9489 & 10.2 & R.TKPHVNVGTIGHVDHGK.T \\
\hline 26 & 38 & 1303.8350 & 1302.8277 & 1302.7759 & 39.8 & K.TTLTAAITTVLAK.T \\
\hline 46 & 57 & 1376.6377 & 1375.6304 & 1375.6255 & 3.53 & R.AFDQIDNAPEEK.A \\
\hline 46 & 59 & 1603.7804 & 1602.7732 & 1602.7638 & 5.86 & R.AFDQIDNAPEEKAR.G \\
\hline 60 & 75 & 1803.9206 & 1802.9133 & 1802.8799 & 18.5 & R.GITINTSHVEYDTPTR.H \\
\hline 156 & 172 & 1965.0006 & 1963.9933 & 1963.9527 & 20.7 & R.ELLSQYDFPGDDTPIVR.G \\
\hline 178 & 188 & 1218.5920 & 1217.5848 & 1217.5564 & 23.3 & K.ALEGDAEWEAK.I \\
\hline 189 & 205 & 1962.0376 & 1961.0303 & 1961.0146 & 8.02 & K.ILELAGFLDSYIPEPER.A \\
\hline
\end{tabular}

\section{A.7. UV absorbance spectroscopy}

UV absorbance spectra were recorded with a Shimadzu UV2600/UV3600 spectrophotometer in a wavelength range of $200-390 \mathrm{~nm}$ with $1 \mathrm{~nm}$ steps. The titration was carried out in a Hellma semi-micro quartz cell with $10 \mathrm{~mm}$ optical path length supplemented with magnetic stirrer and Teflon stopper. Initial concentrations of the WT and $\Delta \mathrm{C} 7-\mathrm{CueR}$ were 14 and $12 \mu \mathrm{M}$, respectively. Samples were buffered with Tris $(20 \mathrm{mM}$ Tris/ $\mathrm{HClO}_{4}, 0.3 \mathrm{mM}$ TCEP, $\mathrm{pH}$ 7.5). 7.0 or $6.0 \mu \mathrm{L}$ aliquots (corresponding to 0.1 eq. $\mathrm{Hg}^{\mathrm{II}}$ per CueR monomer) of a $\mathrm{HgCl}_{2}$ stock solution $\left(c_{\mathrm{Hg}^{\prime \prime}}=2.4 \times 10^{-4} \mathrm{M}\right)$ were added to the protein samples. From all the recorded spectra the spectrum of Tris buffer was subtracted as a baseline. The difference spectra were obtained by subtracting the spectra of apo-protein ( $\Delta A=A_{\mathrm{Hg} \text {-protein }}-A_{\text {apo-protein }}$ ) and the offset of the baseline (i.e. the absorbance measured at $390 \mathrm{~nm})$.

\section{A.8. Circular dichroism spectroscopy}

Far UV circular dichroism spectra were recorded on a Jasco J-815 spectropolarimeter, as well as at the CD1 beamline of the storage ring ASTRID at the Institute for Storage Ring Facilities (ISA), University of Aarhus, Denmark. Camphor- 
sulfonic acid served as a calibration material for the instrument. All spectra were recorded with $1 \mathrm{~nm}$ steps and a dwell time of $2 \mathrm{~s}$ per step, using quartz cells (SUPRASIL, Hellma $\mathrm{GmbH}$, Germany) of $0.1 \mathrm{~mm}$ or $0.2 \mathrm{~mm}$ pathlength, in the wavelength range of 180-330 $\mathrm{nm}$. The raw spectra were baseline-corrected with the water spectrum.

The final concentration of CueR was $20-27 \mu \mathrm{M}$, the actual values are included in each figure captions. 0.5 equivalent of PcopA dsDNA and/or 1 equivalent of metal ions (in forms of their $\mathrm{AgClO}_{4}, \mathrm{HgCl}_{2}$ and $\mathrm{Cd}\left(\mathrm{ClO}_{4}\right)_{2}$ solutions) were added to samples according to the monomeric protein concentration. The storage buffer of the protein was $20 \mathrm{mM}$ Tris $/ \mathrm{HClO}_{4}, \mathrm{pH} 7.5$ with $1 \mathrm{mM}$ TCEP while the storage buffer of the DNA contained 20 $\mathrm{mM}$ Tris $/ \mathrm{HClO}_{4}, \mathrm{pH} 8.0$ and $0.1 \mathrm{mM} \mathrm{NaClO}$.

The thermal denaturation of the protein was monitored by recording CD-spectra in 195$170 \mathrm{~nm}$ range at gradually increasing temperature by $5{ }^{\circ} \mathrm{C}$ with an equilibration time of 2 min, in the range of $\mathrm{T}=15-90{ }^{\circ} \mathrm{C}$. The final sample volume was $100 \mu \mathrm{L}$. Since CueR is rich in $\alpha$-helices, we followed the change of ellipticity at $193 \mathrm{~nm}$.

\section{A.9. Perturbed angular correlation of $\gamma$-rays spectroscopy}

\section{A.9.1. ${ }^{199 m} \mathrm{Hg}$ PAC experiments}

${ }^{199 \mathrm{~m}} \mathrm{Hg}$ PAC measurements were performed at ISOLDE beam line at CERN Radioactive mercury was generated by irradiating a liquid $\mathrm{Pb}$ target with protons $(1 \mathrm{GeV})$. ${ }^{199} \mathrm{mg}$ isotopes were selected with an on-line mass separator, and the ion beam was collected into ca. $150 \mu \mathrm{L}$ ice kept in a Teflon holder cooled by a cold finger.

The radioactive ${ }^{199 \mathrm{~m}} \mathrm{Hg}$ solution was mixed with non-radioactive $\mathrm{HgCl}_{2}$ solution in Tris/ $\mathrm{HClO}_{4}$ buffer $(\mathrm{pH}=7.5$ ), followed by the addition of the wild type or truncated CueR protein (in $20 \mathrm{mM}$ Tris $/ \mathrm{HClO}_{4}, 1 \mathrm{mM}$ TCEP, $\mathrm{pH}$ 7.5). As the next step PcopA dsDNA (in $20 \mathrm{mM}$ Tris $/ \mathrm{HClO}_{4}, 0.1 \mathrm{mM} \mathrm{NaClO}_{4}, \mathrm{pH}$ 8.0) was added. The $\mathrm{pH}$ was adjusted to 7.46 (at $25^{\circ} \mathrm{C}$ ) or $5.73\left(\right.$ at $25^{\circ} \mathrm{C}$ ) by adding Tris or MES buffers and solutions of $\mathrm{NaOH}$ or $\mathrm{HClO}_{4}$. Finally, sucrose $(55 \% w / w)$ was added to the mixtures and dissolved. The data were recorded on a 6-detector $\left(\mathrm{BaF}_{2}\right)$ instrument at $1{ }^{\circ} \mathrm{C}$. The $\mathrm{pH}$ values of samples were verified after the measurements and the decay of radioactive mercury.

The fitting was carried out using 300 data points (except the first 10 due to systematic errors in these), using a Lorentzian line shape for the static line broadening. The background subtraction in each of the coincidence groups was estimated using channels 550-600 (i.e. $~ 12$ lifetimes of the intermediate nuclear level after $t_{0}$ ). $t_{0}$ for each group was 
determined using data from an experiment at the beginning of the beam time and at the end of the beam time, and gave values which were all the same within one channel (0.05 ns). Fourier transformation of the data and fits were carried out using 300 data points and a Keiser-Bessel window with the window parameter equal to 4 . The time resolution and the time per channel were $0.52 \mathrm{~ns}$ and $0.05019 \mathrm{~ns}$, respectively. Certain coincidence groups in the spectra of WT CueR $(11,17$, and 23; all of which have detector 5 providing the stop pulse) exhibited systematic deviation (different from that originating from NQIs, and visible as a "bump" 100 channels after $t_{0}$ ) from the exponential decay of the intermediate nuclear level, and these groups were not included in data analysis.

\section{A.9.2. ${ }^{111} \mathrm{Ag}$ and ${ }^{111 \mathrm{~m}} \mathrm{Cd} \mathrm{PAC}$ experiments}

Metallic Pd powder (2.54 mg and $2.8 \mathrm{mg}$ respectively), enriched to $98.6 \%$ in ${ }^{110} \mathrm{Pd}$ (Oak Ridge National Lab, batch 214301) was enclosed in a quartz ampoule and irradiated for 4 days and 5 days respectively in a thermal neutron flux of $(1.1-1.3) \cdot 10^{15} \mathrm{~cm}^{-2} \mathrm{~s}^{-1}$ in the beam tube V4 of the high flux reactor at Institut Laue-Langevin in Grenoble, France. Thermal neutron capture on ${ }^{110} \mathrm{Pd}$ produces short-lived ${ }^{111} \mathrm{Pd}$ which beta-decays with 23.4 minutes half-life to ${ }^{111} \mathrm{Ag}$. The samples were shipped to Hevesy Lab, Risø, Denmark, where radiochemical separation of ${ }^{111} \mathrm{Ag}$ from ${ }^{110} \mathrm{Pd}$ was carried out as described previously.[149]

First, the radioactive ${ }^{111} \mathrm{Ag}$ or ${ }^{111 \mathrm{~m}} \mathrm{Cd}$ solutions in $0.1 \mathrm{M} \mathrm{HNO}_{3}$ were mixed with a non-radioactive $\mathrm{AgClO}_{4}$ or $\mathrm{Cd}\left(\mathrm{ClO}_{4}\right)_{2}$ solution, respectively. The acidic metal ion solutions were neutralized with $\mathrm{NaOH}$. Then, the CueR protein (in storage buffer $20 \mathrm{mM}$ Tris/ $/ \mathrm{HClO}_{4}$, $\mathrm{pH}=7.5,1 \mathrm{mM}$ TCEP) and $35 \mathrm{bp}$ PcopA dsDNA, in storage buffer $20 \mathrm{mM}$ Tris/HClO 4 , $\mathrm{pH}=8.0,0.1 \mathrm{mM} \mathrm{NaClO}$ ) were added. Next, the $\mathrm{pH}$ was adjusted to the required value at RT by adding Tris or MES buffers and solutions of $\mathrm{NaOH}$ or $\mathrm{HClO}_{4}$ taking into account the temperature dependence of the $\mathrm{p} K_{\mathrm{a}}$ value of the buffers and the intended experimental temperature. Finally, sucrose $(55 \% \mathrm{w} / \mathrm{w})$ was dissolved into the mixtures.

To investigate the effect of the addition of $\mathrm{Cl}^{-}$ions on the ${ }^{111} \mathrm{Ag} \mathrm{PAC}$ spectra, $\mathrm{NaCl}$ $\left(c_{\mathrm{NaCl} \text {,stock }}=4 \mathrm{M}\right)$ was added to a sample of $\mathrm{Ag}(\mathrm{I})-\mathrm{CueR}$ in a final concentration of $100 \mathrm{mM}$.

Measurements were carried out at the University of Copenhagen with a PAC instrument consisting of six $\mathrm{BaF}_{2}$ scintillation detectors.[151] During the measurements the temperature was maintained at $1{ }^{\circ} \mathrm{C}$ by a Peltier element or at $-196^{\circ} \mathrm{C}$ by liquid nitrogen.

Evaluation of the PAC data was carried out using the Prelude 32 and Winfit programs. 200 to 400 data points, depending on their information content, were used in the 
fitting procedures, except the first 7 points due to systematic errors experienced in these. Fourier transformation of the data and fits were carried out using a Keiser-Bessel window with a window parameter equal to 6 . The time resolution and time per channel values were $0.981 \mathrm{~ns}$ and $0.562 \mathrm{~ns}$, respectively. A component with pure exponential decay was included in the fit of the ${ }^{111} \mathrm{Ag}$ PAC data recorded at $-196{ }^{\circ} \mathrm{C}$ with an amplitude of $-0.9(1)$ and a decay rate of 22(9) $\mu \mathrm{s}^{-1}$. The difference in amplitude of the ${ }^{111} \mathrm{Ag}$ experiments at $-196{ }^{\circ} \mathrm{C}$ and $1{ }^{\circ} \mathrm{C}$ is a consequence of a shorter sample detector distance for the latter experiment.

\section{A.9.3. Parameters fitted to the ${ }^{199 m} \mathrm{Hg} P A C$-data}

Table A7: Parameters fitted to the ${ }^{199 m} \mathrm{Hg} P A C$-data for the WT CueR. The numbers in parenthesis are the standard deviations of the fitted parameters $a$ : Can be analysed with only one

NQI, but then the fit gives either too low amplitude (high eta, and the fact that the third peak appears to rise above the noise indicates that the high eta NQI alone is not adequate to achieve a good fit) or too high amplitude (low eta). b: faster reorientation may reflect less rigid geometry at site 2. $c$ : It is conceivable that this relatively high value (as compared to the other datasets) may reflect the presence of another NQI (as observed with $0.2 \mathrm{eq} . \mathrm{Hg}(\mathrm{II})$ ), and indeed the fit is not as satisfactory, but the reduced chi-square is not statistically significantly improved by including a second NQI, and therefore, only one NQI is used to fit the data. $d$ : Fast reorientation may reflect exchange between the two species. $e$ : The presence of DNA bound to CueR does not give rise to a measurable change in $1 / \tau_{\text {c }}$

\begin{tabular}{|c|c|c|c|c|c|c|c|c|c|c|}
\hline $\begin{array}{c}\text { Hg(II): WT } \\
\text { CueR }\end{array}$ & $\boldsymbol{c}_{\text {protein,final }}$ & $\boldsymbol{c}_{\text {Hg"final }}$ & $\boldsymbol{c}_{\text {DNA,final }}$ & $\mathbf{p H}$ & $\boldsymbol{v}_{\mathbf{Q}}$ & $\boldsymbol{\eta}$ & $\boldsymbol{\delta}$ & $\mathbf{1} / \boldsymbol{\tau}_{\mathbf{c}}$ & $\boldsymbol{A}$ & $\chi_{\mathbf{r}}{ }^{\mathbf{2}}$ \\
\hline 0.2 & 11.5 & 2.30 & 5.68 & 6.0 & $1.48(1)$ & $0.13(4)$ & $0(1)$ & $7(3)$ & $13(2)$ & 0.82 \\
\hline $0.2^{\mathrm{a}}$ & 11.5 & 2.30 & 5.68 & 8.0 & $1.48(1)$ & $0(1)$ & $0(2)$ & $16(3)^{\mathrm{d}}$ & $9(2)$ & 0.78 \\
\hline 1.0 & 11.5 & 11.5 & 5.68 & 6.0 & $1.474(9)$ & $0.18(2)$ & $0(1)$ & $8(2)$ & $13(1)$ & 0.66 \\
\hline 1.0 & 11.5 & 11.5 & 5.68 & 8.0 & $1.49(2)$ & $0.23(4)^{\mathrm{c}}$ & $2(2)$ & $8(5)$ & $12(2)$ & 0.71 \\
\hline 2.0 & 11.5 & 23.0 & 5.68 & 6.0 & $1.49(1)$ & $0.12(5)$ & $0(2)$ & $17(4)^{\mathrm{b}}$ & $15(1)$ & 0.75 \\
\hline 2.0 & 11.5 & 23.0 & 5.68 & 8.0 & $1.53(1)$ & $0.15(5)$ & $2(2)$ & $10(3)^{\mathrm{b}}$ & $14(2)$ & 0.67 \\
\hline $0.2^{\mathrm{a}}$ & 11.5 & 2.30 & 0 & 8.0 & $1.42(2)$ & $0.1(1)$ & $0(3)$ & $11(4)^{\mathrm{d}}$ & $6(3)$ & 0.71 \\
& & & & & $1.04(4)$ & $0.77(9)$ & $0(6)$ & & $4(2)$ & \\
\hline 1.0 & 11.5 & 11.5 & 0 & 8.0 & $1.49(2)$ & $0(1)$ & $5(2)$ & $7(2)^{\mathrm{e}}$ & $16(2)$ & 0.75 \\
\hline 2.0 & 11.5 & 23.0 & 0 & 8.0 & $1.45(1)$ & $0.23(3)$ & $1(2)$ & $12(4)^{\mathrm{b}}$ & $13(2)$ & 0.80 \\
\hline
\end{tabular}


Table A8: Parameters fitted to the ${ }^{199 m} \mathrm{Hg}$ PAC-data for $\triangle C 7$-CueR with the same sample conditions.

\begin{tabular}{|c|c|c|c|c|c|c|c|c|c|c|}
\hline $\begin{array}{c}\mathbf{H g}(\mathrm{II}): \\
\Delta \mathbf{C 7 - C u e R}\end{array}$ & $\boldsymbol{c}_{\text {protein,final }}$ & $\boldsymbol{c}_{\mathrm{Hg} \text { "ffinal }}$ & $\boldsymbol{c}_{\mathrm{DNA}, \mathrm{final}}$ & $\mathbf{p H}$ & $\boldsymbol{v}_{\mathbf{Q}}$ & $\boldsymbol{\eta}$ & $\boldsymbol{\delta}$ & $\mathbf{1} / \boldsymbol{\tau}_{\mathbf{c}}$ & $\boldsymbol{A}$ & $\chi_{\mathrm{r}}{ }^{2}$ \\
\hline & $(\mu \mathrm{M})$ & $(\mu \mathrm{M})$ & $(\mu \mathrm{M})$ & & $(\mathrm{GHz})$ & & $\times 100$ & $\mu \mathrm{s}^{-1}$ & $\times 100$ & \\
\hline 0.2 & 8.45 & 1.69 & 4.23 & 6.0 & $1.55(2)$ & $0.07(9)$ & $8(2)$ & $23(17)$ & $15(2)$ & 0.62 \\
\hline 0.2 & 8.45 & 1.69 & 4.23 & 8.0 & $1.55(1)$ & $0.16(3)$ & $3(2)$ & $120(27)$ & $14(1)$ & 0.66 \\
\hline 1.0 & 8.45 & 8.45 & 4.23 & 6.0 & $1.55(2)$ & $0.13(5)$ & $6(2)$ & $78(26)$ & $15(2)$ & 0.72 \\
\hline 1.0 & 8.45 & 8.45 & 4.23 & 8.0 & $1.52(2)$ & $0.16(5)$ & $6(2)$ & $16(22)$ & $12(2)$ & 0.75 \\
\hline 2.0 & 8.45 & 16.9 & 4.23 & 8.0 & $1.60(4)$ & $0.15(7)$ & $10(3)$ & $97(37)$ & $16(2)$ & 0.56 \\
\hline
\end{tabular}

\section{A.9.4. Parameters fitted to the ${ }^{111} \mathrm{Ag}$ and ${ }^{111 \mathrm{~m}} \mathrm{Cd} P \mathrm{PAC}$-data}

Table A9: Parameters fitted to the ${ }^{111} \mathrm{Ag} P A C$-data. The rotational correlation time was fixed to infinite at $-196{ }^{\circ} \mathrm{C}$ because it is assumed that the protein is completely immobilized.

\begin{tabular}{|c|c|c|c|c|c|c|c|}
\hline Protein & $T$ & $\omega_{0}$ & $\eta$ & $\delta$ & $1 / \tau_{c}$ & $A$ & $\chi_{r}^{2}$ \\
\hline & $\left({ }^{\circ} \mathrm{C}\right)$ & $(\mathrm{rad} / \mathrm{ns})$ & & $\times 100$ & $\mu \mathrm{s}^{-1}$ & $\times 100$ & \\
\hline WT & -196 & $\begin{array}{l}0.555(2) \\
0.41(1)\end{array}$ & $\begin{array}{l}0.510(8) \\
0.39(4)\end{array}$ & $\begin{array}{l}2.5(6) \\
16(2)\end{array}$ & $\begin{array}{l}0(\text { fix }) \\
0(\text { fix }) \\
22(9)\end{array}$ & $\begin{array}{l}-2.3(4) \\
-7.4(1) \\
-0.9(1)\end{array}$ & 0.93 \\
\hline$\Delta \mathrm{C} 7$ & -196 & $\begin{array}{l}0.553(7) \\
0.36(1)\end{array}$ & $\begin{array}{l}0.49(2) \\
0.36(6)\end{array}$ & $\begin{array}{l}2.5 \text { (fix) } \\
20 \text { (fix) }\end{array}$ & $\begin{array}{l}0(\text { fix }) \\
0(\text { fix }) \\
18(3)\end{array}$ & $\begin{array}{l}-1.3(3) \\
-8(1) \\
-3.5(2)\end{array}$ & 0.92 \\
\hline $\begin{array}{l}\text { S77C- } \\
\Delta C 7\end{array}$ & -196 & $0.37(1)$ & $0.46(4)$ & 20(fix) & $\begin{array}{l}0(\text { fix }) \\
23(4)\end{array}$ & $\begin{array}{l}-12(1) \\
-2.9(2)\end{array}$ & 0.95 \\
\hline
\end{tabular}

Table A10: Parameters fitted to the ${ }^{111} \mathrm{Ag} P A C$ and ${ }^{111 m} \mathrm{Cd}$ PAC-data for WT CueR. The rotational correlation time was fixed to infinite at $-196{ }^{\circ} \mathrm{C}$ because it is assumed that the protein is completely immobilized.

\begin{tabular}{|c|c|c|c|c|c|c|c|}
\hline Isotope & $\mathbf{T}$ & $\boldsymbol{\omega}_{\mathbf{0}}$ & $\boldsymbol{\eta}$ & $\boldsymbol{\Delta}$ & $\mathbf{1} / \boldsymbol{\tau}_{\mathbf{c}}$ & $\mathbf{A}$ & $\boldsymbol{\chi}_{\mathbf{r}}{ }^{2}$ \\
\hline & $\left({ }^{\circ} \mathrm{C}\right)$ & $(\mathrm{rad} / \mathrm{ns})$ & & $\times 100$ & $\mu \mathrm{s}^{-1}$ & $\times 100$ & \\
\hline${ }^{111} \mathrm{Ag}$ & -196 & $\begin{array}{c}0.555(2) \\
0.41(1)\end{array}$ & $\begin{array}{c}0.510(8) \\
0.39(4)\end{array}$ & $\begin{array}{c}2.5(6) \\
16(2)\end{array}$ & $\begin{array}{c}0(\mathrm{fix}) \\
0(\mathrm{fix})\end{array}$ & $\begin{array}{c}-2.3(4) \\
-7.4(1)\end{array}$ & 0.93 \\
\hline${ }^{111} \mathrm{Ag}$ & 1 & $0.426(1)$ & $0.384(6)$ & $1.5(6)$ & $6(4)$ & $-6.3(6)$ & 0.90 \\
\hline${ }^{111 \mathrm{~m}} \mathrm{Cd}$ & 1 & $0.11(2)$ & $0.5(5)$ & $9(14)$ & $6(4)$ & $9(2)$ & 0.78 \\
\hline
\end{tabular}




\section{A.10. Cloning of the reporter system}

The fusion of the $\operatorname{cop} A$ promoter and egfp was carried out in two-step PCR with KOD Plus DNA polymerase. First, the PcopA promoter from E. coli K12 genomic DNA and the $e g f p$ gene from EGFP-C1 DNA were amplified by using EcoRI/copA/SD forward, EGFP/copA/SD reverse and copA/SD/EGFP forward, BamHI/Terminal/EGFP reverse primers (Table A11), respectively. Then, the two gene segments were connected and amplified in a second PCR reaction using the EcoRI/copA/SD forward and BamHI/Terminal/EGFP reverse primers. Thereby, the PcopA::egfp fusion gene was obtained.

The PcopA::egfp fragment and pUC119 plasmid were digested with EcoRI and BamHI enzymes (Fermentas) at $37^{\circ} \mathrm{C}, 1 \mathrm{~h}$. After a subsequent purification the digested insert and plasmid were ligated with Ligation High enzyme. Mach1 competent cells were transformed with the ligation mixture and spread onto ampicillin containing LB plates. The pUC119-copA-EGFP plasmid was purified with NucleoBond Xtra Midi Kit (Takara).

The gene of the CueR protein was amplified with HindIII-SD-CueR forward and PstI-EcolintxnTer-CueR reverse primers from pET-21a-CueR plasmid. Importantly, the amplified DNA segment encompassed a SD sequence, the cueR gene and a terminator sequence. The SD-CueR-Term DNA segment was inserted into pUC119-copA-EGFP plasmid between HindIII and PstI restriction sites resulting the pUC119-CueR-copA-EGFP plasmid. Later, the cueR gene only and also fused to a terminator were cloned similarly to the pUC119-copA-EGFP plasmid. In the PCR HindIII-CueR forward and CueR-PstI or Term-PstI revers primers were used. The product plasmids were named pUC119-CueRcopA-EGFP\# and pUC119-CueRTerm-copA-EGFP.

As the first step to clone the pUC119-EGFP plasmid, the egfp gene was amplified in a PCR by KOD Plus Polymerase from EGFP cDNA template with BamHI-EGFP forward and EGFP-EcoRI reverse primers. The amplified DNA segment was inserted into pUC119 plasmid between the BamHI and EcoRI sites. Ligation was carried out with Ligation High $\left(16^{\circ} \mathrm{C}, 30 \mathrm{~min}\right)$, then Mach1 cells were transformed using the ligation reaction mixture and spread onto ampicillin containing LB plates. The pUC119-EGFP plasmid was purified with NucleoBond Xtra Midi Kit (Takara).

After the cloning, all plasmids were sequenced to confirm the success of the experiments. 
Table A11: Sequences of primers used in cloning. Restriction enzyme sites are underlined.

\begin{tabular}{c|c}
\hline Name & Sequence (5' $\mathbf{- 3}$ ') \\
\hline EcorRI/copA/SD F & GGAATTCCTCACCCCGGTG \\
EGFP/copA/SD R & CGCCCTTGCTCACCATAAAACACTCCTTTAAGACAG \\
copA/SD/EGFP F & CTGTCTTAAAGGAGTGTTTTATGGTGAGCAAGGGCG \\
BamHI/Terminal/ & CGGGATCCATGAAAAAAGCGCCGGTCTTCGGCGCTTGA \\
EGFP & TTACTTGTACAGCTCGTCCA \\
\hline HindIII-SD-CueR F & CTTAAGCTTAGGAGTGTTTTATGAACATCAGCGATGTAGCAA \\
PstI-EcolintxnTer- & ACGCTGCAGATGAAAAAAGCGCCGGTCTTCGGCGCTTGATCAC \\
CueR R & CCTGCCCGATGATGA \\
\hline HidIII-CueR F & GGGAAGCTTATGAACATCAGCGATG \\
CueR-PstI R & TTCTGCAGTCACCCTGCCCGATG \\
Term-PstI R & TTCTGCAGATGAAAAAAGCGCCGGTCT \\
\hline BamHI-EGFP F & CGGGATCCATGGTGAGCAAGGGCGT \\
EGFP-EcoRI R & GAATTCTTACTTGTACAGCTCGTCCA \\
\hline
\end{tabular}

\section{A.11. Detection of EGFP expression: Fluorescence spectroscopy} and microscopy

\section{A.11.1. Protein induction}

Bacterial pre-cultures were grown in $5 \mathrm{~mL}$ of Luria-Bertani (LB) medium supplemented with the appropriate antibiotic at $37^{\circ} \mathrm{C}$, overnight. $0.5 \mathrm{~mL}$ of the pre-culture was transferred into $4.5 \mathrm{~mL}$ fresh $\mathrm{LB}+$ antibiotics and incubated at $37^{\circ} \mathrm{C}$ until the $\mathrm{OD}_{600}$ reached 0.6. The Plac promoter was induced by adding IPTG to a final concentration of $0.2 \mathrm{mM}$, whereas the $\mathrm{PcopA}$ was induced by adding $\mathrm{CuSO}_{4}$ solution to a final concentration of $0.1,1.0 \mathrm{mM}$. After adding the inducing agents, samples were incubated at $37^{\circ} \mathrm{C}$ for $3 \mathrm{~h}$.

\section{A.11.2. Sample preparation and imaging with fluorescent microscopy}

Bacteria from 0.5 - $1 \mathrm{~mL}$ culture were collected by centrifuging gently (4 krpm, 2 min) and washed with $1 \mathrm{~mL}$ PBS buffer. Cells were fixed by re-suspending in $300 \mu \mathrm{L}, 4 \%$ $w / V$ paraformaldehyde solution. After $10 \mathrm{~min}$, the cells were separated by centrifugation and washed twice with $1 \mathrm{~mL}$ PBS. Then, the cells were re-suspended in $0.5 \mathrm{~mL}$ PBS containing $0.5 \% \mathrm{w} / \mathrm{V}$ Triton $\mathrm{X}-100$ surfactant, incubated for $30 \mathrm{~min}$ and washed again twice with $1 \mathrm{~mL}$ PBS. Finally, bacteria were re-suspended in $30 \mu \mathrm{L}$ of $5000 \times$ diluted DAPI (in PBS). $1 \mu \mathrm{L}$ of bacterial suspension was mixed with $4 \mu \mathrm{L}$ mounting media on a glass slide of S1111 (Matsunami Glass Ind). After covering and sealing, the slides were stored 
in a dark box at RT. Imaging was carried out with a LSM700 (Carl Zeiss) laser scanning confocal microscope. Images were acquired and analysed with ZEN (Carl Zeiss) software.

\section{A.11.3. Sample preparation and measurement with fluorescent microplate} reader

E. coli cultures were grown in $5 \mathrm{ml} \mathrm{M9}$ minimal media supplemented with the appropriate antibiotics at $37{ }^{\circ} \mathrm{C}$ until the $\mathrm{OD}_{600}$ reached $\sim 0.6$. Protein expression was induced at $37^{\circ} \mathrm{C}$ for $3 \mathrm{~h}$. After the induction, the $\mathrm{OD}_{600}$ was measured. Next, $1 \mathrm{~mL}$ of the culture was transferred to an Eppendorf tube and washed with PBS, and re-suspended in 1 mL PBS. $200 \mu \mathrm{L}$ of the suspension was loaded into a well of a 96-well flat bottom black polystyrene microplate (Iwaki).

Fluorescence intensity was measured at the top of the wells with an Infinite M1000Pro (Tecan) microplate reader using Tecan i-control (Tecan) software. The temperature was maintained at $37{ }^{\circ} \mathrm{C}$ during the measurement. The settings of the measurement are included in Table A12.

Table A12: Settings of the fluorescence measurements with Infinite M1000Pro microplate reader

\begin{tabular}{l|c}
\hline \multicolumn{1}{c|}{ Parameter } & Value \\
\hline Multiple Reads per Well (Square (filled)) & $2 \times 2 \mathrm{MEAN}$ \\
Multiple Reads per Well (Border) & $500 \mu \mathrm{m}$ \\
Excitation Wavelength & $488 \mathrm{~nm}$ \\
Emission Wavelength & $520 \mathrm{~nm}$ \\
Excitation Bandwidth & $15 \mathrm{~nm}$ \\
Emission Bandwidth & $15 \mathrm{~nm}$ \\
Gain & $70 / \mathrm{Manual}$ \\
Flash Frequency & $400 \mathrm{~Hz}$ \\
Integration Time & $20 \mu \mathrm{s}$ \\
\hline
\end{tabular}

